\title{
Mechanisms of sexual polyploidization and inheritance in triploid citrus populations
}

PhD THESIS PRESENTED BY

JOSÉ CUENCA IBÁÑEZ

SUPERVISORS:

DR. LUIS NAVARRO LUCAS

DR. PATRICK OLLITRAULT

TUTOR:

DR. Ma JOSÉ DÍEZ 

Durante estos años, muchas han sido las personas que han contribuido de una forma o de otra en el desarrollo de esta tesis, por lo que gran parte de ella les pertenece. A todos ellos, debo y quiero expresarles mi gratitud.

En primer lugar, quiero dar las gracias al IVIA y a su ex-director, Dr. Florentino Juste, por haberme dado la oportunidad de desarrollar mi trabajo en este centro. Quiero agradecer al Dr. Luis Navarro su confianza en mí para trabajar en su grupo (hace ahora 13 años) y realizar posteriormente esta tesis doctoral bajo su dirección. Durante todos estos años, su consejo y guía han sido imprescindibles para mi formación como profesional. Quiero agradecer de forma especial al Dr. Patrick Ollitrault, codirector de esta tesis, su apoyo y confianza en mi trabajo desde el principio. Su gran capacidad para orientar las investigaciones ha sido definitiva para el desarrollo de esta tesis, la cual no se habría podido concebir sin su inestimable participación. Quiero dar las gracias también a mi tutora, Dra. $\mathrm{M}^{\mathrm{a}}$ José Díez, por estar siempre dispuesta a ayudar en cualquier tarea necesaria para el desarrollo de la tesis.

Quiero dar las gracias a mis compañeros del Laboratorio de Cultivo de Tejidos. A Pepe Juárez, su apoyo incondicional y confianza en mi; siempre he recibido de él buenos consejos y me ha enseñado todo lo que puedo saber sobre cultivo in vitro. A Pablo Aleza debo agradecerle, ante todo, su amistad y, por supuesto, su colaboración en todos los trabajos desarrollados en esta tesis. Gracias también a Juana $\mathrm{M}^{\mathrm{a}}$, Carmen, Toni, Vio, Cloti y Marga por ayudarme siempre en todo lo que he necesitado. Quiero agradecer a mis compañeros del laboratorio CIRAD-IVIA, su inestimable ayuda en este trabajo y su paciencia para aguantarme (Frederique, Juan, María, Marta, Ana, Houssem). De forma especial, quiero dar las gracias a Andrés (Dr. García-Lor et al) por su amistad, su gran predisposición a ayudarme y colaboración en esta tesis.

Agradecer también a todos aquéllos que en algún momento me han aconsejado y guiado en mis investigaciones (José Guerri, Leandro Peña, Gema Ancillo, José A. Pina, Alejandro Medina). Gracias a todos mis compañeros del centro, tanto a los que trabajan en los laboratorios (Ana, Elsa, Nuria, Berta, Montse, Jesús, Karelia, Vero, Toni, Daniel, Sandra, Pilar, Sawsen) como a los que trabajan en el campo o invernaderos (Vicente Lloris, José Manuel, Octavio (Paco), Fran, Aurelio, José Lloris, Diego, Raquel, Toni, Ramón, Ferran) y, en especial, a Rafa Montalt y Josep Peris (xufa) por ser más amigos que compañeros. Quiero agradecer a todos los que, de alguna forma, han convivido conmigo durante estos años (administración, conserjería, cafetería, limpieza, mantenimiento). Quiero recordar también a todos los que han pasado por el IVIA durante un tiempo más o menos largo (Magda, Mamen, Pedro, Álida, Giovanni, Jorge, Regina, Inma, Diana, Ezequiel, Lucía, Águeda, Marta, Esther) y especialmente a Mari Cruz, Frank, Rosa y José Manuel, con los que he convivido intensamente durante varios años.

Por supuesto, quiero dar las gracias a mi familia, mi padre, y mis hermanos $\mathrm{y}$, en especial, a mi madre, que seguro que está orgullosa de mí.

Por último, quiero dedicarle esta tesis muy especialmente a mi mujer $\mathrm{M}^{\mathrm{a}}$ Carmen, por entenderme y apoyarme en todo momento, ya que sin su ayuda y comprensión, esta tesis no se habría podido realizar. Y a mi chiquitín Andreu (y a mi futuro bebé), quiero agradecerle los momentos de alegría, su sonrisa y sus abrazos, que hacen que aprecie lo realmente importante de la vida. 



\section{CONTENTS}

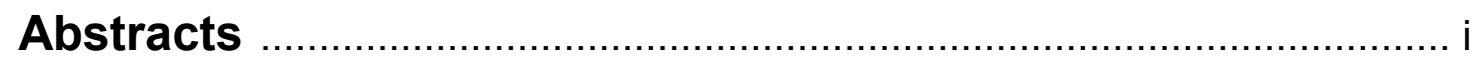

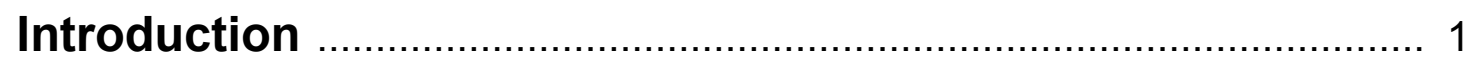

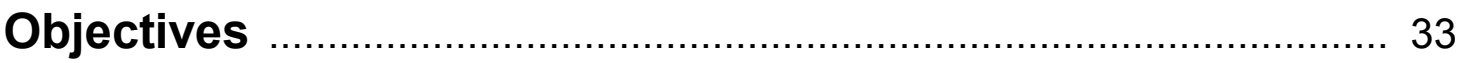

Chapter 1: Assignment of SNP allelic configuration in polyploids using competitive allele-specific PCR: application to citrus triploid progenies 39

Chapter 2: Multilocus half-tetrad analysis and centromere mapping in citrus: evidence of SDR mechanism for $2 n$ megagametophyte production and partial chiasma interference in mandarin cv 'Fortune'

Chapter 3: Maximum-likelihood method based on parental heterozygosity restitution of centromeric loci identifies SDR as the predominant mechanism leading to $2 n$ megagametophytes in $C$. reticulata 85

Chapter 4: Genetically based location from triploid Populations and gene ontology of a 3.3-Mb genome region linked to Alternaria brown spot resistance in citrus reveal clusters of resistance genes

General discussion 145

Conclusions 155

Annex 159 



\section{Abstract}

Citrus is the main fruit crop in the world and Spain is the $6^{\text {th }}$ producer and the major exporter for the fresh fruit market. Seedlessness is one of the most important fruit quality traits for this market since consumers do not accept seedy fruits. Recovery of triploid hybrids has become an important breeding strategy to develop new seedless citrus varieties and several of them have been already released from citrus breeding programs worldwide. Despite the undisputable importance of polyploidy in plant species, their genetics are much less well known than those of their diploid counterparts.

Citrus triploid hybrids can be routinely recovered from sexual polyploidization $(2 x \times 2 x)$ or interploid crosses $(2 x \times 4 x$ and $4 x \times 2 x)$. In $2 x \times 2 x$ sexual crosses, spontaneous triploid hybrids arise from the union of an unreduced $(2 n)$ megagametophyte with haploid pollen. In the case of interploid sexual crosses $(2 x \times 4 x$ and $4 x \times 2 x)$, triploid hybrids result from the fecundation of a diploid gamete arising from the tetraploid parent and a haploid gamete arising from the diploid parent. The genetic and phenotypic structures of triploid populations greatly depend on the parental heterozygosity restitution (HR) in the diploid gamete at each locus, which is mainly affected by the triploid recovery strategy. In $2 x \times 2 x$ crosses, HR depends on the underlying mechanism leading to the unreduced gamete formation, which are genetically equivalent to First Division Restitution (FDR) or Second Division Restitution (SDR) mechanisms. Moreover, under each restitution mechanism, HR also depends on the locus-centromere genetic distance. In the case of interploid crosses, parental heterozygosity restitution from tetraploid parents depends on the double reduction frequency. In citrus, the unreduced gamete formation mechanism is still controversial; FDR has been the mechanism proposed for sweet orange, whereas SDR has been proposed for clementine. On the other hand, inferring the allelic configurations of genetic markers is a main challenge in polyploidy crops to infer genotypic and gametic structures with the objective to analyze meiosis and inheritance mechanisms.

According to this scientific context, the objectives of the thesis where: (i) to develop a new approach for allele dosis assignation when using co-dominant markers, (ii) to implement and apply methods for the analysis of $2 n$ gametes origin and locate centromeres, and (iii) to take advantage of this knowledge to locate a major gene of resistance to Alternaria Brown Spot (ABS) which is a major constraint for triploid mandarin breeding.

For microsatellite (SSR) markers, we have demonstrated that triploid progeny genotyping can be successfully performed using the microsatellite allele-counting peak ratio (MAC-PR) method. However, SSR analysis remains relatively costly and time consuming compared with actual SNP genotyping methods. Moreover, with the increasing availability of EST databases and whole genome sequences, SNPs have become the most abundant and powerful polymorphic markers that can be selected along the entire genome. In this thesis, a new method based on competitive allele-specific PCR has been developed to assign SNP allele dosage in an accurate, simple, and cost effective way. Combining the MAC-PR and the new developed SNP 
genotyping methods offers the possibility to utilize a broad range of molecular markers in genotyping triploid genotypes. Both methods have been used in further works included in this thesis.

SDR has been demonstrated as the mechanism underlying unreduced gamete production in 'Fortune' mandarin by genotyping triploid progenies with SSR markers. In addition, a new method to locate the centromere, based on the best fit between observed heterozygosity restitution within a linkage group and theoretical functions under either partial or no chiasma interference hypotheses has been developed and successfully applied.

To expand the knowledge of the mechanism underlying unreduced gamete formation to other citrus genotypes besides clementines and 'Fortune' mandarin, a maximum likelihood method based on parental heterozygosity restitution of centromeric loci was developed and successfully applied in sixteen mandarin cultivars. The new method developed in the study allows inferring the restitution mechanism both at population level and even at individual level. Maternal origin of $2 n$ gametes was confirmed for all triploid hybrids and SDR was proposed as the restitution mechanism for all analyzed progenies.

The information acquired from the mode of heterozygosity restitution in citrus was useful to determine the genetic and phenotypic structures of new triploid populations arising from different breeding strategies. We studied these structures for the resistance to Alternaria brown spot (ABS), a serious fungal disease producing necrotic lesions on fruits and young leaves in susceptible citrus genotypes. In the present work, different approaches were combined taking advantage of the particular genetic structures of $2 n$ gametes resulting from SDR to map a genome region linked to $A B S$ resistance in triploid citrus progeny. The monolocus dominant inheritance of the susceptibility, proposed on the basis of diploid population studies, was corroborated in triploid progeny. A 3.3 Mb genomic region linked to ABS resistance was located near the centromere on chromosome III, which includes clusters of resistance genes. SSR and SNP markers were developed for an efficient early selection of ABS resistant hybrids and they are currently used in our breeding program to perform marker assisted selection.

The knowledge obtained in this thesis on the mechanism of sexual polyploidization and inheritance of concrete traits in citrus will allow implementing much more efficient triploid breeding programs on the basis of current and future needs. Indeed, applied outcomes of this $\mathrm{PhD}$ are already routinely used in the IVIA triploid breeding program. 


\section{Resumen}

Los cítricos son el principal cultivo frutal del mundo, siendo España el sexto productor mundial y el primer país exportador para el mercado en fresco. La ausencia de semillas constituye una de las características más importantes relacionadas con la calidad de los frutos, no siendo aceptados por los consumidores los frutos con semillas. La obtención de híbridos triploides se ha convertido en una estrategia importante para desarrollar variedades sin semillas, algunas de las cuales ya están disponibles en el mercado. A pesar de la importancia de las plantas poliploides, la genética de las mismas es mucho menos conocida que en plantas diploides.

Los híbridos triploides de cítricos se pueden obtener de forma rutinaria a partir de mecanismos de poliploidización sexual $(2 x \times 2 x)$ o mediante cruzamientos interploides $(2 x \times 4 x$ ó $4 x \times 2 x)$. En los cruzamientos $2 x \times 2 x$, se producen híbridos triploides espontáneos que proceden de la unión de un óvulo no reducido $(2 n)$ con polen haploide. En el caso de cruzamientos interploides, los híbridos triploides resultan de la fecundación de un gameto diploide procedente del parental tetraploide con polen haploide procedente del parental diploide. Las estructuras genéticas y fenotípicas de las poblaciones triploides obtenidas dependen en gran medida de la restitución de heterocigosidad parental (HR) en el gameto diploide para cada locus, lo que está influido principalmente por la estrategia de obtención de estas poblaciones. En cruzamientos $2 x$ $\times 2 x, \mathrm{HR}$ depende del mecanismo que da lugar a la formación del gameto no reducido; estos mecanismos son genéticamente equivalentes a una restitución en la primera división meiótica (FDR) o una restitución en la segunda división meiótica (SDR). Además, para cada mecanismo de restitución de heterocigosidad, HR depende a su vez de la distancia genética entre el locus considerado y el centrómero. En caso de cruzamientos interploides, la restitución de la heterocigosidad del parental tetraploide depende de la frecuencia de doble reducción. En los cítricos, existe cierta controversia sobre el mecanismo de formación de gametos no reducidos. En el caso de naranjo dulce, el mecanismo propuesto es FDR, mientras que para el clementino se ha propuesto SDR. Por otro lado, la asignación de las configuraciones alélicas de marcadores genéticos en especies poliploides es esencial para inferir las estructuras genotípicas y gaméticas con el objetivo de estudiar los mecanismos de meiosis y herencia. En este contexto, los objetivos científicos de la tesis han sido: (i) desarrollar un nuevo método para asignar dosis alélicas utilizando marcadores codominantes, (ii) implementar y aplicar nuevas estrategias para analizar el origen de los gametos no reducidos y localizar centrómeros y (iii) utilizar el conocimiento generado para localizar un gen mayor de resistencia a la mancha marrón producida por el hongo Alternaria, que supone actualmente un inconveniente en los programas de mejora de mandarino.

En el caso de marcadores microsatelites (SSRs), se ha demostrado que el genotipado de poblaciones triploides puede llevarse a cabo mediante el método microsatellite allele-counting peak ratio (MAC-PR). Sin embargo, el empleo de marcadores SSR es relativamente costoso y lento, en comparación con los métodos actuales de genotipado de SNP. Además, con la creciente disponibilidad de bases de datos procedentes de ESTs y secuenciación completa de 
genomas, los SNP se han convertido en los marcadores polimórficos más abundantes y efectivos que se pueden utilizar. En la presente tesis, se ha desarrollado un método basado en PCR competitiva específica de alelos para asignar las dosis alélicas de SNPs de una forma precisa, simple y efectiva. La combinación de este nuevo método con el MAC-PR ofrece la posibilidad de emplear un gran abanico de marcadores moleculares para el genotipado de poblaciones triploides. Ambos métodos se han empleado en los trabajos descritos a lo largo de esta tesis.

Mediante la utilización de marcadores SSR, se ha demostrado que el mecanismo que da lugar a la formación de gametos no reducidos en el mandarino 'Fortune' es SDR. Además, se ha desarrollado y aplicado un nuevo método para localizar centrómeros comparando los datos de HR observados dentro de un grupo de ligamiento y funciones teóricas bajo modelos de interferencia parcial y no interferencia.

Para ampliar el conocimiento sobre los mecanismos de origen de los gametos no reducidos a otros genotipos, se ha desarrollado y aplicado un método de máxima similitud basado en la HR de marcadores centroméricos. Este nuevo método permite identificar el mecanismo de origen tanto a nivel poblacional como a nivel individual. Como resultado, se ha confirmado que SDR es el mecanismo de origen de los óvulos diploides en todas las poblaciones de híbridos triploides analizadas.

La información obtenida anteriormente sobre el mecanismo de origen de los gametos no reducidos ha sido utilizada para determinar las estructuras genéticas y fenotípicas de nuevas poblaciones triploides obtenidas mediante diferentes estrategias. En este sentido, se han analizado estas estructuras para la resistencia a la mancha marrón (ABS), una enfermedad fúngica importante en los cítricos que produce lesiones necróticas sobre los frutos y hojas jóvenes de los genotipos susceptibles. En la presente tesis, a partir del conocimiento de la estructura genética particular proveniente de SDR como mecanismo de origen de los gametos no reducidos, se han combinado diferentes estrategias para analizar la resistencia a ABS en poblaciones triploides de cítricos. Se ha corroborado en estas poblaciones triploides la herencia monolocus dominante propuesta a partir de estudios en poblaciones diploides. Además, se ha localizado un región genómica de $3.3 \mathrm{Mb}$ ligada a la resistencia a ABS cerca del centrómero en el cromosoma III, en la que se incluyen varios grupos de genes de resistencia. También se han desarrollado marcadores SSR y SNP para realizar una selección temprana de híbridos resistentes, los cuales están siendo utilizados actualmente en el programa de mejora del IVIA para selección asistida por marcadores.

El conocimiento generado en esta tesis sobre los mecanismos de poliploidización sexual y la herencia de caracteres concretos en cítricos permitirá un desarrollo más eficiente de los programas de mejora en base a necesidades actuales y futuras. De hecho, los resultados de aplicación práctica obtenidos en esta tesis están siendo utilizados actualmente. 


\section{Resum}

Els cítrics són el principal conreu fruiter del món, sent Espanya el sisé productor mundial i el primer exportador de fruita fresca. L'absència de llavors constitueix actualment una de les característiques més importants relacionades amb la qualitat des fruits, no sent acceptables per part dels consumidors els fruits amb llavors. L'obtenció de híbrids triploides s'ha convertit en una estratègia important per al desenvolupament de varietats sense llavors, algunes de les quals estan disponibles al mercat. Però, a pesar de la importància de les espècies poliploides, la seua genètica és menys coneguda que en espècies diploides.

Els híbrids triploides de cítrics es poden obtindre de forma rutinària mitjançant mecanismes de poliploidització sexual $(2 x \times 2 x)$ o mitjançant creuaments interploides $(2 x \times 4 x$ ó $4 x \times 2 x)$. Als creuaments $2 x \times 2 x$ es produeixen híbrids triploides espontanis que procedeixen de la unió d'un òvul no reduït $(2 n)$ amb pol-len haploide. En el cas de creuaments interploides, els híbrids triploides resulten de la fecundació d'una gàmeta diploide procedent del parental tetraploide amb pol-len haploide procedent del parental diploide. Les estructures genètiques i fenotípiques de les poblacions triploides obtingudes depenen en gran mesura de la restitució d'heterozigosis parental (HR) en la gàmeta diploide per a cada locus, el que està influït principalment per l'estratègia d'obtenció de les poblacions triploides. Als creuaments $2 x \times 2 x$, HR depèn del mecanisme que origina la formació de la gàmeta no reduïda; aquestos mecanismes són genèticament equivalents a una restitució a la primera divisió meiòtica (FDR) o una restitució a la segona divisió meiòtica (SDR). A més, per a cada mecanisme de restitució d'heterozigosis, la HR per un locus depèn de la distància genètica entre el locus considerat i el centròmer. En cas de creuaments interploides, la restitució d'heterozigosis del parental tetraploide depèn de la freqüència de doble reducció. En el cas del cítrics, existeix certa controvèrsia sobre el mecanisme d'origen de les gàmetes no reduïdes. En cas de taronger dolç, el mecanisme que s'ha proposat es FDR, mentre que per al clementí s'ha proposat SDR. D'un altra banda, l'assignació de les configuracions al-lèliques de marcadors genètics en espècies poliploides és essencial per a inferir les estructures genotípiques i gamètiques amb l'objecte d'estudiar els mecanismes de meiosi i herència. En aquest context, els objectius científics de la present tesi doctoral són: (i) desenvolupar un nou mètode per a assignar dosis al-lèliques utilitzant marcadors moleculars codominants, (ii) implementar i aplicar noves estratègies per a analitzar l'origen de les gàmetes no reduïdes i localitzar centròmers i (iii) utilitzar el coneixement generat per a localitzar un gen major de resistència a la taca marró produïda pel fong Alternaria, que suposa actualment un inconvenient per als programes de millora de mandarí.

En el cas de marcadors microsatèl-lits (SSR), s'ha demostrat que el genotipatge de poblacions triploides pot realitzar-se mitjançant el métode microsatellite allele-counting peak ratio (MACPR). No obstant això, l'ús de marcadors SSR és relativament costós i lent en comparació als actuals mètodes de genotipatge de SNPs. A més, amb la creixent disponibilitat de bases de dades procedents d'ESTs i seqüenciació completa de genomes, els SNP s'han convertit en els marcadors polimòrfics més abundants i efectius que es poden utilitzar. En la present tesi, s'ha 
desenvolupat un mètode basat en PCR competitiva específica d'al-lels per a assignar les dosis al-lèliques de SNP d'un forma senzilla, precisa i efectiva. La combinació d'aquest nou mètode amb el MAC-PR ofereix la possibilitat d'utilitzar un gran nombre de marcadors moleculars per al genotipatge de poblacions triploides. Ambdós mètodes s'han emprat en els treballs descrits al llarg de la present tesi.

Mitjançant la utilització de marcadors SSR, s'ha demostrat que el mecanisme d'origen de les gàmetes no reduïdes en el mandarí 'Fortune' és SDR. A més, s'ha desenvolupat i aplicat un nou mètode per a localitzar centròmers comparant les dades de HR observades dins d'un mateix grup de lligament amb funcions teòriques baix models d'interferència parcial i no interferència.

Per a ampliar el coneixement sobre els mecanismes d'origen de les gàmetes no reduïdes a altres genotips, s'ha desenvolupat i aplicar un mètode de màxima similitud basat en la HR de marcadors centromèrics. Aquest nou mètode permet la identificació del mecanisme d'origen tant a nivell poblacional com a nivell individual. Com a resultat, s'ha confirmat que SDR és el mecanisme d'origen del òvuls diploides en totes les poblacions d'híbrids triploides analitzats.

La informació obtinguda sobre aquest mecanisme d'origen ha sigut posteriorment utilitzada per a determinar les estructures genètiques i fenotípiques de noves poblacions triploides obtingudes mitjançant diferents estratègies. En aquest sentit, s'han analitzat aquestes estructures per a la resistència a la taca marró (ABS), una infermetat fúngica importat en els cítrics que produeix lesions necròtiques als fruits i fulles joves dels genotips susceptibles. En la present tesi, a partir del coneixement de l'estructura particular provinent de SDR com a mecanisme d'origen de les gàmetes no reduïdes, s'han combinat diferents estratègies per a analitzar la resistència a ABS en poblacions triploides de cítrics. S'ha confirmat en aquestes poblacions l'herència monolocus dominant proposada a partir d'estudis sobre poblacions diploides. A més, s'ha localitzat una regió genòmica lligada a la resistència a ABS prop del centròmer del cromosoma III, on s'han trobat diversos grups de gens de resistència. També s'han desenvolupat marcadors SSR i SNPs per a realitzar una selecció primerenca dels híbrids resistents, els quals estan sent utilitzats actualment al programa de millora del IVIA per a selecció assistida per marcadors.

El coneixement generat a aquesta tesi sobre el mecanismes de poliploidització sexual i I'herència de caràcters concrets en cítrics permetrà un dessenvolupament més eficient dels programes de millora en base a les necessitats actuals i futures. De fet, els resultats amb aplicació més pràctica obtinguts en aquesta tesi doctoral estan sent utilitzats actualment. 
Introduction 



\section{Contents}

1. ECONOMIC IMPORTANCE OF CITRUS …............................................................ 5

2. TAXONOMY, ORIGIN AND DIVERSITY OF CITRUS AND RELATED GENERA ........... 6

2.1 Taxonomy

2.2 Origin and distribution of cultivated citrus

2.3 The origin of intraspecific diversity

3 NEEDS IN CITRUS BREEDING 11

3.1 General objectives of scion breeding

3.2 Special focus on breeding for Alternaria brown spot resistance

4 BREEDING FOR SEEDLESS MANDARINS

4.1 Seedlessness at the diploid level
4.1.1 Managing sterility and self-incompatibility
4.1.2 Spontaneous mutation and induced mutagenesis
4.1.3 Genetic transformation

4.2 Ploidy manipulation for seedlessness. Recovery of triploid hybrids
4.2.1 Origin of polyploid citrus
4.2.2 Methods for triploid breeding

\section{MECHANISMS OF SEXUAL POLYPLOIDIZATION AND} GENETIC STRUCTURES OF TRIPLOID POPULATIONS

5.1 Mechanisms of unreduced gamete formation $(2 x \times 2 x$ crosses $)$

5.1.1 Heterozygosity restitution in the unreduced gametes and centromere mapping

5.1.2 Mechanisms of unreduced gamete formation in citrus

5.2 Diploid gametes from tetraploid parents (interploid crosses)

6 MOLECULAR RESOURCES FOR CITRUS GENETICS AND BREEDING

6.1 Molecular markers and genetic maps in citrus

6.2 Specific challenge for polyploid species genotyping

6.3 Whole-genome sequencing

6.4 Marker-trait association studies and marker assisted selection 



\section{ECONOMIC IMPORTANCE OF CITRUS}

Citrus is the main fruit crop in Spain and worldwide. Total citrus production was over 128 million tons with 9.2 million hectares of cultivated surface in 2011. Main producer countries are Brazil, China, USA, India, Mexico and Spain (FAO, 2013).

From the agronomic point of view, four varietal groups can be differentiated: oranges, mandarins, lemons/limes and grapefruits. World production is led by oranges, with 70 million tons $(60 \%)$ followed by mandarins, with 24.5 million tons $(21 \%)$, lemons/limes, with 14 million tons $(12 \%)$ and grapefruits, with 8 million tons (7\%) (FAO, 2013, Figure 1).

About one third of citrus fruit production is processed, mainly for orange juice production. Main countries in juice production are United States and Brazil, which produce more than $85 \%$ of the world market. Relating to mandarins, more than $90 \%$ of world production is destined to fresh consumption (USDA, 2013). Mediterranean countries mainly destine their citrus production for the fresh fruit market, exporting about 3.3 million tons of mandarins in 2011 (FAO, 2013). Clementine mandarins and related fruit from Spain and Morocco dominate the easy-peelers category (Ladaniya, 2008).

Spain produced 6.3 million tons in 2011 , with a cultivated surface of over 330.000 ha, mainly producing oranges (51\%) and mandarins (36\%) (Figure 1). Spain exports $57 \%$ of citrus fruit production. The Valencia region is the first Spanish citrus producer with 3.5 million tons and a cultivated surface of over 170.000 ha, which represents $56 \%$ of total Spanish citrus production (MAGRAMA, 2013). Valencia region's production (Figure 1) is led by mandarins (48\%) and oranges $(46 \%)$. Within the mandarin group, $70 \%$ of production is based on clementines and within the orange group, $81 \%$ of production is based on navel oranges (GVA, 2013).

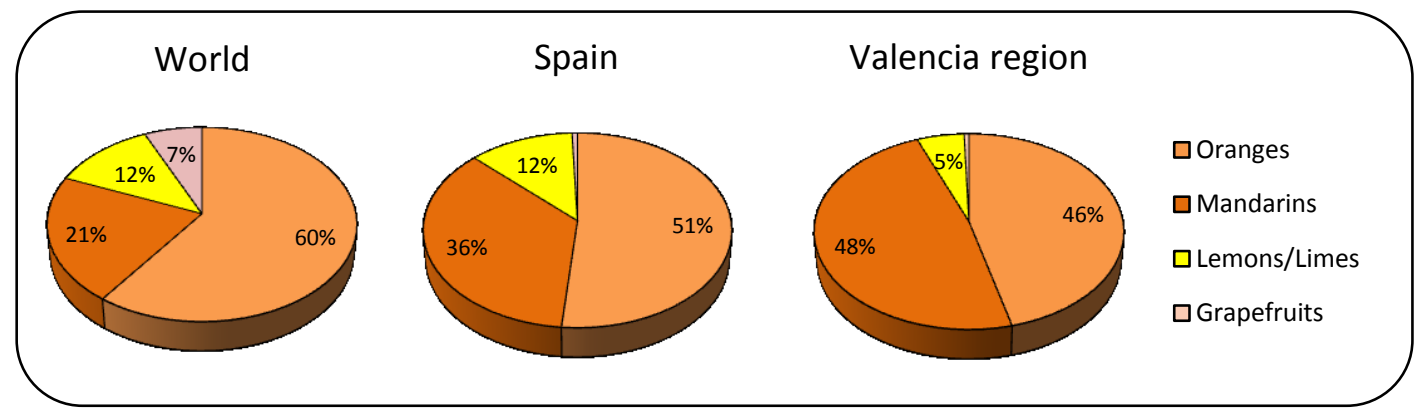

Figure 1. Proportion of the citrus production by group, worldwide, in Spain and in the Valencia region (FAO, 2013; GVA, 2013; MAGRAMA, 2013). 


\section{TAXONOMY, ORIGIN AND DIVERSITY OF CITRUS AND RELATED GENERA}

\subsection{Taxonomy}

Citrus and related genera are classified within the order Geraniales, suborder Geraniineae and family Rutaceae. This family comprises six subfamilies, with the Aurantioideae one containing Citrus and related genera. The subfamily Aurantioideae is divided into two tribes, Clauseneae y Citreae. Tribe Citreae is also subdivided into three sub tribes, with the Citrinae one comprising the true citrus sub tribe group, which includes Eremocitrus, Microcitrus, Clymenia, Fortunella, Poncirus and Citrus genera. The commonly grown citrus cultivars and rootstocks belong to these last three genera.

Fortunella is a genus with several species known as kumquats, all being small trees with a later flowering time than Citrus species, relatively cold tolerant and resistant to citrus canker and Phytophthora spp. They bear small fruits with sweet tasting rind. This genus includes four species: Fortunella margarita (Lour.) Swing., F. japonica (Thunb.) Swing., F. polyandra (Ridl.) Tan. and F. hindsii (Champ.) Swing. Kumquats have been cultivated in China for long time and are recently being used as parents in citrus breeding programs.

Poncirus includes only the Poncirus trifoliata (L.) Raf species. Its use is exclusively as a rootstock in some producing areas and as parent in rootstock breeding programs, due to its resistance to Citrus Tristeza Virus, citrus nematode (Tylenchulus semipenetrans), Phytophthora parasitica and $P$. citrophthora and its cold tolerance. Its derived hybrids with sweet oranges, ['Carrizo' and 'Troyer' citranges (C. sinensis $\times P$. trifoliata)] are the main rootstocks used in Spain; a cross derived from grapefruit and Poncirus (C. paradisi $\times P$. trifoliata) known as Citrumelo 'CPB-4475' is also used as a rootstock in some citrus producing Spanish areas.

Botanical classification within the Citrus genus has been a challenge for a long time. The most widely accepted taxonomic systems today are those of Swingle (Swingle, 1943; Swingle and Reece, 1967) and Tanaka (1977), who recognized 16 and 162 species, respectively.

Swingle divided the Citrus genus into two subgenus, Papeda and Eucitrus, mainly distinguishable by the fruit edibility. Papeda fruits contain essential oil agregates which causes sour and unpleasant taste into their juice, whereas Eucitrus fruits contain juice free of essential oils with sweet or acid taste. Papeda subgenus includes six species: Citrus ichangensis Swing., C. latipes (Swing.) Tan., C. hystrix D.C., C. micrantha Wester, C. celebica Koord. and C. macroptera Montr. Eucitrus genus includes ten species: C. medica L., (citron), C. aurantium L. (sour orange), C. limon (L.) Burn. f. (lemon), C. aurantifolia (Christm.) Swing. (lime), C. grandis (L.) Osb. (pummelo or shadock), C. sinensis (L.) Osb. (sweet orange), C. reticulata Blanco (mandarin), C. paradisi Macf. (grapefruit), C. indica Tan. and C. tachibana (Mak.) Tan., with the last two species being of less commercial importance. 
Tanaka divided the Citrus genus into two subgenera, Archicitrus and Metacitrus, including 162 species. However, in relation to the most commercially important species, differences with the Swingle classification mostly affect lemons, limes and mandarins. Tanaka divides limes into three species, C. aurantifolia (Christm.) Swing. (Mexican, Galego, Key or West Indian limes), C. latifolia Tan. (Bearss, Tahití or Persian limes) and C. limettioides Tan. (Palestine sweet lime).

The mandarin group is the main germplasm for citrus breeding. Its classification is particularly controversial. Swingle defines only one species (C. reticulata Blanco), (Swingle and Reece, 1967), whereas Tanaka includes also C. deliciosa Ten. (Mediterranean or Willowleaf mandarin), C. unshiu Marc. (satsumas), C. clementina Hort. ex Tan. (clementines), C. tangerina Hort. ex Tan. (Dancy mandarin), C. nobilis Lour. (King mandarin) and other less important species (Tanaka, 1977). From an agronomic point of view, Tanaka's classification is better adapted to the characteristics of the different agronomic groups, and it is widely used to manage germplasm collections (Krueger and Navarro, 2007). Recent molecular studies (García-Lor et al., 2013b) on mandarins reveal that the genomes of most 'mandarin-like' genotypes are complex admixtures of five parental mandarin groups and even include contributions from the other ancestral populations. In the same study, a mitochondrial analysis with indel markers revealed four mitotypes in which mandarin and 'mandarin-like' genotypes were represented.

\subsection{Origin and distribution of cultivated citrus}

Scora (1975) and Barrett and Rhodes (1976) suggested that there are only three basic true species within the subgenus Citrus: C. medica L. (citron), C. reticulata Blanco (mandarin) and C. maxima (L.) Osb. (pummelo or shaddock). Recently, this thesis has gained support from various biochemical and molecular studies (Herrero et al., 1996; Federici et al., 1998; Nicolosi et al., 2000; Gulsen and Roose, 2001; Barkley et al., 2006; Li et al., 2010; Penjor et al., 2013), suggesting that current citrus groups arise from only four ancestors: citron, mandarin, pummelo and C. micrantha Wester (a 'Papeda' wild citrus). Other cultivated species within Citrus derive from hybridizations between these true species or closely related genera followed, mainly, by natural mutations (Gmitter et al., 1992; Davies and Albrigo, 1994; Nicolosi et al., 2000; GarcíaLor et al., 2012; Ollitrault et al., 2012b; Uzun and Yesiloglu, 2012; García-Lor et al., 2013b; Figure 2). In addition, other groups of cultivars originated from hybridizations between ancestral or secondary species are of commercial importance, as tangors (sweet orange $\times$ mandarin hybrids) and tangelos (mandarin $\times$ grapefruit hybrids). 


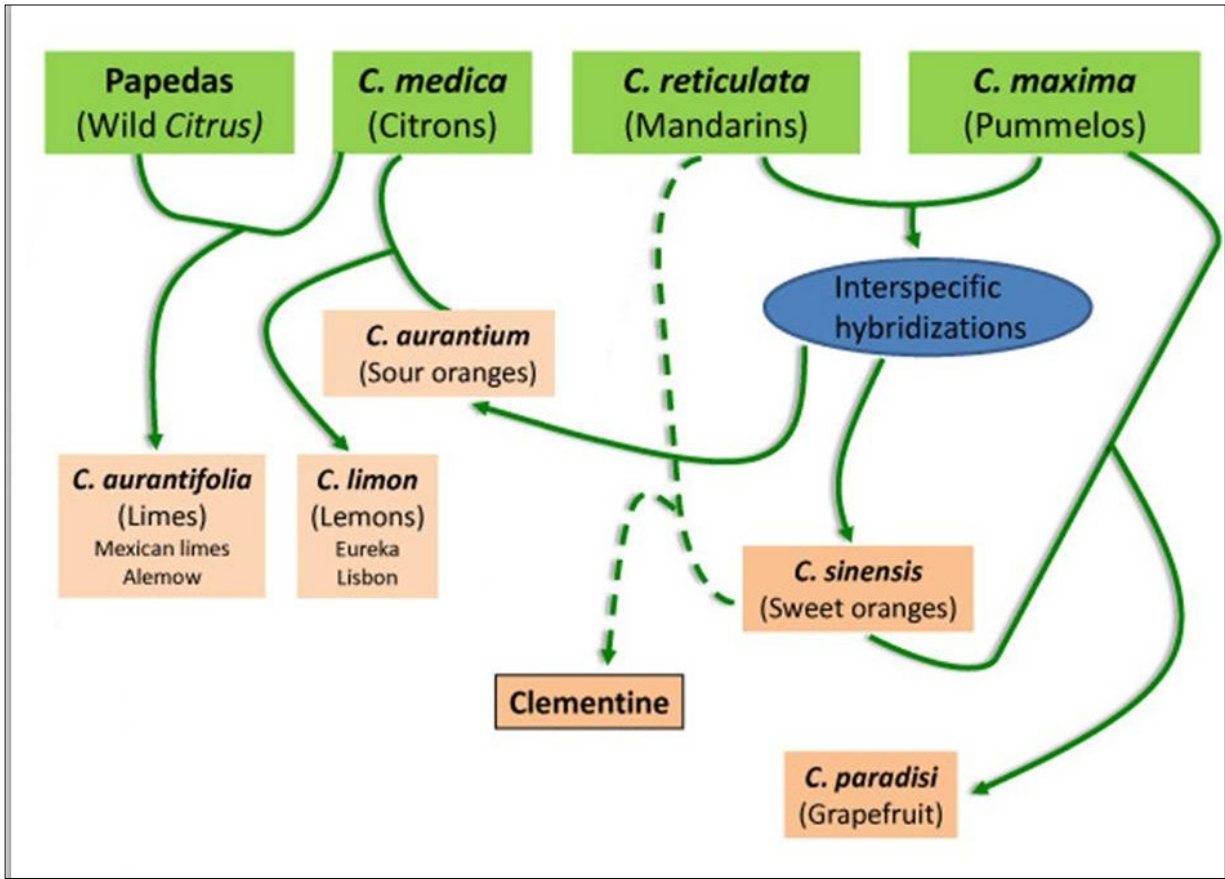

Figure 2. Schematic representation of the origin of the main citrus groups. Modified from Ollitrault et al., (2012b).

All citrus species and related genera, excluding grapefruit, are thought to have been originated in tropical and subtropical regions in Asia and Malaysian archipelago, from where they were extended to the other continents (Webber, 1967; Chapot, 1975; Ollitrault and Navarro, 2012; Figure 3).

Citron was the first citrus genotype reported in Spain in the $7^{\text {th }}$ century. It was cultivated in the Andalousia region, probably introduced from Italy by the Romans (Zaragoza, 2007).

Sour orange is a natural hybrid of a mandarin and a pummelo (Li et al., 2010). Sour orange was expanded in the $10^{\text {th }}$ century by Arab marketers from India to Iraq, Syria, Palestine, Egypt and North Africa, and from there introduced in Spain, Sicilia and Sardinia. Many studies have suggested that lemon is likely to be a natural hybrid of a citron and a lime (Scora, 1975; Barrett and Rhodes, 1976) or a hybrid of citron and sour orange (Nicolosi et al., 2000; Gulsen and Roose, 2001). Lemon is thought to have been introduced in Spain at the same time or little later than sour orange. At that time, all these species are reported to be cultivated in south regions in Spain (Zaragoza, 2007). 


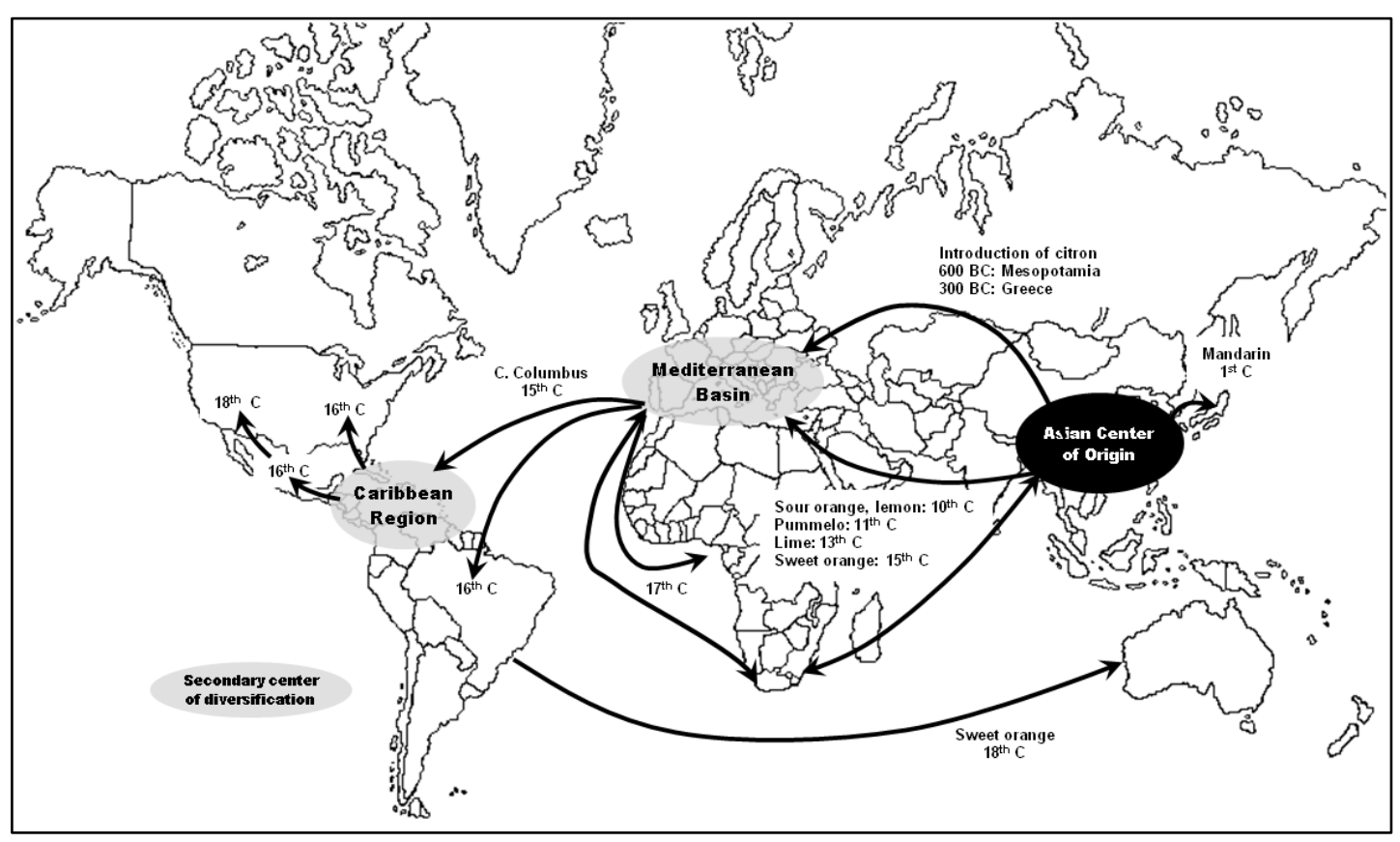

Figure 3. Origin and worldwide distribution of citrus. From Ollitrault and Navarro (2012).

Nicolosi et al. (2000) proposed that sweet orange was derived from a single cross based on equal proportions of alleles from mandarin and pummelo. However, Barkley et al. (2006) and Luro et al. (2008) suggested one or more backcrosses with mandarin and, therefore, its genetic background is mainly derived from mandarin and a small proportion from pummelo. Sweet orange was introduced in Spain four or five centuries later than sour orange, about half $15^{\text {th }}$ century, by Genovese through their commercial relations with Orient. However, it is known that Portuguese greatly contributed to their diffusion around the Iberian Peninsula and Italy, by importing seeds of better and sweeter varieties (Zaragoza, 2007).

Citrus were distributed from the Mediterranean area by three routes: by the Arabs to Africa between eleventh and thirteenth centuries; Christopher Columbus introduced them to Haiti in 1493 and the British and the Dutch introduced them in Capetown in 1654. Due to discovery of America and its gradual conquest, occurred the establishment of citrus in Mexico (1518), Brazil (1540), Florida (1565), Peru (1609) and Texas (1890). The Portuguese introduced citrus in South Africa in 1654. The first settlers brought oranges, lemons and limes from Brazil to Australia in 1769.

Mandarin was the latest citrus species introduced in Spain, by the $19^{\text {th }}$ century. It was extended around north areas in the Valencia region since 1845 (Zaragoza, 2007). The highly diverse group of mandarin includes numerous species, most of which derive from natural intergeneric and intespecific crosses, while others, which are commercially important, derive from man-made crosses (Nicolosi, 2007). 
Grapefruit was probably originated from a pummelo $\times$ sweet orange spontaneous hybridization in the Barbados Island. It was imported to Spain from California and Florida and first reported to be cultivated in Valencia in 1929 (Herrero, 1929).

\subsection{The origin of intraspecific diversity}

Most of the cultivars of orange, grapefruit, and lemon are believed to have originated from nucellar seedlings or budsports. Barrett and Rhodes (1976) reported variations in orange, lemon, grapefruit and lime based on mutations occurred on one ancestor tree. Consequently, the amount of genetic diversity within these groups is relatively low, in spite of phenotypic differences among varieties. Conversely, mandarins, pummelos, and citrons have higher levels of genetic diversity since many of the cultivars have arisen through sexual hybridization.

Mandarin germplasm was classified as C. reticulata Blanco by Swingle and Reece (1967) and Mabberley (1997). On the contrary, Webber (1967) classified mandarin genotypes into four different groups: king, satsuma, mandarin, and tangerine. Tanaka (1977) divided mandarins into five groups that included 36 species, based on morphological differences in the tree, leaves, flowers, and fruits. The mandarin group has high amount of cultivars, some of them originated from hybridization and the others derived from mutation. So, in the mandarins from hybrid origin there is a clear genetic variation. On the other hand, low level of diversity observed in the cultivars occurred by mutation, such as satsuma and clementine groups (Bretó et al., 2001; Barkley et al., 2006; Uzun and Yesiloglu, 2012). In the mandarin group germplasm, there are many hybrid accessions derived from mandarin $\times$ mandarin, mandarin $\times$ grapefruit (as tangelo), mandarin $\times$ orange (as tangor) or mandarin $\times$ tangelo. Clementine was classified by Tanaka as a Citrus species (C. clementina Hort. ex Tan.); currently, this species is one of the most important cultivated mandarins, especially in the Mediterranean countries.

Sweet orange originated as a natural hybrid between mandarin and pummelo (Barrett and Rhodes, 1976; Luro et al., 1994; Fang et al., 1997; Uzun and Yesiloglu, 2012). Recently, García-Lor et al. (2012) proposed that both parents of sweet orange have an interspecific origin. Orange cultivars are classified into four groups: common, low acidity, pigmented and navel oranges. It is considered that sweet oranges varieties originated by mutation from one ancestor tree. So, despite of differences in morphological characters, low level of genetic diversity is observed. Nevertheless, pigmented varieties, which accumulate anthocyanin, have a gene encoding a transcription factor (Ruby gene) and can be differentiated from other orange groups (Butelli et al., 2012).

Most lemons have highly similar morphological and biochemical characters, and they are reported to have originated by mutation from a single parental lemon tree (Gulsen and Roose, 2001; Luro et al., 2008; Uzun and Yesiloglu, 2012). 
Grapefruits have a nucellar and mutation origin and genetic variation among common them is very low. High level of similarity was found in grapefruit cultivars in various studies (Scora, 1988; Gmitter et al., 1992; Fang et al., 1997; Moore et al., 2000; Nicolosi et al., 2000).

\section{NEEDS IN CITRUS SCION BREEDING}

The modern citrus industry is based on grafted plant, with the scion cultivar budded on a rootstock (Khan and Kender, 2007). It allows producing disease free planting material without the juvenile phase when coupled with efficient certification schemes (Navarro et al., 1975). Moreover, the rootstock is a major component for (i) resistance to soil pathogens such as Phytophthora spp and nematodes, (ii) resistance to the Citrus tristeza virus and (iii) for adaptation to adverse environmental conditions (salinity, water deficit, calcareous soils, cold...). The rootstocks also modulate some characteristics of the scion such as fruit quality, productivity or maturing time (Khan and Kender, 2007). However, these last characteristics are mainly determined by the scion genotype, as well as tolerance to diseases affecting the crown of the tree.

\subsection{General objectives of scion breeding}

In relation with specific market demands and environmental conditions (biotic and abiotic constraints), the main goal of breeding may vary between the production areas. However, some general trends can be outlined. For juice processing, cultivars with a high percentage of pigmented juice and sugar content in their fruits are desirable (Ollitrault et al., 2008). For the fresh fruit market, expanding the harvesting period with high quality seedless fruits is currently the main objective of scion breeding (Navarro et al., 2005; Recupero et al., 2005; Roose and Williams, 2007; Aleza et al., 2010a; Cuenca et al., 2010). Biological mechanisms leading to seedlessness and breeding strategies targeting this trait are detailed in paragraph 4.

The fresh fruit market requests pomological qualities (easy peeling, seedlessness, external appearance) and organoleptic qualities (aroma, taste, acidity, sugar). Since the definition of organoleptic quality varies with the consumer, citrus breeders must therefore endeavor to develop a wide range of varieties likely to meet these diverse needs. Nutritional quality based on vitamin C, carotenoid and polyphenol contents are now considered as breeding criteria in some projects (Alquézar et al., 2009; Sdiri et al., 2012).

Resistance to some diseases that cause considerable damage in orchards is also an important objective in breeding programs. These include Huanglongbing (ex citrus greening) caused by the bacterium Candidatus Liberibacter asiaticus in Asia, South Africa and recently in Brazil and Florida; Citrus canker, caused by the bacterium Xanthomonas citri pv. citri, in most tropical and subtropical areas; cercosporiosis, caused by the fungus Cercospora aurantia, in 
Africa; Mal secco, caused by the fungus Phoma tracheiphila, in the Mediterranean Basin for lemon, citrus variegated chlorosis, caused by the bacterium Xylella fastidiosa and Sudden Death in Brazil (Ollitrault and Navarro, 2012). Alternaria Brown Spot, caused by the fungus Alternaria alternata pv. citri, is a major problem for some susceptible mandarin cultivars such as 'Fortune'. In Spain, this cultivar has been widely cultivated, but now replaced due to its high disease susceptibility (Vicent et al., 2004; Navarro et al., 2005). More details on this disease and the potential for resistant cultivar breeding are given in next paragraph 3.2. Ranges of varietal susceptibility have been established for several important diseases and tolerant or resistant parents are selected in some breeding projects. However, in the case of Huanglongbing, no exploitable resistance source has been identified. In this sense, approaches involving genetically-modified organisms are being currently exploited (Alquézar et al., 2012).

\subsection{Special focus on breeding for Alternaria Brown Spot resistance}

Alternaria Brown Spot (ABS) is a serious fungal disease, which induces necrotic lesions on fruits and young leaves, defoliation and fruit drop in susceptible citrus genotypes. ABS is caused by the tangerine pathotype of Alternaria alternata (Fr.) Keissl. (Akimitsu et al., 2003).

The disease was first observed in Australia in 1903 on 'Emperor' mandarin (Pegg, 1966), and was further detected in citrus-growing regions in America, the Mediterranean Basin, South Africa, Iran and China (Goes et al., 2001; Timmer et al., 2003; Golmohammadi et al., 2006; Wang et al., 2010). In Spain, the disease was first detected in 1998 (Vicent et al., 2000) and it is currently widespread in most citrus-growing areas.

Due to the environmental flexibility of the fungus, the disease causes severe epidemics in humid areas, as well as in semi-arid regions (Timmer et al., 2003). The pathogen sporulates on affected tissues and conidia are disseminated by air currents and rain splash. Warm temperatures and prolonged wetness on the tree are required for infection.

Currently, ABS control is strongly based on the application of fungicides. Sprays must be scheduled to protect susceptible organs during the critical periods for infection. Depending on the climate of the region and the susceptibility of the cultivar, between 4 and 10 fungicide sprays per year are needed to produce symptomless quality fruit for the fresh market (Swart et al., 1998; Bhatia et al., 2003; Peres and Timmer, 2006; Vicent et al., 2007). Systematic application of fungicides for $A B S$ control over years may create environmental problems and public health concerns (Vicent et al., 2009). Moreover, and despite of this high number of sprays, disease control is not always satisfactory and the production of susceptible cultivars such as 'Fortune' or 'Nova', among others, has declined significantly during recent years in Spain, which are being removed or substituted by resistant cultivars (Navarro et al., 2005).

Due to constraints of the citrus reproductive system (particularly apomixis of many genotypes, specific qualities or capacity to produce $2 n$ gametes (see paragraph 5 ) several ABS- 
susceptible monoembryonic cultivars are being used as parents in many mandarin breeding programs, both at diploid and triploid level (Mourao Fo et al., 1996; McCollum, 2007; Aleza et al., 2010a, 2010b; Cuenca et al., 2010; Grosser et al., 2010; Aleza et al., 2012c, 2012d; Froelicher et al., 2012; Navarro et al., 2012). For example, 'Fortune' mandarin has been the most used female parent in $2 x \times 2 x$ triploid breeding programs (Recupero et al., 2005; Navarro et al., 2012). It can produce several fold spontaneous triploid genotypes than other cultivars used as female parents, such as 'Fina' or 'Moncada' (Aleza et al., 2010b) and quality transmitted to its progenies have been demonstrated by the newly released varieties (Recupero et al., 2005; Aleza et al., 2010a; Cuenca et al., 2010). These programs have also shown that resistant triploid hybrids can be obtained when using 'Fortune' as female parents. 'Murcott' and 'Ponkan' are widely used parents in many diploid breeding programs carried out in Japan or Brazil (JinPing et al., 2009; Schinor et al., 2012). Their fruits present good quality and late ripening and its segregations are expected to be of major interest in those regions. However, they are also ABS susceptible, resulting in the segregation between resistant and susceptible hybrids in their progeny.

Other ABS-susceptible cultivars, such as 'Minneola', 'Nova', 'Fairchild', 'Fremont', 'Page', 'Orlando', 'Pixie', or 'Daisy' are also used as parents in diploid and triploid breeding programs (Aleza et al., 2012c; Williams, 2012).

Knowledge about inheritance and segregations of ABS-resistance for different hybridizations at diploid and triploid level, and for different strategies to produce triploid hybrids would greatly improve the choice of breeding parents and the managing of future hybridizations.

The tangerine pathotype of $A$. alternata, which causes ABS in citrus, has a gene cluster $(A C T T)$ located in a small (<2.0 Mb) conditionally dispensable chromosome, responsible of ACT-toxin I biosynthesis (Ajiro et al., 2010). Another selective toxin, named ACT-toxin II (or ACTG-toxin), was also identified by Kono et al. (1986); however, ACT-toxin I (ACT-toxin, hereafter) is at least tenfold more toxic to citrus. This host-specific toxin (HST) is released during the germination of conidia, rapidly affecting the integrity of plasma membrane of susceptible host cells (Kohmoto et al., 1993).

The mode of action of ACT-toxin is still ambiguous; however, a rapid loss of electrolytes from leaf tissues and invaginations in the plasma membranes of cells affected by the toxin indicates that its primary action site is likely to be the plasma membrane (Akimitsu et al., 2003). Moreover, there are indirect evidences suggesting the presence of toxin receptors in the plasma membrane of susceptible citrus genotypes (Tsuge et al., 2012). The damage to host cells caused by these toxins is extremely rapid, and the time required for cell death is extremely short (Maekawa et al., 1984; Kohmoto et al., 1993; Otani et al., 1995). Due to the rapid effect of the ACT-toxin, the incubation period is very short and lesions are visible just one or two days after infection was initiated (Canihos et al., 1999). However, although HSTs are highly toxic to host plant cells and cause cell death, the establishment of infection by the pathogen is probably 
caused by a genotype-specific suppression of defence responses rather than the induction of cell death (Tsuge et al., 2012). In addition, recent studies indicated that the mitigation of reactive oxygen species (ROS) produced by the host plants is essential for pathogenicity (Yang and Chung, 2012).

Several studies have been carried out to determine the resistance or susceptibility to ABS in citrus genotypes (Hutton and Mayers, 1988; Goes et al., 2001; Vicent et al., 2004; Dalkilic et al., 2005; Reis et al., 2007; de Souza et al., 2009). Although there are some discrepancies among them, resistance is clear for clementine (C. clementina), 'Willowleaf' (C. deliciosa) and satsuma (C. unshiu) mandarins. Susceptibility has also been well established for 'Dancy' and 'Fortune' mandarins, 'Orlando', 'Minneola' and 'Nova' tangelos and 'Murcott' tangor. Other cultivars such as 'Ellendale' tangor, and some sweet oranges and grapefruits have been characterized as sensitive or resistant depending on the authors.

ACT-toxins were found to be structurally analogous metabolites to those produced by Japanese pear (AK-toxins) and strawberry pathotypes (AF-toxins), that are esters of 9,10epoxy-8-hydroxy-9-methyl-decatrienoic acid (EDA; Figure 4); (Nakashima et al., 1985; Nakatsuka et al., 1986; Kohmoto et al., 1993). Resistance to pear and strawberry pathotypes, and also for the apple pathotype, is controlled by a single recessive allele (Kohmoto et al., 1993; Tsuge et al., 2012). Inheritance of ABS resistance in citrus has been described as a monogenic control (Dalkilic et al., 2005; Gulsen et al., 2010), also controlled by a single recessive allele. Therefore, resistant citrus cultivars are considered to be recessive homozygous for this locus, whereas susceptible cultivars could be heterozygous or dominant homozygous.

However, all these resistance/susceptibility evaluations have been conducted on diploid genotypes, and data on triploid segregations are still unknown. Moreover, there is no information about genetic location of ABS resistance locus or markers strongly linked to it. This information should be very useful in order to perform marker-assisted selection in very early stages of a breeding program, both at diploid and triploid level, and to identify candidate resistance genes. 


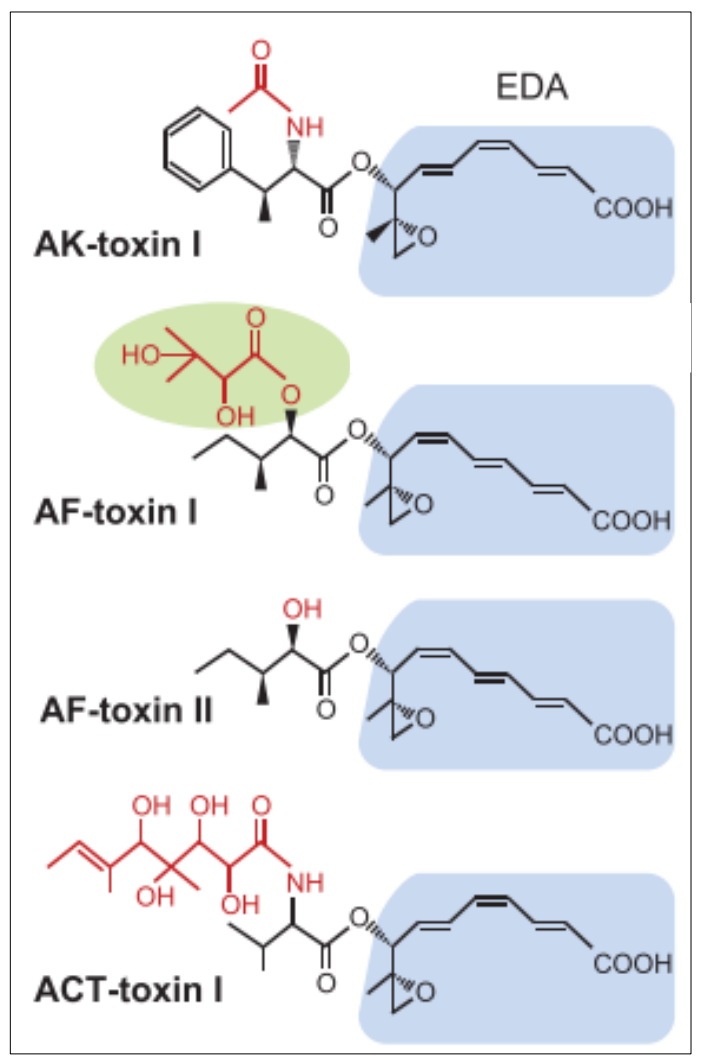

Figure 4. Chemical structures of HSTs produced by Alternaria alternata. AK-toxin I produced by the pear pathotype, AF-toxins (I and II) produced by the strawberry pathotype and ACT-toxin I produced by the tangerine pathotype, sharing the EDA: 9,10-epoxy-8-hydroxy-9-methyl-decatrienoic acid. From Tsuge et al. (2012). 


\section{BREEDING FOR SEEDLESS MANDARINS}

Seedlessness is one of the most important economic traits relating to fruit quality for freshfruit marketing, and it is also desirable for juice industry because of the unfavourable aromatic compounds associated with the presence of seeds in the fruit (Ollitrault et al., 2008). The presence of a large number of seeds in citrus fruits greatly decreases consumer acceptability, even in fruits with high organoleptic quality (Navarro et al., 2004). Therefore, presence of seeds is considered as an obstacle in releasing newly selected high quality mandarins (Vardi et al., 1996). Development of seedless cultivars has become a major goal in many citrus breeding programs around the world (Navarro et al., 2004; Recupero et al., 2005; Ollitrault et al., 2007b; Roose and Williams, 2007; Aleza et al., 2010a; Cuenca et al., 2010).

A citrus cultivar is considered to be seedless if it is able to produce normal fruits that contain no seeds, aborted seeds, or a significantly reduced number of seeds. Strong sterility or selfincompatibility coupled with parthenocarpy is necessary for stable seedless fruit production (Ollitrault et al., 2008). Parthenocarpy is the ability of a cultivar to produce fruits without fertilization. Therefore, parthenocarpy, coupled with a lack of cross- or self-fecundation, can yield seedless fruit (Vardi et al., 2008). Some level of parthenocarpy seems to be widely present in citrus germplasm, resulting in the production of seedless fruit, even in the absence of pollination (Chao, 2005). For this reason, the cultivation of self-incompatible parthenocarpic genotypes like clementines in isolated blocks results in seedless fruit production (Vardi et al., 2008). This implies that, for diversification programs, male and female sterility must be selected, particularly for areas such as the Mediterranean Basin, where the main seedless easy peeler cultivar is the self-incompatible clementine (Ollitrault et al., 2008).

From a genetic point of view, seedlessness in citrus can be achieved at diploid level essentially by managing sterility or self-incompatibility, genetic transformation or mutation (spontaneous or induced) of diploid (seedy) elite genotypes. Other widely used option is ploidy manipulation, to produce triploid hybrids.

\subsection{Seedlessness at the diploid level}

\subsubsection{Managing sterility and self-incompatibility}

Various levels of male sterility at diploid level were reported in citrus. Chromosome aberrations (Iwamasa, 1966), such as asynapsis, reciprocal translocation, inversion or failure of the spindle formation are the most widespread factors of pollen sterility (Nakamura, 1943; Raghuvanshi, 1962; Iwamasa and Iwasaki, 1963; Iwamasa, 1966). Other mechanisms of male sterility not caused by chromosome aberrations are also known, such as anther abortion or early degeneration of pollen mother cells (Osawa, 1912; Frost, 1948; Iwamasa, 1966). To 
develop new seedless cultivars efficiently, genetic analysis of male sterility has been conducted and particularly the analysis of anther abortion observed in 'satsuma' mandarins or 'Encore' mandarin. This male sterility is due to nucleo-cytoplasmic interaction and is probably controlled by more than two major nuclear genes (Iwamasa, 1966; Nakano et al., 2001; Yamamoto et al., 2001). Seedless cultivars with aborted anthers have been released in Japan (Nishiura, 1964; Matsumoto et al., 1991)). A recent study reveals that dysfunctional mitochondria seemed to cause male sterile phenotype in a cybrid pummelo (Zheng et al., 2012).

Female sterility is also a very important trait closely related to seedlessness and is a heritable characteristic (Yamamoto et al., 2001). Female sterility results from degeneration of embryo sac (Osawa, 1912) or abortion of zygote (Nesumi et al., 2001) due to chromosome aberrations.

The gametophytic self-incompatibility found in citrus is a genetically controlled phenomenon preventing seed set in self-pollinated plants producing functional gametes. In selfincompatible accessions, no pollen tubes are found in the ovaries (Ton and Krezdorn, 1967). Various accessions including almost all of pummelo, some mandarins and several natural or artificial hybrids are self-incompatible. However, many of them produce seedy fruits because of their female fertility and cross-pollination (Miwa, 1951; Mustard et al., 1956; Krezdorn and Robinson, 1958).

\subsubsection{Spontaneous mutations and induced mutagenesis}

Spontaneous mutations have played an important role in the development of new cultivars, characterized by better fruit colour, longer time periods to fruit maturity, and seedlessness. Despite of the very low frequency of spontaneous mutation, the majority of clementines, satsumas and oranges cultivars arose from spontaneous mutations (Vardi et al., 2008).

Induced mutagenesis can improve characters from the original cultivar, maintaining its genetic background (Hearn, 1984; Spiegel-Roy, 1990; Spiegel-Roy and Vardi, 1992; Vardi et al., 1996; Shu, 2009). Gamma irradiation $\left({ }^{60} \mathrm{Co}\right)$ and chemical mutagens are used to induce mutations on seeds or buds, producing several times more mutants than the spontaneous mutation (Zhang et al., 1988). Traits induced by mutagenesis include plant size, blooming time and fruit ripening, fruit colour, alterations in self-compatibility and resistance to pathogens (Predieri, 2001). 'Star Ruby' was the first citrus commercial cultivar obtained by irradiating seeds of 'Hudson' grapefruit; later, 'Rio Red' grapefruit was obtained by irradiation of 'Ruby Red' grapefruit (Hensz, 1971).

Seedlessness is the main goal in the induced mutagenesis of diploid elite cultivars. Examples of recently released seedless cultivars, obtained by induced mutation of diploid mandarin budwood are: 'Nulessin' (from 'Clemenules'), 'Mor' (from 'Murcott'), 'Orri' (from 'Orah'), 'Tango' (from 'Nadorcott'), 'DaisySL' (from 'Daisy'), 'FairchildSL' (from 'Fairchild'), 
'NovaSL' (from 'Nova'), 'Murta' (from 'Murcott'), 'Moncalina' (from 'Moncada') and 'Nero' (from 'Clemenules').

\subsubsection{Genetic transformation}

Traditional breeding programs have been hampered by the long citrus juvenile phase, polyembryony, self-incompatibility and limited knowledge on trait inheritance. Genetic engineering provides a fast and effective way to introgress specific genes in plants aiming to improve targeted traits. Inducing parthenocarpy by genetic engineering and seed-ablated strategy by expressing the cytotoxin gene (Barnase) has been experimented for molecular breeding of seedless citrus. (Li et al., 2002; Li et al., 2003) reported the generation of 'Ponkan' and 'Valencia' sweet orange transgenic plants, through Agrobacterium-mediated transformation of embryogenic calluses with a chimeric ribonuclease gene (barnase) under the control of an anther tapetum-specific promoter (pTA29). Similar approach was developed by (Koltunow et al., 2000) in Mexican limes for decreasing seed set. However, the commercialization of these products is limited by consumers' reluctance to buy genetically modified foods (Vardi et al., 2008).

\subsection{Ploidy manipulation for seedlessness. Recovery of triploid hybrids}

\subsubsection{Origin of polyploid citrus}

Polyploidy is a major component of angiosperms evolution (Grant, 1981; Soltis and Soltis, 1993; Wendel and Doyle, 2005). Many plant species result from autopolyploidization or allopolyploidization events and polyploidization should be considered as the most common of the sympatric speciation mechanism (Otto and Whitton, 2000). For a long time, chromosome doubling (autopolyploidization) was considered by most authors (Stebbins, 1971) as the major mechanism leading to polyploidy. However, Harlan and DeWet (1975) argued that spontaneous chromosome doubling must be relatively rare, while polyploidization arising from unreduced gametes (allopolyploidization) seems much more frequent. These conclusions are now assumed by numerous plant evolutionists (Bretagnolle and Thompson, 1995; Ramsey and Schemske, 1998; Ramsey, 2007).

Diploidy is the general rule in Citrus and its related genera, with a basic chromosome number $x=9$ (Krug, 1943). However, some triploid and tetraploid genotypes have been early detected in citrus germplasm or seedlings (Longley, 1925; Lapin, 1937; Iwasaki, 1943). Longley (1925) was the first to formally identify a tetraploid wild form, the 'Hong Kong' kumquat. Other examples of the few natural polyploids found in the germplasm of Aurantioideae are the triploid 'Tahiti' lime, tetraploid strains of Poncirus trifoliata, allotetraploid Clausena excavata, tetraploid Clausena harmandiana and hexaploid Glycosmis pentaphylla (Ollitrault et al., 2008). 
In citrus germplasm, apomictic (nucellar polyembryony) and non-apomictic genotypes are found (Cameron and Frost, 1968). Spontaneous autotetraploidization seems to occur frequently in apomictic citrus genotypes by chromosome doubling of nucellar tissue (Aleza et al., 2011). In non-apomictic genotypes, doubled-diploid plants are not found in the citrus germplasm, but can be artificially produced by treatment of micro-grafted shoot-tips or embryogenic callus with colchicine and oryzalin to achieve chromosome doubling (Tachikawa et al., 1961; Barret, 1974; Gmitter and Ling, 1991; Gmitter et al., 1991; Aleza et al., 2009b). Stable tetraploid plants of different mandarins have been developed for use as male and female parents in interploid hybridizations (Aleza et al., 2012c, 2012d).

Somatic hybridization of two diploid genotypes also allows obtaining tetraploid plants (Grosser et al., 2010; Grosser and Gmitter, 2011). Tetraploid genotypes arising from chromosome doubling, chemical treatments or somatic hybridization are widely used as male parents in breeding programs (Aleza et al., 2012c). Also, tetraploid genotypes are currently interesting to be used as rootstocks (Saleh et al., 2008; Allario et al., 2011; Dambier et al., 2011; Grosser and Gmitter, 2011).

Spontaneous triploidization in citrus has been reported to arise from unreduced (2n) gametes (Soost, 1987; Iwamasa et al., 1988; Luro et al., 2004), probably due to the abortion of the second meiotic division in the megaspore (Esen et al., 1979; Luro et al., 2004), whereas non-reduced pollen seems to be extremely rare in citrus (Esen et al., 1979; Luro et al., 2004). It appears that most of the spontaneous triploids arising from diploid parents are found in small and abnormal seeds (Esen and Soost, 1971, 1973; Geraci et al., 1975; Aleza et al., 2010 b), which are unlikely to germinate without implementation of an embryo rescue procedure. Unreduced gametes due to meiotic restitution and/or other variant meiotic events and resultant polyploidy have been documented in many plant species (Dewitte et al., 2012; Singh et al., 2012).

\subsubsection{Methods for triploid breeding}

Obtaining triploid hybrids has become an important breeding strategy to develop new seedless citrus commercial varieties (Starrantino, 1992; Navarro et al., 2004; Ollitrault et al., 2008). Indeed, many triploid varieties have been released from citrus breeding programs worldwide, including 'Oroblanco' and 'Melogold' grapefruits (C. grandis $\times$ C. paradisi) (Cameron and Bernett, 1978; Soost, 1987), and 'Winola' (Spiegel-Roy and Vardi, 1992). More recently, 'Shasta Gold $\AA$ ', 'Tahoe Gold $\AA$ ' and 'Yosemite Gold®' triploid mandarins were released by the USA program in California (Roose et al., 2002); 'Tacle', 'Clara', 'Mandared', 'Mandalate' and other triploid mandarins were released by the Italian program (Recupero et al., 2005) and 'Garbi' (Aleza et al., 2010a) and 'Safor' mandarins (Cuenca et al., 2010) were released by the Spanish program. 
Triploid genotypes have generally been considered to be an evolutionary dead-end because they have very low fertility and tend to produce aneuploid gametes, due to problems of chromosome pairing during meiosis (Otto and Whitton, 2000; Ollitrault et al., 2008). Cytogenetic studies have shown that during meiosis of citrus triploid hybrids, trivalent, bivalent and univalent associations are formed (Cameron and Frost, 1968), producing sterile gametes. Moreover, the abortion of megasporogenesis during the period between the first division of embryo-sac and the fecundated egg-cell is common (Fatta Del Bosco et al., 1992). For this reason, citrus triploid plants are generally sterile, although they can occasionally produce fruits with very few seeds.

Triploid hybrids have been produced by sexual hybridizations of $2 x \times 2 x, 2 x \times 4 x$ and $4 x$ $\times 2 x$, endosperm culture (Wang and Chang, 1978; Gmitter et al., 1990) or by diploid + haploid somatic hybridizations (Kobayashi et al., 1995; Ollitrault et al., 1996b). In citrus germplasm, apomictic (polyembryonic) and non-apomictic (monoembryonic) genotypes can be found (Frost and Soost, 1968). The majority of citrus genotypes are apomictic, with the exception of all citrons (C. medica), pummelos (C. grandis), clementines (C. clementina) and some mandarins. One of the major limitations of any sexual hybridization strategy in citrus is that it is extremely difficult to use apomictic cultivars as female parents to produce large progeny and monoembryonic genotypes have to be used as female parents. Concerning polyembryonic cultivars, (Wakana et al., 1981) showed that triploid zygotic embryos should be found with diploid nucellar embryos in small seeds. However, the practical possibility to select these triploid embryos is limited greatly by the polyembryony (Geraci et al., 1977; Wakana et al., 1981). To avoid this problem, Geraci et al. (1977) proposed a very early rescue of zygotic embryos from immature fruits, but it seems that selection of triploids from polyembryonic seedlings has not found real applications in citrus breeding.

Sexual polyploidization $(2 \mathrm{x} \times 2 \mathrm{x}$ crosses): $\mathrm{In}$ this case, spontaneous triploid hybrids arise from the union of a $2 n$ megagametophyte with haploid pollen (Cameron and Frost, 1968; Esen and Soost, 1971, 1973; Geraci et al., 1975; Ollitrault et al., 1996a; Luro et al., 2004; Chen et al., 2008a; Aleza et al., 2010b). The recovery of triploid citrus hybrids arising from unreduced (2n) megagametophytes produced by diploid plants was described in the 1970s (Esen and Soost, 1971, 1973). Cytogenetic studies (Esen and Soost, 1971) showed that triploid embryos are associated with pentaploid endosperm, indicating that triploid hybrids result from the fertilization of unreduced ovules by normal haploid pollen. Moreover, this ratio between the ploidy level of embryos and endosperm is responsible for seed size reduction. The frequency of such events is generally low (Cameron and Frost, 1968; Esen and Soost, 1971; Geraci et al., 1975) and extensive breeding programs based on this type of hybridization require very effective methodologies for embryo rescue and ploidy evaluation of large progenies. The mechanisms that lead to unreduced gamete formation and their genetic consequences are explained at point 5.1 of this introduction. 
Interploid crosses $(2 x \times 4 x$ and $4 x \times 2 x)$ : Interploid crosses have been used by breeders to obtain triploid hybrids. Triploid plants recovered from interploid crosses result from the fecundation of a diploid gamete arising from the tetraploid parent and a haploid gamete arising from the other parent. Taking advantage of the spontaneous chromosome doubling in apomictic genotypes, most of the early triploid breeding projects were based in the use of these spontaneous tetraploid genotypes as male parents $(2 x \times 4 x$ hybridization; Cameron and Frost, 1968; Esen et al., 1978; Oiyama et al., 1981; Starrantino and Recupero, 1981; Aleza et al., 2012c). More recently, the recovery of tetraploid monoembryonic genotypes (Aleza et al., 2009b) allowed developing the $4 x \times 2 x$ strategy at large scale (Aleza et al., 2012d).

Segregation and recombination of tetraploids is complex (Wu et al., 2001a, 2001b). Indeed, it depends on (i) preferential pairing between homeologous chromosomes that defines the proportion of bivalent and multivalent formation (Wu et al., 2001b) and (ii) double reduction frequency in case of tetravalent formation (Mather, 1936). More details on tetraploid meiosis and resulting structure of diploid gametes are given in paragraph 5.2.

Involvement of somatic hybridization in triploid breeding: Somatic hybridization via protoplast fusion is an approach that has been used in the creation of triploids and novel tetraploid germplasm for improving rootstock and scion varieties (Raza et al., 2003; Ollitrault et al., 2007a). The first somatic hybrid of citrus was produced by Ohgawara et al. (1985) and numerous inter and intrageneric somatic hybrids have been produced until now (Grosser and Gmitter, 1990; Louzada et al., 1992; Louzada et al., 1993; Ollitrault et al., 1995; Grosser et al., 2000; Mendes et al., 2001; Grosser et al., 2010; Dambier et al., 2011; Grosser and Gmitter, 2011). Somatic hybridization could be used to produce quality tetraploid breeding parents that can be used in a conventional interploid breeding program to generate seedless triploids or to produce them directly by haploid + diploid protoplast fusion (Ollitrault et al., 1996b; Guo et al., 2000). However, a successful somatic hybridization program requires a complete and long-term effort, and mainly, this last approach have failed to have a major impact on crop development because of difficulties in protoplast isolation, culture and plant regeneration in many elite crop genotypes, small availability of haploid parents and the elevated ploidy levels resulting when somatic hybrid plants could be produced (Grosser et al., 2000; Grosser and Gmitter, 2011).

Endosperm culture: This technique could be a tool to overcome the barriers of sexual hybridization that results from nucellar embryony and can theoretically be applied to all germplasm with female fertility. Successful regeneration of triploid plantlets has been reported by Wang and Chang (1978) and Gmitter et al. (1990). However, the step of shoot or embryos regeneration from endosperm calli appears a critical step (Jaskani et al., 1996) that practically limits greatly the application of this technique for breeding purpose. Indeed, it appears difficult to obtain large recombining populations to apply efficient field selection. 


\section{MECHANISMS OF SEXUAL POLYPLOIDIZATION AND GENETIC STRUCTURES OF TRIPLOID POPULATIONS}

\subsection{Mechanisms of unreduced gamete formation $(2 x \times 2 x$ crosses $)$}

Although polyploids can originate by an increase of chromosome number either during somatic growth or during meiosis, the major route is now considered to be via the formation of unreduced $(2 n)$ gametes (Harlan and DeWet, 1975). The formation of $2 n$ gametes occurs in several plant species and can give rise to triploids that can serve as a bridge to the establishment of an even set of chromosomes in subsequent generations (Henry et al., 2005).

Unreduced gametes most commonly arise through meiotic defects and the so-called meiotic nuclear restitution was described for the first time by Rosenberg (1927). Meiosis is a specialized cell division that is essential for sexual reproduction. It involves a single round of DNA replication followed by two rounds of chromosome division to produce cells with half the chromosome number of the mother cell. During meiotic prophase I, the meiosis-specific events of pairing and recombination between homologous chromosomes occur. These processes are important not only for generating genetic variability in the offspring but also for establishing the attachments between chromosomes required for the subsequent divisions (Brownfield and Kohler, 2011). In the first meiotic division, the homologous chromosomes are separated in what is referred to as a reductional division. Second meiotic division resembles mitosis in that it involves the separation of sister chromatids and is referred to as an equational division.

Mechanisms underlying meiotic restitution are still unclear, although more attention has been placed on this complex meiotic process in recent years (Cai and Xu, 2007). Several meiotic aberrations related to spindle formation, spindle function and cytokinesis lead to unreduced gamete formation in plants. Up to seven major mechanisms of $2 n$ gamete formation have been cytogenetically characterized: premeiotic doubling; first-division restitution (FDR); chromosome replication during the meiotic interphase; second-division restitution (SDR); postmeiotic doubling; indeterminate meiotic restitution and apospory (Peloquin et al., 1989; Lim et al., 2001; Dewitte et al., 2012). However, FDR and SDR are considered the predominant mechanisms of $2 n$ gamete formation (Bretagnolle and Thompson, 1995; Tavoletti et al., 1996; Cai and Xu, 2007). Failure of the first (FDR) or second division (SDR) leads to the formation of restitution nuclei with unreduced chromosomes. If the first meiotic division fails at anaphase I, all the chromosomes stay on the equatorial plate to form one restitution nucleus with the same chromosome number as the mother cell at the first division, which usually undergoes normal second meiotic division. This failure is characterized by an equational division of the entire chromosome complement (as in mitosis) and the formation of two nuclei with unreduced chromosome number. In case of SDR, the first meiotic division proceeds normally, but the second division fails at anaphase II, resulting in two nuclei with unreduced chromosomes (Cai and $\mathrm{Xu}, 2007$ ). Therefore, a FDR $2 n$ gamete contains non-sister chromatids, while a SDR $2 n$ gamete contains two sister chromatids [(Tang and Luo, 2002); Figure 5] 


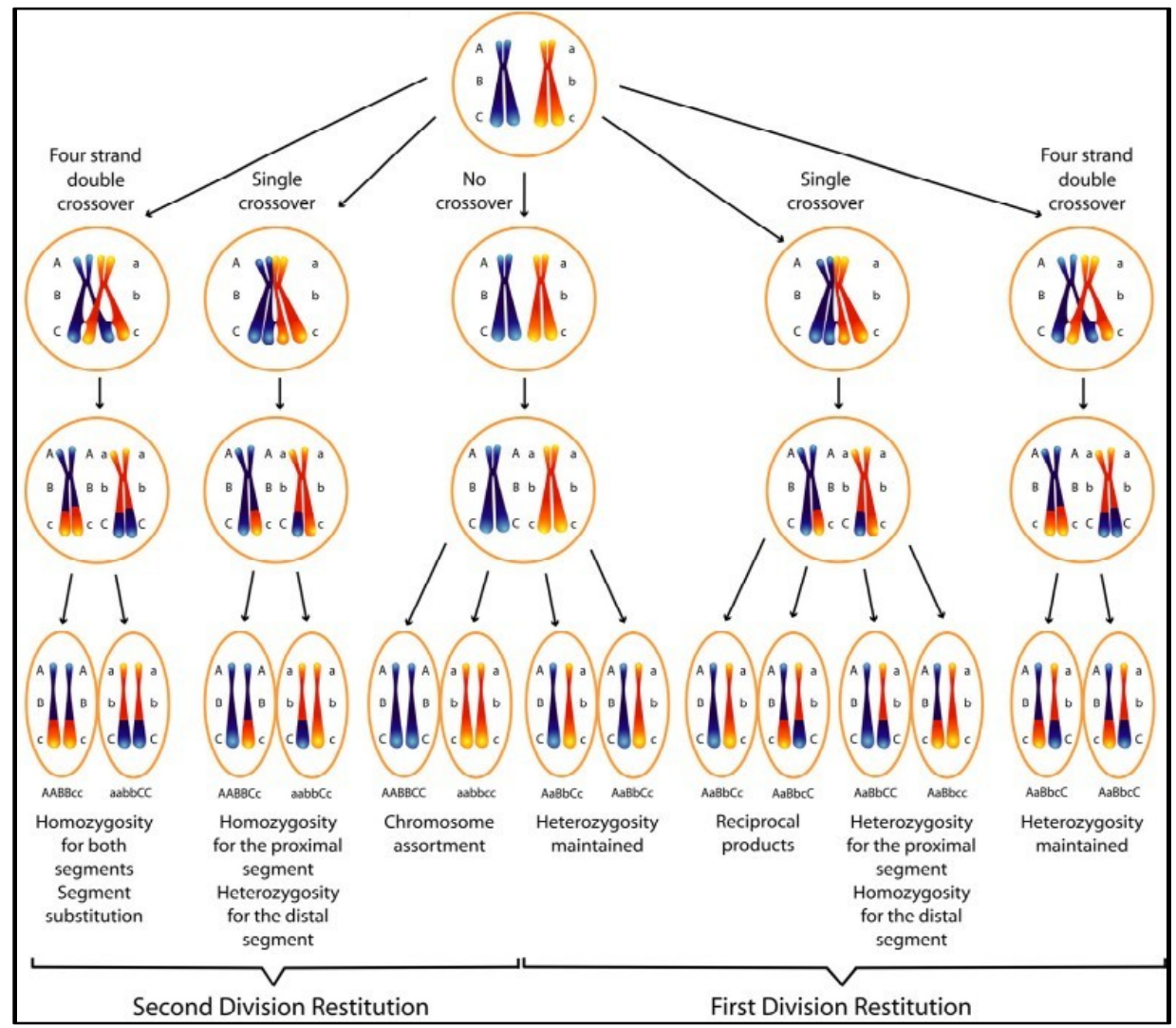

Figure 5. Genetic constitution of unreduced gametes resuting from FDR and SDR mechanisms. From Barba-Gonzalez et al. (2008).

From the cytogenetic point of view, several mechanisms lead to FDR or SDR-unreduced gamete formation. Semi-heterotypic division (Rosenberg, 1927), mitotised-meiosis (Stebbins, 1932; 1950), pseudohomoeotypic division (Gustafsson, 1935), aberrant cytokinesis (Ramanna, 1974), parallel spindle (Mok and Peloquin, 1975) and fused spindle (Ramanna, 1979) produce FDR 2n-gametes (Ramanna, 1979; Peloquin et al., 1989; Vorsa and Rowland, 1997). In the same way, mechanisms genetically equivalent to SDR, known as premature cytokinesis 1 and 2 (Mok and Peloquin, 1975) have been reported (Veilleux, 1985; Bretagnolle and Thompson, 1995).

In addition to that, other mechanisms have been described leading to unreduced gametes genetically different than those coming from SDR or FDR. Lim et al. (2001) described the Indeterminate meiotic restitution (IMR) as a novel type of meiotic nuclear restitution mechanism, in which numerically disproportionate numbers of chromosomes occur due to a restitution mechanism which cannot be categorized as either FDR or SDR. In this case, although the $2 n$ gamete can have the euploid number, each set has not contributed the same number (Dewitte et al., 2012). Premeiotic (chromosome doubling before meiosis) and postmeiotic (chromosome doubling after meiosis) restitution and cytomixis have also been proposed as possible mechanisms for the production of $2 n$ gametes (Bastiaanssen et al., 1998). 
The identification of the mechanisms behind the formation of $2 n$ gametes is complex. However, the use of cytological techniques (genomic in situ hybridization-GISH or fluorescent in situ hybridization-FISH) or marker analysis on polyploid progeny may provide accurate or additional information on these mechanisms (Lim et al., 2001; Crespel and Gudin, 2003; Dewitte et al., 2012). Molecular cytological approaches have been successfully used in the case of allopolyploids, where the constituent genomes can be clearly discriminated. This includes the unequivocal identification of not only genomes and individual alien chromosomes but also recombinant segments in the sexual polyploid progenies. Through DNA in situ hybridization, genomes of allopolyploids can be more critically assigned and intergenomic translocations and recombination events can be detected (Takahashi et al., 1997; Karlov et al., 1999; Lim et al., 2001; Ramanna and Jacobsen, 2003; Barba-Gonzalez et al., 2005). However, although both GISH and FISH are powerful tools for parental genome analysis, few studies in citrus have been reported, partly because citrus chromosomes are very small and indistinguishable (BarbaGonzalez et al., 2005; Jaskani et al., 2007). In contrast, molecular marker analysis has proved as a very useful tool to estimate the heterozygosity transmission through the diploid gametes to polyploid progenies and, therefore, to identify the mechanism underlying unreduced gamete formation (Barone et al., 1995; Vorsa and Rowland, 1997; Bastiaanssen et al., 1998; Barcaccia et al., 2003; Luro et al., 2004; Chen et al., 2008a; Hayashi et al., 2009).

Although production of $2 n$ gametes is highly affected by environmental factors (De Storme and Geelen, 2013), several heritability assays show that the rate of $2 n$ gamete production is under a strong genetic control and is often determined by a few loci (Ramsey and Schemske, 1998; Barcaccia et al., 2003; de Storme and Geelen, 2011). Mok and Peloquin (1975) and Qu et al. (1995) suggested that four recessive genes determined the $2 n$ gamete formation in potatoes. Zhang et al. $(2000 ; 2007)$ indicated that a single major recessive gene determined the $2 n$ gamete formation in Chinese cabbage, and it is tightly linked to a centromere. Recent research on Arabidopsis thaliana has led to many advances in elucidating the molecular mechanisms underlying unreduced gamete formation, as well as the first genes in which mutations result in the production of viable $2 n$ gametes (Brownfield and Kohler, 2011). D'Erfurth et al. (2008) were the first to successfully isolate and characterize the Arabidopsis thaliana Parallel Spindle1 (AtPS1) gene involved in $2 n$ gamete production due to an abnormal orientation of spindles at meiosis II. Mutations in Arabidopsis DYAD/SWITCH1 and maize AG0104 and AM1 induce a complete loss of meiosis I, and consequently convert the meiotic cell cycle into a mitotic one (D'Erfurth et al., 2009). De Storme and Geelen (2011) observed and characterized another unreduced gamete producer mutant called jason. Mutants of two other genes (OSD1/GIG1 and TAM/CYCA2;1) were shown to omit the second meiotic division in both male and female sporogenesis at high frequency resulting in the formation of highly homozygous $2 n$ pollen and egg cells (d'Erfurth et al., 2009). 


\subsubsection{Heterozygosity restitution in the unreduced gametes and centromere mapping}

The genetic structures of $2 n$ gametes depend on their origin mechanisms and are very different for SDR and FDR. Such origin particularly affects the transmission of the parental heterozygosity in relation to the distance to the centromere. With FDR, the non-sister chromatids transmit the parental heterozygosity from the centromere to the first crossover point. With SDR the two sister chromatids are homozygous between the centromere and the first crossover point. It results in that the SDR $2 n$ gametes have lower levels of heterozygosity than the FDR ones (Bretagnolle and Thompson, 1995).

The heterozygosity transmitted through $2 n$ gametes can be estimated by analysis of the progeny with molecular markers. Several reports on Solanum spp. indicate that FDR gametes transmit $70-80 \%$ of the parental heterozygosity, whereas SDR gametes transmit about 30-40\% (Douches and Quiros, 1988; Werner and Peloquin, 1990, 1991; Barone et al., 1995). Such values were also reported in other crops: roses, ryegrass, Begonia and Vaccinium darrowi (Vorsa and Rowland, 1997; Crespel and Gudin, 2003; Chen, 2007; Dewitte et al., 2012). In general, FDR is more than twice as effective in transmitting heterozygosity as SDR (Peloquin et al., 2008).

For both FDR and SDR mechanisms, the rate of parental heterozygosity transmission $(\mathrm{H})$ is a function of the rate of single crossing over (Co) between the centromere and the considered locus (Zhao and Speed, 1996). From the centromere to the telomere, it varies between 0 and 100\% for SDR ( $\mathrm{H}=\mathrm{Co}$ ) and from 100 to $50 \%$ for FDR $(\mathrm{H}=1-1 / 2 \mathrm{Co})$, with the hypothesis that single chiasma frequency between the centromere and the locus vary between 0 for centromeric locus and $100 \%$ for telomeric ones (Park et al., 2007). Such model assumes a complete chromosome arm interference (a first crossing over in chromosome arm totally prohibits the occurrence of a second one). Such assumption has been verified from half tetrad analysis (HTA) of some plants such as potatoes (Park et al., 2007) and animals such as salmon (Lindner et al., 2000). However, numerous cases of incomplete chromosome interference have been described both in plants and animals (Broman et al., 2002; Copenhaver et al., 2002; Esch and Weber, 2002; Saintenac et al., 2009; Giraut et al., 2011). Under no interference, H varies between 1 and $2 / 3$ for FDR and from 0 to 2/3 for SDR, from the centromere to the telomere (Figure 6). 


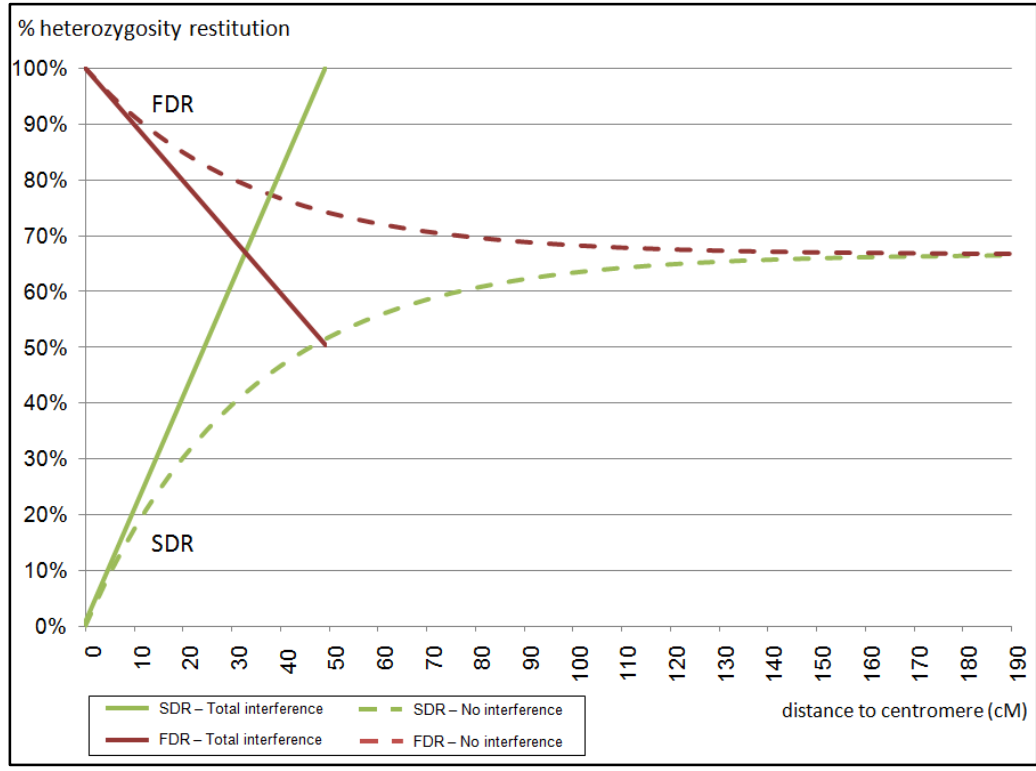

Figure 6. Theoretical curves of heterozygosity restitution as function of genetic distance to the centromere for FDR and SDR without chiasma interference and total interference models.

Conversely, the relation between the heterozygosity restitution at a locus and the distance of this locus to the centromere allow mapping centromere in linkage groups. The centromere is a specialized domain in most eukaryotic chromosomes that ensures delivery of one copy of each chromosome to each daughter cell during cell division by the mechanisms of kinetochore nucleation, spindle attachment, and sister chromatid cohesion.

Half-tetrad analysis (HTA) has been used in several plant and animal species for centromere mapping. HTA is an approach comparable to tetrad analysis, although based on only two chromatids from a single meiosis. These two chromatids remain together due to omission of the first (FDR) or the second (SDR) meiotic division, resulting in numerically unreduced gametes (Douches and Quiros, 1988; Kauffman et al., 1995; Lindner et al., 2000; Okagaki et al., 2008). HTA could be used without a previous genetic map of the markers and can be applied with a predefined order of markers (Tavoletti et al., 1996) or without any previous information about marker position (Da et al., 1995). However, many models of HTA are based on the hypothesis of complete interference, which not always occurs. Indeed, pattern of heterozygosity restitution along the chromosome may vary between the different models of chiasma interference assumed (Zhao and Speed, 1998a). Therefore, a method which allows comparing a large range of partial interference model functions is suitable.

Once centromere is mapped, molecular markers close to it could be identified (Mendiburu and Peloquin, 1979) and, therefore, the mode of $2 n$ gamete formation could be determined through analysis of the segregating marker in the progeny. 


\subsubsection{Mechanisms of unreduced gamete formation in citrus}

Cytogenetic studies showed that triploid embryos are associated with pentaploid endosperm, indicating that triploid hybrids result from the fertilization of unreduced ovules by normal haploid pollen (Esen and Soost, 1971). Esen et al. (1979) proposed that $2 n$ eggs result from the abortion of the second meiotic division in the megaspore (SDR) in citrus. This hypothesis has been corroborated for clementine (Citrus clementina Hort. ex Tan.) by molecular marker analysis (Luro et al., 2004). However, Chen et al., (2008a) proposed that $2 n$ eggs of sweet orange (C. sinensis (L.) Osb.) resulted from first meiotic division restitution (FDR). It is, therefore, important to shed light on the mechanism underlying $2 n$ gamete formation in a wide range of citrus genotypes used as female parents in $2 x \times 2 x$ triploid breeding programs.

\subsection{Diploid gametes from tetraploid parents (interploid crosses)}

There is a basic distinction between autopolyploids and allopolyploids, both having multiple sets of chromosomes. Autopolyploids result from a variation of ploidy within a single species, so chromosomes are of the same type and have the same origin. Allopolyploids refer to the association of two differentiated genomes, through the process of hybridization and subsequent chromosome doubling, so both the type and the origin of chromosome are different (Gallais, 2003). Allopolyploids are generally considered to be much more prevalent in nature than are autopolyploids but, as detected from a growing number of genetic analyses, autopolyploids should be more common than previously assumed (Soltis and Soltis, 2000). An immediate consequence of polyploidy is the change in gametic and segregation frequencies (Comai, 2003).

In allopolyploids, identical or at least fully homologous genomes occur in pairs, but different pairs of a genome have a strong pairing barrier (Sybenga, 1996). Because only homologous chromosomes pair, allopolyploids strictly exhibit bivalent formation (two chromosomes pair) at meiosis and undergo disomic inheritance for each locus (Gallais, 2003).

For autopolyploids, all the chromosomes are homologous and have equal opportunities to pair at meiosis. Since pairing can start at different chromosomal sites, homologous chromosomes may switch partners, leading to multivalent formation (more than two chromosomes pair) and a type of inheritance called polysomic (Jackson and Jackson, 1996; Sybenga, 1996; Hauber et al., 1999). Heterozygosity transmission from an autotetraploid to its diploid gamete depends on the double reduction frequency, defined as the probability of two sister chromatids occurring in the same gamete (Marsden et al., 1987). Although segregation patterns depend on the frequency of crossing over between the centromere and a given loci, and therefore, they are expected to vary with the position of the locus on the chromosome, little empirical information concerning the frequency of double reduction is available (Gallais, 2003). This frequency assumes maximum values of 0 (random chromosome segregation), 1/7 (with 
pure random chromatid segregation), and 1/6 (with maximum equational segregation; (Muller, 1914; Mather, 1936). The average rate of parental heterozygosity restitution is $2 / 3$ in case of random segregation, while it will be only $5 / 9$ in case of maximum chomatid equational segregation.

It appears that many tetraploids have not systematic disomic or tetrasomic inheritance, but display intermediary inheritance (Danzmann and Bogart, 1983; Marsden et al., 1987; Jackson and Jackson, 1996). Indeed, allo- and autotetraploids (with disomic and tetrasomic inheritance, respectively) are the extremes of a range (Figure 7). In cases where parents are divergent but have retained enough homology to prevent exclusive preferential pairing, inheritance patterns intermediate between di- and tetrasomic can be expected (Stift et al., 2008). For example, in citrus Kamiri et al. (2011) showed that a somatic hybrid between lemon and mandarin had an intermediate inheritance with preferential tetrasomic tendency, while an intergeneric somatic hybrid between Poncirus and mandarin displayed an intermediary inheritance with preferential disomic tendency (Kamiri et al., 2012).

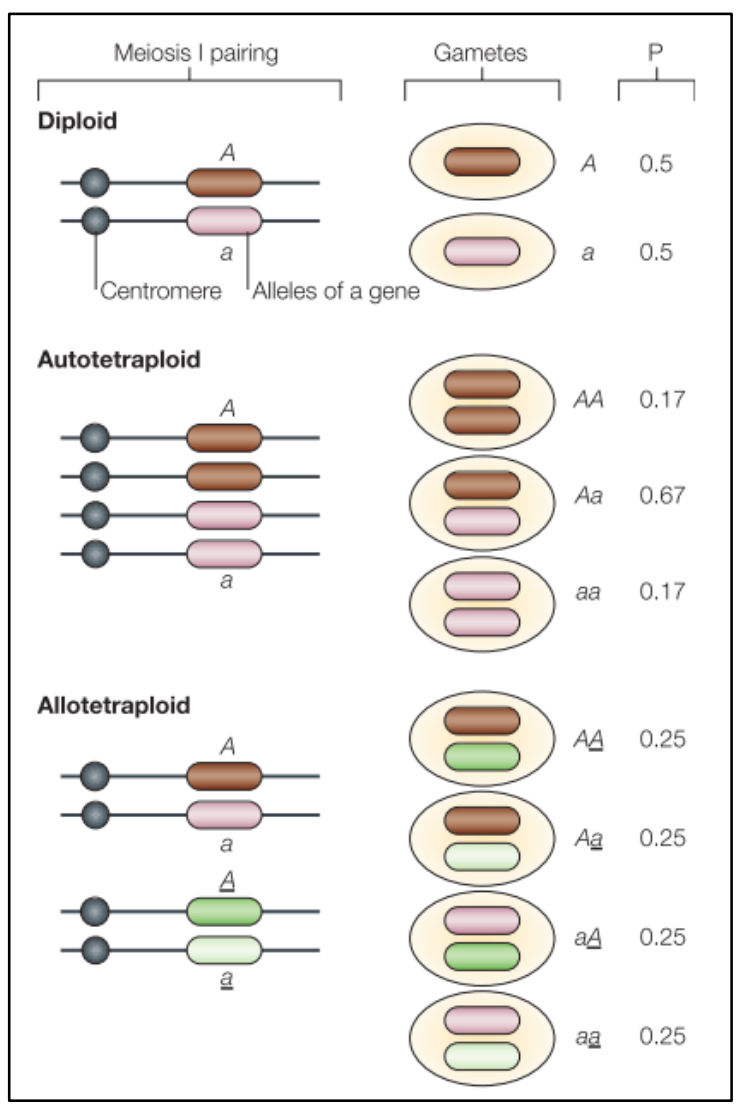

Figure 7. Meiotic arrangements and gametic output in diploids, autotetraploids and allotetraploids. A diploid heterozygote Aa produces two types of gamete in equal proportion $(P)$. An autotetraploid with genotype AAaa produces, under the model of random chromosome segregation three types of gamete. An allotetraploid with genotype AaAa produces four types of gamete. From Comai (2003). 


\section{MOLECULAR RESOURCES FOR CITRUS GENETICS AND BREEDING}

\subsection{Molecular markers and genetic maps in citrus}

Molecular markers are specific fragments of DNA that can be identified within the whole genome and are transmitted by the standard laws of inheritance from one generation to the next. The development of molecular markers based on DNA sequences has provided a useful tool for enlarging the knowledge of inheritance of economically important characters. A wide variety of DNA-based markers have been developed, both PCR-based and non-PCR-based (Agarwal et al., 2008).

Since isozymes markers (Torres et al., 1978; 1982; Roose, 1988), several kinds of nuclear markers have been used for citrus genetic studies such as Random Amplified Polymorphic DNA [RAPDs; (Luro et al., 1994)], Sequence Characterized Amplified Regions [SCARs; (Nicolosi et al., 2000)], Restriction Fragment Length Polymorphism [RFLPs; (Federici et al., 1998)], Intersimple sequence repeat [ISSRs, (Fang et al., 1997)], Amplified Fragment Length Polymorphism (AFLPs; (Liang et al., 2007; Pang et al., 2007) and Cleaved Amplified Polymorphic Sequences (CAPs) from ESTs (Lotfy et al., 2003). Single-stranded conformational polymorphism (SSCP) analysis has been used for cytoplasm characterization (Olivares-Fuster et al., 2007). In the last 10 years, a limited number of Simple Sequence Repeat (SSRs) have been derived from genomic libraries (Kijas et al., 1997; Barkley et al., 2006; Froelicher et al., 2008): 56 SSRs were obtained from the Genbank citrus EST data (Chen et al., 2006) and more than 200 SSR markers have been developed (Luro et al., 2008) from the 1,600 microsatellite sequences from 37,000 ESTs characterized by Terol et al. (2007). The same group identified more than 7,600 SSRs from BAC end sequencing (Terol et al., 2008) that have been used to develop SSR markers allowing direct anchoring of the genetic and physical maps (Ollitrault et al., 2012a). In addition to genetic mapping, SSRs have been used for the analysis of genetic diversity (Luro et al., 2001; Barkley et al., 2006; García-Lor et al., 2013b), characterization of somatic hybrids, discrimination between zygotic and nucellar seedlings (Ruiz et al., 2000; Ruiz and Asins, 2003), control of the origin of plants obtained by induced gynogenesis (Froelicher et al., 2007), molecular characterization of triploid cultivars (Aleza et al., 2010a; Cuenca et al., 2010) and the analysis of the origin of unreduced gametes (Luro et al., 2004; Chen et al., 2008a).

More recently, the availability of large set of sequencing data has opened the way for insertion-deletion (InDel) and single nucleotide polymorphism (SNP) marker development (García-Lor et al., 2012; Ollitrault et al., 2012, 2012b; García-Lor et al., 2013b).

A very important outbreak for efficient use of molecular markers in genetics and breeding is the availability of genetically mapped codominant markers anchored with the physical sequence. Such citrus reference map was established recently for clementine (Ollitrault et al., 2012a). Despite the heterogeneous dispersion of markers, this medium density reference map 
(961 markers for $1084.1 \mathrm{cM}$ ) constitutes a good framework for further marker-trait association studies, and it has been used to enable the chromosome assembly of the reference whole genome citrus sequence (Wu et al., 2013).

\subsection{Specific challenge for polyploid species genotyping}

Despite the undisputable importance of polyploid plant species, the genetics of these plant species are less well known than those of their diploid counterparts, which is especially evident in research fields as DNA analysis (Esselink et al., 2004). Indeed, the estimation of molecular marker allele copy number has long been considered a challenge for polyploid species with polysomic inheritance, while it is essential to assign the allelic configuration for different types of heterozygotes for accurate population genetic studies. In segregating polyploid progenies, the population genetic structure can provide relevant information about the underlying meiosis mechanisms that take place in the formation of these progenies, which also greatly affect character segregation (Hutten et al., 1993; Tai and DeJong, 1997; Douches and Maas, 1998; Barcaccia et al., 2003; Brownfield and Kohler, 2011). Moreover, allelic dosage can affect gene expression and phenotype. Therefore, the determination of allelic dosages is particularly important for marker/trait association studies (De Jong et al., 2003; Sjoling et al., 2005). However, there is a major problem to define which allele(s) occur in more than one copy when the number of displayed DNA alleles in a sample is less than the possible maximum number for that ploidy level in species with polysomic inheritance, such as SNP markers, which are mostly biallelic. For a triploid plant with two detected alleles, two heterozygous configurations are possible (2:1 or 1:2); for a tetraploid plant, three different allelic configurations are possible (3:1, $2: 2$ or 1:3). With higher ploidy levels, the number of possible allelic configurations becomes even larger (Esselink et al., 2004).

Several techniques have been used to estimate allele dosage in polyploids, such as the useful MAC-PR method (Esselink et al., 2004) for SSR markers; however, SSR analysis remains relatively costly and time consuming compared with present SNP genotyping methods. Moreover, with the increasing availability of EST databases and whole genome sequences, SNPs have become the most abundant and powerful polymorphic markers that can be selected along the entire genome (Edwards and Batley, 2010).

Techniques for SNP genotyping include allele-specific primer extension (Kwok, 2001), temperature-switch PCR (Tabone et al., 2009), array methodologies (Ishikawa et al., 2005), and targeted pyrosequencing (Ahmadian et al., 2000). The application of SNP markers has been limited primarily to diploid organisms, while the application of these markers to polyploid organisms for allele dosage estimation remains limited. The usefulness of SNPlex ${ }^{\mathrm{TM}}$ (Berard et al., 2009) and Illumina Golden Gate ${ }^{\mathrm{TM}}$ assays (Akhunov et al., 2009) for polyploid wheat genotyping has been demonstrated. However, these techniques are more suitable for 
genotyping large numbers of samples over numerous markers than for performing small scale analysis.

It is, therefore, important to develop alternative methods that offer a wider spectrum of genotyping possibilities to infer SNP allelic configurations in polyploid plants, particularly in citrus, for small- to larger-scale projects.

\subsection{Whole-genome sequencing}

Genomics has provided new tools for crop improvement, helping to identify and select candidate genes responsible of agronomic characters of interest, and allowing the development of fast methods to incorporate these characters into crop plants (Terol et al., 2007).

Citrus, with a basic chromosome number of 9 , has a relatively small genome size. Haploid genomes of $C$. sinensis and $C$. clementina are, respectively, $380 \mathrm{Mb}$ and $370 \mathrm{Mb}$ of size (Arumuganathan and Earle, 1991).

BAC libraries of sweet orange, clementine, and satsuma have been established in the last few years in Spain, Japan, and the USA. The Spanish Citrus Genomic Consortium has constructed three BAC libraries from the clementine mandarin (EcoR I, Hind III, and Mbol) containing a total of 57,000 clones with an average insert size of $120 \mathrm{~kb}$ (19x coverage). 28,000 BAC clones were end-sequenced and these sequences analyzed (Terol et al., 2008). The Citrus Genome Analysis Team from Japan is engaged in the construction of a physical map of citrus by HICF (High-Information-Content Fingerprinting) analysis of a BAC library from the 'satsuma' mandarin consisting of 37,000 clones, with $13.3 x$ coverage of the citrus genome. A BAC library of 'Ridge Pineapple' sweet orange was produced in USA (USDA-ARS, Ft. Pierce, $\mathrm{FI}$, USA) containing 18,432 clones (BamHI/Mbo I) with an average insert size of $145 \mathrm{~kb}$, or an estimated $7 x$ coverage. A total of 16,727 clones from this library have been fingerprinted and assembled into 472 contigs (http://phymap.ucdavis.edu:8080/citrus/).

A low-coverage $(1.2 \mathrm{X})$ shotgun sequence of the $C$. sinensis genome has revealed the difficulties related to high heterozygosity, and lead the International Citrus Genomic Consortium to select a haploid clementine (Aleza et al., 2009a) as the model for whole citrus genome sequencing. The International Consortium for Citrus Genomics has recently released the whole genome sequence of the haploid clementine, assembled in pseudo-chromosome [www.phytozome.net, (Wu et al., 2013)]. This reference sequence is currently used as template to organize sequences of the highly heterozygous species such as $C$. sinensis, $C$ paradisi, and C. limon

Recently, Xu et al. (2013) sequenced and assembled a dihaploid genome of sweet orange and mapped the parental diploid genomic DNA sequence reads to the haploid reference genome to complete the construction of the heterozygous genome map. The availability of the 
sweet orange and clementine genome sequence provides a valuable genomic resource for citrus genetics and breeding improvement.

In addition, the complete chloroplast genome sequence of $C$. sinensis was published by Bausher et al. (2006). It is 160.129 bp in length and contains 133 genes (89 protein-coding, 4 rRNAs, and 30 distinct tRNAs).

\subsection{Marker-trait association studies and marker assisted selection}

Quantitative Trait Loci (QTLs) and genetic association studies are used to find candidate genes or genome regions that contribute to a specific phenotypic trait, by testing for a correlation between phenotypic diversity and genetic variation (Lewis and Knight, 2012). Then, the identified DNA markers can be used to infer the presence of allelic variation in the genes underlying these traits and to assist plant breeding (marker-assisted selection - MAS). Selection can be carried out at the seedling stage, allowing more effectively selection of target genotypes and resulting in faster variety development and releasing (Bertrand et al., 2008). This is of particular interest for tree species with long juvenile phase, such citrus.

The detection of major genes and QTLs controlling traits is based on the linkage disequilibrium between closely linked loci. Significant genetic association may be interpreted as either direct association, in which the genotyped molecular marker is the true causal variant conferring phenotypic variation; or indirect association, in which a molecular marker in linkage disequilibrium with the true causal variant is genotyped. Distinguishing between direct and indirect association is challenging and may require resequencing of the candidate region, dense genotyping of all available markers, or functional studies to confirm the role of a putative mutation in the phenotypic trait (Lewis and Knight, 2012). In citrus, only a few characters of agronomic interest have been linked to molecular markers, such as RAPD markers linked to dwarfing (Cheng and Roose, 1995), RAPD markers linked to a gene controlling fruit acidity (Fang et al., 1997), SSR markers linked to CTV resistance from Poncirus trifoliata (Gmitter et al., 1996; Yang et al., 2003; Asins et al., 2004; Bernet et al., 2004), AFLP markers linked to nucellar embryony (García et al., 1999; Kepiro and Roose, 2010) and the dominant PCR assay for the anthocyan content of pulp from blood orange due to a transposable element in the 5' extremity of the Ruby gene (Butelli et al., 2012). Other characters of interest have been tagged to QTLs, such as salinity tolerance (Moore et al., 2000) and nematode resistance (Ling et al., 2000). Alternaria brown spot resistance has also been tagged with molecular markers. (Dalkilic et al., 2005) reported two RAPD markers with loose linkage with the locus (15.3 cM and 36.7 $\mathrm{CM}$ far from $\mathrm{ABS}$ resistance locus in the same side). More recently, (Gulsen et al., 2010) identified two flanking SRAP markers at $3 \mathrm{cM}$ and $13 \mathrm{cM}$. However, markers tightly (or completely) linked to ABS resistance would greatly improve the selection of resistant genotypes

in early development stages and avoid growing susceptible genotypes (false positives) or discard resistant ones (false negatives). 
Objectives 

Sexual polyploidization through unreduced gamete formation is currently a central approach in citrus triploid breeding programs aiming to develop new seedless cultivars. However, despite the undisputable importance of polyploid plant species, their genetics are less well known than those of their diploid counterparts, which is especially evident in research fields as DNA analysis. Indeed, the estimation of molecular marker allele copy number has long been considered a challenge for polyploid species with polysomic inheritance, while it is essential to assign the allelic configuration for different types of heterozygotes for accurate population genetic studies. For SSR markers, these allelic configurations in polyploids can be assigned using the microsatellite allele counting - peak ratios method (MAC-PR). However, SSR analysis remains relatively costly and time consuming compared with actual SNP genotyping methods; moreover, with the increasing availability of SNP information in citrus, an efficient method for SNP genotyping allowing inferring allele doses in polyploid genotypes appears essential for optimal integration of molecular tools in citrus triploid breeding. Allelic configurations in triploid segregating polyploid progeny, particularly in citrus, should provide useful information in the underlying meiosis mechanisms that take place in the formation of these progeny and other genetic studies.

The genetic structure of triploid progeny arising from unreduced gametes depends on their mechanism of origin, being very different for first-division restitution (FDR) and second-division restitution (SDR). Moreover, for a concrete gene, segregations in triploid populations also depend on the gene-centromere distance. In this context, deep knowledge of the mechanism underlying meiotic nuclear restitution producing unreduced gametes and location of centromeres are crucial to optimize breeding strategies based on sexual hybridization. Moreover, trait segregations in triploid populations still not well understood, due to the complexity of polyploid genomes and eventually non-Mendelian segregations. In the case of citrus, the inheritance of very few characters has been studied on triploid progenies and genetic determinants underlying their segregations have not been characterised in any case.

Alternaria brown spot (ABS) is a major fungal disease which affects susceptible mandarin cultivars and causes a substantial loss of production and fruit quality, limiting the number of usable breeding parents for triploid breeding. Knowledge on segregations for ABS-resistance for different breeding strategies and the identification of linked molecular markers would greatly improve the breeding efficiency for resistant cultivar selection.

The specific objectives of the PhD thesis are the following:

\section{Objective 1: To implement a versatile SNP genotyping method to efficiently assign allelic configuration in polyploid plants}

With the increasing availability of SNPs markers in citrus, which have become the most abundant and powerful polymorphic markers that can be selected along the entire genome, a new method to assign SNP allele dosage in an accurate, simple, and cost effective way, usable in small- to large-scale projects will be developed. 
Objective 2: To shed light on the mechanism underlying unreduced gamete formation in a wide range of citrus genotypes used as female parents in $2 x \times 2 x$ triploid breeding programs

The origin of unreduced megagametophytes in citrus is still controversial, although differences in genetic structures are expected for FDR and SDR origin. Moreover, segregations for concrete loci depend on the locus-centromere distance and are different for each mechanism. In this context, three objectives have been developed:

2.1 To develop and apply a method for centromere mapping which allows comparing a large range of partial interference model functions

2.2 To develop and apply a method for identifying unreduced gamete formation mechanism both at population and at individual level based on markercentromere distances

2.3 To investigate the origin of unreduced gametes for sixteen mandarin genotypes used as female parents

Objective 3: To gain knowledge about inheritance, genetic and molecular determinism of ABS-resistance

The mode of inheritance for ABS-resistance has been previously studied at diploid level, but segregations on triploid populations still unknown. Moreover, development of molecular markers for an early selection of ABS resistant hybrids would greatly improve the efficiency of breeding programs. In this context, three objectives have been developed:

3.1 To analyze segregations of ABS-resistance for different parents and strategies of triploid breeding

3.2 To locate a chromosome region associated with the ABS-resistance and to identify candidate resistance genes in the located region

3.3 To develop molecular markers for marker-assisted selection in citrus breeding programs for ABS-resistance 
The manuscript is structured in four chapters, corresponding to published or in preparation scientific articles:

Chapter 1: Assignment of SNP allelic configuration in polyploids using competitive allele-specific PCR: application to citrus triploid progenies. Cuenca, et al. (2013). Annals of Botany 111: 731 - 742. Objective 1.

Chapter 2: Multilocus half-tetrad analysis and centromere mapping in citrus: evidence of SDR mechanism for $2 \boldsymbol{n}$ megagametophyte production and partial chiasma interference in mandarin cv 'Fortune'. Cuenca et al. (2011). Heredity 107: 462 - 470. Objective 2.

Chapter 3: Maximum-likelihood method based on parental heterozygosity restitution of centromeric loci identifies SDR as the predominant mechanism leading to $2 n$ megagametophytes in C. reticulata. Cuenca et al. Annals of Botany, Submitted. Objective 2.

Chapter 4: Genetically based location from triploid populations and gene ontology of a 3.3-Mb genome region linked to Alternaria brown spot resistance in citrus reveal clusters of resistance genes. Cuenca et al. (2013). PLOS ONE 8(10): e76755. Objective 3. 



\section{Chapter 1}

\section{Assignment of SNP allelic configuration in polyploids using competitive allele-specific PCR: application to citrus triploid progenies}

José Cuenca, Pablo Aleza, Luis Navarro and Patrick Ollitrault

Annals of Botany (2013) 111: 731 - 742. doi:10.1093/aob/mct032 

Abstract

Background: Polyploidy is a major component of eukaryote evolution. Estimation of allele copy numbers for molecular markers has long been considered a challenge for polyploid species, while this process is essential for most genetic research. With the increasing availability and whole genome coverage of SNP markers, it is essential to implement a versatile SNP genotyping method to efficiently assign allelic configuration in polyploids.

Scope: This work evaluates the usefulness of the KASPar method, based on competitive allelespecific PCR, for the assignment of SNP allelic configuration. Citrus was chosen as a model because of its economic importance, the ongoing worldwide polyploidy manipulation projects for cultivar and rootstock breeding, and the increasing availability of SNP markers.

Conclusions: Fifteen SNP markers were successfully designed that produced clear allele signals that were in agreement with previous genotyping results at the diploid level. The analysis of DNA mixes between two haploid lines (Clementine and pummelo) at 13 different ratios revealed very high correlation (average $=0.9796 ; S D=0.0094$ ) between the allele ratio and two parameters [theta angle $=\tan ^{-1}(y / x)$ and $y^{\prime}=y /(x+y)$ ] derived from the two normalised allele signals ( $x$ and $y$ ) provided by KASPar. Separated cluster analysis and analysis of variance (ANOVA) from mixed DNA simulating triploid and tetraploid hybrids provided $99.71 \%$ correct allelic configuration. Moreover, triploid populations arising from $2 n$ gametes and interploid crosses were easily genotyped and provided useful genetic information. This work demonstrates that the KASPar SNP genotyping technique is an efficient way to assign heterozygous allelic configurations within polyploid populations. This method is accurate, simple, and cost effective. This genotyping technique has been successfully applied to two citrus triploid populations arising from $2 n$ gametes and interploid crosses. Moreover, this method appears to be useful for quantitative studies, such as relative allele-specific expression analysis and bulk segregant analysis. 


\section{Introduction}

Polyploidy is a major component of eukaryote evolution, particularly in angiosperms (Grant, 1981; Soltis and Soltis, 1993; Wendel and Doyle, 2005). Many plant species result from autopolyploidization or allopolyploidization events, and polyploidization is considered the most common sympatric speciation mechanism (Otto and Whitton, 2000). Despite the undisputable importance of polyploid plant species, the genetics of these plant species are less well known than those of their diploid counterparts. Indeed, the estimation of molecular marker allele copy number has long been considered a challenge for polyploid species with polysomic inheritance, while it is essential to assign the allelic configuration for different types of heterozygotes for accurate population genetic studies. In segregating polyploid progenies, the population genetic structure can provide relevant information about the underlying meiosis mechanisms that take place in the formation of these progenies, which also greatly affect character segregation (Hutten et al., 1993; Tai and DeJong, 1997; Douches and Maas, 1998; Barcaccia et al., 2003; Brownfield and Kohler, 2011). Moreover, allelic dosage can affect gene expression and phenotype. Therefore, the determination of allelic dosages is particularly important for marker/trait association studies (De Jong et al., 2003; Sjoling et al., 2005). When parents of a polyploid progeny share one allele, only the dosage allele estimation allows knowing the alleles transmitted by each parent to heterozygous progeny. Therefore, knowledge of allelic dosage in polyploids appears to be essential for studies using single nucleotide polymorphisms (SNPs) markers, most of which are biallelic.

Several techniques have been used to estimate allele dosage in polyploid genotypes or tissues. When analysing microsatellite markers (SSRs), the microsatellite allele counting - peak ratios method (MAC-PR; (Esselink et al., 2004) is especially useful. However, SSR analysis remains relatively costly and time consuming compared with actual SNP genotyping methods. Moreover, with the increasing availability of EST databases and whole genome sequences, SNPs have become the most abundant and powerful polymorphic markers that can be selected along the entire genome (Edwards and Batley, 2010).

Several SNP genotyping methods have been developed. Some methods are based on electrophoretic separation after PCR amplification, including allele-specific primer extension (Kwok, 2001) and temperature-switch PCR (Tabone et al., 2009). High-throughput genotyping can be obtained using array methodologies (Sapolsky et al., 1999; Ishikawa et al., 2005); other techniques are based on pyrosequencing ${ }^{\text {TM }}$ (Ronaghi et al., 1998; Ahmadian et al., 2000). However, the application of SNP markers has been limited primarily to diploid organisms, while the application of these markers to polyploid organisms for allele dosage estimation remains limited. Rickert et al. (2002) reported the use of pyrosequencing ${ }^{\mathrm{TM}}$ in polyploid potatoes, with some sequence-specific limitations. The usefulness of SNPlex ${ }^{\mathrm{TM}}$ (Berard et al., 2009) and Illumina Golden Gate ${ }^{\mathrm{TM}}$ assays (Akhunov et al., 2009) for the genotyping of polyploid wheat has been demonstrated. For genotype calling in tetraploid species with SNP analysis using the Illumina GoldenGate ${ }^{\mathrm{TM}}$ array, Voorrips et al. (2011) developed an algorithm using mixture 
models, but they assumed Hardy Weinberg equilibrium within the population, which does not occur in all segregating polyploid progeny. Microarray data (Kirov et al., 2006; Meaburn et al., 2006; Steer et al., 2007) have also been used to estimate allelic frequencies in bulk populations or DNA pools, i.e., to perform genome-wide association scans. Array analysis is more suitable for genotyping large numbers of samples over numerous markers than for performing small scale analysis, as array analysis lacks flexibility in term of the numbers and panels of SNP loci that can be analyzed. Targeted pyrosequencing ${ }^{\mathrm{TM}}$ (Gruber et al., 2002; Neve et al., 2002; Wasson et al., 2002; Lavebratt et al., 2004) can be useful for performing allele frequency estimation for a few genes in pooled DNA, but this technique remains relatively costly and time consuming. It is, therefore, important to develop alternative methods that offer a wider spectrum of genotyping possibilities to infer SNP allelic configurations in polyploid plants in small- to larger-scale projects.

The KBiosciences Competitive Allele-Specific PCR SNP genotyping system (KASPar) is a homogeneous fluorescent endpoint genotyping system (Cuppen, 2007), that utilises a unique form of competitive, allele-specific PCR and combines the use of a highly specific 5'-3' exonuclease-deleted Taq DNA polymerase with two competitive, allele-specific, tailed forward primers and one common reverse primer. This system is simple and cost effective compared to other SNP genotyping assays and is well adapted to low-to-medium throughput genotyping projects (Chen et al., 2010). This technology has been successfully applied to the study of humans, animals, and plants (Nijman et al., 2008; Bauer et al., 2009; Cortés et al., 2011; Rosso et al., 2011).

Citrus is mainly diploid. However, many modern breeding projects for the production of seedless mandarins based on the production of triploid hybrids (Ollitrault et al., 2008; Aleza et al., 2010b, 2012c, 2012d) and tetraploid rootstocks are promising (Saleh et al., 2008; Dambier et al., 2011; Grosser and Gmitter, 2011). Triploid populations in citrus can arise from unreduced gametes in crosses between diploid parents or from interploid (diploid $x$ tetraploid or tetraploid $x$ diploid) crosses. Sexual polyploidization resulting from $2 n$ megagametophyte production is routinely exploited for triploid citrus breeding (Aleza et al., 2010b). In such crosses, segregation of a marker depends on the parental genetic structure, the relative distance to the centromere, and the mode of restitution (First Division Restitution [FDR] or Second Division Restitution [SDR]). The MAC-PR method has been successfully applied to demonstrate the SDR origin of the $2 n$ gametes arising from the 'Fortune' mandarin cultivar and to locate the centromere in one chromosome (Cuenca et al., 2011). For interploid crosses, marker segregations are almost exclusively dependent on the parental genetic conformation and preferential chromosome pairing. SSR markers were also used to analyse the meiotic behaviour of a tetraploid interspecific somatic hybrid of C. deliciosa + C. lemon (Kamiri et al., 2011), concluding that there was predominant tetrasomic segregation. However, the low availability of SSR markers displaying favourable parental allelic structure that can be used to differentiate male and female contributions to the hybrids limits such studies to just a few areas of the genome. Conversely, 
large SNP resources have become available from extensive sequencing projects (Terol et al., 2007; Terol et al., 2008; Gmitter et al., 2012; Ollitrault et al., 2012b).

The objective of the present work was to evaluate the potential of the KASPar method to assess SNP allelic configurations in polyploid plants. Citrus was chosen as a model system because of its economic importance, the worldwide ongoing polyploidy manipulation projects for cultivar and rootstock breeding, and the increasing availability of SNP markers.

The quantitative value of the KASPar assay was estimated by pooling DNA from two haploid lines at several relative concentrations, simulating, among others, triploid and tetraploid heterozygous progeny. A method was developed for semi-automated polyploid genotype calling and applied for allelic configuration analysis of 170 triploid hybrids from two families arising from both sexual polyploidization and interploid crosses.

\section{Material and methods}

\section{Sample preparation}

\section{DNA pool preparation:}

Genomic DNA from two haploid lines, Citrus maxima (Burm.) Merr. (pummelo) cv 'Chandler' and C. clementina Hort. ex Tan. [clementine; (Aleza et al., 2009a)] was isolated using a Plant DNAeasy Kit from Qiagen Inc. (Valencia, CA, USA) following the manufacturer's protocol. DNA concentrations were estimated with PicoGreen ${ }^{\circledR}$ and adjusted to $30 \mathrm{ng} / \mu \mathrm{l}$. DNA from the two haploid lines were pooled at ratios of $9: 1,5: 1,3: 1,2: 1,3: 2,1: 1,2: 3,1: 2,1: 3,1: 5$, and 1:9. Five samples (replications) of each haploid line and pool were prepared and used to test the accuracy of the technique.

\section{Simulation of triploid and tetraploid hybrid samples by pooling DNA from haploid lines:}

Two subsets of haploid DNA pool, one corresponding to $2: 1$ and 1:2 ratios that simulated heterozygous triploid genotypes and the other corresponding to $3: 1,1: 1$, and 1:3 ratios that simulated tetraploid heterozygous genotypes, were jointly used with the haploid genotypes to test the capability of the technique to discriminate among different types of heterozygotes within triploid and tetraploid populations.

\section{Natural triploid populations:}

$2 x \times 2 x$ crosses: 'Fortune' (C. clementina $\times$ C. tangerina) and 'Willowleaf' (C. deliciosa Ten.) diploid mandarins and 39 triploid hybrids segregating from this cross (Aleza et al., 2010b) were selected to test the accuracy of the technique by analysing two replicates of each sample. Moreover, 86 triploid hybrids from 'Clementine' (C. clementina) × 'Nadorcott' (C. reticulata 
Blanco) population (Aleza et al., 2010b) were also analyzed as individual samples to perform genotype calling.

$4 x \times 2 x$ cross: Tetraploid 'Clementine' (C. clementina $4 x$ ) and diploid 'Pink' pummelo (C. maxima $2 x$ ) and 88 triploid hybrids segregating from this cross (Aleza et al., 2012d) were also analyzed. Tetraploid 'Clementine' was obtained by treating buds of the diploid 'Clementine' with colchicines (Aleza et al., 2009b); therefore, this genotype should be duplex (aabb) for all heterozygous loci.

\section{SNP selection}

\section{SNPs for the analysis of signal-dosage correlation:}

To validate the quantitative value that was obtained from the KASPar assay using pooled DNA, seven SNPs differentiating the two haploid lines (C. maxima and C. clementina) were selected from previous genotyping data obtained on the Illumina GoldenGate $®$ platform (Ollitrault et al., 2012b). These SNPs were also used to test the accuracy of the technique in genotyping repetitions of the same sample over the 'Fortune' $\times$ 'Willowleaf' triploid population.

\section{SNPs for triploid population analysis:}

Three out of seven SNPs used for the previous analysis, and eight other SNP markers, were selected to test the capacity of the technique for differentiating between heterozygous genotypes within two triploid populations, one arising from a $2 x \times 2 x$ cross, and the other from a $4 x \times 2 x$ cross. These SNPs are heterozygous for 'Clementine' and homozygous or heterozygous with null allele for 'Nadorcott' and 'Pink'.

\section{SNP genotyping}

All samples were genotyped for the SNP markers using KASPar technology by KBioscience ${ }^{\circledR}$ (http://www.kbioscience.co.uk/). The KASPar ${ }^{\mathrm{TM}}$ Genotyping System is a competitive, allele-specific dual Förster Resonance Energy Transfer (FRET)-based assay for SNP genotyping. It uses two FRET cassettes where fluorometric dye [FAM (6-carboxyfluorescein) or $V I C \otimes]$ is conjugated to primer but quenched via resonance energy transfer; ROX dye (6-carboxy-X-rhodamine, succinimidyl ester) is used to normalise the data. Sample DNA is amplified with a thermal cycler using allele-specific primers, leading to the separation of fluorometric dye and quencher when the FRET cassette primer is hybridised with DNA. Primers were designed by $\mathrm{KBioscience} \AA$, based on the SNP locus flanking sequence (approximately 50 nt on each side of the SNP). Two 40-mer allele-specific oligonucleotides and one common 20mer oligonucleotide were defined for each locus. Detailed information for all SNP markers can be found in Additional File 1. Additional details about this genotyping method can be found in Cuppen (2007). 


\section{Data analysis method}

Normalised signals from each SNP allele ( $x$ and $y$ ) were provided by KBioscience $₫$ services, and two-dimensional plot representations were obtained using SNPViewer software (http://www.kbioscience.co.uk/software/SNP\%20viewer\%20intro.html). From the $x$ and $y$ normalised values, the theta angle $\left[\theta=\tan ^{-1}(y / x) ; 0^{\circ} \leq \theta \leq 90^{\circ}\right]$ and the relative $y$ allele signal $\left[y^{\prime}=y /(x+y) ; 0 \leq y^{\prime} \leq 1\right]$ of each sample were calculated. Further analyses were carried out that considered the $y^{\prime}$ parameter, as this parameter was found to provide better clustering and genotype calling of the samples.

Data from all haploid lines and DNA pools with different allele configurations (9:1, 5:1, $3: 1,2: 1,3: 2,1: 1,2: 3,1: 2,1: 3,1: 5$, and 1:9) were tested for correlations between doses and both the theta angle and $y$ ' values that were obtained. Cluster analysis (MacQueen, 1966) using the farthest-neighbour method with standardised squared euclidean distances and ANOVA were performed from the normalised allele signals $(x, y)$ jointly and from the $y$ ' parameter data for each SNP.

Data from triploid and tetraploid simulated populations were also analyzed separately by cluster analysis and ANOVA. Replications of the same samples were used to test the precision of the technique by genotype calling.

All statistical data were analyzed using Statgraphics ${ }^{\circledR}$ Plus v5.1 software (Rockville, MD, USA).

\section{Results}

\section{Marker design and data acquisition}

Primers for the KASPar assay were successfully designed by KBioscience $®$ for all 15 of the submitted SNP surrounding sequences. Data acquisition for $x$ and $y$ allele signals allowed successful allelic calling for 2535 out of 2563 marker/genotype combinations (98.91\%). The validity of the genotyping results was verified by comparing the results for 24 diploid varieties with previous data obtained with an Illumina GoldenGate $\AA$ array. Complete conformity was observed (data not shown).

\section{Analysis of the correlation between relative allele signals and relative allele frequencies in the DNA pools}

To confirm the value of the KASPar assay for producing semi-quantitative data, equimolar DNA extracts from two haploid lines (clementine and pummelo) were mixed at 13 different relative concentrations, and five replicates were analyzed for each of seven SNP markers. The correlations between relative allele signals and relative doses were analyzed. 
An example of correlation analysis between relative allele dosage and signals is shown in Figure 1.1 for the CiC2840-01 SNP marker. From $x$ and $y$ signal values (Figure 1.1A), theta angle $\left[\theta=\tan ^{-1}(y / x)\right.$; Figure 1.1B] and the relative $y$ allele signal $\left[y^{\prime}=y /(x+y)\right.$; Figure 1.1C] of each haploid line sample and DNA pool were calculated. High values of correlation coefficients between both parameters and relative allele dosage in the DNA pools were obtained for all analyzed SNP markers, with an average of 0.9796 and a standard deviation of 0.0094 for the $y$ ' parameter and an average of 0.9710 and a standard deviation of 0.0176 for angle theta. Correlation values obtained for the $y$ ' parameter were slightly superior to those obtained by angle theta for six of the seven SNP markers that were analyzed (Table 1.1).

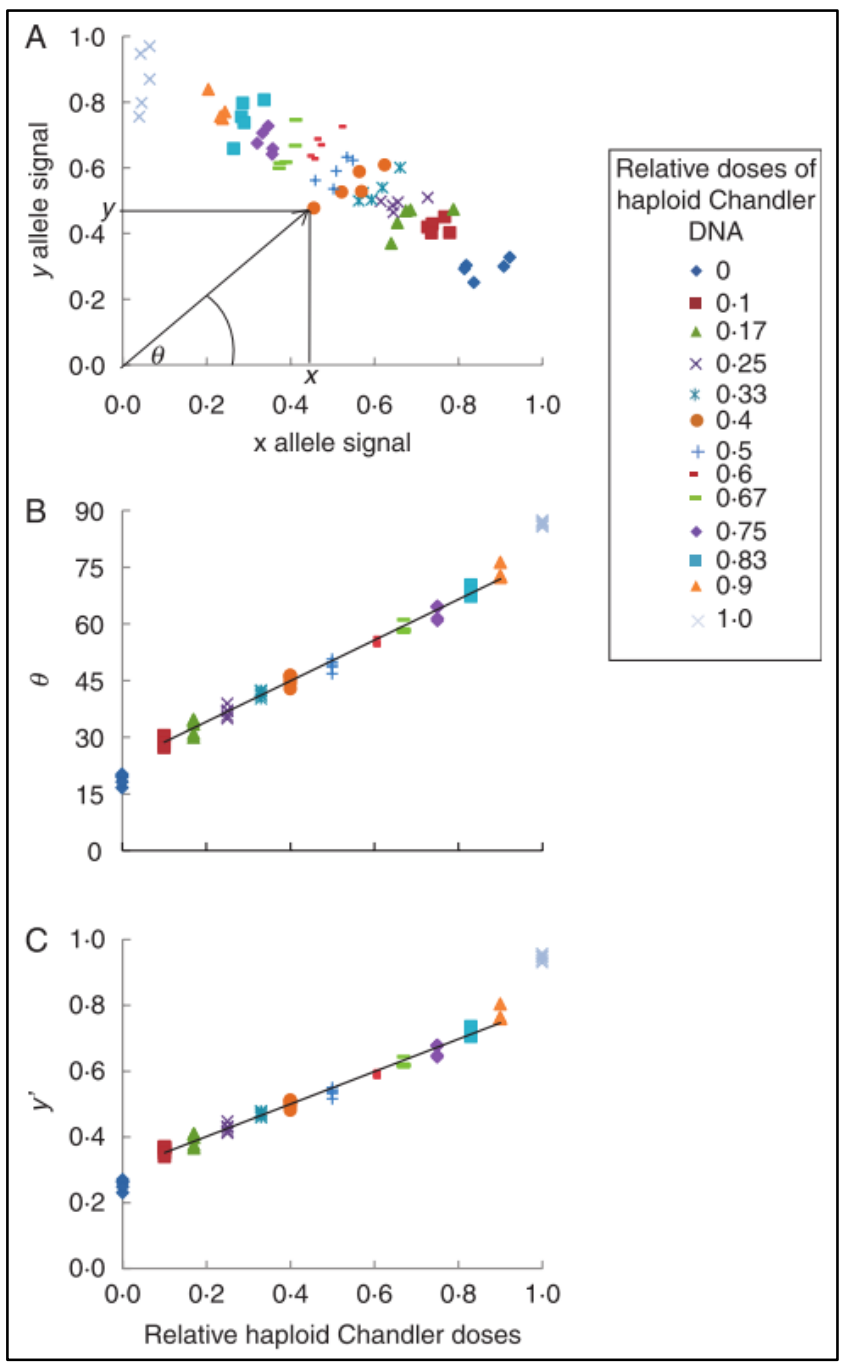

Figure 1.1. Correlation study of allele doses and $x, y$ signals for the CiC2840-01 SNP marker. (A) Plot of normalized $x$, y allele signals. (B) Correlation between relative haploid Chandler doses and theta angle $[\theta=$ $\left.\tan ^{-1}(y / x)\right]$. (C) Correlation between relative haploid Chandler doses and the $y^{\prime}$ parameter $\left[y^{\prime}=y(x+y)\right]$. 
Table 1.1. Correlation coefficients between relative allele dosage and allele signals from DNA pools at intermediate proportions for theta angle and $y$ ' parameter for the seven SNP markers analyzed.

\begin{tabular}{ccc}
\hline SNP Marker & Correlation coefficient for angle $\boldsymbol{\theta}$ & Correlation coefficient for $\boldsymbol{y}$ ' parameter \\
\hline CiC2840-01 & 0,9941 & 0.9919 \\
CiC5089-06 & 0,9753 & 0.9779 \\
CiC5785-01 & 0,9580 & 0.9747 \\
DXS-M618 & 0,9881 & 0.9923 \\
F3H-M309 & 0,9788 & 0.9803 \\
FLS-M400 & 0,9535 & 0.9717 \\
TRPA-M593 & 0,9492 & 0.9684 \\
\hline AVERAGE & 0.9710 & 0.9796 \\
\hline
\end{tabular}

For some markers (CiC5785-01, F3H-M309, FLS-M400, and TRPA-M593; Figure 1.2), the lineal regression established from the mixed sample did not fit with the signals from the pure sample. For all these markers, the relative signals corresponding to the haploid 'Chandler' allele in the DNA mixes appear to be lower than expected in relation to the relative DNA dosages. This can probably be attributed to PCR allele competition between the 'Clementine' and 'Chandler' allele in the DNA mixes.

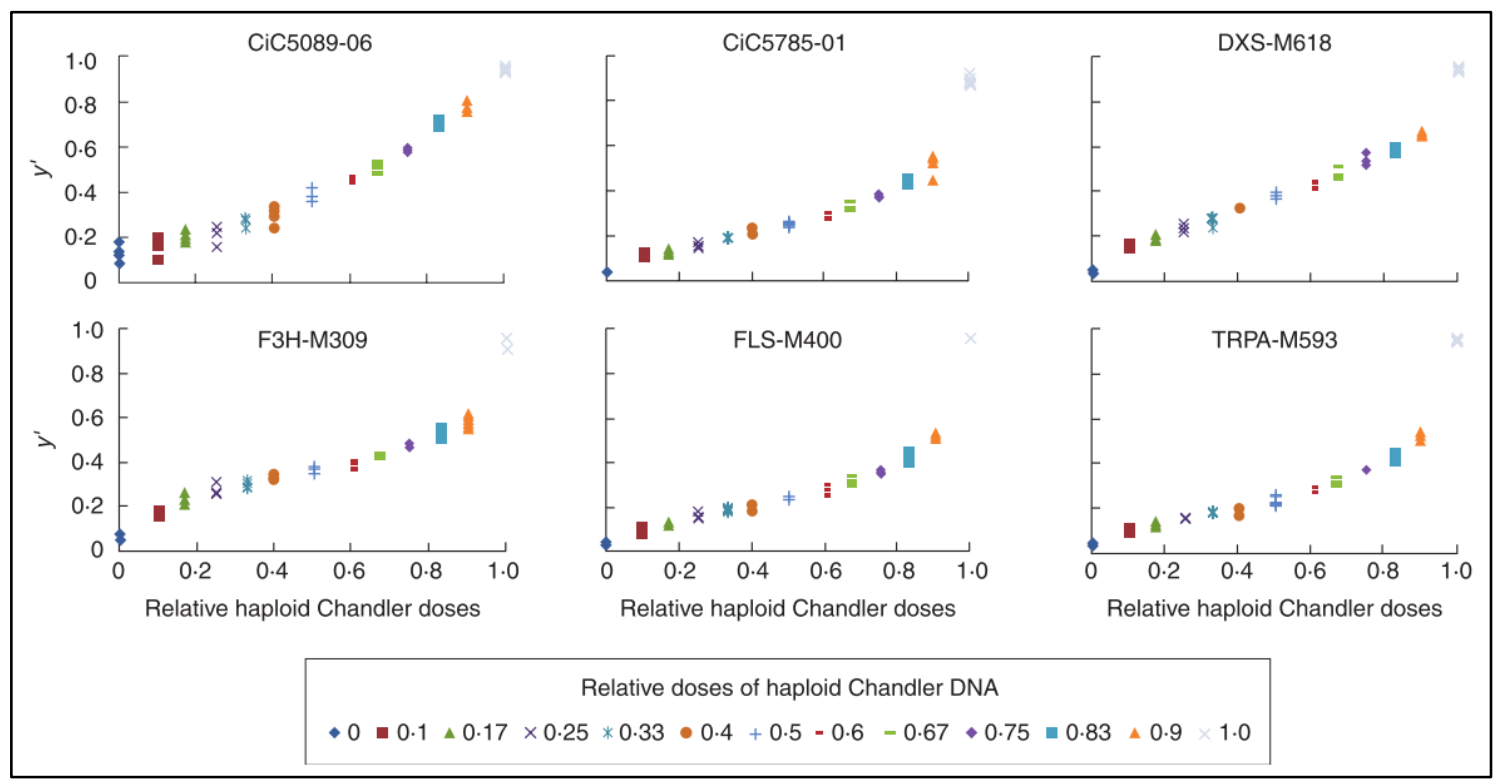

Figure 1.2. Correlation study between the relative haploid Chandler doses and the $y^{\prime}$ parameter for six SNP markers.

However, in the DNA mixes, the correlations between allele signals and allele doses remained high for these markers (between 0.9684 and 0.9803 ) testifying for a very good lineal regression between relative signals of the two alleles and relative allele dosages. 
These data indicate that the KASPar technique, using either the $y^{\prime}$ parameter or the theta angle, can be useful for a quantitative analysis of the relative allele frequency in a genotype or DNA pool. Because $y$ ' produced a slightly higher correlation coefficient, this parameter was employed in further analyses.

\section{Cluster analysis and ANOVA for simulated triploid and tetraploid allele dosage}

Separated cluster analyses and ANOVA from relative $y$ allele signals ( $y^{\prime}$ parameter) in triploid and tetraploid simulated populations were performed. With diallelic markers, for a triploid heterozygous genotype, there are only two allelic configurations to distinguish: $a a b$ and $a b b$ (duplex and simplex of a-allele). For a heterozygous tetraploid genotype, three allelic configurations may be differentiated: $a a a b$, $a a b b$, and $a b b b$ (triplex, duplex and simplex of $a-$ allele). With higher ploidy levels, the number of possible allelic configurations becomes even larger ( $n-1$ configurations for $n$ ploidy).

ANOVA analysis (Table 1.2) revealed a complete and correct classification of the average value of the different configurations that were simulated. An example of the $x$ and $y$ allele signals, the frequency histogram for the $y$ ' parameter and the LSD intervals for the mean from ANOVA for simulating triploid and tetraploid populations, is provided for the CiC2840-01 SNP marker in Figure 1.3.

Table 1.2. Homogeneous groups formed, and F-values from ANOVA analysis of SNPs from DNA pools simulating triploid and tetraploid populations showing the percentage of correctly classified replications by cluster analysis based on the $y$ ' parameter.

\begin{tabular}{|c|c|c|c|c|c|c|c|c|c|c|c|c|c|}
\hline \multirow[b]{2}{*}{ SNP Marker } & \multicolumn{6}{|c|}{ Simulating $3 n$ populations } & \multicolumn{7}{|c|}{ Simulating $4 \mathrm{n}$ populations } \\
\hline & $1: 0$ & $2: 1$ & $1: 2$ & $0: 1$ & $\begin{array}{c}\text { F value } \\
\text { from } \\
\text { ANOVA }\end{array}$ & $\begin{array}{c}\% 3 n \\
\text { correctly } \\
\text { classified }\end{array}$ & $1: 0$ & $3: 1$ & $1: 1$ & $1: 3$ & $0: 1$ & $\begin{array}{c}\text { F value } \\
\text { from } \\
\text { ANOVA }\end{array}$ & $\begin{array}{c}\% 4 n \\
\text { correctly } \\
\text { classified }\end{array}$ \\
\hline CiC2840-01 & a & $b$ & c & $d$ & 2975.34 & $100 \%$ & a & $b$ & c & $d$ & e & 1644.48 & $100 \%$ \\
\hline CiC5089-06 & a & $\mathrm{b}$ & c & $d$ & 1045.50 & $100 \%$ & a & $b$ & c & $d$ & e & 673.68 & $96 \%$ \\
\hline CiC5785-01 & a & $\mathrm{b}$ & c & $d$ & 5110.86 & $100 \%$ & a & $\mathrm{b}$ & c & $d$ & e & 6084.71 & $100 \%$ \\
\hline DXS-M618 & a & $\mathrm{b}$ & c & $d$ & 2938.98 & $100 \%$ & a & $\mathrm{b}$ & c & $d$ & e & 3013.55 & $100 \%$ \\
\hline F3H-M309 & a & $b$ & c & $d$ & 2063.52 & $100 \%$ & a & $b$ & $c$ & $d$ & e & 1445.66 & $100 \%$ \\
\hline FLS-M400 & a & b & c & $d$ & 10046.43 & $100 \%$ & a & b & $c$ & $d$ & e & 10459.43 & $100 \%$ \\
\hline TRPA-M593 & a & $\mathrm{b}$ & c & $d$ & 11140.59 & $100 \%$ & a & $\mathrm{b}$ & c & d & e & 6666.05 & $100 \%$ \\
\hline AVERAGE & & & & & & $100 \%$ & & & & & & & $99.43 \%$ \\
\hline
\end{tabular}




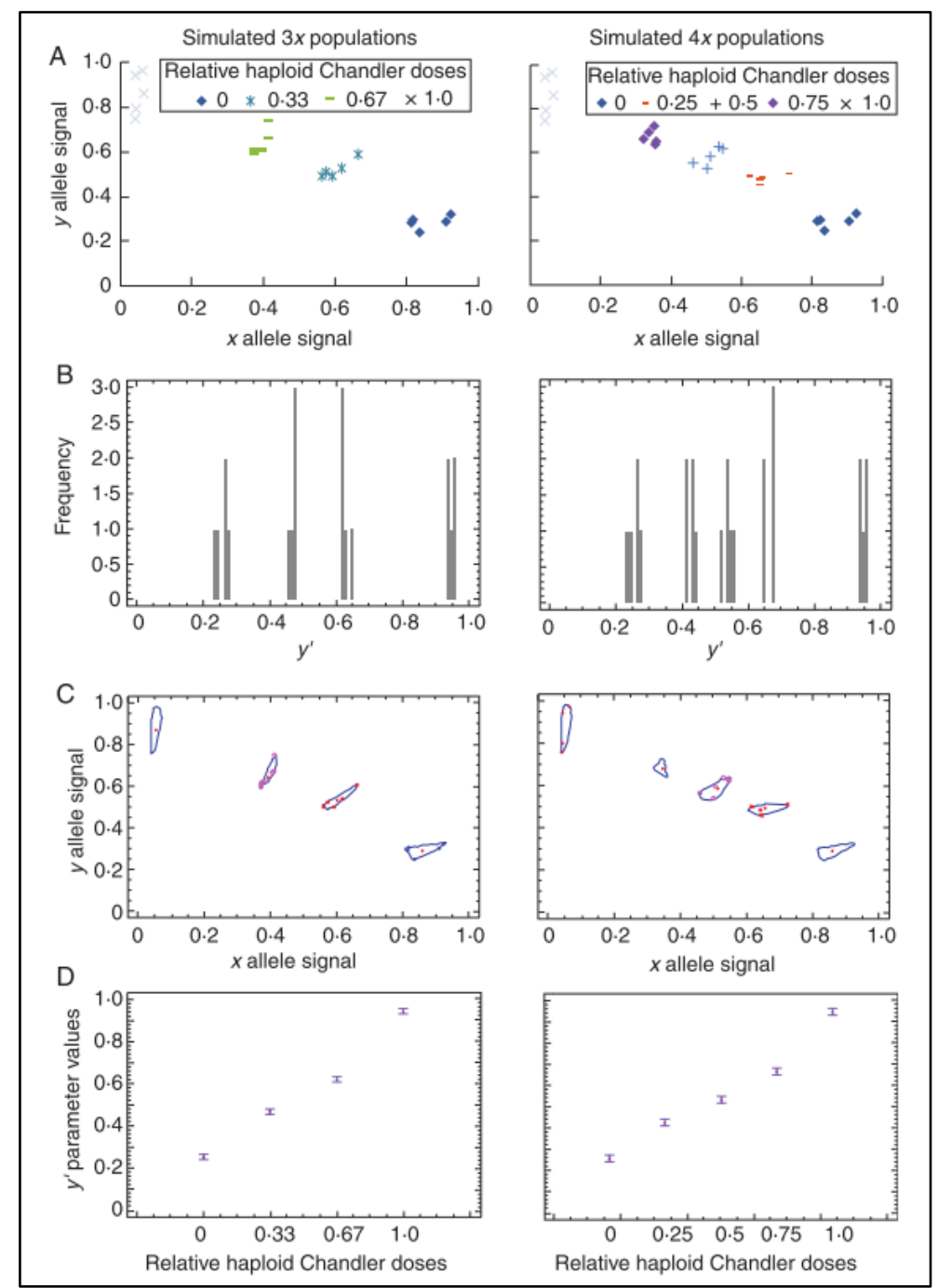

Figure 1.3. Study of simulating triploid and tetraploid populations for the CiC2840-01 SNP marker. (A) Plot of normalized $x, y$ allele signals. (B) Frequency histogram for the $y^{\prime}$ parameter. (C) Cluster analysis. (D) Least significant difference intervals for the mean obtained from ANOVA.

Moreover, all expected homogeneous groups were formed by cluster analysis using the farthest-neighbour method with standardised squared euclidean distances. All of the triploid sample replications and $99.43 \%$ of the tetraploid ones were correctly classified; only one replication for the CiC5089-06 SNP marker was classified into an incorrect cluster (Table 1.2).

\section{Allelic configuration of triploid populations}

\section{Accuracy of genotype calling for duplicated triploid samples:}

Thirty-nine triploid hybrids arising from 'Fortune' $2 n$ gametes in the 'Fortune $\times$ Willowleaf' hybridization were analyzed for seven SNPs, with two technical replications. All SNPs had the following allelic configuration: 'Fortune': $a b$ and 'Willowleaf' mandarin: aa. 
Therefore, depending on the origin of the diploid gamete, three genotypic clusters were expected: $a a a, a a b$, and $a b b$. Samples with replications that were classified in the same cluster and thus genotyped with the same allelic conformation reached $97.44 \%$. Errors in classification were observed in five of the seven SNP markers analyzed. Considering a replicate for the same DNA sample (with different allele calling between replicates) to be classified correctly, the average error rate for further routinely genotyping without replicates was estimated to be $1.28 \%$.

To perform the genotype calling of triploid progeny, cluster analyses were performed according to the expected genotypes for each population and the parental-specific allelic configuration of each marker.

\section{$\underline{2 x} \times 2 x$ triploid progeny:}

When crossing a heterozygous female parent $(a b)$ with homozygous parents (aa), maternal heterozygosity restitution (HR) is reflected in the duplex (aab) triploid hybrids. Under the SDR restitution mechanism, HR is directly linked with the distance from the locus under consideration to the centromere and, therefore, the frequency of HR can be estimated from this distance, as proposed by Cuenca et al. (2011). To validate genotype calling for triploids resulting from a $2 x \times 2 x$ cross, three SNP markers (CiC3440-07, CiC5785-01 and CiC6278-01) mapped in chromosome II were selected. Indeed, Cuenca et al. (2011) located the centromere position for the corresponding linkage group at $59.6 \mathrm{cM}$ of the current clementine's reference genetic map (Ollitrault et al., 2012a) using the $C x(C o)^{4}$ partial interference model. The expected $\mathrm{HR}$ for the three considered markers (also mapped in the clementine map) was estimated using the same partial interference model.

Cluster analyses were performed from $y^{\prime}$ parameter values of each hybrid over 11 analyzed SNPs (including the three markers on chromosome II) within the 'Clementine $x$ Nadorcott' population to carry out genotype calling. Figure 1.4A shows an example of cluster analysis for the CiC2840-01 SNP marker. 


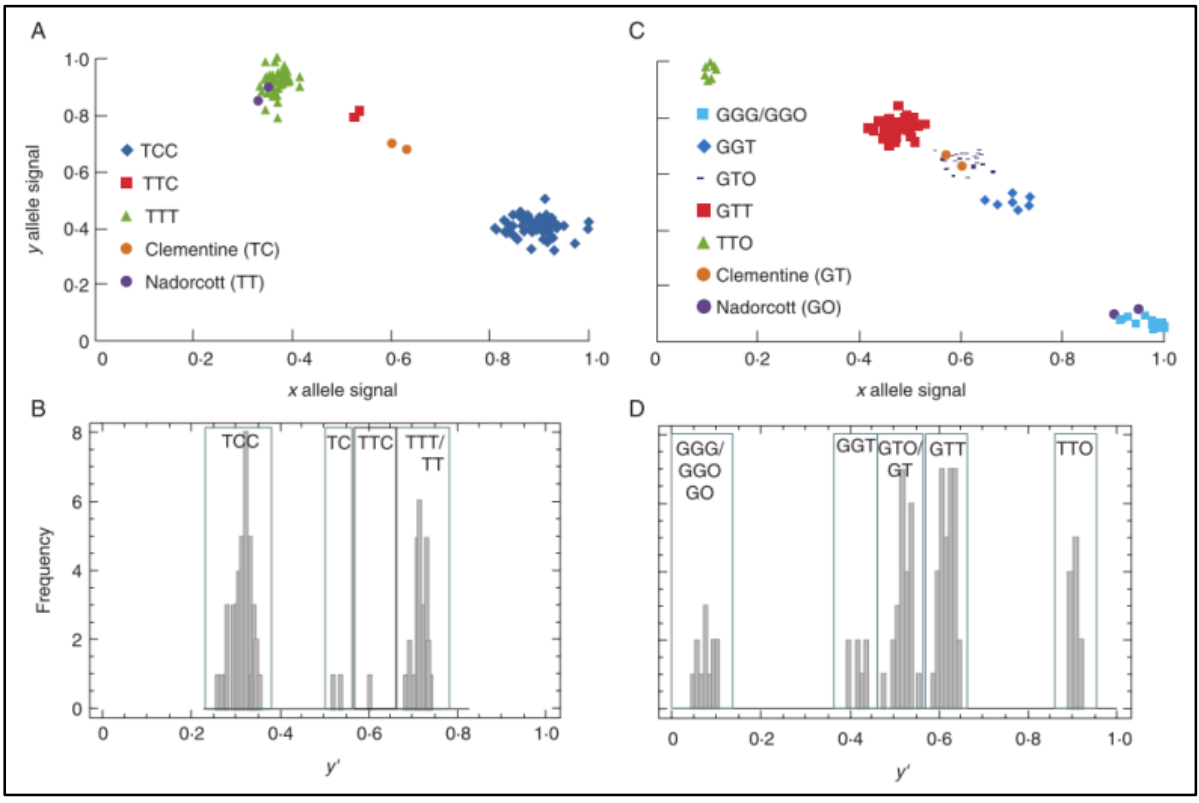

Figure 1.4. Plot of normalized $x, y$ allele signals and histogram representing genotype calling from cluster analysis over 85 triploids from the 'Clementine $\times$ Nadorcott' cross. (A, B) CiC2840-01 (ab $\times$ aa); (C, D) $\mathrm{CiC} 1749-05(a b \times a 0)$.

The cluster analysis allowed the detection of null alleles in the male parent for two markers. Indeed, if the supposed homozygous parent in fact had heterozygosity for a null allele, five clusters should be obtained ( $a b x a 0$ : $a a b, a b 0$, aaalaa0, $a b b$, and bb0), where one cluster contains both $a b 0$ triploids and $a b$ diploid genotypes. Such a cluster configuration was observed for the CiC0610-01 and CiC1749-05 SNP markers (Figure 1.4C,D).

On average, over all of the markers, $99.37 \%$ of the samples were assigned to a cluster and, therefore, could be accurately called.

For the three markers of LGII, the observed HR values were not significantly different than those estimated from respective markers and centromere locations in the clementine map (Table 1.3). This provides additional validation of the accuracy of polyploid genotype calling using the method presented in this study. 
Table 1.3. Results of 3-SNP genotype calling for the 'Clementine $\times$ Nadorcott' triploid population from $2 n$ gametes for markers heterozygous for 'Clementine' and homozygous for 'Nadorcott', including the conformity $\left(x^{2}\right.$ test) of the observed $\% H R$ with the theoretical one calculated from the distance from each locus to the centromere on chromosome II.

\begin{tabular}{|c|c|c|c|c|c|c|c|c|}
\hline SNP marker & $\begin{array}{c}\text { Map position } \\
\text { (cM) }\end{array}$ & NI & aaa & aab & $a b b$ & $\begin{array}{c}\text { \%HR } \\
\text { (aab) } \\
\text { observed }\end{array}$ & $\begin{array}{l}\text { \%HR estimated } \\
\text { from map } \\
\text { position } \\
\text { (centromere } \\
\text { at } 59.6 \mathrm{cM} \text { ) }\end{array}$ & $\begin{array}{c}X^{2} \\
\text { (p value) }\end{array}$ \\
\hline CiC3440-07 & 67.22 & 86 & 37 & 10 & 39 & $11.63 \%$ & $13.59 \%$ & $\begin{array}{c}0.282 ; \mathrm{NS} \\
(p=0.5954)\end{array}$ \\
\hline CiC5785-01 & 44.73 & 84 & 32 & 17 & 35 & $20.24 \%$ & $28.23 \%$ & $\begin{array}{l}2.648 ; N S \\
(p=0.1037)\end{array}$ \\
\hline CiC6278-01 & 57.01 & 86 & 46 & 0 & 40 & $0.00 \%$ & $4.21 \%$ & $\begin{array}{l}3.780 ; \mathrm{NS} \\
(p=0.0519)\end{array}$ \\
\hline
\end{tabular}

$\mathrm{NI}$ : number of individuals genotyped; $a a a, a a b$ and $a b b$ : number of individuals of each genotype; NS: non significantly different at alpha=0.05)

For the eight remaining markers, the observed HR allowed us to estimate the relative distances of these markers from the centromere (Table 1.4), revealing markers with centromeric locations (less than $5 \mathrm{cM}$ distance from centromere: CiC1380-05, CiC2840-01, and CiC458101).

Table 1.4. Results of 8-SNP genotype calling for the 'Clementine $\times$ Nadorcott' triploid population from $2 n$ gametes for markers heterozygous for 'Clementine' and homozygous or heterozygous with null allele for 'Nadorcott', showing the estimated marker-centromere distance.

\begin{tabular}{|c|c|c|c|c|c|c|c|c|}
\hline SNP marker & NI & aaa & aab & abb & ab0 & bb0 & $\begin{array}{c}\text { \% HR } \\
\text { (aab+ab0) } \\
\text { observed }\end{array}$ & $\begin{array}{c}\text { Estimated distance } \\
\text { to centromere (cM) }\end{array}$ \\
\hline CiC0610-01 & 86 & 22 & 22 & 14 & 22 & 6 & $51.16 \%$ & 27.42 \\
\hline CiC0868-01 & 86 & 39 & 14 & 33 & - & - & $16.8 \%$ & 9.23 \\
\hline CiC1380-05 & 86 & 43 & 1 & 42 & - & - & $1.16 \%$ & 0.75 \\
\hline CiC1749-05 & 85 & 11 & 33 & 7 & 24 & 10 & $67.06 \%$ & 40.61 \\
\hline CiC1757-02 & 86 & 42 & 12 & 32 & - & - & $13.95 \%$ & 7.80 \\
\hline CiC2840-01 & 85 & 46 & 2 & 37 & - & - & $2.35 \%$ & 1.49 \\
\hline CiC4581-01 & 86 & 37 & 6 & 43 & - & - & $6.98 \%$ & 4.15 \\
\hline CiC5089-06 & 84 & 27 & 40 & 17 & - & - & $47.62 \%$ & 25.23 \\
\hline
\end{tabular}

$\mathrm{Nl}$ : number of individuals genotyped; aaa, aab, abb, ab0 and bb0: number of individuals of each genotype. 


\section{$\underline{4 x \times 2 x \text { triploid progeny: }}$}

Triploid genotyping was also performed for progeny arising from a cross between doubled diploid 'Clementine' (Aleza et al., 2009a) and 'Pink' pummelo. When crossing a duplex tetraploid parent $(a a b b)$ with a homozygous diploid parent $(a a)$, three clusters can be expected (triplex-aaa, duplex-aab, and simplex-abb), where maternal heterozygosity restitution is reflected into the duplex $(a a b)$ triploid hybrids. On average, over all of the markers, $97.08 \%$ of the samples were assigned to a cluster and, therefore, could be accurately called.

The genetic structure of the triploid progeny arising from 'Clementine $4 x^{\prime} \times$ 'Pink' is shown in Table 1.5, which indicates the percentage of heterozygosity restitution. For the other loci, HR values varied, ranging from $52.94 \%$ for CiC4581-01 to $69.41 \%$ for CiC5089-06. The average HR value over all loci was $59.64 \%$.

Table 1.5. Results of 7-SNP genotype calling for the 'Clementine $4 x \times$ Pink' triploid population, indicating the heterozygosity restitution in Clementine $4 x(\% \mathrm{HR})$ at each locus.

\begin{tabular}{|c|c|c|c|c|c|}
\hline SNP marker & NI & aaa & aab & abb & \%HR (aab) observed \\
\hline CiC3440-07 & 88 & 17 & 50 & 21 & $56.82 \%$ \\
\hline CiC0868-01 & 87 & 11 & 58 & 18 & $66.67 \%$ \\
\hline CiC1380-05 & 87 & 19 & 53 & 15 & $60.92 \%$ \\
\hline CiC4581-01 & 85 & 19 & 45 & 21 & $52.94 \%$ \\
\hline CiC5089-06 & 85 & 15 & 59 & 11 & $69.41 \%$ \\
\hline CiC5785-01 & 80 & 22 & 43 & 15 & $53.75 \%$ \\
\hline CiC6278-01 & 86 & 22 & 49 & 15 & $56.98 \%$ \\
\hline
\end{tabular}

$\mathrm{NI}$ : number of individuals genotyped; $a a a, a a b$ and $a b b$ : number of individuals of each genotype. 
The KASPar method is a powerful technique for assigning SNP allelic configurations in polyploid progeny

Several techniques have been used to estimate allele dosage in polyploids, such as the MAC-PR method (Esselink et al., 2004) for SSR markers, and techniques for SNP genotyping, including allele-specific primer extension (Kwok, 2001), temperature-switch PCR (Tabone et al., 2009), array methodologies (Ishikawa et al., 2005), and targeted pyrosequencing ${ }^{\mathrm{TM}}$ (Ahmadian et al., 2000). Our study demonstrates that the KASPar technique (Cuppen, 2007) is an alternative method to infer SNP allelic configurations in polyploid plants that offers a wider spectrum of genotyping possibilities. The KASPar method is simple and cost effective compared to other SNP genotyping assays and is well adapted to low- to medium-throughput genotyping projects. In addition to the markers published herein, 51 KASPar markers were successfully developed to analyze triploid and tetraploid citrus populations (Aleza et al., 2012a, 2012b; Cuenca et al., 2012). KASPar markers were also successfully developed (41 over 42 tested) and transferred in the true citrus group (Citrus, Fortunella, Poncirus, Microcitrus and Eremocitrus genera) from SNPs mining by sequencing within a Citrus collection (García-Lor et al., 2013a). When SNPs are mined in large discovery panel, this offers the opportunity to selects markers without additional variation in the flanking DNA sequence used as template for the competitive PCR of the KASPar assay and therefore to have a high success in marker development. KASPar markers were successfully developed in a large range of plant (Cortes et al., 2011; Rosso et al., 2011; Byers et al., 2012) and animal (Nijman et al., 2008; Murad et al., 2009; Luciano et al., 2010) species demonstrating its universal applicability.

The SNP genotyping and data analysis method presented in this study is simple and effective for genotyping triploid and tetraploid progeny and can be also used in the quantitative analysis of allele-specific expression. Allele signals $(x, y)$ obtained from KBioscience ${ }^{\circledR}$ can easily be transformed into $y^{\prime}\left[y^{\prime}=y /(x+y) ; 0 \leq y^{\prime} \leq 1\right]$, which is a very useful parameter to cluster analyzed samples. Theta angles $\left[\theta=\tan ^{-1}(y / x) ; 0^{\circ} \leq \theta \leq 90^{\circ}\right]$ can also be used to analyse data, but the $y$ ' parameter offers better clustering results. Quantitative analyses for correlation of the allele signals, and the allele doses and sample clustering carried out in this work, were powerful techniques for assigning allelic configurations in simulated triploid and tetraploid citrus genotypes for all SNP markers that were analyzed (100\% of the triploids were correctly classified triploids as well as $99.43 \%$ of the tetraploids). The analysis of concrete triploid hybrids with technical replications confirmed the high degree of accuracy of the technique (error < $1.5 \%)$. This SNP genotyping and data analysis method allowed us to distinguish among very close allele ratios, and it can also be efficiently employed for the analysis of higher ploidy levels. Moreover, the segregations observed with this technique have allowed us to identify heterozygous null alleles in one parent for some of the markers. Diploid progeny genotyping confirmed these conclusions for null alleles in 'Pink' pummelo (Ollitrault et al., 2012a). 


\section{PCR drift can affect allelic configuration inference in natural polyploid germplasm}

Interpretation of relative allele dosage for markers based on relative polymerase chain reaction (PCR) product intensities has been reported for various plants (Buteler et al., 1999; Julier et al., 2003; Landergott et al., 2006; Martins et al., 2009) and animals (McQuown et al., 2002). The limits of such direct allele doses evaluation are associated with PCR selection caused by differential primer affinity and PCR drift resulting from random events during early cycles of PCR (Wagner et al., 1994).

In this study, such PCR drift has been observed for some markers, displaying incongruence between the lineal regressions established from the mixed DNA pools and the pure sample. However, the correlations between allele signals and allele doses in the DNA pools remained high for these markers. Therefore, as lineal regression appears to offer a good approximation of the doses/relative signal relationship, a control with two dosage points should be sufficient to establish a function that correlates both parameters.

Heterozygous diploid genotypes are suitable for determining the 1:1 ratios that are used as a baseline for calculations of allele quantification in the other heterozygous genotype. In the analysis of citrus triploid progeny, the location of different clusters relative to the heterozygous diploid parent allowed us to assign the alternate theoretical triploid heterozygous allelic configuration.

The situation is much more complicated when analysing polyploid germplasm of unknown origin. Indeed, the variability in the flanking regions of the SNPs that were studied (where the primers were defined) should result in different levels of relative PCR competition and, therefore, should avoid proper allele dose identification from relative $x / y$ signals. This is inherent to all PCR genotyping methods. Perhaps, as suggested by (Landergott et al., 2006) for the MAC-PR method, the KASPar assay may be very useful for determining the allelic configuration within crossing families, but it would not be generally applicable for estimating allelic dosage in polyploid germplasm without previous verification of the stability of relative allele amplification. An approach to limit the PCR drift associated with variation in the flanking area of the studied SNP should be to select SNPs flanked by conserved sequences. Such information is available in SNP mining studies where large discovery panels are used while there is generally no information of flanking sequence of microsatellite markers. This should be an important advantage of using SNPs rather than microsatellite markers for assignment of allelic configuration in polyploids. 


\section{Potential of KASPar for semi-quantitative estimation of allele-specific expression analysis or allelic frequency estimation in DNA extracted from pools}

Many genetic variants resulting in phenotypic differences are mediated through changes in gene expression. Variation in gene expression can be due to polymorphisms either at the gene locus (cis) or in other genes that influence gene expression (trans) or cis/trans interactions (Rockman and Kruglyak, 2006). Allele-specific expression (ASE) studies have introduced a creative method to uncover the respective contributions of cis- and trans-regulatory variation (Ronald et al., 2005; Main et al., 2009). Allelic imbalance in non-imprinted genes has been shown to be common in humans, maize, and Arabidopsis (Lo et al., 2003; Guo et al., 2004; Zhang et al., 2009; Zhang and Borevitz, 2009). Moreover, ASE analysis should enable the integration of potentially differential allelic functionality in association models between gene expression and phenotype. Therefore, gene expression analysis is a critical step for better understanding genotype/phenotype relationships.

Analysis of allele-specific expression in relation to genomic structure requires the assessment of DNA and RNA allele dosage. It can be done by different methods: Northern (Guo et al., 1996), RNA-FISH (Herzing et al., 2002), SNP-specific array-based (Bjornsson et al., 2008), Solexa (Main et al., 2009) or RNA-seq (Rozowsky et al., 2011).

Furthermore, the estimation of allelic frequencies on pooled DNA is of great interest both in ecological studies of plants (Ritland, 2002), animals (Shaw et al., 1998; Coop et al., 2010; Grant, 2010) or micro-organisms (Brauer et al., 2006; Wenger et al., 2010), and in bulk segregant analysis to locate genes involved in phenotypic variation (Quarrie et al., 1999; Tabor et al., 2000; Yang et al., 2007).

The high correlation coefficient values between relative allele dosage and SNP allele signals obtained with the KASPar technique, and the ability of this technique to distinguish between close relative allele dosages at the DNA level, has been demonstrated in this study. Moreover were able to detect a 0.1 allele frequency within DNA pools. This technique is a promising method for performing semi-quantitative analysis of relative allele-specific expression by analysing cDNA compared to genomic DNA, to complement global gene expression studies performed by real-time PCR. The KASPar technique may also be useful for allele frequency estimation in populations from DNA pools as mentioned before. For such studies, it should be interesting to extend the range of relative allele dosages to estimate the lowest differences distinguishable with this technique. 


\section{Application for citrus genetics and breeding}

Triploid citrus breeding is one of the most efficient techniques for the production of seedless mandarins (Ollitrault et al., 2008; Aleza et al., 2010b, 2012c, 2012d), and tetraploid rootstocks are promising tools that enable plants to adapt to various abiotic stresses (Saleh et al., 2008; Dambier et al., 2011). Triploid populations in citrus can arise from $2 x \times 2 x$ crosses or from interploid crosses. Discriminating between different types of heterozygotes within triploid progeny is especially useful for population genetic structure studies and marker/trait association analysis.

Knowing the allelic configuration in triploid and tetraploid progeny is also necessary to identify the mechanism of $2 n$ gamete formation. The maternal heterozygosity restitution values of under $50 \%$ obtained in this study, which were estimated from a 'Clementine $\times$ Nadorcott' progeny for nine markers (CiC0868-01, CiC1380-05, CiC1757-02, CiC2840-01, CiC3440-07, CiC4581-01, CiC5089-06, CiC5785-01, and CiC6278-01), confirm the conclusion of (Luro et al., 2004 ), that the $2 n$ gamete in clementine arose from SDR, as in the 'Fortune' mandarin (Cuenca et al., 2011), while (Chen et al., 2008a) proposed FDR for sweet orange. Moreover, this study allowed us to identify several centromeric markers that should be very useful for further analyses of the origin of $2 n$ gametes in different cultivars and genotypes, as it was done for potatoes (Douches and Quiros, 1988; Werner et al., 1992).

Most tetraploid citrus germplasm arose from chromosome duplication of nucellar cells (Aleza et al., 2011) or were obtained by bud chemical treatment (Aleza et al., 2009b) of diploid genotypes. These tetraploids are, therefore, doubled diploids with the same aabb genomic structure at each heterozygous locus $(a b)$ of the parental diploid line. For such tetraploids, the parental restitution $(P R)$ of the heterozygosity to the diploid gamete depends on preferential pairing between chromosomes. In the case of total preferential pairing (disomic segregation), parental heterozygosity is transferred to all gametes $(P R=100 \%)$. In the case of total random pairing (tetrasomic segregation), the PR ranged from $55 \%$ to $66 \%$, depending on the double reduction frequency (Marsden et al., 1987). In this study, the PR results for the tetraploid (doubled diploid) Clementine ranged from $52.94 \%$ for the CiC4581-01 marker to $69.41 \%$ for the CiC5089-06 marker, which is in agreement with the expected PR values under tetrasomic segregation (Kamiri et al., 2011).

In the case of triploid and tetraploids obtained by somatic hybridization (Dambier et al., 2011; Grosser and Gmitter, 2011), the assignment of allelic configuration will be useful for revealing genome regions acquired from each parent, as well as potential chromosome fragment elimination or duplication. 


\section{Conclusions}

This work demonstrates that the KASPar SNP genotyping technique, combined with the cluster analysis method we proposed, enables the efficient assignment of heterozygous allelic configuration within polyploid populations. This method is accurate, simple, and cost effective. It has been successfully applied to two citrus triploid populations arising from $2 n$ gametes and interploid crosses. Moreover, correlation studies, cluster analysis and ANOVA support the usefulness of this method for performing relative quantitative studies, such as relative allelespecific expression analysis or, eventually, bulk segregant analysis.

\section{Supplementary information}

Table 1.S1. SNP information and genotyping of the parents used in this study

Description: Detailed information of the 15 SNPs used in this work, including the GeneBank accessions, genomic sequences surrounding each SNP and the genotyping of the progeny parents. 
Table 1.S1. SNP information and genotyping of the parents used in this study.

\begin{tabular}{|c|c|c|c|c|c|c|c|c|c|c|}
\hline SNP marker & $\begin{array}{l}\text { GENEBANK } \\
\text { ACCESION }\end{array}$ & Genomic sequence surrounding the SNP & $\begin{array}{c}\text { Haploid } \\
\text { Chandler }\end{array}$ & $\begin{array}{c}\text { Haploid } \\
\text { Clementine }\end{array}$ & Fortune & Willowleaf & \multicolumn{2}{|c|}{$\begin{array}{l}\text { Clementine } \\
2 x \quad 4 x\end{array}$} & Nadorcott & Pink \\
\hline CiC0610-01 & ET093305 & $\begin{array}{l}\text { CAACTTAAAATCCCACTTTACTCTTTCCACATGGGCCGTCATGA } \\
\text { TGGTGTTTTTGACTGC[A/G]CTTGTTACTTCCACTAAAACCCTTTT } \\
\text { AAAGATTGCAGATCTCTTTGTTTGAGTTAAAATAT }\end{array}$ & - & - & - & - & $A G$ & - & G0 & - \\
\hline СiC0868-01 & ET095107 & $\begin{array}{l}\text { ACAGTTTCTGGGATCCAYATTTGATACCAACTTCATTTCAAGGG } \\
\text { TAACTTTCAGGAACTA[A/G]GATACAGTATGTGCCTTTAAATTCT } \\
\text { ATTAATCACGTGGGATCATTACGATGTCTTGCTTT }\end{array}$ & - & - & - & - & CT & СCTT & CC & TT \\
\hline CiC1380-05 & ET072553 & $\begin{array}{l}\text { TTGCTCGAGAAGTCAAAACTTTACAGGAATGCATTACTGGCCT } \\
\text { ATCTGGAGAGAAAGCTC[A/G]AGTACAGAAGGACTGCAATGAG } \\
\text { TTGAGGGCCATAAACGAGGATTTGTTATCCCGACAAAA }\end{array}$ & - & - & - & - & CT & ССTT & $\mathrm{CC}$ & 00 \\
\hline CiC1749-05 & ЕT097636 & $\begin{array}{l}\text { ACATTACTCTGTCTACCCCGCAGATACTAATAAGGTATTTATGA } \\
\text { TCATGTTTTTGCTTCT[A/C]ATATTGCTGACTTCTGCTGTTTTTGG } \\
\text { TTTGGAATTGATGTTCTGTGATTGATGTGGAGTCA }\end{array}$ & - & - & - & - & GT & - & G0 & - \\
\hline CiC1757-02 & ET097717 & $\begin{array}{l}\text { GTTTTCAGCTTTGAAAAAATCAGATACTTCCTCTCGAGTCAAGG } \\
\text { TAGGTTCTTATCACTT[A/C]CCATCTTCTATATCTGATGCATCTC } \\
\text { TGTTAAAGAAGCGATCTGAACTTGAAATTTCAGAT }\end{array}$ & - & - & - & - & $A C$ & - & CC & - \\
\hline CiC2840-01 & ET103429 & $\begin{array}{l}\text { TTTATTTATTTACTTATGTATTTGTTTTGTAAATTTTTAATATTTC } \\
\text { AGATCCGCACAYAT[A/G]GCGAAAAGAGCGTTGTACGGTTCGT } \\
\text { TGAGGCTCACGAGTTCATTGACTGTGGACATATCC }\end{array}$ & C & T & CT & CT & $\mathrm{CT}$ & - & TT & - \\
\hline СiC3440-07 & ET077539 & $\begin{array}{l}\text { TTTTTATTTTTATTTTTATTCTTATTTTTGCCTCTTGAATCCATCG } \\
\text { GTATTCCTGGCTAT[A/G]AAAGAGAAGTTCAACTTCTAGCCGAA } \\
\text { TTAACTATATTAACTGCCATTCCAAATATGTTGA }\end{array}$ & - & - & - & - & $A G$ & AAGG & GG & G0 \\
\hline CiC4581-01 & ET109034 & $\begin{array}{l}\text { CCATTCAAATAAAAATCCTAAACATTCAATCATTAACAATCACA } \\
\text { GAGATGAAATTCCCAG[A/C]GGTTCAATAAGGCTGGTGGTTCT } \\
\text { CAAAGCACTGAACTGCATAATATAAAATAGGAAAAAG }\end{array}$ & - & - & - & - & $A C$ & AACC & AA & AA \\
\hline
\end{tabular}


Table 1.S1-cont. SNP information and genotypes of the parents used in this study.

\begin{tabular}{|c|c|c|c|c|c|c|c|c|c|c|}
\hline SNP marker & $\begin{array}{l}\text { GENEBANK } \\
\text { ACCESION }\end{array}$ & Genomic sequence surrounding the SNP & $\begin{array}{l}\text { Haploid } \\
\text { Chandler }\end{array}$ & $\begin{array}{c}\text { Haploid } \\
\text { Clementine }\end{array}$ & Fortune & Willowleaf & & $\begin{array}{c}\text { ntine } \\
4 x\end{array}$ & Nadorcott & Pink \\
\hline CiC5089-06 & ET111533 & $\begin{array}{l}\text { TCAGAACAACATAAAAATACCACTTTTKTTTTTTAGAAGTGGA } \\
\text { GGAAATTTCAGTGAAGA[A/G]CAGGAAGGCATCACATCTGAT } \\
\text { TCAAACAGTGAGATTGATGGGAAAGAAATTCTAACCAG }\end{array}$ & C & $\mathrm{T}$ & CT & CT & CT & ССТT & $\mathrm{CC}$ & CC \\
\hline CiC5785-01 & ET082673 & $\begin{array}{l}\text { TCAACCACCTTGATAAATGAACAAAAGGAGGCTTAAACTTTG } \\
\text { ACTTCAATTTTAGCCATT[A/T]GTTATGTTCAATCTAATGATTA } \\
\text { TAATGATTGCAATTTAAGACGCTTTGATTGAATTACTA }\end{array}$ & $\mathrm{T}$ & A & AT & AT & AT & AATT & TT & TT \\
\hline CiC6278-01 & ET085551 & $\begin{array}{l}\text { CCTATTATGTTTATTTAAATTGTTGGTGGACGATAAAATTTAT } \\
\text { TGGCCAATTCAGAATTC[A/C]TAGTCATAATGAAATTCTGTAC } \\
\text { ACATAAAAAGCCAAATGGGTGACTCAGTTCTTTGTGTA }\end{array}$ & - & - & - & - & $A C$ & AACC & AA & 00 \\
\hline DXS M618 & DN959423 & $\begin{array}{l}\text { GGTGCAGGACATAGTTCCACAAGCATCTCTGCTGGTCTTGG } \\
\text { TATGTACTTC[G/A]CTCTCTTAATATTTTCCTTTCATCAATCTA } \\
\text { GAGAAATTGTAGGATGCAGAATAC }\end{array}$ & A & G & AG & $A G$ & - & - & - & - \\
\hline F3H-M309 & JX630066 & $\begin{array}{l}\text { CTAAGCCGTCGAGTTTTTGTGACCAAAGGGACAGAATCTAA } \\
\text { TGAGTTTAAGGA[T/C]ATGGTGGTAGAGCTCATGACGTCAGC } \\
\text { TGGATTTTTCAACATTGGTGATTTTATACCC }\end{array}$ & C & $\mathrm{T}$ & CT & CT & - & - & - & - \\
\hline FLS-M400 & AB011796 & $\begin{array}{l}\text { GGGTTGATCATCTCTTCCACAGGGTTTGGCCTCCGTCTTCT } \\
\text { ATCAACTACCGCTT[T/C]TGGCCCAACAACCCTCCTTCTTAC } \\
\text { CGGTGAATGTT }\end{array}$ & C & $\mathrm{T}$ & CT & $\mathrm{CT}$ & - & - & - & - \\
\hline TRPA-M593 & EF028327 & $\begin{array}{l}\text { GGCACGACAGCATTCGTGAGCATGTGGATGCATAACGTGG } \\
\text { CAGCAGCAGTGAT[G/C]ATGATGCCAGTGGCCACTGGGATC } \\
\text { TTACAGAACTTGCCAGAGGTTC }\end{array}$ & C & G & CG & GG & - & - & - & - \\
\hline
\end{tabular}





\section{CHAPTER 2}

Multilocus half-tetrad analysis and centromere mapping in citrus: evidence of SDR mechanism for $2 n$ megagametophyte production and partial chiasma interference in mandarin cv 'Fortune'

José Cuenca, Yann Froelicher, Pablo Aleza, José Juárez, Luis Navarro and Patrick Ollitrault

Heredity (2011) 107: $462-470$. doi:10.1038/hdy.2011.33 



\section{Abstract}

The genetic structure of $2 n$ gametes and, particularly, the parental heterozygosity restitution at each locus depends on the meiotic process by which they originated, with first division restitution and second-division restitution (SDR) being the two major mechanisms. The origin of $2 n$ gametes in citrus is still controversial, although sexual polyploidization is widely used for triploid seedless cultivar development. In this study, we report the analysis of $2 n$ gametes of mandarin cv 'Fortune' by genotyping 171 triploid hybrids with 35 simple sequence repeat markers. The microsatellite DNA allele counting-peak ratios method for allele dosage evaluation proved highly efficient in segregating triploid progenies and allowed half-tetrad analysis (HTA) by inferring the $2 n$ gamete allelic configuration. All $2 n$ gametes arose from the female genitor. The observed maternal heterozygosity restitution varied between 10 and $82 \%$, depending on the locus, thus SDR appears to be the mechanism underlying $2 n$ gamete production in mandarin cv 'Fortune'. A new method to locate the centromere, based on the best fit between observed heterozygosity restitution within a linkage group and theoretical functions under either partial or no chiasmata interference hypotheses was successfully applied to linkage group II. The maximum value of heterozygosity restitution and the pattern of restitution along this linkage group would suggest there is partial chiasma interference. The implications of such a restitution mechanism for citrus breeding are discussed. 


\section{Introduction}

Sexual polyploidization has been widely exploited in several plant-breeding programmes (Ramanna and Jacobsen, 2003). Diploidy is the general rule in Citrus and related genera, with a basic chromosome number $x=9$. However, sexual polyploidization is currently a central approach used in triploid citrus-breeding programs, aiming to develop new seedless 'mandarin type' cultivars (Ollitrault et al., 2008); very large triploid progenies have been obtained from $2 x \times 2 x$ crosses and several cultivars patented (Aleza et al., 2010b). The recovery of triploid citrus hybrids arising from $2 n$ megagametophytes produced by diploid plants was described in the 1970s (Esen and Soost, 1971, 1973; Aleza et al., 2010b). Cytogenetic studies (Esen and Soost, 1971) showed that triploid embryos are associated with pentaploid endosperm, indicating that triploid hybrids result from the fertilization of unreduced ovules by normal haploid pollen. According to the genotype, the frequency of duplication in the female gametes can range from below $1 \%$ to over $20 \%$. Esen et al. (1979) proposed that $2 n$ eggs result from the abortion of the second meiotic division in the megaspore (SDR) in citrus. This hypothesis has been corroborated for clementine (Citrus clementina Hort. ex Tan.) by molecular marker analysis (Luro et al., 2004). However, Chen et al. (2008a) proposed that $2 n$ eggs of sweet orange (C. sinensis (L.) Osb.) resulted from first meiotic division restitution (FDR). The genetic configuration of $2 n$ gametes depends on the mechanism of their formation (Figure 2.1), and the rate of parental heterozygosity restitution is directly linked with the rate of effective chiasma between the centromere and the considered locus (Mendiburu and Peloquin, 1976; Park et al., 2007). It is, total and null until the first chiasma for FDR and SDR, respectively. It is, thus, essential to gain a better understanding of the mechanisms underlying $2 n$ gamete formation to optimise sexual polyploidy breeding schemes and to carry out trait-association studies of breeding populations.

The objective of the present work was to shed light on the mechanism underlying $2 n$ gamete formation in 'Fortune' mandarin (C. clementina $\times$ C. tangerina Hort. ex Tan.) by Simple Sequence Repeat (SSR) marker analysis. 'Fortune' mandarin is widely used in triploid breeding because of its fruit qualities, late maturing period and relatively high percentage of $2 n$ eggs. This diploid cultivar is highly fertile, producing an average of 18.5 seeds per fruit, including $6.5 \%$ of seeds arising from $2 n$ gametes (our unpublished data). Without the previous knowledge of centromere position, and to avoid the risk of misinterpreting data due to an insufficient or biased set of markers, we selected 35 SSR markers according to their position on the clementine map (Ollitrault et al., 2011). A general approach is proposed to estimate the centromere position by best-fit value between observed data and theoretical functions of heterozygosity restitution for no interference and partial interference models. For this purpose, we used the functions developed by Zhao and Speed (1998b) for ordered tetrads, based on the random spindlecentromere attachment hypothesis (Griffiths et al., 1996), and extended by the same authors to half-tetrad analysis (HTA; (Zhao and Speed, 1998a). The results obtained were compared with the method proposed by Tavoletti et al. (1996) using the multilocus structure of half-tetrads. 
Finally, we discuss the implications of the $2 n$ gamete restitution mechanisms for citrus triploid breeding.

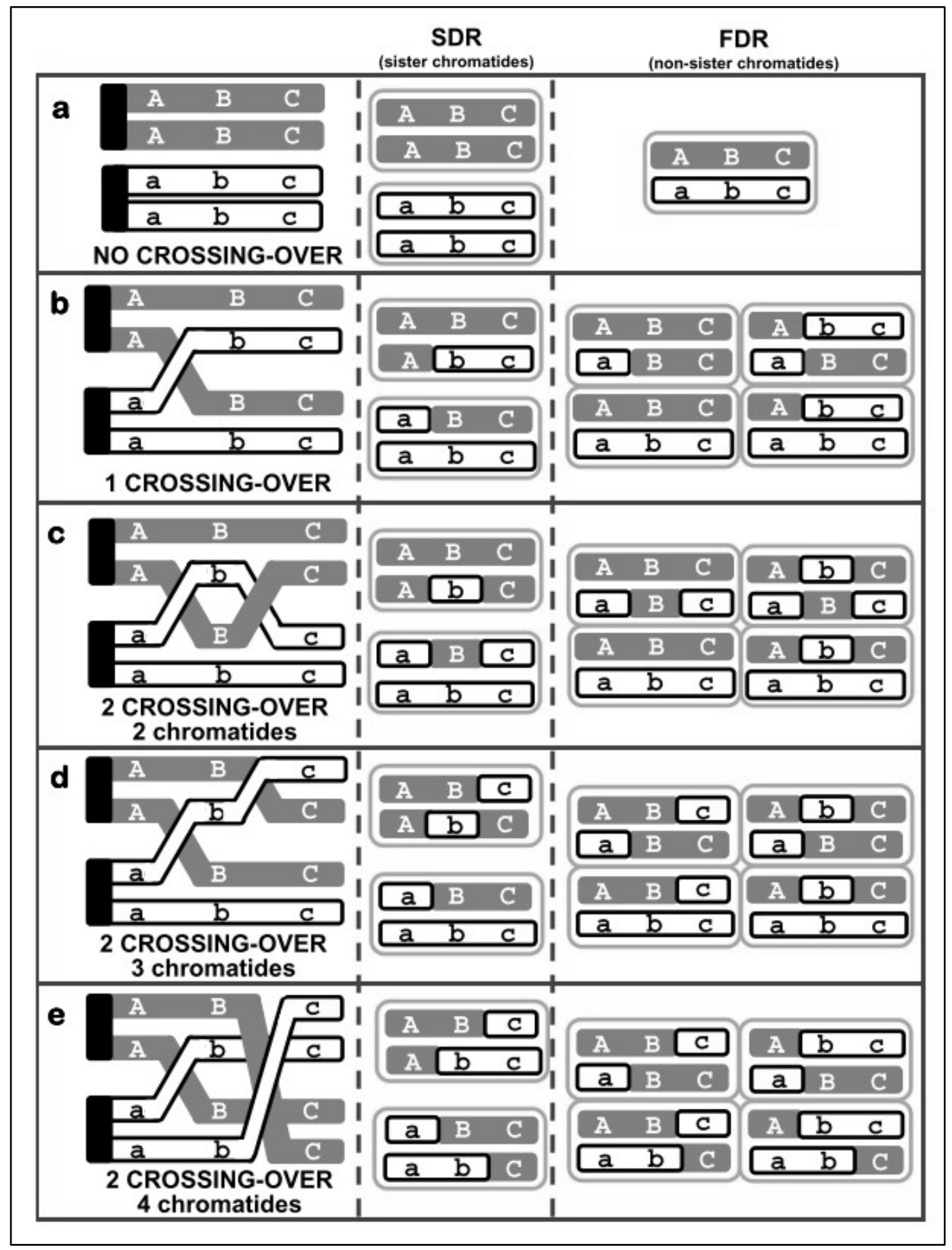

Figure 2.1. SDR and FDR $2 n$ gametes resulting from: (a) no crossover;(b) one crossover; (c) two crossovers involving two chromatids; (d) two crossovers involving three chromatids and (e) two crossovers involving four chromatids. 


\section{Materials and methods}

\section{Plant material}

The mechanism underlying $2 n$ gamete formation in 'Fortune' mandarin was investigated in 171 triploid hybrids, derived from four crosses between 'Fortune' mandarin (C. clementina Hort. ex Tan. $\times$ C. tangerina Hort. ex Tan.) as female diploid genitor and 'Ellendale' ( $C$. reticulata Blanco $\times$ C. sinensis (L.) Osb.), 'Common Mandarin' (C. deliciosa Ten.), 'Minneola' (C. paradisi Macf $\times$ C. tangerina) or 'Murcott' (C. reticulata $\times$ C. sinensis) as male diploid genitors. Parental accessions and hybrids were grown at the 'Instituto Valenciano de Investigaciones Agrarias' orchards in Moncada, Valencia, Spain. Practical details on how the triploid populations were established from diploid $x$ diploid crosses by embryo rescue and triploid selection by flow cytometry, can be found in Aleza et al. (2010b). Genomic DNA of triploid hybrids and their parents was isolated using the Plant DNAeasy kit from Qiagen Inc. (Valencia, CA, USA), following the manufacturer's protocol.

\section{Triploid progeny genotyping}

SSR markers that proved heterozygous for 'Fortune' were selected to genotype each triploid progeny, depending on the polymorphism existing between 'Fortune' and the male genitor. Thirty-five microsatellite loci were used to analyze the triploid progenies: CAC15, TAA41 (Kijas et al., 1997), CX6F03, CX6F23 (Chen et al., 2008b), mest121 (Luro et al., 2008), mest56, mest192, mest123 (Aleza et al., 2011), mest104, mest110, mest247, mest488 (François Luro, personal communication; mail to luro@corse.inra.fr for further information), mCrCIR07F11 (Kamiri et al., 2011), Ci01C07, Ci02B07, Ci08C05, mCrCIR01E02, mCrCIR01F04a, mCrCIR06A12, mCrCIR06B05, mCrCIR06B07, mCrCIR07E12 (Froelicher et al., 2007) and thirteen new designed primers (mCrCIR01C06, mCrCIR02A09, mCrCIR02D09, mCrCIR02F12, mCrCIR02G01, mCrCIR02G02, mCrCIR03B07, mCrCIR03C08, mCrCIR03G05, mCrCIR04H06, mCrCIR05A05, mCrCIR07D05, mCrCIR07D06; Table 2.1). The polymerase chain reactions (PCRs) were performed with wellRED oligonucleotides (Sigmaß) with the following protocol: Eppendorf® Mastercycler epgradient S; reaction volume $15 \mu \mathrm{l}$ : $0.8 \mathrm{U}$ Taq polymerase (N.E.E.D.®), reaction buffer $-750 \mathrm{mM}$ Tris $\mathrm{HCl}(\mathrm{pH}$ 9), $50 \mathrm{mM} \mathrm{KCl,} 200 \mathrm{mM}$ $\left(\mathrm{NH}_{4}\right)_{2} \mathrm{SO}_{4}, 0.001 \%$ BSA-, $0.1 \mathrm{mM}$ of each dNTP, $5 \mathrm{mM} \mathrm{MgCl}, 3 \mu \mathrm{M}$ of each primer, $30 \mathrm{ng}$ DNA; PCR program: $94^{\circ} \mathrm{C} 5 \mathrm{~min} ; 40$ cycles of $30 \mathrm{sec}$ at $94^{\circ} \mathrm{C}, 1 \mathrm{~min}$ at $50-55^{\circ} \mathrm{C}$ and 30 sec at $72^{\circ} \mathrm{C}$; final elongation $10 \mathrm{~min}$ at $72^{\circ} \mathrm{C}$ ). Separation was carried out by Capillary Gel Electrophoresis (CEQ ${ }^{\mathrm{TM}} 8000$ Genetic Analysis System; Beckman Coulter Inc.). Data collection and analysis were carried out with GenomeLab ${ }^{\text {TM }}$ GeXP version 10.0 software. 
Table 2.1. New primers designed to amplify the markers used in this study

\begin{tabular}{|c|c|c|c|c|c|}
\hline $\begin{array}{c}\text { Marker } \\
\text { name }\end{array}$ & $\begin{array}{c}\text { EMBL } \\
\text { accession }\end{array}$ & Sequence Forward 5'-3' & Sequence Reverse 5'-3' & $\begin{array}{c}\text { Annealing } \\
\text { Temperature } \\
\left({ }^{\circ} \mathrm{C}\right)\end{array}$ & $\begin{array}{c}\text { Observed } \\
\text { alleles in } \\
\text { Fortune }\end{array}$ \\
\hline $\mathrm{mCrCIR01C06}$ & AJ567393 & GGACCACAACAAAGACAG & TGGAGACACAAAGAAGAA & 50 & $133-165$ \\
\hline mCrCIR02A09 & FR677568 & ACAGAAGGTAGTATTTTAGGG & TTGTTTGGATGGGAAG & 50 & $160-162$ \\
\hline mCrCIR02D09 & FR677569 & AATGATGAGGGTAAAGATG & ACCCATCACAAAACAGA & 55 & $231-239$ \\
\hline $\mathrm{mCrCIR02F12}$ & FR677570 & GGCCATTTCTCTGATG & TAACTGAGGGATTGGTTT & 55 & $121-123$ \\
\hline mCrCIR02G01 & FR677571 & ATACCAAAACCCCAAAG & CTTTGACCCAAGCAAG & 55 & $291-296$ \\
\hline $\mathrm{mCrCIR02G02}$ & FR677572 & CAATAAGAAAACGCAGG & TGGTAGAGAAACAGAGGTG & 55 & $112-122$ \\
\hline $\mathrm{mCrCIR03B07}$ & FR677573 & САССТТТСССТТССА & TGAGGGACTAAACAGCA & 55 & $264-278$ \\
\hline $\mathrm{mCrCIR03C08}$ & FR677576 & CAGAGACAGCCAAGAGA & GCTTCTTACATTCCTCAAA & 55 & $210-223$ \\
\hline mCrCIR03G05 & FR677578 & CCACACAGGCAGACA & CCTTGGAGGAGCTTTAC & 50 & $199-228$ \\
\hline $\mathrm{mCrCIR04H06}$ & FR677579 & GGACATAGTGAGAAGTTGG & CAAAGTGGTGAAACCTG & 55 & $190-196$ \\
\hline mCrCIR05A05 & FR677580 & ATACCTGTGAGCGTGAG & ССТСТТСССТТССАТТ & 50 & $144-162$ \\
\hline mCrCIR07D05 & FR677574 & TCGTTCTTGCTTTTCCAC & GAATCAAACTACССТССАAT & 55 & $206-208$ \\
\hline mCrCIR07D06 & FR677581 & ССTTTTCACAGTTTGCTAT & TCAATTCCTCTAGTGTGTGT & 55 & $166-188$ \\
\hline
\end{tabular}

\section{2n gamete allelic structure inference from triploid hybrid genotypes}

For a locus bearing totally different parental allelic configurations $\left(A_{1} A_{2} X A_{3} A_{4}\right)$, the genotype of the $2 n$ gamete was directly read from the triploid hybrid structure. When the male and female genitor shared one allele $\left(A_{1} A_{2} X A_{2} A_{2}\right.$ and $\left.A_{1} A_{2} X A_{2} A_{3}\right)$, the inference of the $2 n$ female gamete structure was carried out from the measured allele dosage by the microsatellite DNA allele counting-peak ratio method [MAC-PR; (Esselink et al., 2004)], for the triploid hybrids that have inherited the common allele from the male genitor. The validation of the MAC-PR method for the analyzed loci and populations is given as Supplementary Information.

\section{Identification of $2 n$ gamete origin by single-locus analysis}

Once female gamete structures were inferred, the percentages of heterozygosity were calculated for each locus in the whole population and for each genotype over all analyzed loci. Without previous knowledge about relative markers/centromere position, the observation of heterozygosity restitution over $50 \%$ for a single locus is not informative because it could have come from either FDR or SDR; however, theoretical heterozygosity restitutions lower than $50 \%$ are only found for SDR (Park et al., 2007). When such low values of heterozygosity restitution were observed for a marker, we compared the highest probability of such a population structure under the SDR and FDR hypothesis. Under SDR, the highest probability for such an observation is obtained for a centromere position, leading to a theoretical proportion of $h$ heterozygous gametes, whereas the best theoretical proportion of heterozygous gametes to fit with such observed data is 0.5 in the case of FDR. Thus, logarithm of the odds ratios (LODs) were estimated as: 


$$
L O D=\log _{10}\left[\frac{p(S D R)}{p(F D R)}\right]=\log _{10}\left[\frac{h^{n h} \cdot(1-h)^{(1-h) \cdot n}}{0.5^{n h} \cdot(0.5)^{(1-h) \cdot n}}\right]
$$

with $h$ being the heterozygosity transmission observed for the marker and $n$, the number of genotypes analyzed with this marker.

\section{Comparison of observed heterozygosity restitution within a linkage group with theoretical functions to infer the $2 n$ gamete formation mechanism and centromere position}

To integrate the information on all loci of the same linkage group coming from different populations, we propose a method based on the comparison between observed heterozygosity restitution among a linkage group with theoretical restitution functions under different models. We have tested FDR and SDR mechanisms, for no-interference and partial chiasma interference on a chromosome arm (and no between-arm interference) assuming several centromere positions (interval of $0.5 \mathrm{cM}$ between two theoretical adjacent positions of the centromere). Discrepancies between the different models and the observed data were estimated by the sum of the squared differences between observed and theoretical values at the marker map positions. Under one model of restitution (FDR or SDR), let Fit(c) be the value of the sum of the squared distance for each position of the centromere; the best theoretical centromere position under this model is deduced by searching $c$, which minimises Fit(c). The confidence interval (95\%) for the centromere position was estimated by bootstrap on the loci (500 bootstraps). For this analysis, we have used the marker position of the clementine genetic map (Ollitrault et al., 2011), which should be very similar to the Fortune map, because 'Fortune' is a hybrid between Clementine and Dancy mandarin.

No interference model. According to Zhao and Speed (Zhao and Speed, 1998b), assuming that the number of chiasmata in an interval follows a Poisson process (no interference model corresponding to Haldane's map function), the probabilities of a tetrad displaying a first division segregation (FDS; (Griffiths et al., 1996) pattern and a second division segregation (SDS; (Griffiths et al., 1996) pattern are as follows: $p(F D S)=\frac{1}{3}\left(1+2 e^{-3 d}\right)$ and $p(S D S)=\frac{2}{3}\left(1-e^{-3 d}\right)$, where $d$ is the genetic distance in Morgan units (Haldane's map function) between a given locus and the centromere. Under the FDR mechanism for $2 n$ gamete formation, the FDS tetrads and half of the SDS tetrads transfer the parental heterozygosity, while under the SDR mechanism, the restitution of parental heterozygosity will result from SDS tetrads (Zhao and Speed, 1998a). 
We can thus derive the rates of heterozygosity transmission $(\mathrm{H})$ as function of the distance to the centromere $(d): \mathrm{H}(\mathrm{d})=\frac{1}{3}\left(1+2 e^{-3 d}\right)+\frac{1}{3}\left(1-e^{-3 d}\right)=\frac{1}{3}\left(2+e^{-3 d}\right)$ for FDR and $H(d)=\frac{2}{3}\left(1-e^{-3 d}\right)$ for SDR. According to this model, from the centromere to the telomere, $\mathrm{H}$ varies between 1 and 2/3 for FDR and from 0 to 2/3 for SDR (Figure 2.2).

Let $p$ and $c$, respectively, be the positions of a locus and of the centromere in a linkage group. As Haldane's map function is additive, the distance between the considered locus and the centromere is $d=|p-c|$. The heterozygosity restitution $\mathrm{H}(\mathrm{d})$ as a function of the distance to the centromere $(d)$ can thus be applied to any locus position $(p)$ on the clementine's genetic map after transposition according to each theoretical position of the centromere $(c)$ on the linkage group: $\mathrm{H}(\mathrm{p})=\frac{1}{3}\left(2+e^{-3|(p-c)|}\right)$ for FDR and $\mathrm{H}(\mathrm{p})=\frac{2}{3}\left(1-e^{-3|(p-c)|}\right)$ for SDR. Theoretical curves of $H(p)$ are presented in Figure 2 for FDR and SDR models.

Partial interference models. There are several proposals in the literature to incorporate chiasma interference in relating the map distance and SDS ordered tetrad proportion. (Zhao and Speed, 1998b) developed functions for ordered tetrad frequencies derived from the chi-square chiasma interference models, which provide good fits to data from different organisms (Zhao et al., 1995). Moreover, most map functions could be approximated by one of the chi-square models (Zhao and Speed, 1996). The model is represented in the form $C x(C o)^{m}$, where $m$ is a parameter positively related to the interference level. For $m>0$, the SDS proportion rises above $2 / 3$ and as $m$ increases, the maximal frequency of SDS increases (Zhao and Speed, 1998b). Likewise for the no interference model, the restitution of heterozygosity by half-tetrad under FDR and SDR can be directly derived from the SDS tetrad frequency for the different chi-square models; as examples, Figure 2 shows the pattern of heterozygosity restitution along a linkage group for the $\mathrm{Cx}(\mathrm{Co})$ and $\mathrm{Cx}(\mathrm{Co})^{4}$ models. The heterozygosity restitution at any position $(p)$ on the Clementine's genetic map can therefore be inferred for each theoretical position of the centromere $(c)$ on the linkage group and thus, Fit(c) evaluated. The genetic map is established according to the map function corresponding to each considered chi-square model (Foss et al., 1993). 


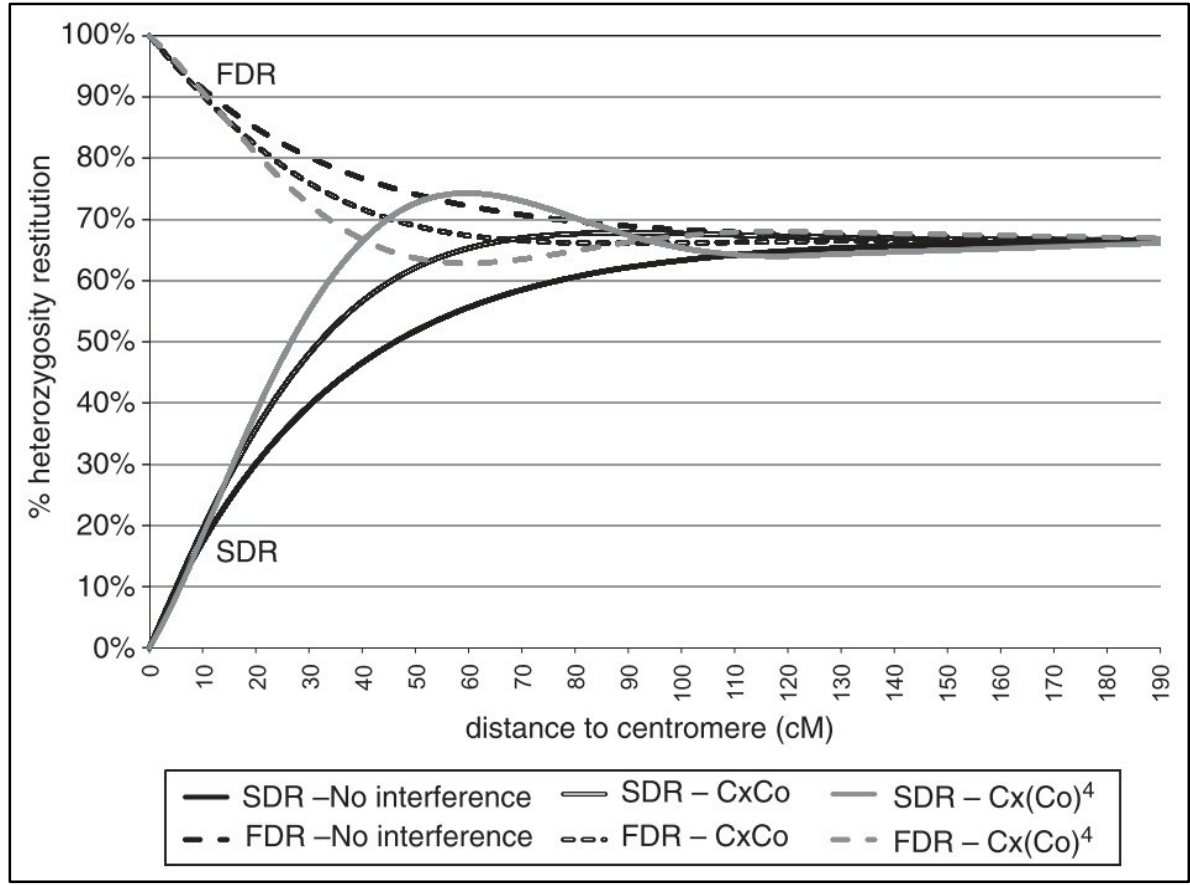

Figure 2.2. Theoretical curves of heterozygosity restitution as function of genetic distance to the centromere for FDR and SDR without chiasma interference and two $x^{2}-\left(C x(C o)^{m}\right)$ models of partial interference.

\section{Identification of the mode of $2 n$ gamete formation and localization of the centromere by half-tetrad multilocus structure analysis}

Multilocus analyses were performed on 87 genotypes and five loci mapped in the linkage group whose order was obtained from the current map of clementine (Ollitrault et al., 2011). The analysis was made according to Tavoletti et al. (1996) assuming that multiple crossovers do not occur between contiguous markers. Under this hypothesis, each crossover between two markers, $i$ and $i+1$, leads to a change from homozygosity to heterozygosity in the case of SDR and a half change from heterozygosity to homozygosity in the case of FDR. Thus, the distance between two adjacent markers $\left(d_{\mathrm{MM}+1}\right)$ can be estimated by the proportion of $2 n$ gametes with changes (homozygosity versus heterozygosity; $\mathrm{C}_{\mathrm{M}(\mathrm{M}+1}$ ) between the two markers. For FDR, $d_{M M i+1}=C_{M_{M} i+1}$ and for SDR, $d_{M i M i+1}=1 / 2 C_{M M i+1}$.

The probability of the observed multilocus progeny under the different models (FDR or SDR with different centromere positions) was calculated according to Tavoletti et al. (1996). Detailed formulas can be found in supplementary information. Both under FDR and SDR models, the centromere position was virtually moved from before the first considered locus along the linkage group to after the last considered locus (intervals of $0.5 \mathrm{cM}$ ) and the relative probability was estimated for each position. The LOD between best position under SDR and FDR was calculated in order to determine the mode of $2 n$ gamete restitution and the position of the centromere was considered as the one producing the highest relative probability under the identified mode of restitution. The confidence interval was estimated following the LOD drop-off 
method (Lander and Botstein, 1989). After determining the centromere position, chiasma interference can be estimated for each chromosome arm with three point linkage mapping as follows:

Let $r_{M_{1} M_{2}}$ denote the observed recombination rate (heterozygous to homozygous and vice versa) between the locus 1 and 2; $r_{M_{2} M_{3}}$ the observed one between locus 2 and 3; and $r d$ the observed rate of double recombination between the three loci. Thus, chromosome interference (I) is: $\quad \mathrm{I}=1-\left[\frac{r d}{r_{M_{1} M_{2}} \cdot r_{M_{2} M_{3}}}\right]$

\section{Results}

\section{Genotyping of triploid progenies}

Thirty-five heterozygous SSR markers in 'Fortune' were selected and used for genotyping the different triploid families according to their polymorphism between Fortune and the male genitors. Overall, 22, 18, 21 and 26 of these markers were polymorphic between the two parents for the families with 'Minneola', 'Common Mandarin', 'Ellendale' and 'Murcott' (Table 2.2) as male parent.

Table 2.2. Polymorphism observed among 'Fortune' mandarin and the male genitors for the 35 heterozygous loci in 'Fortune'.

\begin{tabular}{|c|c|c|c|c|c|c|c|c|}
\hline & \multicolumn{4}{|c|}{ Heterozygous } & \multicolumn{3}{|c|}{ Homozygous } & \multirow{2}{*}{ No Data } \\
\hline & Num & TP & $1 \mathrm{CA}$ & $2 \mathrm{CA}$ & Num & TP & $1 \mathrm{CA}$ & \\
\hline Minneola (P1) & 25 & 0 & 16 & 9 & 6 & 1 & 5 & 4 \\
\hline Common mandarin (P2) & 19 & 1 & 10 & 8 & 7 & 1 & 6 & 9 \\
\hline Ellendale (P3) & 19 & 4 & 9 & 6 & 8 & 4 & 4 & 8 \\
\hline Murcott (P4) & 13 & 6 & 6 & 1 & 14 & 7 & 7 & 8 \\
\hline
\end{tabular}

Num: number of SSR markers for each class; TP: SSRs totally polymorphic between Fortune and male parent; CA: SSRs with common alleles between Fortune and male parent. Numbers in grey cells indicate primers used for genotyping each population. Codes in brackets indicate population (e.g. P1: Fortune $\mathrm{X}$

The unambiguous differentiation of allele dosage in heterozygous triploids has been confirmed by the very clear bimodal distribution of the peaks area ratio of the different triploid hybrids for all markers (Supplementary information). The loci with total allelic differentiation between female and male genitors enabled (based on heterozygosity transmission or allele dosage estimation) the genitor producing the $2 n$ gametes for each triploid hybrid to be identified unequivocally. Maternal origin of the $2 n$ gamete has been observed for all the analyzed triploids; therefore, based on the maternal origin of the $2 n$ gamete and allele dosage, it was possible to infer the $2 n$ gamete structure from the triploid hybrid genotypes. Potential allelic segregation 
distortion in the $2 n$ gamete population was tested for each marker by $x^{2}$ analysis (Table 2.3); only one of them (CiO2B07) showed significant distortion.

Table 2.3. Heterozygosity restitution (\% HR) for each analyzed locus, $X^{2}$ test for allelic segregation, and LOD SDR/FDR for markers with less than $50 \%$ of heterozygosity restitution, linkage group (LG), number of individuals (NI) and populations (NP) analyzed.

\begin{tabular}{|c|c|c|c|c|c|c|c|c|c|c|c|}
\hline Marker name & $\% \mathrm{HR}$ & $x^{2}$ & $\begin{array}{c}\text { LOD } \\
\text { SDR/FDR } \\
\end{array}$ & LG & $\begin{array}{c}\mathrm{NI} \\
\text { (NP) }\end{array}$ & Marker name & $\begin{array}{l}\% \\
\text { HR }\end{array}$ & $x^{2}$ & $\begin{array}{c}\text { LOD } \\
\text { SDR/FDR } \\
\end{array}$ & LG & $\begin{array}{c}\mathrm{NI} \\
\text { (NP) }\end{array}$ \\
\hline mCrCIR06B05 & 16.1 & 1.76 & 16.29 & 1 & $\begin{array}{c}149 \\
\text { (P1-P2-P3-P4) }\end{array}$ & $\mathrm{CX6F03}$ & 65.4 & 0.24 & & V & $\begin{array}{c}153 \\
\text { (P1-P2-P3-P4) }\end{array}$ \\
\hline mest121 & 36.9 & 0.60 & 0.97 & I & $\begin{array}{c}65 \\
(\mathrm{P} 2-\mathrm{P} 3)\end{array}$ & mCrCIR06A12 & 70.1 & 0.00 & & v & $\begin{array}{l}67 \\
(\mathrm{P} 4)\end{array}$ \\
\hline CAC15 & 17.58 & 0.17 & 9.02 & II & $\begin{array}{c}91 \\
(\mathrm{P} 1-\mathrm{P} 4)\end{array}$ & mCrCIR07E12 & 67.3 & 0.38 & & v & $\begin{array}{c}101 \\
(\mathrm{P} 2-\mathrm{P} 4)\end{array}$ \\
\hline Ci01C07 & 75.26 & 0.75 & & II & $\begin{array}{c}97 \\
\text { (P1-P2-P3) }\end{array}$ & mest56 & 69.7 & 0.45 & & v & $\begin{array}{c}132 \\
(\mathrm{P} 1-\mathrm{P} 3-\mathrm{P} 4)\end{array}$ \\
\hline CX6F23 & 14.29 & 0.14 & 16.35 & II & $\begin{array}{c}133 \\
(\mathrm{P} 1-\mathrm{P} 3-\mathrm{P} 4)\end{array}$ & mest104 & 59.4 & 0.96 & & V & $\begin{array}{c}128 \\
(\mathrm{P} 1-\mathrm{P} 3-\mathrm{P} 4)\end{array}$ \\
\hline mCrCIR02D09 & 82.46 & 0.27 & & II & $\begin{array}{c}171 \\
(\mathrm{P} 1-\mathrm{P} 2-\mathrm{P} 3-\mathrm{P} 4)\end{array}$ & mCrCIR01C06 & 64.3 & 0.39 & & $\mathrm{VI}$ & $\begin{array}{c}129 \\
(\mathrm{P} 1-\mathrm{P} 3-\mathrm{P} 4)\end{array}$ \\
\hline mCrCIR02G01 & 79.41 & 0.07 & & II & $\begin{array}{l}34 \\
(\mathrm{P} 2)\end{array}$ & mCrCIR01E02 & 68.5 & 0.32 & & $\mathrm{VI}$ & $\begin{array}{c}124 \\
\text { (P1-P3-P4) }\end{array}$ \\
\hline mCrCIR03C08 & 34.33 & 0.73 & 1.45 & II & $\begin{array}{l}67 \\
\text { (P4) }\end{array}$ & mCrCIR02F12 & 74.4 & 0.43 & & $\mathrm{VI}$ & $\begin{array}{c}164 \\
(\mathrm{P} 1-\mathrm{P} 2-\mathrm{P} 3-\mathrm{P} 4)\end{array}$ \\
\hline $\mathrm{mCrCIR04H06}$ & 61.54 & 0.00 & & II & $\begin{array}{c}130 \\
\text { (P1-P3-P4) }\end{array}$ & mest123 & 65.2 & 0.20 & & $\mathrm{VI}$ & $\begin{array}{l}66 \\
\text { (P4) }\end{array}$ \\
\hline mCrCIR05A05 & 78.03 & 0.02 & & II & $\begin{array}{c}132 \\
\text { (P1-P3-P4) }\end{array}$ & mest192 & 67.0 & 0.24 & & $\mathrm{VI}$ & $\begin{array}{c}103 \\
(\mathrm{P} 2-\mathrm{P} 4)\end{array}$ \\
\hline mCrCIR06B07 & 73.13 & 0.44 & & II & $\begin{array}{c}67 \\
(\mathrm{P} 2-\mathrm{P} 3)\end{array}$ & mest488 & 74.1 & 0.24 & & $\mathrm{VI}$ & $\begin{array}{c}139 \\
(\mathrm{P} 1-\mathrm{P} 3-\mathrm{P} 4)\end{array}$ \\
\hline mCrCIR07D05 & 26.67 & 0.00 & 1.47 & II & $\begin{array}{l}30 \\
(\mathrm{P} 1)\end{array}$ & mCrCIR03B07 & 34.1 & 2.97 & 3.03 & VII & $\begin{array}{c}135 \\
(\mathrm{P} 2-\mathrm{P} 3-\mathrm{P} 4)\end{array}$ \\
\hline mest110 & 73.53 & 0.17 & & II & $\begin{array}{c}102 \\
\text { (P1-P2-P3) }\end{array}$ & mCrCIR01F04a & 39.8 & 0.57 & 1.07 & VIII & $\begin{array}{c}118 \\
(\mathrm{P} 1-\mathrm{P} 3-\mathrm{P} 4)\end{array}$ \\
\hline mest247 & 80.00 & 0.07 & & II & $\begin{array}{c}35 \\
\text { (P2) }\end{array}$ & mCrCIR02A09 & 65.1 & 0.60 & & VIII & $\begin{array}{c}86 \\
(\mathrm{P} 1-\mathrm{P} 4)\end{array}$ \\
\hline TAA41 & 73.74 & 0.31 & & II & $\begin{array}{c}99 \\
(\mathrm{P} 3-\mathrm{P} 4)\end{array}$ & mCrCIR02G02 & 10.3 & 0.03 & 13.62 & VIII & $\begin{array}{c}87 \\
(\mathrm{P} 2-\mathrm{P} 4)\end{array}$ \\
\hline mCrCIR03G05 & 72.2 & 0.02 & & IV & $\begin{array}{c}97 \\
(\mathrm{P} 3-\mathrm{P} 4)\end{array}$ & Сi02B07 & 72.3 & 4.57 & & IX & $\begin{array}{c}101 \\
(\mathrm{P} 1-\mathrm{P} 2-\mathrm{P} 4)\end{array}$ \\
\hline \multirow[t]{2}{*}{ mCrCIR07D06 } & 11.94 & 0.02 & 19.05 & IV & $\begin{array}{c}134 \\
(\mathrm{P} 1-\mathrm{P} 2-\mathrm{P} 4)\end{array}$ & $\mathrm{Ci08C05}$ & 17.4 & 0.16 & 13.85 & IX & $\begin{array}{c}138 \\
(\mathrm{P} 1-\mathrm{P} 2-\mathrm{P} 4)\end{array}$ \\
\hline & & & & & & mCrCIR07F11 & 41.6 & 0.01 & 0.77 & IX & $\begin{array}{c}125 \\
(\mathrm{P} 1-\mathrm{P} 3-\mathrm{P} 4) \\
\end{array}$ \\
\hline
\end{tabular}

\section{Maternal heterozygosity restitution in the $2 n$ eggs}

Restitution of maternal heterozygosity in each $2 n$ gamete (based on all analyzed loci) varied between $15.38 \%$ and $100 \%$, with $54.98 \%$ as mean value. The unimodal distribution of heterozygosity restitution in the $2 n$ megaspores among the analyzed genotypes suggests that all these $2 n$ gametes arise from the same mechanism (Figure 2.3). 


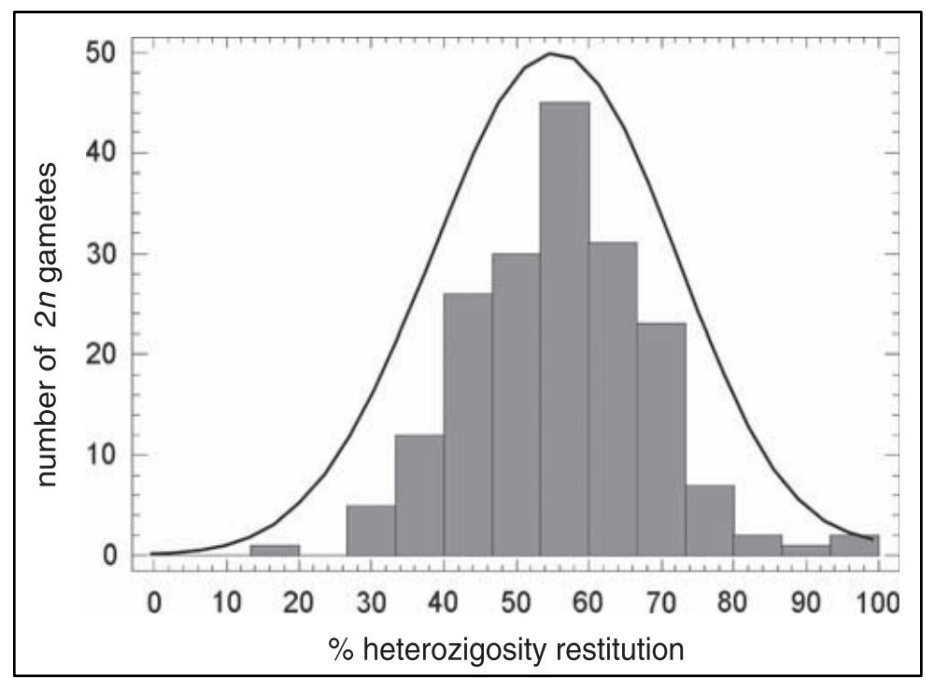

Figure 2.3. Distribution and density trace of the heterozygosity restitution rates estimated for each $2 n$ megaspore (estimation of restitution rates based on all markers).

\section{Global heterozygosity restitution for each marker}

Rate of maternal heterozygosity restitution was calculated for 35 loci, covering eight out of nine linkage groups from the current map for Clementine (Table 2.3); the average rate was $55.23 \%$ and values varied from $10.34 \%$ ( $\mathrm{mCrCIRO2G02}$ marker) up to $82.46 \%$ ( $\mathrm{mCrCIRO2DO9}$ marker). Twelve of the analyzed markers displayed $<50 \%$ maternal heterozygosity restitution. For these markers, LODs of SDR/FDR probabilities were calculated and varied between 0.77 and 19.05. These observations could only fulfil the SDR hypothesis, with markers that are close to the centromere, and rule out the FDR scenario.

\section{Pattern of heterozygosity restitution within linkage group II and centromere mapping}

Twelve of the analyzed markers in linkage group II of the Clementine genetic map (Ollitrault et al., 2011) were used to perform this analysis. Taking into account marker order and the distances between them (Haldane's map function), the pattern of heterozygosity is represented in Figure 2.4 (dots). From one side of the linkage group to the other, the heterozygosity decreases from $82.46 \%$ for $\mathrm{mCrCIR02D09}$ marker to $14.29 \%$ for $\mathrm{CX} 6 \mathrm{~F} 23$ marker and increases again up to $80 \%$ as the position rises on the map. Such a pattern within a linkage group is totally incompatible with the FDR model, in which the opposite variation is expected and the lowest theoretical restitution value would be $50 \%$. Therefore, the search for the centromere position producing the best fit between the theoretical function of heterozygosity restitution and the observed data was only conducted under the SDR hypothesis. Under the SDR hypothesis with no interference, the best estimation of centromere position is $10.1 \pm 6.4$ cM from CX6F23 marker (Figure 2.4). Without chiasma interference, the maximum theoretical heterozygosity restitution is $2 / 3$, while we have observed values over $75 \%$ for five telomeric 
markers (two of them with very low $p$-value: mCrCIR02D09, $p=10^{-5}$ and mCrCIR05A05, $p=0.006$ ), suggesting the existence of chiasma interference. On the other hand, the maximum restitution found over all analyzed markers was $82.5 \%$ while $100 \%$ should be expected for telomeric markers in case of total interference. Therefore, among the $x^{2}$ models proposed by Zhao and Speed (1998a) for partial interference, we have tested the $\mathrm{Cx}(\mathrm{Co})^{4}$ model, allowing a maximum restitution of heterozygosity close to $75 \%$. Under this model of chiasma interference and SDR hypothesis, the best estimation of centromere position is $11.8 \pm 7.1 \mathrm{cM}$ from CX6F23 marker (Figure 2.5). This model fits better with the observed data than the no interference model $(\mathrm{Fit}(c)=0.08$ and $\mathrm{Fit}(c)=0.24$ respectively).

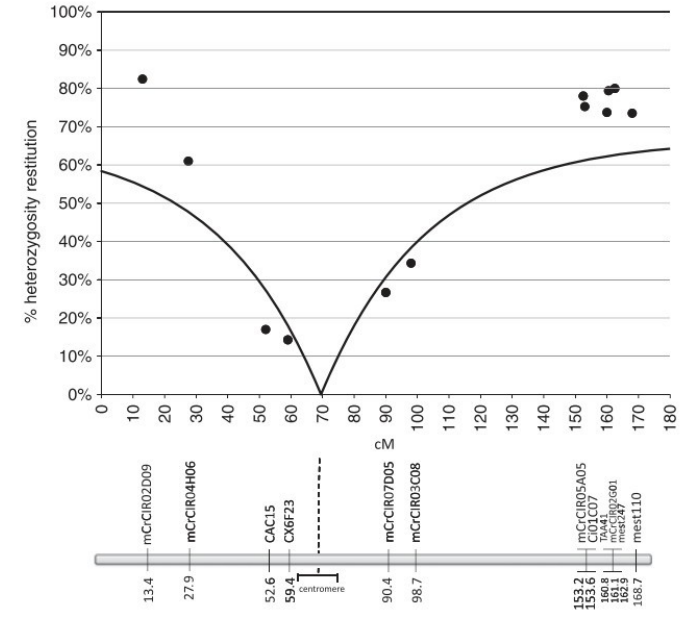

Figure 2.4. Observed heterozygosity restitution values for markers in linkage group II (dots) and theoretical heterozygosity restitutions (line) for the best-fitting centromere position under SDR model without chiasma interference (markers in $\mathrm{x}$ axis are positioned according to Clementine genetic map using Haldane's map function).

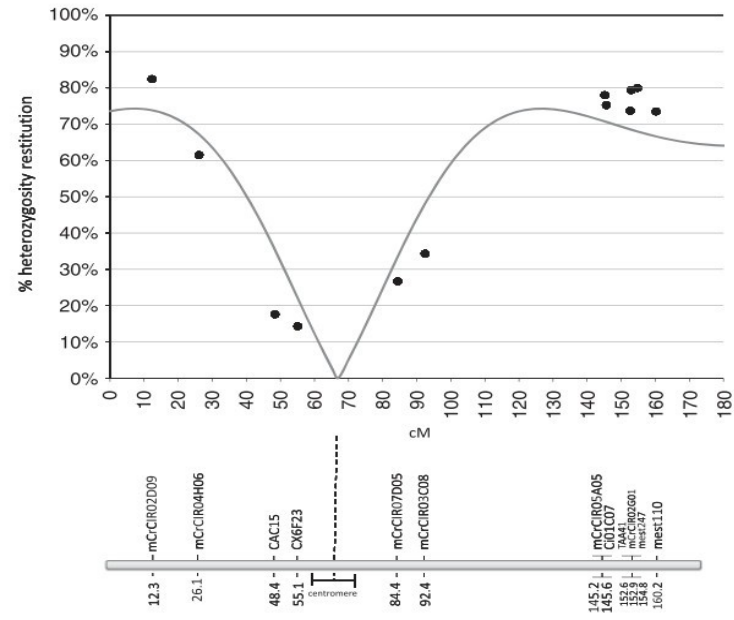

Figure 2.5. Observed heterozygosity restitution values for markers in linkage group II (dots) and theoretical heterozygosity restitutions (line) for the best-fitting centromere position under SDR and the $\mathrm{Cx}(\mathrm{Co})^{4}$ model of partial interference (markers in $x$ axis are positioned according to Clementine genetic map using the corresponding $\mathrm{Cx}(\mathrm{Co})^{4}$ map function). 


\section{Multilocus half-tetrad structure analysis in linkage group II}

Considering homozygosity and heterozygosity at each locus, 15 different multilocus profiles have been observed. These profiles and the number of corresponding $2 n$ gametes are given in Table 2.4 .

Table 2.4. Heterozygous (HE) and homozygous ( $\mathrm{HO})$ profiles for 87 genotypes and five simple-sequence repeat markers within linkage group II.

\begin{tabular}{cccccc}
\hline $\mathbf{N}$ & $\mathbf{M} 1$ & $\mathbf{M} 2$ & $\mathbf{M}$ & $\mathbf{M}$ & $\mathbf{M}$ \\
\hline 8 & $\mathrm{HE}$ & $\mathrm{HE}$ & $\mathrm{HE}$ & $\mathrm{HE}$ & $\mathrm{HE}$ \\
1 & $\mathrm{HE}$ & $\mathrm{HE}$ & $\mathrm{HE}$ & $\mathrm{HE}$ & $\mathrm{HO}$ \\
3 & $\mathrm{HE}$ & $\mathrm{HE}$ & $\mathrm{HE}$ & $\mathrm{HO}$ & $\mathrm{HE}$ \\
5 & $\mathrm{HE}$ & $\mathrm{HE}$ & $\mathrm{HO}$ & $\mathrm{HO}$ & $\mathrm{HO}$ \\
30 & $\mathrm{HE}$ & $\mathrm{HE}$ & $\mathrm{HO}$ & $\mathrm{HO}$ & $\mathrm{HE}$ \\
1 & $\mathrm{HE}$ & $\mathrm{HE}$ & $\mathrm{HO}$ & $\mathrm{HE}$ & $\mathrm{HE}$ \\
7 & $\mathrm{HE}$ & $\mathrm{HO}$ & $\mathrm{HO}$ & $\mathrm{HO}$ & $\mathrm{HO}$ \\
18 & $\mathrm{HE}$ & $\mathrm{HO}$ & $\mathrm{HO}$ & $\mathrm{HO}$ & $\mathrm{HE}$ \\
1 & $\mathrm{HE}$ & $\mathrm{HO}$ & $\mathrm{HE}$ & $\mathrm{HE}$ & $\mathrm{HE}$ \\
1 & $\mathrm{HO}$ & $\mathrm{HO}$ & $\mathrm{HO}$ & $\mathrm{HO}$ & $\mathrm{HO}$ \\
7 & $\mathrm{HO}$ & $\mathrm{HO}$ & $\mathrm{HO}$ & $\mathrm{HO}$ & $\mathrm{HE}$ \\
1 & $\mathrm{HO}$ & $\mathrm{HO}$ & $\mathrm{HE}$ & $\mathrm{HE}$ & $\mathrm{HE}$ \\
1 & $\mathrm{HO}$ & $\mathrm{HE}$ & $\mathrm{HO}$ & $\mathrm{HE}$ & $\mathrm{HO}$ \\
2 & $\mathrm{HO}$ & $\mathrm{HE}$ & $\mathrm{HE}$ & $\mathrm{HO}$ & $\mathrm{HE}$ \\
1 & $\mathrm{HO}$ & $\mathrm{HE}$ & $\mathrm{HO}$ & $\mathrm{HO}$ & $\mathrm{HE}$ \\
\hline $\mathbf{H}$ & 85.06 & 59.77 & 18.39 & 14.94 & 82.76 \\
\hline
\end{tabular}

$\mathrm{N}$, Number of genotypes for each profile; M1, mCrCIR02D09; M2, mCrCIR04H06; M3, CAC15; M4, CX6F23; M5, mCrCIR05A05; H, heterozygosity restitution percentage for 87 genotypes. Gray shading indicates heterozygous regions.

Probabilities of the observed $2 n$ gamete population under the FDR and SDR hypotheses for moving centromere positions have been calculated from this table. The LOD value of the SDR highest probability / FDR highest probability was 6.8 , confirming that SDR is the most probable model. Under the SDR hypothesis, the probability variation as a function of the centromere position suggests that the most probable position is between $2.25 \mathrm{cM}$ and 7.00 $\mathrm{cM}$ (Morgan's map function; which is between $2.30 \mathrm{cM}$ and $7.54 \mathrm{cM}$ with Haldane's map function) close to the CX6F23 marker, between the former and the mCrCIR05A05 marker. This confidence interval overlaps the ones of the estimations done by the best fit method. If up to two crossovers per chromosome occur, it is possible to observe phase-changing between two markers when complementary crossovers take place (i.e. two crossovers involving all four chromatids) via the SDR restitution mechanism (Figure 2.1). The HTA analysis detected 16 complementary crossovers, by revealing allelic phase changes between markers in homozygosity, as shown in Table 2.5; only two double crossovers affecting a chromatid pair have been identified. 
Table 2.5. Number of observed crossing over events on each arm in chromosome II for 87 genotypes and five markers

\begin{tabular}{cccccccc}
\hline & & \multicolumn{7}{c}{ Arm 1 } \\
\hline & Number c.o. & $\mathbf{0}$ & $\mathbf{1}$ & $\mathbf{2}$ & $\mathbf{3}$ & $\mathbf{4}$ & \\
\hline \multirow{3}{*}{ Arm 2 } & $\mathbf{0}$ & 1 & 9 & 0 & $1(1)$ & 0 & $\mathbf{1 2 . 6 4 \%}$ \\
& $\mathbf{1}$ & 3 & 56 & $7(7)$ & $5(3)$ & $1(1)$ & $\mathbf{8 2 . 7 6 \%}$ \\
& $\mathbf{2}$ & 0 & $4(4)$ & 0 & 0 & 0 & $\mathbf{4 . 6 0 \%}$ \\
\hline & & $\mathbf{4 . 6 0 \%}$ & $\mathbf{7 9 . 3 1 \%}$ & $\mathbf{8 . 0 5 \%}$ & $\mathbf{6 . 9 0 \%}$ & $\mathbf{1 . 1 5 \%}$ & \\
\hline
\end{tabular}

Numbers in brackets indicate detected complementary crossovers: percentages of crossover events $(0,1,2,3,4)$ in each chromosome arm are given in bold.

\section{Interference analysis}

Considering centromere position between $C X 6 F 23$ and mCrCIR07D05 markers, the interference coefficient was estimated for each arm of chromosome II with three markers per side. For arm 1, analyzing 87 genotypes for mCrCIR02D09, mCrClR04H06 and CX6F23 markers, the interference coefficient was found to be 0.73 . For the other arm, the interference estimation was 0.53 , analysing $662 n$ gametes for $m C r C I R 03 C 08, m C r C I R 05 A 05$ and TAA41 markers.

\section{Discussion}

MAC-PR is an efficient method to determine allelic configurations in triploid citrus segregating progenies

In this work, the HTA is based on gamete allelic configuration inferred from triploid progeny genotyping. MAC-PR has been proposed to deal with differential amplification intensities among alleles in polyploid plant species (Esselink et al., 2004) for allele dosage estimation. Under the PCR conditions used for citrus SSR analysis, we have successfully verified the correlation between allele dosage and PCR product ratio. Finally, the very clear bimodal distribution of estimated doses for the 35 analyzed SSR markers among triploid hybrids ruled out the occurrence of random PCR drift in our amplifications and validated the MAC-PR approaches for triploid citrus progenies genotyping. A basic assumption of the MACPR method is the repeatability of relative allelic amplification intensities among individuals and, thus, the total homology of primer sites for DNA fragments producing the same allele (same PCR product size). Homoplasy of SSR markers was found at interspecific levels in citrus (Barkley et al., 2009), and could limit general application of MAC-PR. 'Fortune' mandarin and most of the male genitors used in our study are closely related, which should explain why we have not encountered this difficulty because of the by-descent homology of alleles. 


\section{Origin of $2 n$ gamete producing triploids in citrus}

We observed that all the 171 analyzed triploid hybrids show maternal heterozygosity restitution for at least one marker. This confirms that all triploid hybrids found in the progenies of $2 x \times 2 x$ crosses with 'Fortune' mandarin as female genitor arose from $2 n$ megaspores. This result is in agreement with the cytogenetic observations done by Esen and Soost (1971), and with previous molecular observations (Luro et al., 2004; Chen et al., 2008a; Ferrante et al., 2010). In the present work, the restitution heterozygosity rates significantly lower than $50 \%$ for several markers (distributed in 6 of the 8 represented linkage groups) and the pattern of heterozygosity inside linkage group II, definitively ruled out the FDR hypothesis. Multilocus $2 n$ gamete allelic configuration in the same linkage group also revealed that SDR was much more likely to be the mechanism underlying unreduced gamete formation than FDR (LOD=6.8). Moreover, this analysis enabled us to detect four strand (complementary) double crossovers by phase changes of several homozygous markers. Such phase changes between homozygous positions are only possible under the SDR hypothesis if up to two crossovers per arm are considered. This conclusion for SDR is in agreement with that proposed by (Luro et al., 2004), who observed low heterozygosity restitution in C. clementina $2 n$ megagametophyte. The conclusion of FDR given for sweet orange (Chen et al., 2008a) is questionable because of the low number of analyzed markers. Indeed, the unambiguous identification of FDR without previous location of the centromere must be based on a large set of markers with good genome coverage. In the same way, the results of Ferrante et al. (2010), based on a very low number of individuals and markers for each parental genotype are not sufficient to prove the authors's conclusions of SDR for 'Fortune' and 'Wilking' mandarin and FDR for lemon. Systematic analysis of $2 n$ gamete allelic configuration with the same set of loci, close and far from the centromere, will shed light on whether SDR is the only mechanism underlying $2 n$ egg formation in citrus, or whether there is a different mechanism depending on genotype or environmental conditions.

\section{Analysis of the pattern of heterozygosity restitution within a linkage group is an alternative way to map the centromere compared with half tetrad multilocus allelic configuration analysis}

Centromere mapping has been carried out in several crops (Douches and Quiros, 1988; Okagaki et al., 2008) and animals (Kauffman et al., 1995; Lindner et al., 2000), using half-tetrad analysis. In the present work, half-tetrad analysis has been carried out in two ways: by multilocus allelic conformation analysis, as described in Tavoletti et al. (1996) and by comparison of observed and theoretical pattern of heterozygosity restitution rate within the linkage group under several models. Both methods estimated the centromere position to be between CX6F23 and mCrCIR07D05 markers. Confidence intervals of the positions obtained with the two methods overlapped, validating the best fit method. The fitting curve adjustment has the advantage of potential application to a set of loci analyzed in different progenies 
(between a same parent producing the $2 n$ eggs but different male parents), potentially enlarging the usable set of markers to all those heterozygous for the female $2 n$ gamete producer. It could potentially be used to compare a large range of interference model functions. Furthermore, this method should be easily applied to dominant markers by estimating the heterozygous restitution as $1-2 f$ (with $f$ being the frequency of homozygous progeny for the recessive allele). However, it requires the use of an existing genetic map and assumes that crossover distribution is similar during normal meiosis and $2 n$ gamete formation. Multilocus allelic HTA is advantageous in that it can be used without a previous genetic map of the markers and can be applied with a predefined order of markers (Tavoletti et al., 1996; Da et al., 1995) as we have done, or without any previous information about marker position (Da et al., 1995). An excel template has been developed for easy identification of restitution model (FDR or SDR) and positioning of centromere within a linkage group, from heterozygosity restitution data for a set of mapped loci. It includes an estimation of confidence interval for the centromere position by bootstrap on the loci. It is available under request to the authors.

\section{Evidence for positive chiasma interference in citrus cv 'Fortune'}

Many models of half-tetrad analysis are based in the hypothesis of complete interference. In the present work, the analysis of multilocus configuration in linkage group II revealed the occurrence of up to four crossovers in the same chromosome arm and thus, incomplete interference. It is confirmed by the maximum restitution values between $75 \%$ and $82 \%$ observed for five of the markers, while for SDR, the maximum restitution should be $66.6 \%$ under the no interference hypothesis and should reach $100 \%$ for total interference. A better

adjustment was found between observed data and theoretical curve with the $\mathrm{Cx}(\mathrm{Co})^{4}$ chi-square model for partial interference than the no interference one. Interference values were estimated by three point analysis for each arm of linkage group II, with results suggesting that it should be higher for one arm (0.73) than for the other (0.53). Such variation of interference level between different parts of the genome has also been observed in Arabidopsis (Drouaud et al., 2007), in human (Lian et al., 2008) and in mouse (Broman et al., 2002).

\section{Implications for citrus breeding}

Seedlessness is one of the most important characteristics for the citrus fresh fruit market. An efficient way to achieve this aim is to obtain triploid mandarin varieties. Sexual triploidization is a classical method to obtain triploid citrus hybrids (Ollitrault et al., 2008). Indeed, some genotypes such as 'Temple', 'Wilking', and 'Fortune' mandarin (Esen and Soost, 1973; Aleza et al., 2010b) are well known for their production of diploid megagametophytes. The other classical method to create triploid citrus progenies is inter-ploidy hybridization with doubled-diploid. Assuming an SDR origin of $2 n$ gametes in 'Fortune' mandarin, sexual polyploidization may lead to lower average of heterozygosity restitution than interploid 
hybridization, whatever the segregation model considered for the doubled diploid (Marsden et al., 1987). As heterozygosity and epistatic interactions are maintained for a great number of individuals in the progeny from interploid crosses with doubled-diploid, this triploid breeding strategy should be more efficient than $2 x \times 2 x$ hybridization for developing new cultivars that are phenotypically close to 'Fortune mandarin' genitor. Conversely, $2 x \times 2 x$ hybridization should produce more polymorphic progenies, by creating larger number of new multilocus allelic combinations (David et al., 1995), providing the opportunity to select innovative products within the perspective of market segmentation as a commercial strategy. 


\section{Supplementary information}

\section{Validation of MAC-PR estimation of allele dosage}

The inference of a diploid gamete structure when the two parents share one allele requires the ability to estimate allelic dosage in triploid progenies. In this paper we have used the MAC-PR method (Esselink et al., 2004) to estimate allelic dosage after verification of its applicability in our populations and markers as described below.

In order to verify that the MAC-PR method can be applied to estimate the allelic dosage of our markers in triploid genotypes, with our PCR conditions, a preliminary trial was performed with five markers. The DNA of two haploid lines (from clementine cv 'Nules' and pumello cv 'Chandler') displaying allelic variability were mixed at different ratios (1:2, 1:1, 2:1 and 3:1). Ten replications (PCR and run in the genetic fragment analyzer) were done for each ratio and marker. Area ratios among the two observed peaks (alleles) were calculated for all runs and the correlation between DNA ratio and peak area ratio was analyzed. An illustration is given for the mest56 marker (Figure 2.S1), showing a very high correlation among DNA proportion and peak area ratio $\left(r^{2}=0.9902\right)$. Similar results were observed for the four other markers.

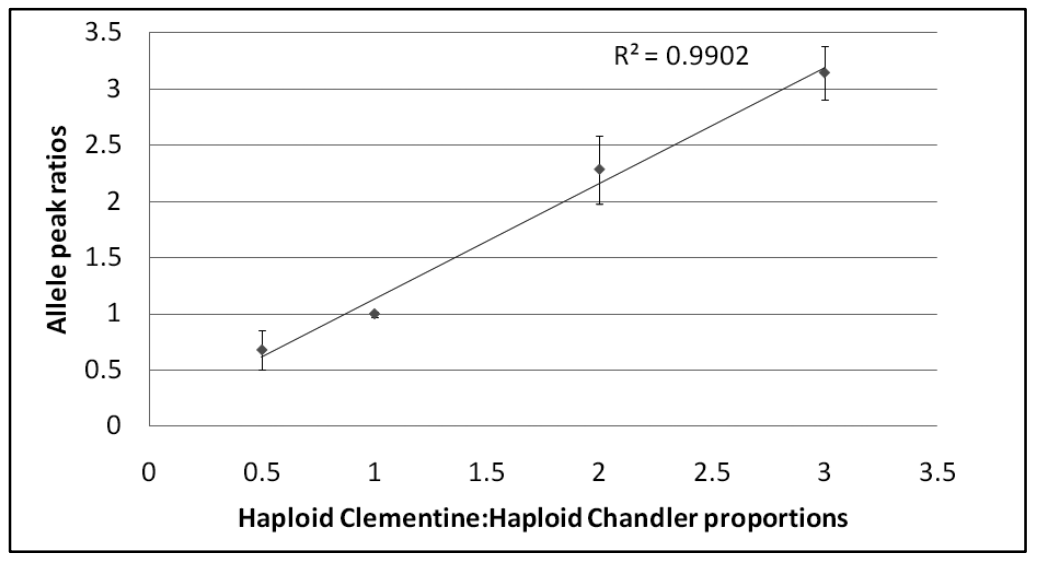

Figure 2.S1. Relationship between several DNA proportions of 'Clementine' and 'Chandler' haploids and peak area ratio for three repetitions of the mest56 marker.

To avoid misinterpretation of allele dosage associated with PCR allele competition, the triploid hybrid peak area ratios were systematically corrected by 'Fortune' genitor peak ratio as:

$$
S D=\frac{S_{1} \cdot F_{2}}{S_{2} \cdot F_{1}}
$$

where $S D$ is the estimated allele dosage ratio in the sample; $S_{i}$ and $F_{i}$ are the peak area for allele $i$ for the analyzed sample and 'Fortune' diploid cultivar, respectively (Figure 2.S2). 


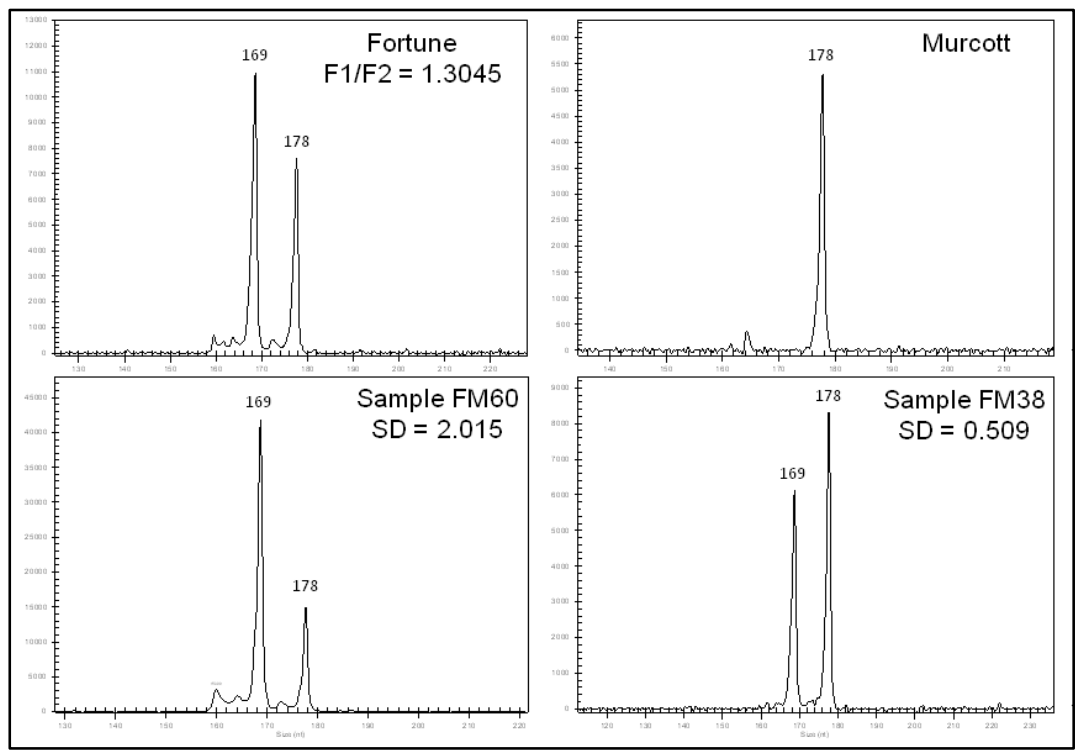

Figure 2.S2. Observed peaks for the CAC15 marker in 'Fortune', 'Murcott', the FM60 hybrid and the FM38 hybrid showing respectively ratio $2: 1$ and $1: 2$ between alleles 169 and $178 . \mathrm{SD}=(\mathrm{S} 1 \cdot \mathrm{F} 2) /(\mathrm{S} 2 \cdot \mathrm{F} 1)$

Ten technical replications (independent PCR) were done for $m \mathrm{CrCIR06B05}$ with two triploid genotypes with ratios $1: 2$ and $2: 1$ to determine the discrimination power of the assignment of observed peak area ratios. The results (Figure 2.S3a) testified the high stability of allele dosage evaluation.

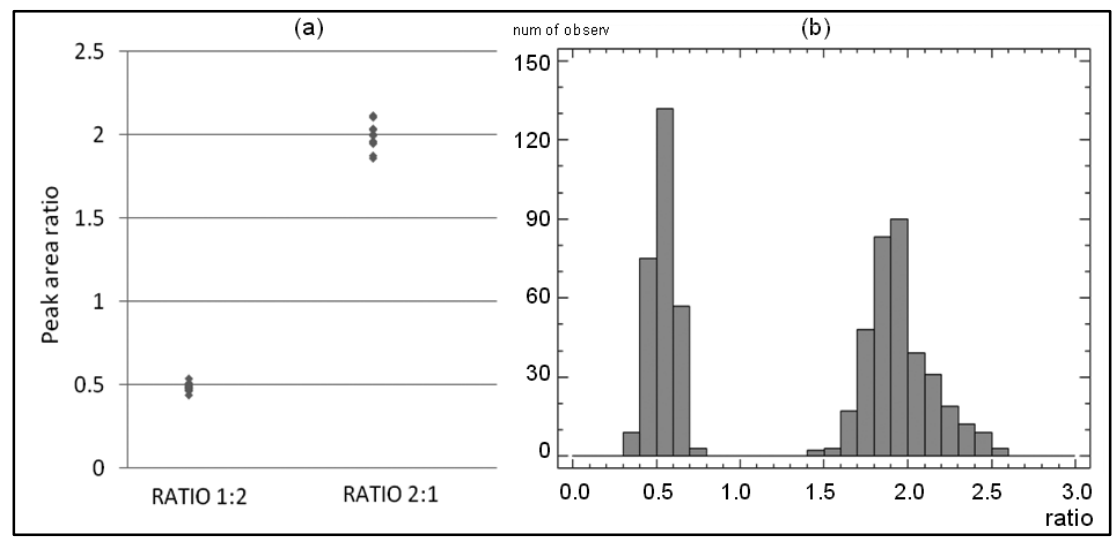

Figure 2.S3. Scatterplot of peak area ratios for ten $P C R$ repetitions of two genotypes with ratios $1: 2$ and $2: 1$ for two alleles of $m C r C I R 06 B 05$ marker (a) and distribution of peak area ratios for all the genotypes and markers showing $1: 2$ and $2: 1$ ratios $(b)$.

The unambiguous differentiation of allele dosage in heterozygous triploids has been confirmed during progeny analysis by the very clear bimodal distribution of the peaks area ratio of the different triploid hybrids for all markers (Figure 2.S3b). These results validate the method of area peak ratios used for genotyping the triploid progenies in this study. 


\section{Method for Half Tetrad Analysis}

The analysis was made according to Tavoletti et al. (1996) assuming that multiple crossovers do not occur between contiguous markers. Under this hypothesis, each crossover between two markers leads to a change from homozygosity to heterozygosity between marker $i$ and $i+1$ in the case of SDR and a half change from heterozygosity to homozygosity in the case of FDR. Thus, the distance between two adjacent markers $\left(\mathrm{d}_{\mathrm{MM} \text { i+1 }}\right)$ can be estimated by the proportion of $2 n$ gametes with changes (homozygosity versus heterozygosity; $\mathrm{C}_{\mathrm{MMM}+1}$ ) between

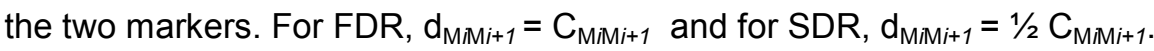

The probability of each observed genotype profile $(G j)$, considering that the locus is homozygous $(\mathrm{Ho})$ or heterozygous $(\mathrm{He})$, was calculated as:

$$
P\left(G_{j}\right)=\left(\Pi P_{M i M i+1}\right)\left(P_{C M a} \cdot P_{C M a+1}\right)
$$

where:

- $\mathrm{P}_{\mathrm{MM} \text { i+1 }}$ is the probability of configuration for two adjacent loci whose interval does not include the centromere; being $\mathrm{P}_{\mathrm{MMM}_{i+1}}=\mathrm{C}_{\mathrm{MM}_{\mathrm{M}+1}}$ in case of configuration change and $\mathrm{P}_{\mathrm{MM}+1=1}=1-\mathrm{C}_{\mathrm{MM} \text { i+1 }}$ when no change occurs between the adjacent loci.

- $\mathrm{P}_{\mathrm{CM} a}$ and $\mathrm{P}_{\mathrm{CM}+1}$ are the probability of the observed configuration for the two loci flanking the centromere, $P_{\mathrm{CMa}}$ (and identically $\left.\mathrm{P}_{\mathrm{CMa}+1}\right)$ values being $\left(1-\mathrm{d}_{\mathrm{CMa}}\right),\left(\mathrm{d}_{\mathrm{CMa}}\right),\left(2 \mathrm{~d}_{\mathrm{CMa}}\right)$ and (1-2 $\mathrm{d}_{\mathrm{CM}}$ ) respectively for the following situation (He, FDR), (Ho, FDR), (He, SDR), (Ho, $\mathrm{SDR}$ ); with $\mathrm{d}_{\mathrm{CMa}}$ being the mapped distance between the centromere and the given flanking locus.

Under FDR or SDR models and different centromere positions, the probability of the observed $2 n$ gamete population $(P)$ is:

$$
P=\mathrm{C} \prod_{\mathrm{i}=1}^{j}\left(G_{j}\right)^{n}
$$

where $n$ is the number of $2 n$ gametes with the genotype $j$ and $\mathrm{C}$ a combinatory coefficient constant for the set of observed data.

Both under FDR and SDR models, the centromere position was virtually moved from before the first considered locus along the linkage group to after the last considered locus (intervals of $0.5 \mathrm{cM}$ ) and relative probability $(\mathrm{P} / \mathrm{C})$ was estimated for each position. The LOD between best position under SDR and FDR was calculated in order to determine the mode of $2 n$ gamete restitution and the position of the centromere was considered as the one producing the highest relative probability under the identified mode of restitution. 


\section{CHAPTER 3}

\section{Maximum-likelihood method based on parental heterozygosity restitution of centromeric loci identifies SDR as the predominant mechanism leading to $2 n$ megagametophytes in C. reticulata}

José Cuenca, Pablo Aleza, José Juárez, Andrés García-Lor, Yann Froelicher,

Luis Navarro and Patrick Ollitrault

Annals of Botany, Submitted 

Abstract

Background: The use of unreduced gametes, resulting in the establishment of sexual polyploids is currently a major strategy for triploid citrus breeding. The origin mechanism of $2 n$ gamete formation, i.e., FDR (First-Division Restitution) or SDR (Second-Division Restitution), greatly impacts the gametic structures and, therefore, the polyploid populations and the efficiency of breeding strategies. Methods previously developed to identify the underlying mechanism require the analysis of a large set of markers over large progeny.

Scope: Simulating populations were used to check the power of the method in terms of individual and marker numbers needed to obtain significant conclusions. This work develops a new maximum-likelihood method to identify the unreduced gamete formation mechanism both at the population and individual levels using independent centromeric markers. This new method was applied to investigate the mechanism in sixteen mandarin genotypes used as female parents in triploid citrus breeding.

Conclusions: Knowledge of marker-centromere distances greatly improves the statistical power of the comparison between the SDR and FDR hypotheses. The importance of selecting markers very close to the centromere to obtain significant conclusions at the individual level has been demonstrated by simulating data and illustrated by our results. All triploid hybrids analyzed originated from $2 n$ megagametophytes. SDR was identified as the unreduced gamete formation mechanism in all mandarin genotypes analyzed. Moreover, SDR was identified as the restitution mechanism for $85.3 \%$ of the analyzed triploid hybrids, whereas $0.6 \%$ of the analyzed triploids were derived from FDR; for $14.1 \%$ of the hybrids, no significant conclusions were obtained. 


\section{Introduction}

Polyploidization is a key source of species diversification and speciation in plants (Harlan and DeWet, 1975; Otto and Whitton, 2000; Soltis and Soltis, 2009) and may occur by somatic chromosome doubling (somatic polyploidization) or sexually through gametic nonreduction (sexual polyploidization) (De Storme and Geelen, 2013). Currently, most researchers consider sexual polyploidization to be the main mechanism of polyploidization in plants (Bretagnolle and Thompson, 1995; Otto and Whitton, 2000; Ramsey and Shemske, 2002).

In sexual polyploidization, polyploids are generated by the formation of diploid gametes, i.e., pollen or eggs that have the somatic rather than the gametophytic chromosome number (Harlan and DeWet, 1975; Bretagnolle and Thompson, 1995; Ramsey and Schemske, 1998; Otto and Whitton, 2000). In most cases, diploid gametes result from a restitution of the meiotic cell cycle (Bretagnolle and Thompson, 1995). In this process, meiotic cell division is converted into a mitosis-like nonreductional process, generating dyads (unreduced gametes) instead of the normal tetrads at the end of meiosis II. This phenomenon is referred to as 'meiotic restitution' and is the predominant mechanism of unreduced gamete formation in plants (Otto and Whitton, 2000; Soltis and Soltis, 2009).

Meiotic aberrations related to spindle formation, spindle function and cytokinesis can lead to unreduced gamete formation in plants. Up to seven major mechanisms of $2 n$ gamete formation have been cytogenetically characterised: premeiotic doubling, first-division restitution (FDR), chromosome replication during the meiotic interphase, second-division restitution (SDR), postmeiotic doubling, indeterminate meiotic restitution, and apospory (Peloquin et al., 1989; Lim et al., 2004; Dewitte et al., 2012). FDR and SDR are the predominant mechanisms of $2 n$ gamete formation. Failure of the first (FDR) or second (SDR) divisions leads to the formation of restitution nuclei with an unreduced chromosome number. An FDR $2 n$ gamete contains nonsister chromatids, while an SDR $2 n$ gamete contains two sister chromatids (Bretagnolle and Thompson, 1995; Tavoletti et al., 1996; Cai and Xu, 2007). 


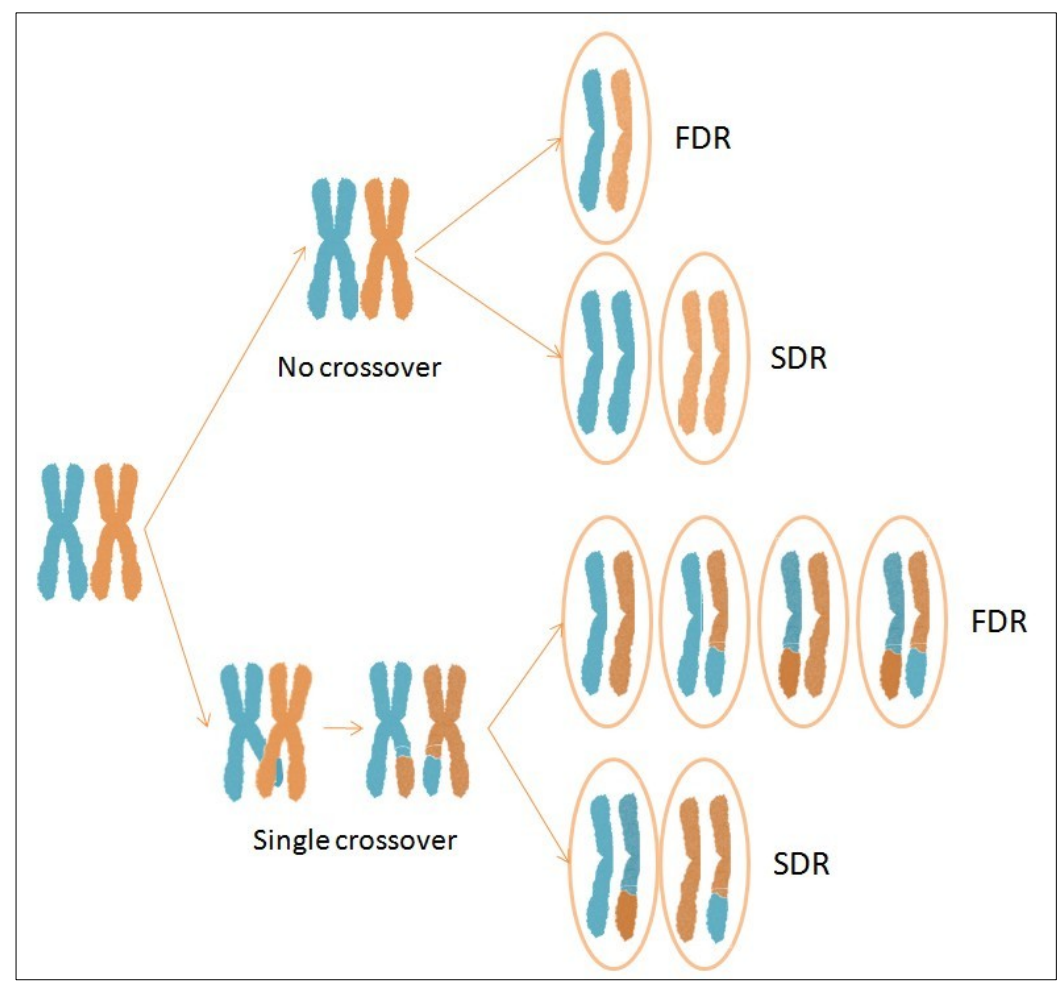

Figure 3.1. Half tetrads resulting from no crossover and single crossover events under FDR and SDR mechanisms of unreduced gamete formation.

The use of unreduced gametes in plant breeding (Ramanna and Jacobsen, 2003; Dewitte et al., 2012), resulting in the establishment of sexual polyploids, is useful for improvement of crops such as lily (Lim et al., 2004; Barba-González et al., 2004; 2005), maize (Rhoades and Dempsey, 1966), potato (Mok and Peloquin, 1975; Jongedijk et al., 1991), rose (Crespel and Gudin, 2003), rye (Lelley et al., 1987), alfalfa (Ortiz and Peloquin, 1991; Barcaccia et al., 2003) and banana (Ortiz, 1997; Ssebuliba et al., 2008).

Diploidy is the general rule in Citrus and its related genera, with a basic chromosome number $x=9$ (Krug, 1943). However, triploid breeding has become an important strategic tool in the development of new seedless citrus commercial varieties (Starrantino, 1992; Ollitrault et al., 2008; Recupero et al., 2005; Aleza et al., 2010a; Cuenca et al., 2010). Indeed, seedlessness is one of the most important economic traits related to fruit quality for fresh-fruit marketing of mandarins (Navarro et al., 2005; Ollitrault et al., 2008).

Spontaneous occurrences of citrus triploid hybrids arising from the union of $2 n$ megagametophytes with haploid pollen have been noted since the seventies (Esen and Soost, 1971, 1973; Luro et al., 2004; Chen et al., 2008a; Aleza et al., 2010b). However, the frequency of such events is generally low (Cameron and Frost, 1968; Esen and Soost, 1971 Geraci et al., 1975) and extensive breeding programs based on this type of hybridization require very effective methodologies for embryo rescue and ploidy evaluation of large progenies (Ollitrault et al., 2008; Aleza et al., 2010b). To date, very few cases of citrus triploid hybrid occurrence in $2 x$ $\times 2 x$ crosses from unreduced pollen have been reported (Luro et al., 2004; Chen et al., 2008a). 
Esen et al. (1979) proposed that, in citrus, $2 n$ eggs result from the abortion of the second meiotic division (SDR) in the megaspore. This hypothesis was corroborated by molecular marker analysis for clementine (Citrus clementina Hort. ex Tan.) (Luro et al., 2004; Aleza et al., 2012b) and for 'Fortune' mandarin (C. clementina $\times$ C. tangerina) (Cuenca et al., 2011). By contrast, Chen et al. (2008a) proposed that $2 n$ eggs of sweet orange (C. sinensis (L.) Osb.) resulted from first meiotic division restitution (FDR).

The origin of $2 n$ gamete formation greatly impacts the gametic structures and, therefore, the polyploid populations and the efficiency of breeding strategies. Under FDR, non-sister chromatids retain parental heterozygosity from the centromere to the first crossover point, and the gametes thus transfer a large proportion of this parental heterozygosity to the progeny. Under SDR, the two sister chromatids are homozygous between the centromere and the first crossover point, and the resultant gametes have lower levels of heterozygosity than FDR gametes (Figure 3.1, Bretagnolle and Thompson, 1995). Several studies based on genetic markers indicate that FDR gametes transmit $70-80 \%$ of the parental heterozygosity, but SDR gametes transmit only 30-40\% (Barone et al., 1995; Douches and Quiros, 1988; Vorsa and Rowland, 1997; Crespel and Gudin, 2003; Buso et al., 1999; Dewitte et al., 2012). Thus, a tighter distribution is expected in FDR-derived populations than in SDR ones because a higher percentage of the parental genome is transferred intact, resulting in a more uniform gamete production (Douches and Maas; 1998). Therefore, insights into the meiotic nuclear restitution mechanisms that produce unreduced gametes are crucial for the optimization of breeding strategies based on sexual hybridization (Errico et al., 2005).

Molecular marker analysis is a valuable tool for the estimation of heterozygosity transmission through diploid gametes to polyploid progenies and, therefore, to identify the mechanisms underlying unreduced gamete formation (Barone et al., 1995; Vorsa and Rowland, 1997; Bastiaanssen et al., 1998; Barcaccia et al., 2003; Luro et al., 2004; Chen et al., 2008a; Hayashi et al., 2009). The models described therein are all based on population analysis and suppose complete chiasma interference.

Cuenca et al. (2011) proposed an approach that takes into account different models of chromosome interference (i.e., no interference, partial interference or complete chiasma interference) when testing for FDR and SDR, and for mapping centromeres to linkage groups. This approach is based on functions of heterozygosity restitution (HR) at the population level along a chromosome in relation to locus-centromere distance (d) (Zhao and Speed, 1998a). Indeed, under FDR or SDR, HR is a direct function of the crossing over frequency between the considered locus and the centromere. It is, therefore, possible to implement the function $(H R=f(d))$ according to the FDR and SDR hypotheses while also taking into account different models of chromosome interference (Figure 3.2). This approach was successfully applied in populations of $2 n$ ovules of 'Fortune' mandarin and 'Fina' clementine, and it was concluded that SDR was the main restitution mechanism and that partial chromosome interference occurs 
(Cuenca et al., 2011; Aleza et al., 2012b). That study also contributed to the discovery of centromere locations in the nine citrus chromosomes.

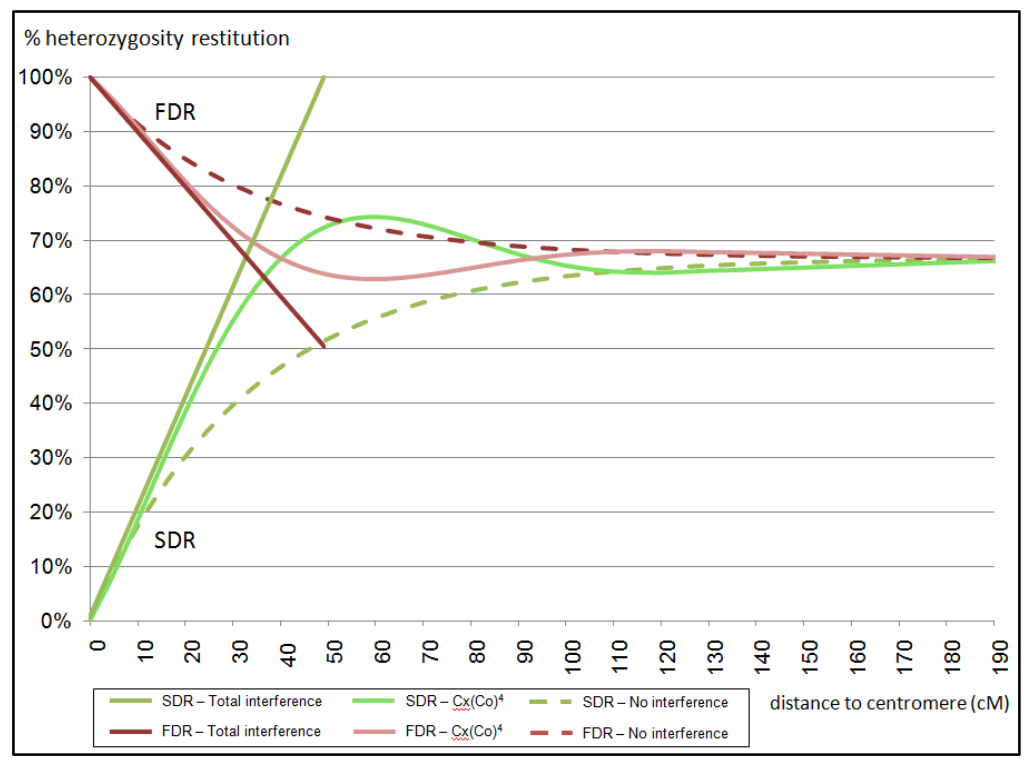

Figure 3.2. Rate (percentage) of heterozygosity restitution in the unreduced gametes under FDR and SDR mechanisms in function of the locus-centromere distance considering the total interference model, the no interference model and the $\mathrm{Cx}(\mathrm{Co})^{4}$ partial interference model. Adapted from Cuenca et al. (2011).

In the present work, we propose a maximum-likelihood approach to test the SDR/FDR mechanism based on the HR of unlinked markers located close to the centromere of different chromosomes. This approach can be applied at the individual or population level. We simulated $2 n$ gamete populations arising from FDR or SDR. This enabled us to identify the number of independent markers necessary to test in order to draw significant conclusions at the individual level in relation to marker/centromere distances, as well as the minimum population size necessary to be able to draw significant conclusions when analysing a defined number of markers.

Taking advantage of the known centromere locations (Aleza et al., 2012b) within the nine linkage groups of the clementine reference genetic map (Ollitrault et al., 2012a), we selected centromeric markers and used this maximum-likelihood method to (i) check the potential variability of origin between individuals for two genotypes in which SDR was proposed to be the predominant polyploidization mechanism as determined by population analysis ('Fortune' mandarin, (Cuenca et al., 2011)) and clementines, (Luro et al., 2004, Aleza et al., $2012 \mathrm{~b}$ ) and (ii) shed light on the mechanism leading to unreduced gamete formation in a range of mandarin genotypes used as female parents in $2 x \times 2 x$ triploid breeding programs. 


\section{Materials and Methods}

\section{Plant materials}

Analyses were performed using 497 triploid hybrids derived from 16 different mandarin genotypes as female parents in $2 x \times 2 x$ cross populations (Table 3.1 ). The genotypes include six clementine and ten hybrid mandarin genotypes. Triploid hybrids were grown at the 'Instituto Valenciano de Investigaciones Agrarias' orchards in Moncada, Valencia, Spain. Practical details for the establishment of triploid populations from $2 x \times 2 x$ crosses by embryo rescue and triploid selection by flow cytometry can be found in Aleza et al. (2010b). All triploid genotypes in the present study were selected after probation of their hybrid status by molecular marker analysis (data not shown). Taxonomic information about both female and male parental accessions is given in Table S3.1 according to the standard classification system for the Citrus genus (Swingle and Reece, 1967; Tanaka, 1977).

Table 3.1. Number of hybrids within each population analyzed in this study

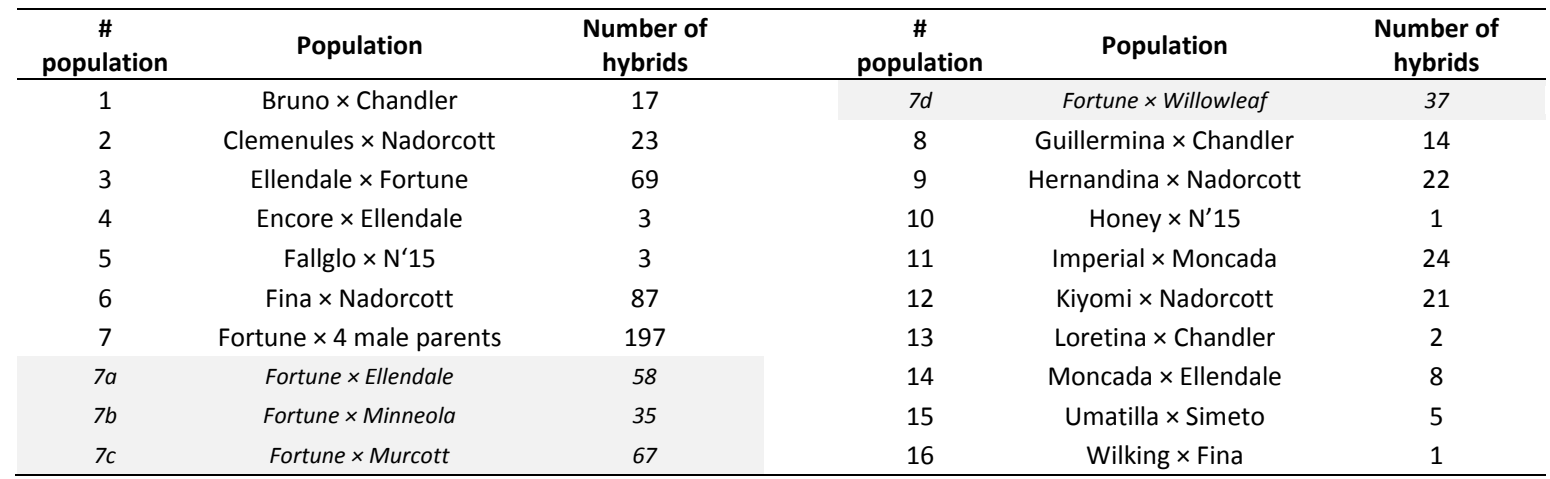

\section{Selection of centromeric markers for the analysis of $2 n$ gamete origin and formation mechanisms}

Triploid citrus hybrids obtained in $2 x \times 2 x$ hybridizations arise from unreduced megagametophytes (Esen and Soost, 1971, 1973; Geraci et al., 1975; Luro et al., 2004; Chen et al., 2008a; Aleza et al., 2010b; Cuenca et al., 2011). Therefore, markers heterozygous for the female parent and displaying polymorphism between the two parents were primarily selected for the molecular characterization of triploid hybrids and analysis of $2 n$ gamete origin.

Centromere positions in all nine clementine chromosomes are known (Aleza et al., $2012 b)$. Molecular markers within $20 \mathrm{cM}$ of the centromere were used in this study because centromere-proximal markers are more informative with regard to the mechanisms of $2 n$ gamete formation than centromere-distal markers (Ollitrault et al., 2012a). Within this range, the lowest expected HR rate is greater than $80 \%$ for FDR, while the highest HR for SDR is $40 \%$ (Figure 
3.2). Twenty-four markers were selected for genotyping the triploid progeny. Between four and seven of these centromeric markers were used for genotyping each population (Table 3.2).

Table 3.2. Centromeric markers used for genotyping each triploid population.

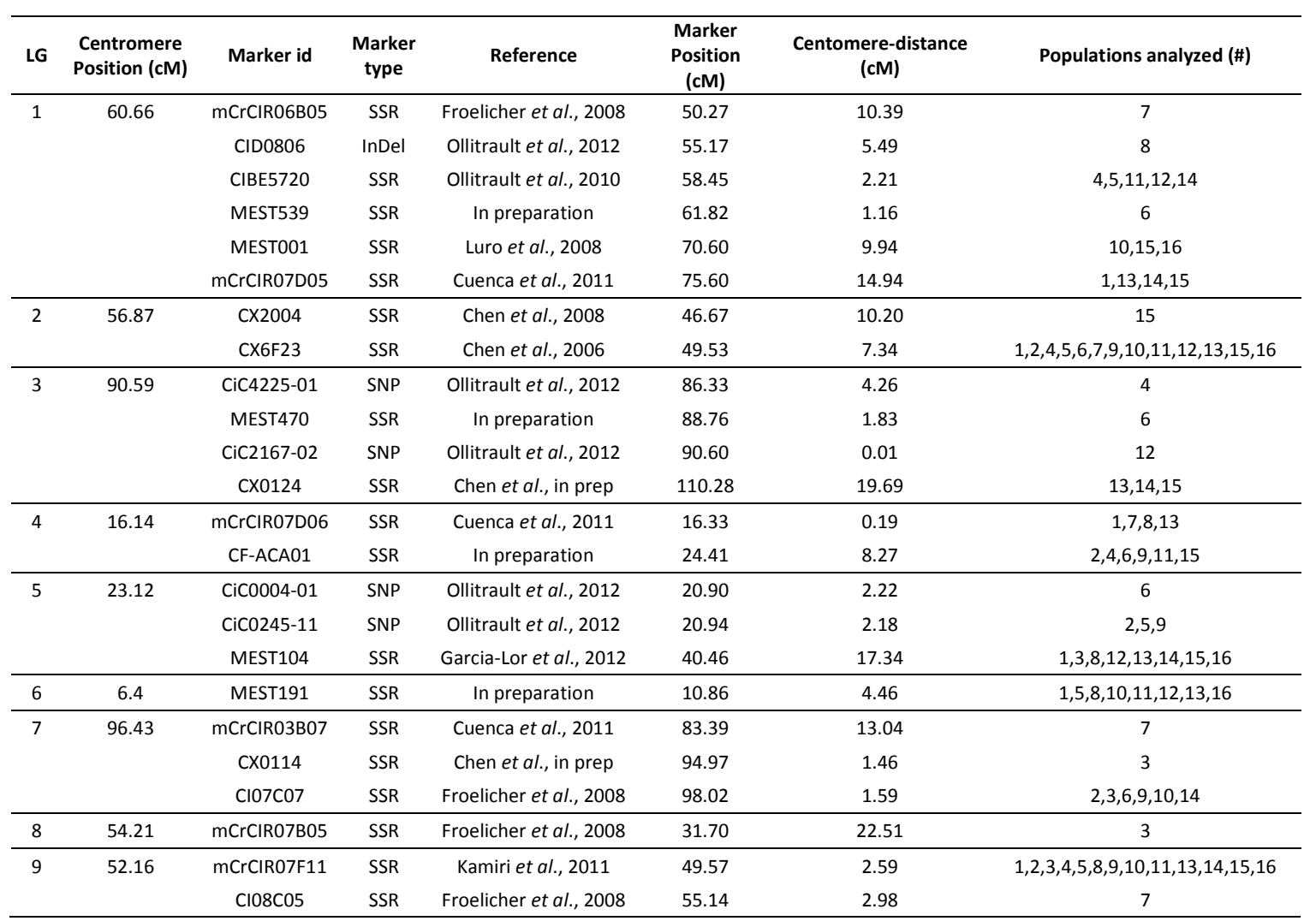

\section{Genotyping of triploid hybrids}

DNA extraction: Leaf DNA of triploid hybrids and their parents was isolated using the Plant DNAeasy kit from Qiagen Inc. (Valencia, CA, USA), following the manufacturer's protocol.

SSR and InDel analyses: Polymerase chain reactions (PCRs) were performed with wellRED oligonucleotides (Sigma-Aldrich $\AA$, St Louis, MO, USA) in a Mastercycler epgradient S (Eppendorf Scientific Inc., Westbury, NY, USA). The reaction (volume, $15 \mu \mathrm{l}$ ) contained $0.8 \mathrm{U}$ Taq polymerase (Fermentas ${ }^{\circledR}$, Burlington, VT, USA), $0.1 \mathrm{mM}$ of each dNTP, $5 \mathrm{mM} \mathrm{MgCl}, 3$ $\mathrm{mM}$ of each primer, and $30 \mathrm{ng}$ of DNA in buffer containing $750 \mathrm{mM} \mathrm{Tris-HCl}(\mathrm{pH} 9), 50 \mathrm{mM} \mathrm{KCl}$, $200 \mathrm{mM}\left(\mathrm{NH}_{4}\right)_{2} \mathrm{SO}_{4}$, and $0.001 \%$ bovine serum albumin. The PCR program was $94^{\circ} \mathrm{C}$ for $5 \mathrm{~min}$; 40 cycles of $30 \mathrm{~s}$ at $94^{\circ} \mathrm{C}, 1 \mathrm{~min}$ at $55^{\circ} \mathrm{C}$ and $30 \mathrm{~s}$ at $72^{\circ} \mathrm{C}$, and a final elongation of $10 \mathrm{~min}$ at $72^{\circ} \mathrm{C}$. Separation was carried out by capillary gel electrophoresis (CEQ 8000 Genetic Analysis System; Beckman Coulter Inc., Fullerton, CA, USA). Data collection and analysis were carried out with GenomeLab GeXP (Beckman Coulter Inc.) version 10.0 software. Identification of allele 
doses in heterozygous triploid hybrids was carried out using the MAC-PR method (Esselink et al., 2004) adapted in Citrus by Cuenca et al. (2011).

SNP analyses: SNP genotyping was performed by Kbioscience ${ }^{\circledR}$ services, using the KASPar technique. Experimental details were as described in Cuppen (2007). Identification of allele doses in heterozygous triploid hybrids was carried out using the relative allele signals as previously described for SNP markers (Cuenca et al., 2013a), based on competitive allelespecific PCR.

\section{Analysis of the parental origin of the $2 n$ gametes producing the triploid hybrids}

For each hybrid, determination of the $2 n$ gamete origin was carried out by identifying the parent that passed double genetic information to the hybrid. For markers displaying $A_{1} A_{2} \times A_{1} A_{1}$ or $A_{1} A_{2} \times A_{1} A_{3}$ configurations, the identification of $A_{1} A_{2} A_{2}$ or $A_{2} A_{2} A_{3}$ (i.e., double dosage of $A_{2}$, the allele specific to the female parent) configurations in the hybrid would imply a female origin of the $2 n$ gamete. For the second combination, the observation of $A_{1} A_{3} A_{3}$ or $A_{2} A_{3} A_{3}$ (i.e., double dosage of $A_{3}$, the allele specific to the male parent) would indicate a male origin.

For markers displaying $A_{1} A_{2} \times A_{3} A_{3}$ configurations in the parents, the identification of $A_{1} A_{2} A_{3}, A_{1} A_{1} A_{3}$, or $A_{2} A_{2} A_{3}$ configurations in the hybrid resulted from a maternal origin of the unreduced gamete, while $A_{1} A_{3} A_{3}$ or $A_{2} A_{3} A_{3}$ resulted from a paternal origin.

For markers with $A_{1} A_{2} \times A_{3} A_{4}$ parental configuration, the identification of the following genotypes $\left(A_{1} A_{1} A_{3}, A_{1} A_{1} A_{4}, A_{1} A_{2} A_{3}, A_{1} A_{2} A_{4}, A_{2} A_{2} A_{3}, A_{2} A_{2} A_{4}\right)$ and $\left(A_{1} A_{3} A_{3}, A_{2} A_{3} A_{3}, A_{1} A_{3} A_{4}, A_{2} A_{3} A_{4}\right.$, $\left.A_{1} A_{4} A_{4}, A_{2} A_{4} A_{4}\right)$ implied, respectively, female and male origin of the $2 n$ gamete.

Once the parental origin of the $2 n$ gamete was identified, the inference of the allelic configurations of the unreduced gametes from triploid hybrid genotyping was carried out as previously described by Cuenca et al. (2011).

\section{Identification of the restitution mechanism at an individual level}

For loci heterozygous for the parent producing the $2 n$ gamete, the probabilities of a $2 n$ gamete being heterozygous or homozygous as a consequence of FDR or SDR mechanisms are direct functions of the marker-centromere distance.

To estimate such probabilities, the function relating HR rate and locus-centromere distance (Cuenca et al., 2011), derived from the $\mathrm{Cx}(\mathrm{Co})^{4}$ partial chiasma interference model developed by Foss et al. (1993) and Zhao and Speed (1998a), could be used. Indeed, Cuenca et al. (2011) showed that this model fit better to 'Fortune' mandarin data (SDR mechanism) than total or no interference models. However, since selected markers are located close to centromeres (as explained above), for our data, the $\mathrm{Cx}(\mathrm{Co})^{4}$ model and the total interference 
model are equivalent (Figure 3.2). To simplify mathematical calculations of probabilities, the total interference model was used. Marker-centromere distances (d) were estimated from the clementine reference genetic map (Ollitrault et al., 2012a) and centromere locations in the clementine map were determined by Aleza et al. (2012b).

The probabilities of a marker being inherited as heterozygous under the SDR $\left[P_{S D R}\left(M_{H e}\right)\right]$ or FDR $\left[P_{F D R}\left(M_{H e}\right)\right]$ mechanisms were directly estimated from the total interference model functions as $P_{\mathrm{SDR}}\left(\mathrm{M}_{\mathrm{He}}\right)=2 \mathrm{~d}$ and $\mathrm{P}_{\mathrm{FDR}}\left(\mathrm{M}_{\mathrm{He}}\right)=(1-\mathrm{d})$. The probabilities of a marker being inherited as homozygous under SDR and FDR were estimated as $P_{S D R}\left(M_{H_{0}}\right)=(1-2 d)$ and $P_{\mathrm{FDR}}\left(\mathrm{M}_{\mathrm{Ho}_{\mathrm{O}}}\right)=\mathrm{d}$, respectively.

Therefore, the LOD values used to compare the probabilities of a heterozygous or a homozygous diploid gamete occurring at a locus, under the two models (SDR/FDR), were calculated respectively as:

$$
\begin{gathered}
\operatorname{LOD}\left(\mathrm{M}_{\mathrm{He}}\right)=\log \left[\mathrm{P}_{\mathrm{SDR}}\left(\mathrm{M}_{\mathrm{He}}\right) / \mathrm{P}_{\mathrm{FDR}}\left(\mathrm{M}_{\mathrm{He}}\right)\right]=\log (2 \mathrm{~d} /(1-\mathrm{d})) \quad \text { and } \\
\operatorname{LOD}\left(\mathrm{M}_{\mathrm{Ho}}\right)=\log \left[\mathrm{P}_{\mathrm{SDR}}\left(\mathrm{M}_{\mathrm{Ho}}\right) / \mathrm{P}_{\mathrm{FDR}}\left(\mathrm{M}_{\mathrm{Ho}}\right)\right]=\log ((1-2 \mathrm{~d}) / \mathrm{d})
\end{gathered}
$$

For each restitution model, the probability of a single unreduced gamete $[P(G)]$ presenting the observed allelic configuration for $i$ unlinked markers $\left(M_{i}\right)$ is the product of the probabilities of the observed genotype at each locus, $P(G)=\pi P_{M i}$, and therefore the LOD value to compare the SDR/FDR models is the sum of the LOD at each locus,

$$
\operatorname{LOD}(\mathrm{G})=\sum \mathrm{LOD}_{\mathrm{Mi}} \text {, }
$$

where $\mathrm{P}_{\mathrm{Mi}}$ and $\mathrm{LOD}_{\mathrm{Mi}}$ are the probability and the LOD value of the observed genotype at the locus $I$, respectively.

As an example, if three unlinked loci $\left(M_{1}, M_{2}\right.$ and $\left.M_{3}\right)$ were heterozygous, homozygous and homozygous, respectively, the probabilities of observing such gametes $\left[P(G) ;\left(M_{1 H e}-M_{2 \mathrm{Ho}^{-}}\right.\right.$ $\left.\mathrm{M}_{3 \mathrm{Ho}}\right)$ ] are, respectively,

$$
\begin{gathered}
P_{S D R}(G)=2 d_{1} \times\left(1-2 d_{2}\right) \times\left(1-2 d_{3}\right) \text { under SDR and } \\
P_{F D R}(G)=\left(1-d_{1}\right) \times d_{2} \times d_{3} \quad \text { under FDR }
\end{gathered}
$$

The LOD value used to compare the probabilities of SDR/FDR models is

$$
\operatorname{LOD}(G)=\log \left(2 d_{1} /\left(1-d_{1}\right)\right)+\log \left(\left(1-2 d_{2}\right) / d_{2}\right)+\log \left(\left(1-2 d_{3}\right) / d_{3}\right)
$$

where $d_{i}$ is the distance from the locus $i$ to its centromere. 
LOD scores greater than 3 (the probability of the observed gamete is more than 1000fold higher under the SDR model than the FDR one; LOD3) or greater than 2 (the probability of the observed gamete is more than 100-fold higher under the SDR model than the FDR one; LOD2) were considered as thresholds indicating that SDR was the mechanism involved in the single unreduced gamete formation, whereas LODs below -3 (or -2) indicate that FDR was the underlying mechanism; for LOD scores between -3 and 3 (or between 2 and -2 ), we considered that the mechanism could not be determined significantly.

\section{Identification of the restitution mechanism at population level}

Considering an infinite population of $2 n$ gametes and a single locus, the probability of observing a sample of gametes $[\mathrm{P}(\mathrm{Pop})]$ with $j$ heterozygous and $k$ homozygous individuals under the SDR and FDR model are, respectively:

$$
\begin{gathered}
P_{S D R}(P o p)=C \times P_{S D R}\left(M_{H e}\right)^{j} \times P_{S D R}\left(M_{H o}\right)^{k}=C \times(2 d)^{j} \times(1-2 d)^{k} \\
P_{F D R}(P o p)=C \times P_{F D R}\left(M_{H e}\right)^{j} \times P_{F D R}\left(M_{H o}\right)^{k}=C \times(1-d)^{j} \times(d)^{k}
\end{gathered}
$$

where $\mathrm{C}$ is a combinatory coefficient constant for the observed sample. Therefore,

$$
\operatorname{LOD}(\mathrm{Pop})=\frac{(2 \mathrm{~d})^{j} \times(1-2 \mathrm{~d})^{k}}{(1-\mathrm{d})^{j} \times(\mathrm{d})^{k}}
$$

If $i$ independent loci are analyzed, the probabilities of the observed sample of gametes occurring under the SDR $\left[\mathrm{P}_{\mathrm{SDR}}(\mathrm{Pop})\right]$ or FDR $\left[\mathrm{P}_{\mathrm{FDR}}(\mathrm{Pop})\right]$ models are the products of the probabilities of the observed sample at each locus

$$
\begin{gathered}
\mathrm{P}_{\mathrm{SDR}}(\mathrm{Pop})=\pi \mathrm{C}_{\mathrm{i}} \times \mathrm{P}_{\mathrm{SDR}}\left(\mathrm{M}_{\mathrm{iHe}}\right)^{j i} \times \mathrm{P}_{\mathrm{SDR}}\left(\mathrm{M}_{\mathrm{iHo}}\right)^{k i}=\pi \mathrm{C}_{\mathrm{i}} \times\left(2 \mathrm{~d}_{\mathrm{i}}\right)^{j i} \times\left(1-2 \mathrm{~d}_{\mathrm{i}}\right)^{k i} \\
\mathrm{P}_{\mathrm{FDR}}(\mathrm{Pop})=\pi \mathrm{C}_{\mathrm{i}} \times \mathrm{P}_{\mathrm{FDR}}\left(\mathrm{M}_{\mathrm{iHe}}\right)^{j i} \times \mathrm{P}_{\mathrm{FDR}}\left(\mathrm{M}_{\mathrm{iHo}}\right)^{k i}=\pi \mathrm{C}_{\mathrm{i}} \times\left(1-\mathrm{d}_{\mathrm{i}}\right)^{j i} \times\left(\mathrm{d}_{\mathrm{i}}\right)^{k i}
\end{gathered}
$$

and therefore,

$$
\operatorname{LOD}(\mathrm{Pop})=\sum \frac{\left(2 d_{i}\right)^{j i} \times\left(1-2 d_{i}\right)^{k i}}{\left(1-d_{i}\right)^{j i} \times\left(d_{i}\right)^{k i}}
$$

where $\mathrm{P}\left(\mathrm{M}_{\mathrm{iHe}}\right), \mathrm{P}\left(\mathrm{M}_{\mathrm{iHo}}\right), j i, k i$ and $d_{i}$ are, respectively, the probability of heterozygous individuals, probability of homozygous individuals, number of heterozygous individuals, number of homozygous individuals and distance to centromere for the locus $i$.

At the population level, LOD scores greater than 3 were considered to indicate that SDR was the mechanism involved in unreduced gamete formation, whereas LODs below -3 indicated 
that FDR was the underlying mechanism. When LOD scores between -3 and 3 were obtained, we considered that the mechanism could not be significantly determined.

\section{Studies to check the power of the method}

We assessed the power of our method using simulated samples of diploid gametes arising from either the FDR or SDR mechanisms. From a theoretical infinite population with heterozygous and homozygous genotype frequencies directly defined by the considered locuscentromere distances $\left(\left[\mathrm{P}_{\mathrm{FDR}}\left(\mathrm{M}_{\mathrm{He}}\right)=(1-\mathrm{d}) ; \mathrm{P}_{\mathrm{FDR}}\left(\mathrm{M}_{\mathrm{Ho}}\right)=\mathrm{d} ; \mathrm{P}_{\mathrm{SDR}}\left(\mathrm{M}_{\mathrm{He}}\right)=2 \mathrm{~d} ; \mathrm{P}_{\mathrm{SDR}}\left(\mathrm{M}_{\mathrm{Ho}}\right)=(1-2 \mathrm{~d})\right]\right.$ as explained above), individual gametes with information for nine markers (the haploid number of chromosome in Citrus) were randomly generated. Then, the LOD values of these gametes were calculated as described above. We estimated the proportion of gametes with significant solutions at LOD3 (LOD value $>3$ or $<-3$ ) and LOD2 (LOD value $>2$ or $<-2$ ) when analysing $1-$ 9 markers mapped at the same centromere distance, but in different chromosomes, and for distances ranging from 0 to $20 \mathrm{cM}$.

Gamete populations were also generated in order to estimate the theoretical number of hybrids that would need to be analyzed in order to obtain significant conclusions for a mechanism, depending on the number of markers used and the marker-centromere distances. From each theoretical population (FDR and SDR populations), 200 replicates of populations (with 1-100 gametes/population) were randomly generated. The generated population LODs were calculated as described above and, for each number of considered markers at a given centromere distance, we identified the minimum number of gametes needed in order to be able to reach a true significant conclusion for at least $99 \%$ of the generated populations $(99 \%$ of replicates with LOD $>3$ for SDR or LOD $<-3$ for FDR).

\section{Results}

\section{Simulation results}

From 1000 randomly selected gametes with nine independent markers (at the same distance from their respective centromere) from a theoretical SDR and FDR infinite population, we analyzed the percentage of replicates with significant LOD value (i.e., LOD3 and LOD2) at a given distance considering the data from 1-9 markers.

Curves corresponding to a significant true answer are shown in Figure 3.3. All curves display a vertical drop to 0 , corresponding to the distance when the maximum theoretical LOD score (when all considered markers are in the most favourable combination for the model) is below the considered threshold. Compared with LOD3, the LOD2 threshold allows maintenance of the progressive decrease of the significant answer with increasing distance. As distance increases, more markers are needed to maintain a high level of significance. 


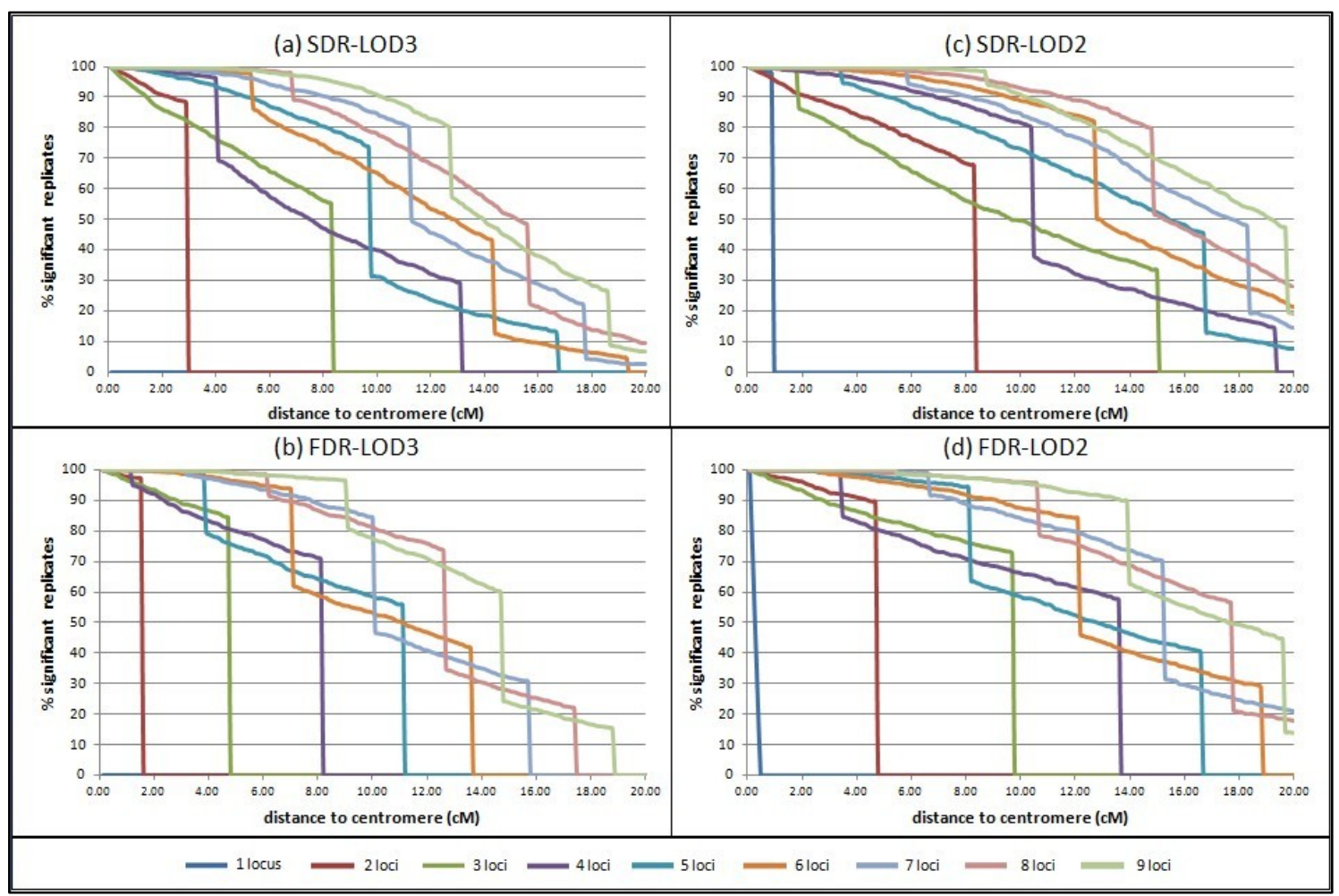

Figure 3.3. Percentage of replicates with significant LOD value considering a LOD3 for (a) theoretical SDR and (b) FDR populations, and considering a LOD2 for (c) SDR and (d) FDR populations.

At LOD3, the usefulness of only one marker is null for both the SDR (Figure 3.3a) and the FDR (Figure 3.3b) models at a very low marker distance from the centromere $(0.1 \mathrm{cM})$. At 5 $\mathrm{CM}$, at least five (for SDR) and six (for FDR) markers are necessary to maintain a $90 \%$ true significant identification of the mechanism. When all markers were at least $10 \mathrm{cM}$ from centromeres, nine markers were necessary to provide a $90 \%$ true significant answer for the SDR population, but only $78 \%$ significant true answers were obtained with nine markers for a FDR population. At $15 \mathrm{cM}$ and nine markers, the true identification rates fall to $44 \%$ and $24 \%$ for SDR and FDR, and, at $20 \mathrm{cM}$, to $6.6 \%$ and $0 \%$, respectively.

If the LOD2 threshold is considered, a single marker was informative in the first $\mathrm{cM}$ interval for the SDR model (Figure 3.3c) but significant replicate number decreases very quickly for FDR (Figure 3.3d). At $5 \mathrm{cM}$, at least four and five markers were necessary to provide $90 \%$ of true significant identification for SDR and FDR populations, respectively. With all markers $10 \mathrm{cM}$ from centromeres, at least eight markers were necessary to provide $90 \%$ true significant answers with an SDR or FDR population. For nine markers, the rate of true significant identification is improved for the SDR population at $15 \mathrm{cM}$ and $20 \mathrm{cM}(70 \%$ and $19 \%$, respectively) as well as for the FDR population (59\% and $14 \%$, respectively) when compared with LOD3.

The rate of false identification (FDR significant conclusion [i.e., LOD $<-3$ or LOD $<-2$ ] for a SDR population, or reciprocally) is very low for both models (SDR or FDR), whatever the 
centromere distance and the number of considered loci. At LOD3, it is under $0.1 \%$ for all conditions and it remains below $1 \%$ for the LOD2 threshold (Figure 3.S1).

At the population level (Figure 3.4), due to the probabilities of the $2 n$ gamete genotypic structure under FDR and SDR models becoming similar as the distance to centromere rises, the number of hybrids needed to obtain significant conclusions for a mechanism increases as an exponential function and is more pronounced when analysing a single marker only.

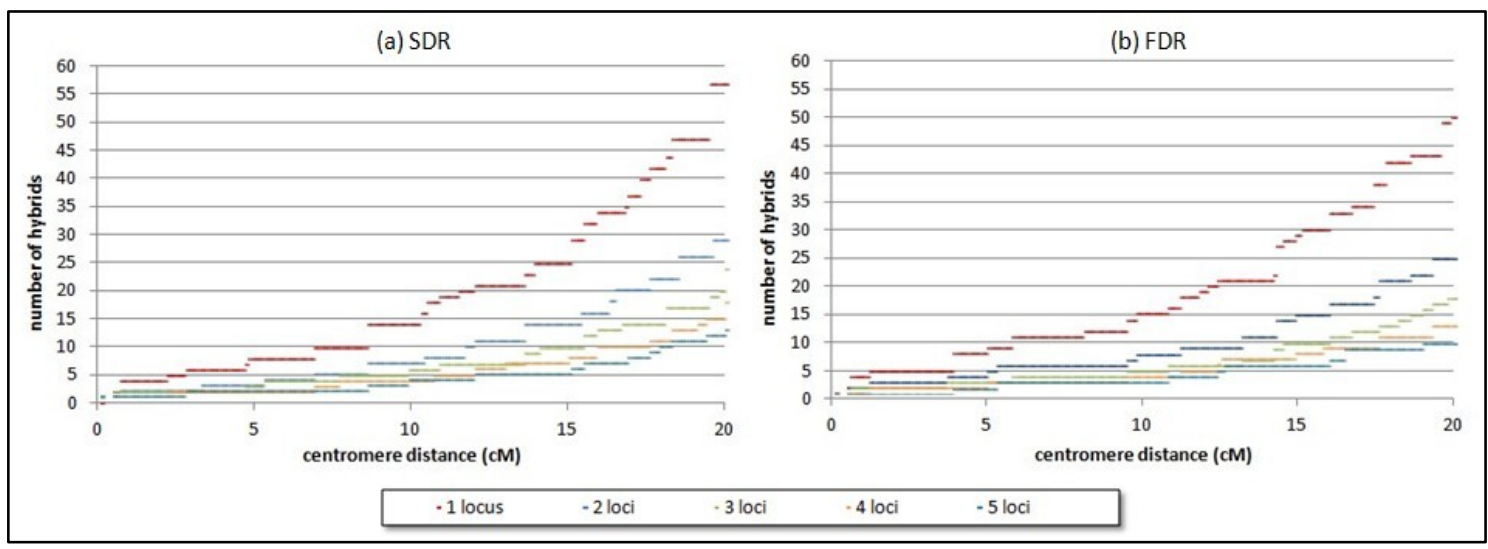

Figure 3.4. Number of hybrids needed to obtain significant conclusions for (a) SDR and (b) FDR mechanisms.

For a concrete locus-centromere distance, the number of hybrids $\left(h_{m}\right)$ needed is related to the number of markers analyzed as: $h_{m}=h_{1} / m$, being $h_{1}$ the number of hybrids needed for one marker and $m$, the number of markers analyzed. For example, for a SDR population model, at $20 \mathrm{cM}, 58$ hybrids are necessary if analysing only one marker, 29 are necessary for two markers, and 20 are necessary for three markers. The number of hybrids needed to provide the same level of conclusive answer is slightly lower for FDR (50 hybrids for one marker at $20 \mathrm{cM}$ ). With these population sizes, no false mechanism identification occurred for the generated populations.

\section{Inference of allelic configuration of triploid hybrids and corresponding 2 n gametes}

Assignment of allelic configuration in heterozygous triploid hybrids was performed using the MAC-PR method for SSR markers [(Esselink et al., 2004); Figure 3.S2] adapted for Citrus by Cuenca et al. (2011) and from relative allele signal for SNP markers as proposed by Cuenca et al. (2013a), based on competitive allele-specific PCR (Figure 3.S3). However, both these methods use a 1:1 dosage correction from the relative allele signals for heterozygous diploid parents $\left(A_{1}: A_{2}, A_{1}: A_{3}\right.$ or $\left.A_{3}: A_{4}\right)$. Therefore, for markers displaying $A_{1} A_{2} \times A_{1} A_{3}$ configuration in the parents, among the heterozygous triploid hybrids only the $A_{1} A_{2} A_{2} / A_{1} A_{1} A_{2}$ or $A_{1} A_{3} A_{3} / A_{1} A_{1} A_{3}$ configurations can be determined using these methods, while no direct allele dosage estimation 
can be obtained for a triploid with $A_{2} / A_{3}$ heterozygosity without a reference for the relative $A_{2} / A_{3}$ allele signal. Similarly, for markers displaying the $A_{1} A_{2} \times A_{3} A_{4}$ configuration, it is not possible to directly estimate allele dosage for the heterozygous triploid hybrids.

When the parental origin of a $2 n$ gamete can be demonstrated using one marker, this allows the estimation of the relative signals of the alleles for another locus in the hybrid under consideration. As an example, consider two loci, $A$ and $B$, with the parental configurations $A_{1} A_{2}$ $\times A_{3} A_{3}$ and $B_{1} B_{2} \times B_{1} B_{3}$, which produce a triploid hybrid with $A_{1} A_{2} A_{3}$ and $B_{2} B_{3}$ allelic configurations. Configuration of the $A$ locus unequivocally reveals a maternal origin of the $2 n$ gamete. Based on the maternal origin of the unreduced gamete, the only possibility for the $B$ locus is $B_{2} B_{2} B_{3}$. Thus, the allelic pattern for this triploid genotype can be used as a reference of the relative allele signal to infer allele dosage for the other triploid hybrids in the same progeny that display $B_{2} / B_{3}$ heterozygosity. A summary of triploid genotypes allowing inference of the $2 n$ gamete genotype and origin, either directly or by inferring allele doses from diploid parents or reference triploid hybrids, is given in additional Table 3.S2. Loci with complete differentiation between the parents $\left(A_{1} A_{2} \times A_{3} A_{4}\right.$ or $\left.A_{1} A_{2} \times A_{3} A_{3}\right)$ are by far the best configurations as they allow unequivocal identification of the $2 n$ gamete parent and unambiguous determination of $2 n$ gamete structure. When the parental origin of a $2 n$ gamete has been determined by triploid patterns at other loci, the $2 n$ gamete structure can be inferred for all triploid hybrids for the loci sharing a single allele between the two parents.

\section{Identification of the unreduced gamete parental origin}

Allelic patterns of the markers allowed unequivocal identification of the origin of the double dosage for each analyzed triploid hybrid. Female parents were the unreduced gamete producers leading to triploid hybrids for all studied parental combinations. No triploid hybrid arising from unreduced pollen was found. It was therefore possible to infer the maternal $2 n$ gamete genotypes for all hybrids and loci.

\section{Identification of the restitution mechanism at the individual level}

LOD score testing the SFR/FDR hypothesis was estimated for each individual $2 n$ gamete from its inferred genotype, as described in the Materials and Methods. Positive LODs were found for 482 hybrids of the 497 analyzed (Figure 3.5), suggesting a large global predominance of the SDR mechanism. The LOD distribution for clementine $2 n$ gametes is displaced to higher values when compared with the distribution for 'Fortune' and other mandarin $2 n$ gametes. Fifty-seven diploid gametes occur with LOD between 9 and 10, and these correspond mostly to the 'Fina' clementine progeny. 


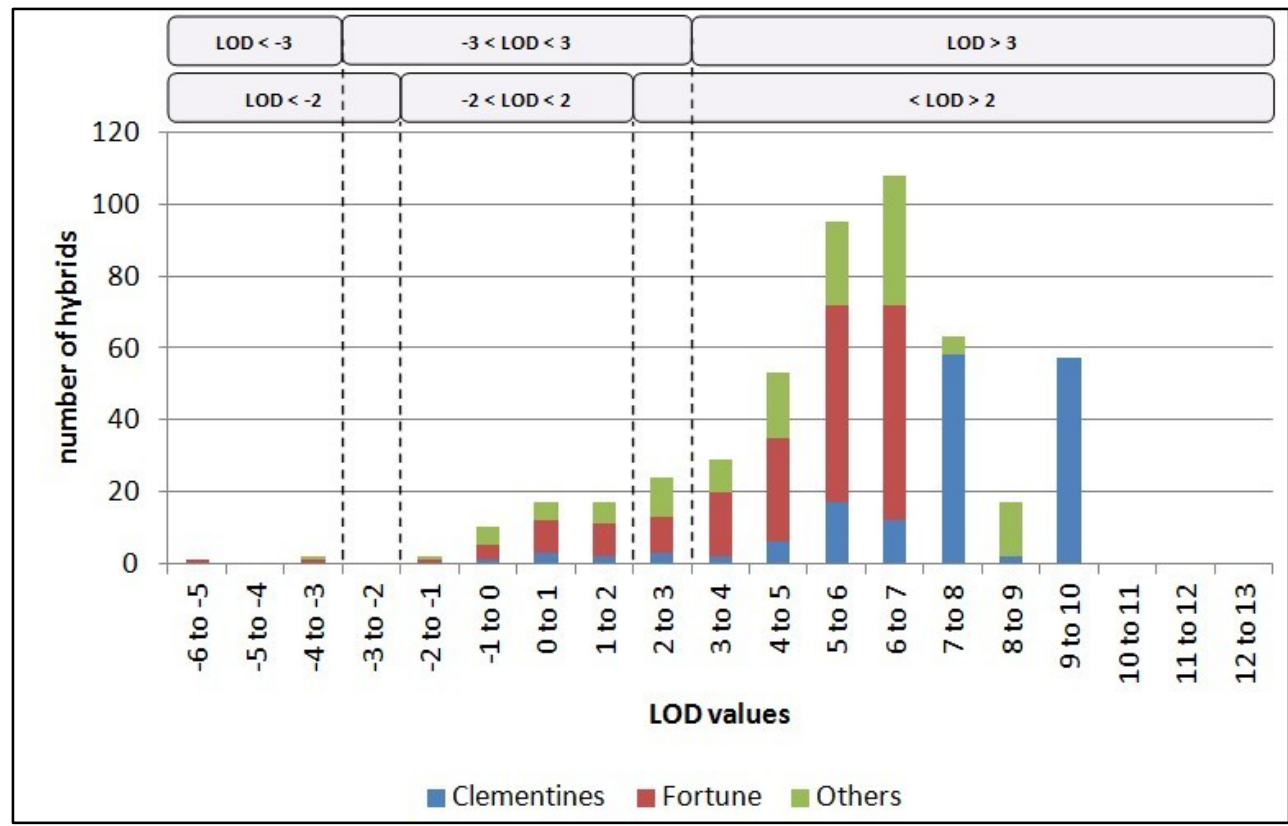

Figure 3.5. Frequency histogram of LOD values obtained for each individual $2 n$ gamete, indicating those arising from clementines, 'Fortune' mandarin and other mandarins analyzed in this study.

When using LOD3 as the threshold, SDR was found to be the restitution mechanism underlying unreduced megagametophyte production for $424(85.3 \%)$ of the analyzed triploid hybrids (Table 3.3). For one triploid hybrid arising from 'Ellendale' and two arising from 'Fortune' $(0.6 \%)$, the FDR mechanism was implicated. The other $70(14.1 \%)$ triploid hybrids did not give significant conclusions for either the SDR or FDR mechanisms. All unreduced gametes arising from 'Encore', 'Fallgo', 'Guillermina', 'Honey', 'Loretina' and 'Wilking' were identified as having an SDR origin, whereas for 33 unreduced gametes arising from 'Fortune' (16.7\%) no significant conclusions were obtained (Table 3.3).

When using LOD2 as the threshold, the percentage of gametes with unidentified origins decreased to $9 \%$. Gametes attributed to SDR increased to $90.1 \%$, with significance achieved for an additional three clementine gametes, another ten from 'Fortune' and an extra 11 from other mandarins. No additional $2 n$ gametes arising from FDR were identified.

\section{Identification of the restitution mechanism at population level}

At the population level, all LOD scores were greater than 3, even for small populations with fewer than five hybrids. Therefore, SDR was identified as the preeminent restitution mechanism producing $2 n$ megagametophyte for all female parents analyzed (Table 3.3). 
Table 3.3. LOD scores for progeny of 16 female parents analyzed at population level and individuals within each population originated by SDR, FDR, or with unidentified origin.

\begin{tabular}{|c|c|c|c|c|c|c|c|c|c|c|c|}
\hline \multirow{2}{*}{ Group } & \multirow{2}{*}{ Female parent } & \multirow{2}{*}{$\mathrm{Nh}$} & \multirow{2}{*}{$\mathrm{Nm}$} & \multirow{2}{*}{$\begin{array}{c}\text { Cd } \\
\text { average } \\
\text { (cM) }\end{array}$} & \multicolumn{2}{|c|}{ LODs $>+3$} & \multicolumn{2}{|c|}{ LODs $-3-+3$} & \multicolumn{2}{|c|}{ LODs $<-3$} & \multirow{2}{*}{$\begin{array}{c}\text { Population } \\
\text { LOD } \\
\text { P }_{S D R} / P_{F D R}\end{array}$} \\
\hline & & & & & number & $(\%)$ & number & $(\%)$ & number & $(\%)$ & \\
\hline Clementine & $\begin{array}{c}\text { 'Bruno' } \\
\text { 'Clemenules' } \\
\text { 'Fina' } \\
\text { 'Guillermina' } \\
\text { 'Hernandina' } \\
\text { 'Loretina' } \\
\end{array}$ & $\begin{array}{c}17 \\
23 \\
87 \\
14 \\
22 \\
2 \\
\end{array}$ & $\begin{array}{l}6 \\
5 \\
6 \\
6 \\
5 \\
7 \\
\end{array}$ & $\begin{array}{l}7.8 \\
4.4 \\
3.7 \\
8.1 \\
4.4 \\
9.5 \\
\end{array}$ & $\begin{array}{c}15 \\
22 \\
83 \\
14 \\
20 \\
2 \\
\end{array}$ & $\begin{array}{c}(88.2) \\
(95.6) \\
(95.4) \\
(100.0) \\
(90.9) \\
(100.0) \\
\end{array}$ & $\begin{array}{l}2 \\
1 \\
4 \\
0 \\
2 \\
0\end{array}$ & $\begin{array}{l}(11.8) \\
(4.4) \\
(4.6) \\
(0.0) \\
(9.1) \\
(0.0) \\
\end{array}$ & $\begin{array}{l}0 \\
0 \\
0 \\
0 \\
0 \\
0\end{array}$ & $\begin{array}{l}(0.0) \\
(0.0) \\
(0.0) \\
(0.0) \\
(0.0) \\
(0.0) \\
\end{array}$ & $\begin{array}{c}98.9 \\
143.3 \\
699.3 \\
91.1 \\
139.0 \\
10.3 \\
\end{array}$ \\
\hline Mandarin & 'Imperial' & 24 & 5 & 5.0 & 23 & $(95.8)$ & 1 & $(4.2)$ & 0 & $(0.0)$ & 138.5 \\
\hline $\begin{array}{c}\text { Hybrid } \\
\text { mandarin }\end{array}$ & $\begin{array}{c}\text { 'Ellendale' } \\
\text { 'Encore' } \\
\text { 'Fallglo' } \\
\text { 'Fortune' } \\
\text { 'Fortune' × 'Ellendale' } \\
\text { 'Fortune' × 'Minneola' } \\
\text { 'Fortune' × 'Murcott' } \\
\text { 'Fortune' × 'Willowleaf' } \\
\text { 'Honey' } \\
\text { 'Kiyomi' } \\
\text { 'Moncada' } \\
\text { 'Umatilla' } \\
\text { 'Wilking' } \\
\end{array}$ & $\begin{array}{c}69 \\
3 \\
3 \\
197 \\
58 \\
35 \\
67 \\
37 \\
1 \\
21 \\
8 \\
5 \\
1 \\
\end{array}$ & $\begin{array}{l}5 \\
5 \\
5 \\
5 \\
5 \\
4 \\
5 \\
4 \\
4 \\
5 \\
4 \\
4 \\
5\end{array}$ & $\begin{array}{c}9.1 \\
4.9 \\
3.7 \\
6.8 \\
6.8 \\
5.2 \\
6.8 \\
6.6 \\
6.1 \\
6.3 \\
10.3 \\
11.3 \\
8.3 \\
\end{array}$ & $\begin{array}{c}50 \\
3 \\
3 \\
162 \\
54 \\
28 \\
53 \\
28 \\
1 \\
20 \\
4 \\
1 \\
1 \\
\end{array}$ & $\begin{array}{c}(72.5) \\
(100.0) \\
(100.0) \\
(82.2) \\
(93.1) \\
(80.0) \\
(79.1) \\
(75.7) \\
(100.0) \\
(95.2) \\
(50.0) \\
(20.0) \\
(100.0) \\
\end{array}$ & $\begin{array}{c}18 \\
0 \\
0 \\
33 \\
4 \\
6 \\
14 \\
8 \\
0 \\
1 \\
4 \\
4 \\
0 \\
\end{array}$ & $\begin{array}{c}(26.1) \\
(0.0) \\
(0.0) \\
(16.7) \\
(6.9) \\
(17.1) \\
(20.9) \\
(21.6) \\
(0.0) \\
(4.8) \\
(50.0) \\
(80.0) \\
(0.0) \\
\end{array}$ & $\begin{array}{l}1 \\
0 \\
0 \\
2 \\
0 \\
1 \\
0 \\
1 \\
0 \\
0 \\
0 \\
0 \\
0 \\
\end{array}$ & $\begin{array}{l}(1.4) \\
(0.0) \\
(0.0) \\
(1.1) \\
(0.0) \\
(2.9) \\
(0.0) \\
(2.7) \\
(0.0) \\
(0.0) \\
(0.0) \\
(0.0) \\
(0.0) \\
\end{array}$ & $\begin{array}{c}282.7 \\
17.9 \\
21.6 \\
933.0 \\
310.5 \\
145.7 \\
326.2 \\
150.6 \\
5.1 \\
162.9 \\
22.1 \\
9.6 \\
15.6 \\
\end{array}$ \\
\hline
\end{tabular}

\section{Discussion}

\section{A powerful maximum-likelihood method to compare FDR and SDR hypothesis at the individual and population level has been developed}

In sexual polyploidization, polyploids are generated by the formation of unreduced diploid gametes. From the cytogenetic point of view, two types of meiotic nuclear restitution leading to $2 n$ gamete formation are considered, FDR and SDR (Bretagnolle and Thompson, 1995; Ramsey and Schemske, 1998; Bastiaanssen et al., 1998; Dewitte et al., 2012; Brownfield and Kholer, 2011). The subsequent union of unreduced and reduced gametes leads to the formation of polyploids.

The identification of the mechanisms driving the formation of $2 n$ gametes is complex. However, the use of cytological or marker analysis on polyploid progeny provide accurate or additional information on these mechanisms (Lim et al., 2001; Crespel and Gudin, 2003; Dewitte et al., 2012). Molecular cytological approaches have been used successfully, including the unequivocal identification of genomes and recombinant segments in the sexual polyploid progenies (Takahashi et al., 1997; Karlov et al., 1999; Lim et al., 2001; Ramanna and Jacobsen, 2003; Barba-Gonzalez et al., 2005). Molecular marker analysis is also useful for the identification of mechanisms underlying unreduced gamete formation, and different approaches based on population analysis have been developed previously. Several methods are based on the analysis of HR rates for randomly chosen unmapped markers (Vorsa and Rowland, 1997; Chen et al., 2008a; Ferrante et al., 2010). These methods require the analysis of a large set of molecular markers to encounter, by chance, the loci with HR lower than $50 \%$ that are only found under SDR (Park et al., 2007). However, when HR over $50 \%$ is observed for all loci, no 
definitive conclusion can be reached without a prior knowledge of their location relative to a centromere. Significant FDR conclusions are therefore difficult to obtain with such non-mapped markers. Half-tetrad analysis (HTA; (Mendiburu and Peloquin, 1979)), based on multiple linked loci, is a powerful method for mapping centromeres or for determining the mode(s) of $2 n$ gamete formation. Tavoletti et al. (1996) developed a multilocus maximum-likelihood method of HTA that permits the estimation of both the relative frequencies of FDR and SDR $2 n$ gametes and the centromere location within a linkage group without relying on previously identified centromeric markers. These methods generally assume complete chiasma interference. The method proposed by Cuenca et al. (2011), based on the HR restitution curve along a linkage group, allows simultaneous identification of the restitution mechanism, raw centromere location, and comparison of several chromosome interference models. This approach is based on the analysis of genotype frequency in relatively large populations and provides global results of the preeminent mechanism; however, determination of the potential coexistence of the two mechanisms in the same progeny was not possible.

In this study, a maximum-likelihood approach based on marker HR with centromeric loci was developed and successfully applied both at the individual and population levels. Knowledge of marker-centromere distances greatly improves the statistical power of the comparison between the SDR and FDR hypotheses. For example, in this study, the restitution mechanism was identified in 'Fortune' as SDR at the population level with a LOD(SDR/FDR) of 933, whereas for the same population using 12 markers without information regarding markercentromere distance, but with HR values under 50\% (Cuenca et al., 2011), the mechanism was identified as SDR with a LOD value of only 6.8 . With the method proposed in the present paper, conclusions at the population level could therefore be obtained from smaller numbers of progeny and fewer markers than with non-located markers.

The theoretical limits of our method were assessed by the simulation of populations arising from FDR or SDR mechanisms. At the population level, considering that the independent markers used are at the same distance from their respective centromeres, the power of the statistical test was directly linked to the product of the number of markers and the number of individuals. That means that the efficiency would be the same for $n$ individuals with $m$ markers as for $2 \cdot n$ individuals with $m / 2$ markers. Moreover, the necessary $n \cdot m$ genotyping points increase exponentially with increasing distance of the marker to the centromere. For example, to obtain a greater than $99 \%$ significant answer, it would be necessary for $n \cdot m$ to be greater than fifty-seven for markers at $20 \mathrm{cM}$, while an $n \cdot m$ value greater than eight and four would be sufficient for markers at $5 \mathrm{cM}$ and $1 \mathrm{cM}$, respectively. The selection of markers as close as possible to their centromere is therefore a key element for successful analysis when low numbers of individuals and markers are used.

In the study of citrus $2 n$ gamete progenies, significant results were obtained for all analyzed populations, even populations of fewer than five individuals. 
One major improvement of our approach over existing methods is that it allows the identification of the restitution mechanism for each individual unreduced gamete. Simulation studies indicated that the proximity of markers to the centromeres is a key factor. With markers closer than $5 \mathrm{cM}$, five markers are sufficient to result in $95 \%$ significant answers, but significance diminishes to less than $78 \%$ and $0 \%$ for nine markers at $10 \mathrm{cM}$ and $20 \mathrm{cM}$ from their centromeres, respectively.

The importance of selecting markers very close to the centromere to obtain significant conclusions at the individual level is illustrated by the results of our citrus analysis. Indeed, a very high percentage of significant results at the individual level (95.4\%) and with high LODs were obtained for the 'Fina' clementine progeny analyzed with markers closer to centromeres than the other progenies.

\section{$2 n$ megagametophytes arising from SDR are the preeminent source of triploid occurrence in $2 x \times 2 x$ hybrid populations using mandarin-like parents}

In this study, the mechanism leading to triploid formation in $2 x \times 2 x$ crosses was elucidated, both at individual and population level, for nineteen parental combinations involving, respectively, sixteen and eleven varieties as female and male parents.

All the 497 triploid hybrids analyzed originated from $2 n$ megagametophytes and, therefore, no $2 n$ pollen contributed to the production of triploids in our parental combinations. These results expand to a large range of genotypes the prior conclusion obtained from cytological studies (Esen and Soost, 1971, 1973) for 'Sukega' (C. paradisi $\times$ C. sinensis), 'Temple' (C. reticulata $\times$ C. sinensis and clementine (C. clementina), indicating that in such $2 x \times$ $2 x$ crosses, triploid embryos were associated with pentaploid endosperm. However, the occurrence of triploids arising from $2 n$ pollen at very low rates has been previously reported in studies using molecular markers for three selections of clementine ('Caffin', 'Commun' or 'SRA85' and 'Muskat'), and 'King' mandarin pollinated with C. deliciosa ('Tardivo di Ciaculi', 'Willow Leaf'), C. reticulata ('Hansen', 'Ananas'), C. paradisi ('Star Ruby') and C. sinensis ('Tarroco Rosso', 'Sanguinelli') (Luro et al., 2004) and for C. sinensis $\times$ Poncirus trifoliata hybridizations (Chen et al., 2008a).

When using the LOD3 threshold, SDR was identified as the restitution mechanism for $85.3 \%$ of the analyzed triploid hybrids, no significant conclusions were obtained for $14.1 \%$ of the hybrids, and $0.6 \%$ of the analyzed triploids were derived from FDR (one triploid hybrid from arising from 'Ellendale' and two arising from 'Fortune'). When the LOD2 threshold was considered, the percentage of individuals with unidentified origin decreased to $9 \%$ and SDR levels increased to $90.1 \%$. Moreover, we conducted individual level analysis of previously studied 'Fortune' mandarin progeny (Cuenca et al., 2011) and the progeny arising from 'Fina' Aleza et al., 2012b), and we confirmed SDR at the individual level for most hybrids, which concurs with the global-level conclusions proposed in these two studies. In the current study, six 
clementine genotypes were also analyzed to discover their unreduced gamete formation mechanism. Results indicate that SDR is the most probable mechanism in the clementine group, in agreement with previous conclusions of Luro et al. (2004) and Aleza et al. (2012b). For the other mandarin varieties, SDR was also the most probable mechanism at the individual level and, therefore, also at the population level. Taken together, our data and those of others suggest that SDR is the major mechanism underlying unreduced megagametophyte formation in most mandarin genotypes.

The mechanism leading to unreduced eggs or pollen was previously elucidated for several plant species (Ramanna and Jacobsen, 2003; De Storme and Geelen, 2013). Bretagnolle and Thompson (1995) identified that both FDR and SDR are responsible for $2 n$ pollen formation, while SDR is more frequent in the formation of $2 n$ eggs. In potatoes, $2 n$ pollen arises predominantly by FDR (Mok and Peloquin, 1975), while $2 n$ megagametophytes arise most frequently by SDR (Stelly and Peloquin, 1986), although SDR-FDR mixture in the formation of $2 n$ eggs has been also found (Conicella et al., 1991). Bilateral sexual polyploidization can arise either from FDR and SDR in Lilium (Lim et al., 2004; Errico et al., 2005; Nadeem, et al., 2010) and alfalfa (Barcaccia et al., 2003). Moreover, Bretagnolle and Thompson (1995) described other several examples of single plant species where FDR and SDR may occur simultaneously, underlining the influence of genotype and environment on the expression of meiotic abnormality factors (Pécrix et al., 2011; Mason et al., 2011).

\section{Implications for citrus triploid breeding}

The genetic and phenotypic consequences of FDR and SDR gametes are highly divergent, and are of potential importance for breeding applications, due to the different parental heterozygosity rate that each mechanism transmit to the polyploid progeny (Errico et al., 2005; De Storme and Geelen, 2013).

Under FDR, the resulting $2 n$ gametes are heterozygous from the centromere to the first crossover point, and hence the gametes retain most parental heterozygosity and epistatic interactions. With the SDR mechanism, the resulting $2 n$ gametes are homozygous from the centromere to the first crossover point, but retain parental heterozygosity on the telomeric regions (Ramanna and Jacobsen, 2003). As a result, SDR-2 $n$ gametes confer a reduced level of heterozygosity than FDR- $2 n$ and show a corresponding greater loss of parental epistasis (Bretagnolle and Thompson, 1995; Dewitte et al., 2012).

If an SDR origin of $2 n$ gametes is assumed for most mandarins, sexual polyploidization may lead to a reduced average of HR and, therefore, loss of epistatic interactions. Therefore, when compared with interploid crosses using doubled diploids (Aleza et al., 2012a, 2012c), the sexual polyploidization strategy should produce more polymorphic progeny by creating a larger number of new multilocus allelic combinations (David et al., 1995). This provides the opportunity 
to select innovative products within the perspective of market segmentation as a commercial strategy.

Consequences of the SDR restitution mechanism would be clearly apparent for a characteristic controlled by a single gene. If the gene is heterozygous in the female parent, most unreduced gametes will be homozygous for that gene if it is located near the centromere, but gametes will be mostly be heterozygous for the gene if it is telomere-proximal (partial interference model; Cuenca et al., 2011). Recently, Cuenca et al. (2013b) analyzed the inheritance of resistance to Alternaria brown-spot fungal disease in triploid progenies arising from crosses between diploid parents. They demonstrated that the resistance was controlled as a recessive trait by a single locus located near a centromere (10.5 cM from the centromere of chromosome 3). If a susceptible female parent is heterozygous, the SDR mechanism leads to approximately $80 \%$ homozygous unreduced gametes, half of which present with two resistant alleles. As Alternaria resistance is a major selective trait when maternal heterozygous parents are used, sexual polyploidization is a more effective strategy than use of interploid crosses in this case, which results in only $16.7-22.5 \%$ of progeny being resistant. For dominant traits controlled by a single centromeric locus, interploid crosses should be more interesting than $2 x \times$ $2 x$ crosses. For characters controlled by major loci more distant than $30 \mathrm{cM}$ from the centromere, the efficiency of the two triploid breeding strategies would be relatively similar. 


\section{Supplementary information}

Table 3.S1. Taxonomic information on parental genotypes used in this study

\begin{tabular}{|c|c|c|c|}
\hline Group & Genotype & Swingle and Reece, 1967 & Tanaka, 1977 \\
\hline \multirow{6}{*}{ clementine } & 'Bruno' & & \\
\hline & 'Clemenules' & & \\
\hline & & Citrus reticulata & Citrus clementina \\
\hline & 'Guillermina' & & 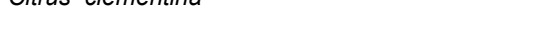 \\
\hline & 'Hernandina' & & \\
\hline & 'Loretina' & & \\
\hline \multirow{2}{*}{ mandarin } & 'Imperial' & & C. reticulata \\
\hline & 'Willowleaf' & & C. deliciosa \\
\hline \multirow{14}{*}{ hybrid mandarin } & 'Ellendale' & C. reticulata $\times$ C. sinensis & C. reticulata $\times$ C. sinensis \\
\hline & 'Encore' & C. reticulata & C. nobilis $\times$ C. deliciosa \\
\hline & 'Fallglo' & & $\begin{array}{l}{[\text { C. clementina } \times(\text { C. paradisi } \times \text { C. tangerina })] \times C \text {. }} \\
\text { temple }\end{array}$ \\
\hline & 'Fortune' & & C. clementina $\times$ C. tangerina \\
\hline & 'Honey' & & C. nobilis $\times$ C. deliciosa \\
\hline & 'Kiyomi' & C. reticulata $\times$ C. sinensis & C. unshiu $\times$ C. sinensis \\
\hline & 'Minneola' & C. reticulata & C. paradisi $\times$ C. tangerina \\
\hline & 'Moncada' & & C. clementina $\times($ C. unshiu $\times$ C. nobilis $)$ \\
\hline & 'Murcott' & C. reticulata $\times$ C. sinensis & (C. reticulata $\times$ C. sinensis) \\
\hline & 'N'15’ & C. reticulata & C. clementina $\times($ C. unshiu $\times$ C. nobilis $)$ \\
\hline & 'Nadorcott' & - & (C. reticulata $\times$ C. sinensis $) \times($ unknown $)$ \\
\hline & 'Umatilla' & C. reticulata $\times$ C. sinensis & C. unshiu $\times$ C. sinensis \\
\hline & 'Simeto' & C. reticulata & C. unshiu $\times$ C. deliciosa \\
\hline & 'Wilking' & & C. deliciosa $\times$ C. nobilis \\
\hline pummelo & 'Chandler' & C. grandis & C. maxima \\
\hline
\end{tabular}


Table 3.S2. Inferring of the $2 n$ gamete parental producer depending on parental configuration and the raw genotype pattern observed.

\begin{tabular}{|c|c|c|c|c|c|c|c|}
\hline $\begin{array}{c}\text { Parental } \\
\text { configuration }\end{array}$ & $\begin{array}{c}\text { Raw } \\
\text { genotype } \\
\text { pattern } \\
\text { observed }\end{array}$ & $\begin{array}{l}\text { Allele doses } \\
\text { estimation } \\
\text { method }\end{array}$ & $\begin{array}{l}\text { Inferred } \\
\text { triploid } \\
\text { genotype }\end{array}$ & $\begin{array}{l}\text { Inferred } 2 n \\
\text { gamete } \\
\text { configuration }\end{array}$ & $\begin{array}{l}\text { Inferred } \\
\text { parental } \\
\text { origin }\end{array}$ & $\begin{array}{c}\text { Inferred } 2 n \\
\text { gamete if } \\
\text { maternal } \\
\text { origin proved }\end{array}$ & $\begin{array}{c}\text { Inferred } 2 n \\
\text { gamete if } \\
\text { paternal } \\
\text { origin proved }\end{array}$ \\
\hline \multirow{12}{*}{$A_{1} A_{2} \times A_{3} A_{4}$} & $\mathrm{~A}_{1} \mathrm{~A}_{2} \mathrm{~A}_{3}$ & D & $\mathrm{A}_{1} \mathrm{~A}_{2} \mathrm{~A}_{3}$ & $A_{1} A_{2}$ & M & $A_{1} A_{2}$ & \\
\hline & $\mathrm{A}_{1} \mathrm{~A}_{2} \mathrm{~A}_{4}$ & D & $\mathrm{A}_{1} \mathrm{~A}_{2} \mathrm{~A}_{4}$ & $A_{1} A_{2}$ & M & $A_{1} A_{2}$ & \\
\hline & $\mathrm{A}_{1} \mathrm{~A}_{3} \mathrm{~A}_{4}$ & D & $\mathrm{A}_{1} \mathrm{~A}_{3} \mathrm{~A}_{4}$ & $\mathrm{~A}_{3} \mathrm{~A}_{4}$ & $P$ & & $\mathrm{~A}_{3} \mathrm{~A}_{4}$ \\
\hline & $\mathrm{A}_{2} \mathrm{~A}_{3} \mathrm{~A}_{4}$ & D & $\mathrm{A}_{2} \mathrm{~A}_{3} \mathrm{~A}_{4}$ & $\mathrm{~A}_{3} \mathrm{~A}_{4}$ & $P$ & & $\mathrm{~A}_{3} \mathrm{~A}_{4}$ \\
\hline & \multirow{2}{*}{$A_{1} A_{3}$} & $\mathrm{TH}$ & $A_{1} A_{1} A_{3}$ & $A_{1} A_{1}$ & M & $\mathrm{A}_{1} \mathrm{~A}_{1}$ & \\
\hline & & $\mathrm{TH}$ & $\mathrm{A}_{3} \mathrm{~A}_{3} \mathrm{~A}_{1}$ & $\mathrm{~A}_{3} \mathrm{~A}_{3}$ & $P$ & & $\mathrm{~A}_{3} \mathrm{~A}_{3}$ \\
\hline & \multirow{2}{*}{$\mathrm{A}_{1} \mathrm{~A}_{4}$} & $\mathrm{TH}$ & $\mathrm{A}_{1} \mathrm{~A}_{1} \mathrm{~A}_{4}$ & $A_{1} A_{1}$ & M & $\mathrm{A}_{1} \mathrm{~A}_{1}$ & \\
\hline & & $\mathrm{TH}$ & $\mathrm{A}_{4} \mathrm{~A}_{4} \mathrm{~A}_{1}$ & $\mathrm{~A}_{4} \mathrm{~A}_{4}$ & $P$ & & $\mathrm{~A}_{4} \mathrm{~A}_{4}$ \\
\hline & \multirow{2}{*}{$\mathrm{A}_{2} \mathrm{~A}_{3}$} & $\mathrm{TH}$ & $\mathrm{A}_{2} \mathrm{~A}_{2} \mathrm{~A}_{3}$ & $\mathrm{~A}_{2} \mathrm{~A}_{2}$ & M & $\mathrm{A}_{2} \mathrm{~A}_{2}$ & \\
\hline & & $\mathrm{TH}$ & $\mathrm{A}_{3} \mathrm{~A}_{3} \mathrm{~A}_{2}$ & $\mathrm{~A}_{3} \mathrm{~A}_{3}$ & $P$ & & $\mathrm{~A}_{3} \mathrm{~A}_{3}$ \\
\hline & \multirow{2}{*}{$\mathrm{A}_{2} \mathrm{~A}_{4}$} & $\mathrm{TH}$ & $\mathrm{A}_{2} \mathrm{~A}_{2} \mathrm{~A}_{4}$ & $\mathrm{~A}_{2} \mathrm{~A}_{2}$ & M & $\mathrm{A}_{2} \mathrm{~A}_{2}$ & \\
\hline & & $\mathrm{TH}$ & $\mathrm{A}_{4} \mathrm{~A}_{4} \mathrm{~A}_{2}$ & $\mathrm{~A}_{4} \mathrm{~A}_{4}$ & $P$ & & $\mathrm{~A}_{4} \mathrm{~A}_{4}$ \\
\hline \multirow{3}{*}{$A_{1} A_{2} \times A_{1} A_{1}$} & $A_{1}$ & D & $A_{1} A_{1} A_{1}$ & $A_{1} A_{1}$ & $\mathrm{NI}$ & $\mathrm{A}_{1} \mathrm{~A}_{1}$ & $\mathrm{~A}_{1} \mathrm{~A}_{1}$ \\
\hline & \multirow{2}{*}{$A_{1} A_{2}$} & DP & $\mathrm{A}_{1} \mathrm{~A}_{2} \mathrm{~A}_{2}$ & $\mathrm{~A}_{2} \mathrm{~A}_{2}$ & M & $\mathrm{A}_{2} \mathrm{~A}_{2}$ & \\
\hline & & DP & $\mathrm{A}_{1} \mathrm{~A}_{1} \mathrm{~A}_{2}$ & $\mathrm{NI}$ & $\mathrm{NI}$ & $A_{1} A_{2}$ & $A_{1} A_{1}$ \\
\hline \multirow{5}{*}{$A_{1} A_{2} \times A_{3} A_{3}$} & $\mathrm{~A}_{1} \mathrm{~A}_{2} \mathrm{~A}_{3}$ & D & $\mathrm{A}_{1} \mathrm{~A}_{2} \mathrm{~A}_{3}$ & $A_{1} A_{2}$ & M & $\mathrm{A}_{1} \mathrm{~A}_{2}$ & \\
\hline & \multirow{2}{*}{$A_{1} A_{3}$} & TH & $A_{1} A_{1} A_{3}$ & $A_{1} A_{1}$ & M & $\mathrm{A}_{1} \mathrm{~A}_{1}$ & \\
\hline & & $\mathrm{TH}$ & $\mathrm{A}_{3} \mathrm{~A}_{3} \mathrm{~A}_{1}$ & $\mathrm{~A}_{3} \mathrm{~A}_{3}$ & $P$ & & $\mathrm{~A}_{3} \mathrm{~A}_{3}$ \\
\hline & \multirow{2}{*}{$\mathrm{A}_{2} \mathrm{~A}_{3}$} & $\mathrm{TH}$ & $\mathrm{A}_{2} \mathrm{~A}_{2} \mathrm{~A}_{3}$ & $\mathrm{~A}_{2} \mathrm{~A}_{2}$ & M & $\mathrm{A}_{2} \mathrm{~A}_{2}$ & \\
\hline & & $\mathrm{TH}$ & $\mathrm{A}_{3} \mathrm{~A}_{3} \mathrm{~A}_{2}$ & $\mathrm{~A}_{3} \mathrm{~A}_{3}$ & $\mathrm{P}$ & & $\mathrm{A}_{3} \mathrm{~A}_{3}$ \\
\hline \multirow{8}{*}{$A_{1} A_{2} \times A_{1} A_{3}$} & $\mathrm{~A}_{1} \mathrm{~A}_{2} \mathrm{~A}_{3}$ & D & $\mathrm{A}_{1} \mathrm{~A}_{2} \mathrm{~A}_{3}$ & $A_{1} A_{2}$ & M & $\mathrm{A}_{1} \mathrm{~A}_{2}$ & \\
\hline & $A_{1}$ & D & $\mathrm{A}_{1} \mathrm{~A}_{1} \mathrm{~A}_{1}$ & $A_{1} A_{1}$ & $\mathrm{NI}$ & $A_{1} A_{1}$ & $\mathrm{~A}_{1} \mathrm{~A}_{1}$ \\
\hline & \multirow{2}{*}{$A_{1} A_{2}$} & DP & $A_{1} A_{1} A_{2}$ & $\mathrm{NI}$ & $\mathrm{NI}$ & $A_{1} A_{2}$ & $A_{1} A_{1}$ \\
\hline & & DP & $A_{1} A_{2} A_{2}$ & $\mathrm{~A}_{2} \mathrm{~A}_{2}$ & M & $\mathrm{A}_{2} \mathrm{~A}_{2}$ & \\
\hline & \multirow{2}{*}{$A_{1} A_{3}$} & DP & $A_{1} A_{1} A_{3}$ & $\mathrm{NI}$ & $\mathrm{NI}$ & $A_{1} A_{1}$ & $A_{1} A_{3}$ \\
\hline & & DP & $\mathrm{A}_{1} \mathrm{~A}_{3} \mathrm{~A}_{3}$ & $\mathrm{~A}_{3} \mathrm{~A}_{3}$ & $P$ & & $\mathrm{~A}_{3} \mathrm{~A}_{3}$ \\
\hline & \multirow{2}{*}{$\mathrm{A}_{2} \mathrm{~A}_{3}$} & TH & $\mathrm{A}_{2} \mathrm{~A}_{2} \mathrm{~A}_{3}$ & $\mathrm{~A}_{2} \mathrm{~A}_{2}$ & M & $\mathrm{A}_{2} \mathrm{~A}_{2}$ & \\
\hline & & $\mathrm{TH}$ & $\mathrm{A}_{2} \mathrm{~A}_{3} \mathrm{~A}_{3}$ & $\mathrm{~A}_{3} \mathrm{~A}_{3}$ & $\mathrm{P}$ & & $\mathrm{A}_{3} \mathrm{~A}_{3}$ \\
\hline
\end{tabular}

D: direct visualization of allelic constitution; DP: inference of allelic doses based on diploid parent reference; TH: inference of allelic doses based on at least one reference triploid hybrid; NI: not identified. Bold letters indicate gamete structures inferred when parental origin has been proved from other markers. 


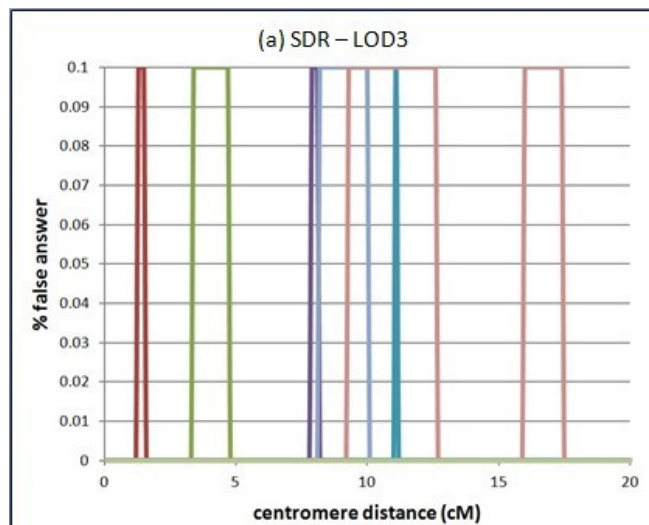

(b) FDR-LOD3

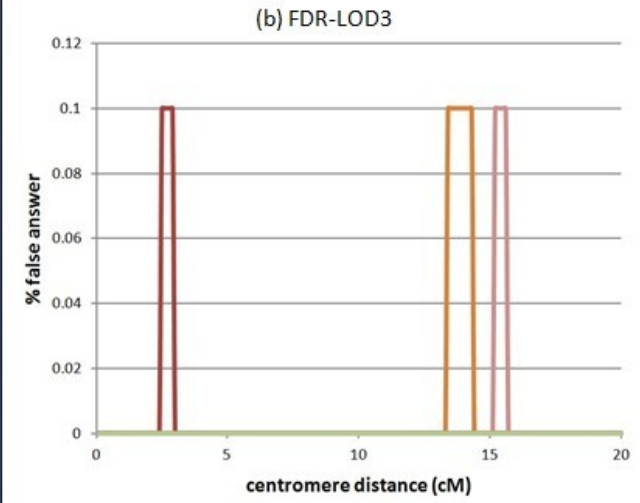

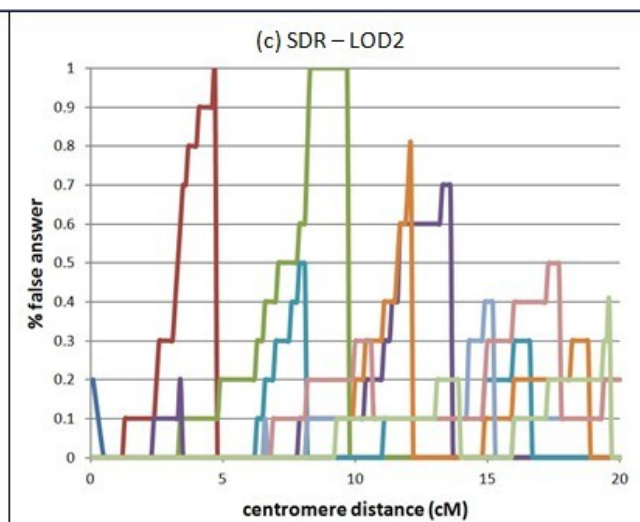

(d) FDR-LOD2

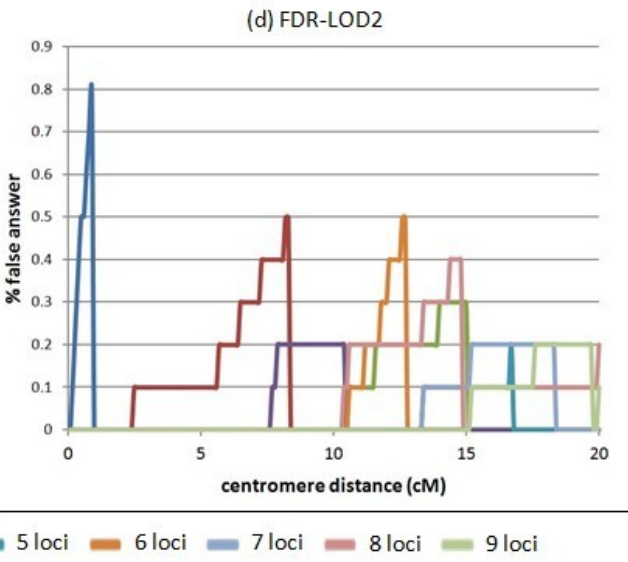

Figure 3.S1. Percentage of significant replicates giving false answer considering a LOD3 for populations arising from (a) SDR and (b) FDR, and considering LOD2 for populations arising from (c) SDR and (d) FDR.

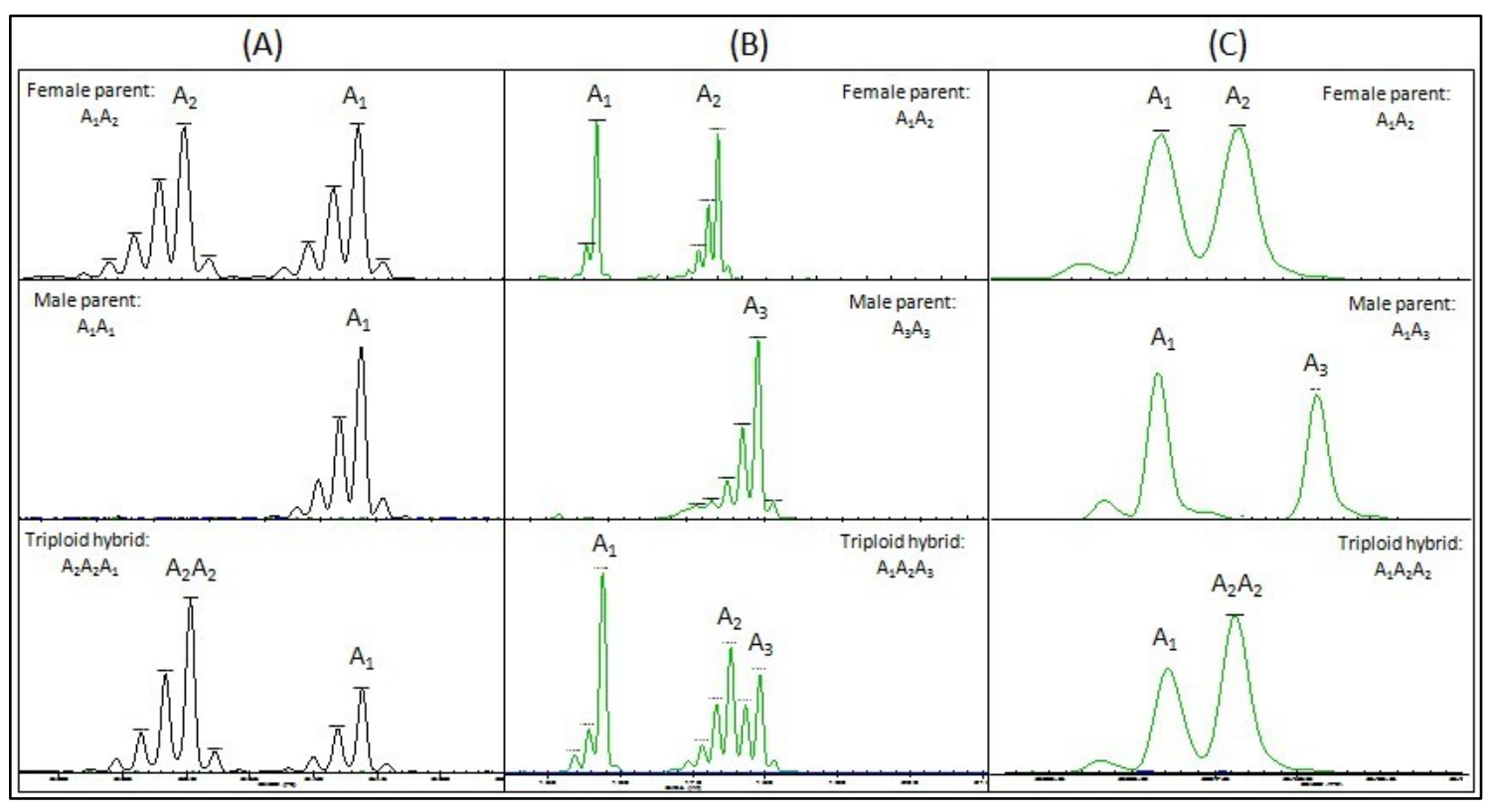

Figura 3.S2. Assignment of allelic configuration in heterozygous triploid hybrids for SSR markers showing (A) $A_{1} A_{2} \times A_{1} A_{1}$ (B) $A_{1} A_{2} \times A_{3} A_{3}$ and (C) $A_{1} A_{2} \times A_{1} A_{3}$ parental configurations. 


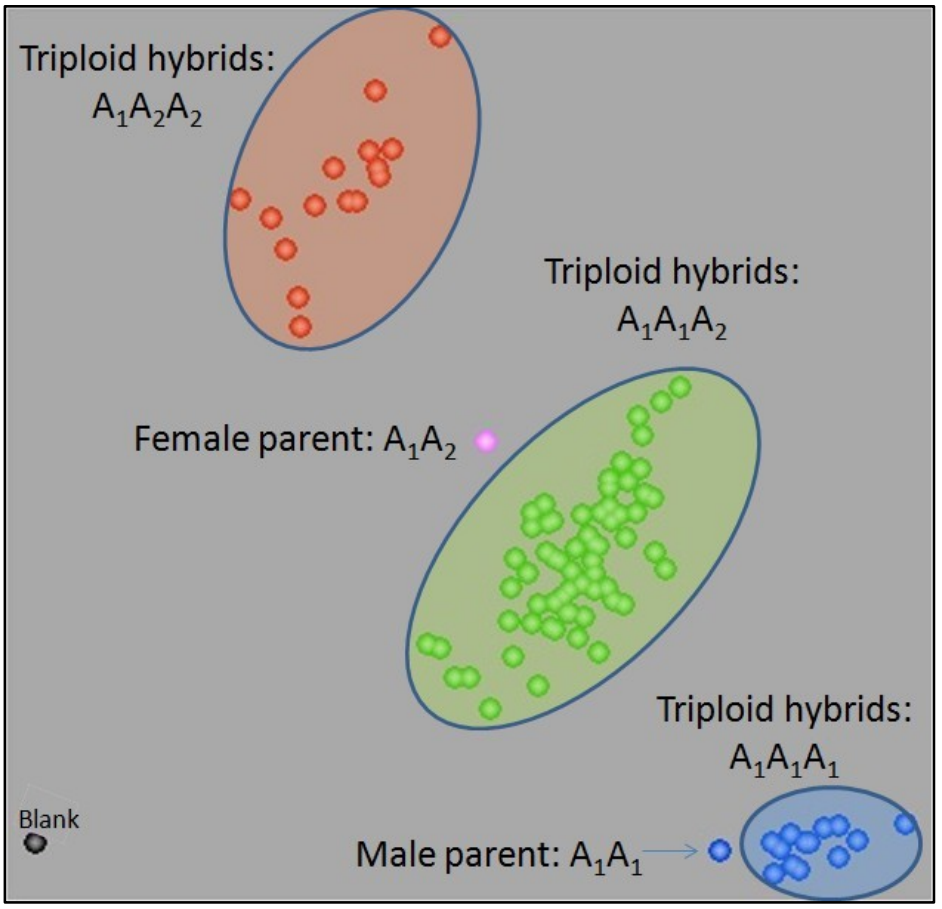

Figura 3.S3. Assignment of allelic configuration in heterozygous triploid hybrids for SNP markers with $A_{1} A_{2}$ $\times A_{1} A_{1}$ parental configurations. 


\section{CHAPTER 4}

Genetically based location from triploid populations and gene ontology of a 3.3-Mb genome region linked to Alternaria brown spot resistance in citrus reveal clusters of resistance genes

José Cuenca, Pablo Aleza, Antonio Vicent, Dominique Brunel,

Patrick Ollitrault and Luis Navarro

PLoS ONE (2013), 8(10): e76755. doi: 10.1371/journal.pone.0076755 

Genetic analysis of phenotypical traits and marker-trait association in polyploid species is generally considered as a challenge. In the present work, different approaches were combined taking advantage of the particular genetic structures of $2 n$ gametes resulting from second division restitution (SDR) to map a genome region linked to Alternaria brown spot (ABS) resistance in triploid citrus progeny. ABS in citrus is a serious disease caused by the tangerine pathotype of the fungus Alternaria alternata. This pathogen produces ACT-toxin, which induces necrotic lesions on fruit and young leaves, defoliation and fruit drop in susceptible genotypes. It is a strong concern for triploid breeding programs aiming to produce seedless mandarin cultivars. The monolocus dominant inheritance of susceptibility, proposed on the basis of diploid population studies, was corroborated in triploid progeny. Bulk segregant analysis coupled with genome scan using a large set of genetically mapped SNP markers and targeted genetic mapping by half tetrad analysis, using SSR and SNP markers, allowed locating a $3.3 \mathrm{Mb}$ genomic region linked to ABS resistance near the centromere of chromosome III. Clusters of resistance genes were identified by gene ontology analysis of this genomic region. Some of these genes are good candidates to control the dominant susceptibility to the ACT-toxin. SSR and SNP markers were developed for efficient early marker-assisted selection of ABS resistant hybrids. 


\section{Introduction}

Alternaria brown spot (ABS) is a serious disease that induces necrotic lesions on fruit and young leaves, defoliation and fruit drop in susceptible citrus genotypes (Akimitsu et al., 2003). The disease was first observed in Australia in 1903 on the 'Emperor' mandarin (Pegg, 1966), and was subsequently detected in citrus-growing regions in America, the Mediterranean Basin, South Africa, Iran and China (Timmer et al., 2003; Golmohammadi et al., 2006; Wang et al., 2010). In Spain, the disease was first detected in 1998 (Vicent et al., 2000), and it is currently widespread in all citrus-growing areas, affecting mainly 'Fortune' and 'Nova' mandarin hybrids. The disease is caused by the tangerine pathotype of the fungus Alternaria alternata (Fr.) Keissl., which carries a gene cluster (ACTT) located in a small $(<2.0 \mathrm{Mb})$ conditionally dispensable chromosome responsible for ACT-toxin biosynthesis (Ajiro et al., 2010). This hostspecific toxin is released during the germination of conidia, rapidly affecting the plasma membrane integrity of susceptible host cells (Kohmoto et al., 1993). There is also indirect evidence suggesting the presence of toxin receptors in susceptible citrus genotypes (Tsuge et al., 2012). In addition, recent studies indicate that the mitigation of reactive oxygen species (ROS) produced by the host plants is essential for pathogenicity (Yang and Chung, 2012). The pathogen sporulates on affected tissues, and conidia are disseminated by air currents and rain splash. Warm temperatures and prolonged wetness on the tree are required for infection. The incubation period is very short, and lesions are visible just 1 or 2 days after infection is initiated, due to the rapid effects of the ACT-toxin (Canihos et al., 1999). The disease causes severe epidemics in humid areas, as well as in semi-arid regions, due to its environmental flexibility (Timmer et al., 2003). Currently, ABS control is primarily based on the application of fungicides. Sprays must be scheduled to protect susceptible organs during the critical periods for infection. Depending on the climate of the region and the susceptibility of the cultivar, between four and ten fungicide sprays per year are needed to produce quality fruit for the fresh market (Bhatia et al., 2003; Peres and Timmer, 2006; Vicent et al., 2007).

Despite this large number of sprays, disease control is not always satisfactory, and cultivation of susceptible cultivars such as the 'Fortune' mandarin has declined significantly in Spain during recent years. In addition, systematic application of fungicides for ABS control over many years may create environmental problems and public health concerns (Vicent et al., 2009). Moreover, in the context of the changing global climate, plant breeding is especially focused on improving resistance to biotic and abiotic stresses.

Several studies have been carried out to determine the resistance or susceptibility to ABS in citrus genotypes (Hutton and Mayers, 1988; Goes et al., 2001; Vicent et al., 2004; Dalkilic et al., 2005; Reis et al., 2007; de Souza et al., 2009). Although there are some discrepancies among the results of these studies, resistance is clearly present in clementine (Citrus clementina Hort. ex Tan), 'Willowleaf' (C. deliciosa Ten) and satsuma (C. unshiu Mark) mandarins. Susceptibility has also been well established for 'Dancy' (C. tangerina Hort. ex Tan) and 'Fortune' (supposed C. clementina Hort. ex Tan $\times$ C. tangerina Hort. ex Tan) mandarins; 
'Orlando', 'Minneola' and 'Nova' tangelos (mandarin × grapefruit hybrids); and the 'Murcott' tangor (supposed mandarin $\times$ sweet-orange hybrid). Other cultivars such as the 'Ellendale' tangor and some sweet oranges and grapefruits have been characterised as sensitive or resistant by different authors. From diploid progeny analysis, it has been proposed that inheritance of ABS resistance in citrus is controlled by a single recessive allele (Dalkilic et al., 2005; Gulsen et al., 2010). Resistance to the strawberry and pear Alternaria pathotypes, which produce toxins structurally analogous to those of the tangerine pathotype, as well as resistance to the apple pathotype, is controlled in the same way, by a single recessive allele (Tsuge et al., 2012). Therefore, resistant cultivars are considered to be recessive homozygous for this locus, whereas susceptible cultivars could be heterozygous or homozygous dominant.

Diploidy is the general rule in Citrus and related genera; however, polyploidy manipulation is currently widely used in triploid citrus breeding programs aimed at developing new seedless mandarin cultivars (Ollitrault et al., 2008). Many of these breeding programs (Mourao Fo et al., 1996; McCollum, 2007; Aleza et al., 2010a, 2010b; Cuenca et al., 2010; Grosser et al., 2010; Aleza et al., 2012c, 2012d; Froelicher et al., 2012; Navarro et al., 2012) use ABS-susceptible cultivars as parents, due to their utility with regard to other important traits (fruit quality, maturing period, production) and particular reproductive biology (monoembryony, high rate of triploid production). The inheritance and efficient selection of resistance to ABS is therefore of central importance to triploid mandarin breeding projects.

Genetic analysis of phenotypical traits and marker-trait association in polyploid species is generally considered as a challenge due to complex segregation, dosage effects and potential non Mendelian inheritance associated with epigenetic variations.

The main factor affecting trait inheritance in triploid families is the strategy used for triploid breeding (Ollitrault et al., 2008), with significant differences between the sexual polyploidization approach $(2 x \times 2 x$ crosses with unreduced $-2 n$ - gamete formation) and interploid crosses $(2 x \times 4 x$ or $4 x \times 2 x)$. Indeed, the choice of strategy affects the transmission of parental heterozygosity to the diploid gamete.

In sexual polyploidization, two factors affect the transmission of parental heterozygosity to the offspring: the mechanism of $2 n$ gamete formation (i.e., first-division restitution [FDR] or second division restitution [SDR]) and the genetic distance from the locus of interest to the centromere (Douches and Quiros, 1988). Therefore, Half-Tetrad Analysis (HTA) based on $2 n$ gametes is an efficient means of genetic mapping (Mendiburu and Peloquin, 1979; Douches and Quiros, 1987; Tavoletti et al., 1996). In $2 x \times 2 x$ citrus crosses, the diploid (unreduced) gamete is transmitted by the female parent (Esen and Soost, 1971; 1973). SDR has been proposed for diploid megagametophyte development in clementines (Luro et al., 2004) and 'Fortune' mandarins (Cuenca et al., 2011), whereas FDR has been reported in sweet oranges (Chen et al., 2008a). Recent studies have revealed that SDR is the main mechanism involved in unreduced gamete formation in the majority of citrus cultivars (Aleza et al., 2012b). For 
interploid crosses, most of the tetraploid parents used in citrus breeding arise from chromosome doubling in nucellar cells of apomictic diploid parents (Aleza et al., 2011). Because mandarins are one of the ancestral species of cultivated citrus (García-Lor et al., 2012), doubled-diploid mandarins should be considered as autotetraploid, and tetrasomic inheritance should be expected (Kamiri et al., 2011). In such a situation, the frequency of diploid gametes that receive a locus in heterozygosis from the tetraploid parent varies between 0.55 and 0.66 , depending on the double-reduction frequency (Marsden et al., 1987).

In addition to the particular transmission of chromosome fragments and parental heterozygosity, the phenotypic trait inheritance in polyploids can be affected by dosage effects (Guo et al., 1996; 2004) and even by neoregulation of gene expression due to epigenomic reformatting (Liu and Wendel, 2003; Osborn et al., 2003), eventually leading to non- Mendelian segregation. Moreover, polyploidy induces morphological variations in leaves and fruits (Starrantino, 1992; Otto and Whitton, 2000; Allario et al., 2011) that should affect fungus colonization. In this context, no data have yet been published regarding the inheritance of ABS resistance in triploid progenies.

Due to its direct applicability in marker-assisted selection, the identification of molecular markers linked to phenotypic variation, e.g., related to disease resistance, is a key step in most breeding programs. Bulked segregant analysis [BSA; (Michelmore et al., 1991)] can be used to identify molecular markers in a genomic region associated with a specific phenotype rapidly. This method is based on linkage disequilibrium between the gene and linked markers in segregating progeny, and the genetic linkage between markers and the causal gene is determined by differences in marker-allele frequencies between resistant and susceptible bulks. For characters controlled by one or a few genes, BSA is an effective technique for detecting alleles linked to phenotypes in a large sample of progeny at a relatively low cost, where the only requirement is that the genotyping technique and molecular markers utilised provide quantitative measurements of allelic frequencies (Liu et al., 2012). This approach should be optimised by coupling BSA with a high-throughput genotyping method using markers covering the whole genome. Genome-wide association studies of pooled DNA samples have been valuable tools in the fast, scalable and economical identification of candidate single nucleotide polymorphisms (SNPs) associated with a phenotype (Brauer et al., 2006; Akhunov et al., 2009; Hyten et al., 2009; Becker et al., 2011; Ricci et al., 2011; Szelinger et al., 2011; Swinnen et al., 2012; Trick et al., 2012). In citrus, very large SNP resources are becoming available from extensive citrus sequencing projects (Terol et al., 2007, 2008; Gmitter et al., 2012; Ollitrault et al., 2012b); meanwhile, new technologies have been developed for very rapidly genotyping large numbers of SNPs in DNA samples. One such technology is the GoldenGate assay from Illumina ${ }^{\text {TM }}$ (Fan et al., 2003; Hyten et al., 2009; Yan et al., 2010), which proved useful in citrus by allowing mapping of 677 SNP markers onto the clementine's consensus map (Ollitrault et al., 2012a). 
The objectives of this study were (i) to confirm Mendelian monolocus inheritance of ABS resistance in triploid progenies, by analysing the segregation of resistance in different interploid crosses, and to confirm the dominance of susceptibility by analysing segregation of resistance in progeny produced by sexual polyploidization and interploid hybridization; (ii) to locate the chromosome region associated with the ABS resistance using a genome scan assay coupled with BSA, followed by targeted genetic mapping by HTA in triploid progenies arising from $2 n$ gametes; and (iii) to identify candidate resistance genes in the located region, taking advantage of the recently released reference whole genome sequence of C. clementina (Wu et al., 2013). A more applied objective was identification of molecular markers for marker-assisted selection (MAS) in citrus breeding programs.

\section{Material and methods}

\section{Plant material}

Seven hundred and fourteen triploid hybrids arising from four $2 x \times 2 x$ crosses, three $2 x$ $\times 4 x$ crosses and their parents were evaluated for field and in vitro infection by $A$. alternata. Parental genotypes included in the citrus germplasm bank and hybrids were grown at the 'Instituto Valenciano de Investigaciones Agrarias' (I.V.I.A.) orchards in Moncada, Valencia, Spain. The plantings were very dense, with conditions very favourable for the development of ABS infection.

Information about parental accessions, their origin, ABS phenotype and references are shown in Table 4.1. The genetic configuration of the $A B S r$ locus (' $A$ ', dominant susceptible allele; 'a', recessive resistant allele) for each parental accession (also given in the table) has been deduced from information about ABS resistance/susceptibility of diploid genotypes, their pedigree and segregation data at the diploid level, under the hypothesis of single locus inheritance. The tetraploids 'Nova' and 'Orlando' resulted from chromosome stock doubling of the Nova and Orlando diploids, respectively (Aleza et al., 2011). The diploid lines are considered to be 'Aa' at the ABSr locus; therefore, the genotypes of the two tetraploid parents should be 'AAaa'. 
Table 4.1. Parental genotypes used in this study, phenotypic information on ABS resistance and deduced $A B S r$ locus genotyping.

\begin{tabular}{|c|c|c|c|c|c|}
\hline Genotype & Origin & Phenotype & Reference & $\begin{array}{l}\text { ABSr } \\
\text { genotype }\end{array}$ & locus \\
\hline 'Fortune' & $\begin{array}{l}\text { C. clementina } \times \\
\text { C. tangerina }\end{array}$ & $\mathrm{S}$ & $\begin{array}{l}\text { (Vicent et al., 2000) } \\
\text { (Reis et al., 2007) }\end{array}$ & $\mathrm{Aa}$ & \\
\hline 'Minneola' & $\begin{array}{l}\text { C. paradisi } \times \\
\text { C. tangerina }\end{array}$ & $S$ & $\begin{array}{l}\text { (Solel, 1991) } \\
\text { (Solel and Kimchi, 1997) } \\
\text { (Peever et al., 1999) } \\
\text { (Elena, 2006) }\end{array}$ & $\mathrm{AA}$ & \\
\hline 'Orlando' & C. paradisi $\times$ C. tangerina & S & $\begin{array}{l}\text { (Solel and Kimchi, 1997) } \\
\text { (Gulsen et al., 2010) }\end{array}$ & $\begin{array}{l}\text { 2x: Aa } \\
\text { 4x: AAaa }\end{array}$ & \\
\hline 'Nova' & 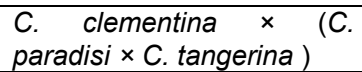 & $\mathrm{S}$ & (Dalkilic et al., 2005) & $\begin{array}{l}\text { 2x: Aa } \\
\text { 4x: AAaa }\end{array}$ & \\
\hline 'Murcott' & (unknown) & $\mathrm{S}$ & $\begin{array}{l}\text { (Solel and Kimchi, 1997) } \\
\text { (Dalkilic et al., 2005) }\end{array}$ & $\mathrm{Aa}$ & \\
\hline 'Willowleaf' & C. deliciosa & $\mathrm{R}$ & (Solel and Kimchi, 1997) & aa & \\
\hline $\begin{array}{l}\text { 'Clemenules' } \\
\text { 'Fina' }\end{array}$ & C. clementina & $\mathrm{R}$ & $\begin{array}{l}\text { (Kohmoto et al., 1991) } \\
\text { (Solel and Kimchi, 1997) } \\
\text { (Elena, 2006) } \\
\text { (Reis et al., 2007) } \\
\text { (Gulsen et al., 2010) }\end{array}$ & aa & \\
\hline 'Nadorcott' & 'Murcott' $\times$ unknown & $\mathrm{R}$ & Our unpublished data & aa & \\
\hline
\end{tabular}

(S) Susceptible phenotype; (R) Resistant phenotype; (A) Susceptible allele; (a) Resistant alelle

Three of the $2 x \times 2 x$ crosses share 'Fortune' as the female parent, with 'Willowleaf' mandarin (93 hybrids), 'Minneola' tangelo (127 hybrids) and 'Murcott' (148 hybrids) as male parents. The other $2 x \times 2 x$ cross was 'Fina' $\times$ 'Nadorcott' (50 hybrids). Details on procedures for establishing the triploid populations from $2 x \times 2 x$ crosses by embryo rescue and triploid selection by flow cytometry can be found in Aleza et al. (2010b).

Two of the $2 x \times 4 x$ crosses share 'Orlando $4 x$ ' as the male parent, with 'Clemenules' (180 hybrids) and 'Fortune' (116 hybrids) as female parents. The other $2 x \times 4 x$ population was 'Clemenules' $\times$ 'Nova 4x' (100 hybrids). Information about procedures for establishing the $2 x \times$ $4 x$ populations can be found in Aleza et al. (2012c).

Moreover, five additional triploid populations arising from $2 x \times 2 x$ and $2 x \times 4 x$ crosses (114 hybrids) were also evaluated for $A B S$ resistance to extend the experiments to other genetic backgrounds. Due to the relatively low number of triploid hybrids within each population, the resultant data have been included as supplementary material (Table 4.S1).

\section{Evaluation of ABS resistance}

Previous studies in diploid genotypes have shown a range of susceptibility level among citrus germplasm, but suggest that immune response could be controlled by a single recessive allele (Dalkilic et al., 2005; Gulsen et al., 2010). In the present study, genotypes have been considered as resistant if no symptoms have been observed neither under field evaluations nor leaf inoculations. Therefore, in this study as in the previous ones at diploid level (Dalkilic et al., 2005; Reis et al., 2007; De Souza et al., 2009; Gulsen et al., 2010), the resistant phenotype corresponds to immune symptom. 
Field evaluation: Symptoms of $A$. alternata were evaluated for all genotypes on trees grown at the I.V.I.A. orchards in spring, when young leaves are more susceptible to ABS and environmental conditions are highly favourable for infection (Vicent et al., 2009). Presence or absence of $A B S$ symptoms on the leaves was recorded in a qualitative manner. For each tree, observations were carried out over three consecutive years (2010, 2011 and 2012).

\section{In vitro inoculation of detached leaves:}

Inoculum production: A virulent single-spore isolate of $A$. alternata (IVIA-A005) isolated from an infected 'Fortune' fruit from Valencia (Spain) was used for inoculations. Abundant conidia were obtained by a method adapted from (Everts and Lacy, 1996). The isolate was grown on potato dextrose agar (PDA) plates at $25^{\circ} \mathrm{C}$ in darkness for $8-10$ days, illuminated with fluorescent lamps (Philips TLD 18W/33) at $25^{\circ} \mathrm{C}$ for $8 \mathrm{~h}$ to initiate conidiophore formation, and then placed in the dark at $18^{\circ} \mathrm{C}$ for $12 \mathrm{~h}$. Conidial suspensions were prepared by pouring sterile water over the colonies and gently rubbing the surface with a sterile glass rod. The suspension was filtered through two layers of cheesecloth, and the spore concentration was adjusted to $10^{5}$ conidia $\cdot \mathrm{ml}^{-1}$ with a haemocytometer. Suspensions with conidial germination lower than $90 \%$ were discarded.

Leaf inoculations: Bioassays were performed immediately after leaf harvest. Young leaves (about $50 \%$ developed) were inoculated with $10^{5}$ conidia $\mathrm{ml}^{-1}$ (Kohmoto et al., 1991). This suspension was sprayed over both upper and lower surfaces of each leaflet, using five leaves per genotype. Controls were inoculated by spraying sterile distilled water. Leaves were incubated in a moist chamber in the dark at $27^{\circ} \mathrm{C}$, and the results were evaluated $48 \mathrm{~h}$ after inoculation. In susceptible genotypes, leaf symptoms appear during the second day after inoculations and very clear necrosis induced by the ACT-toxin can be observed after $48 \mathrm{~h}$ (Figure 4.1).

A genotype was considered resistant when no symptoms of $A B S$ were observed in any leaf, whereas presence of infection was recorded when a clear symptom of ABS was observed in any leaf. The inoculations were repeated when there was doubt regarding interpretation. The complete experiments were carried out twice during spring of 2010 and twice during spring of 2011. 


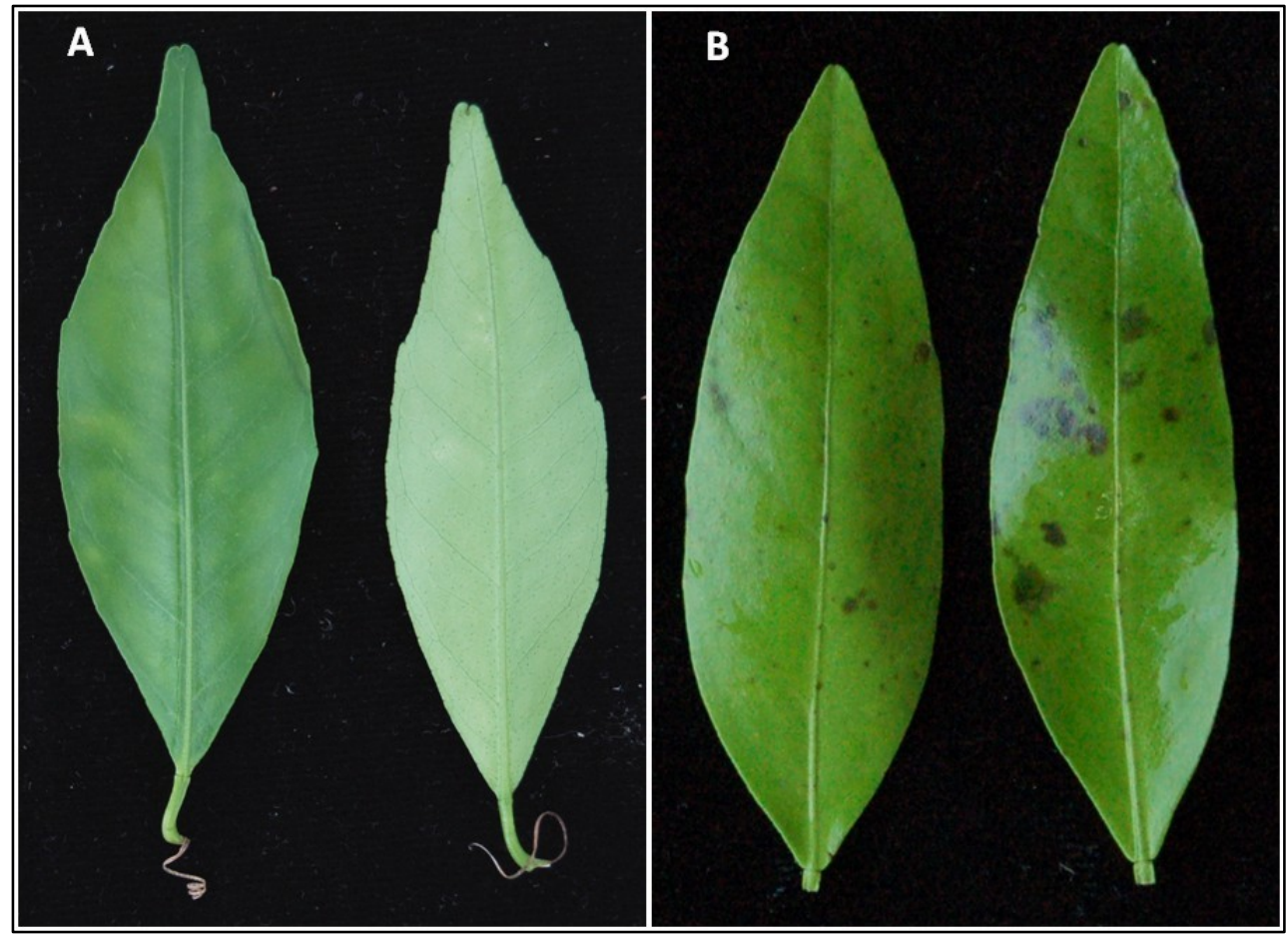

Figure 4.1. Leaves of resistant genotype 'Willowleaf' mandarin (A) and susceptible genotype 'Fortune' mandarin (B) showing ABS symptoms $48 \mathrm{~h}$ after inoculation with a suspension of $10^{5}$ conidia $\cdot \mathrm{ml}^{-1}$.

Two triploid populations derived from $2 x \times 2 x$ crosses ['Fortune' ('Aa') $\times$ 'Minneola' ('AA') and 'Fina' ('aa') $\times$ 'Nadorcott' ('aa')] and three triploid populations derived from $2 x \times 4 x$ crosses ['Clemenules' ('aa') × 'Orlando 4x' ('AAaa'), 'Fortune' ('Aa') × 'Orlando 4x' ('AAaa') and 'Clemenules' ('aa') $\times$ 'Nova 4x' ('AAaa')] were phenotyped to compare the expected and observed proportions of resistant and susceptible genotypes, to confirm the monolocus inheritance and dominance of the ABS susceptibility. For the 'Aa' $\times$ 'AA' cross, all segregation progeny are expected to be susceptible to ABS ('AAA', 'AAa' or 'Aaa'), whereas for the 'aa' $x$ 'aa' cross, all segregation progeny are expected to be ABS resistant ('aaa'). In case of the 'aa' $\times$ 'AAaa' and 'Aa' $\times$ 'AAaa' crosses, the resistant and susceptible proportions depend on heterozygosity restitution (HR) from the tetraploid parent to the progeny, which varies between 0.55 and 0.66 depending on the double-reduction frequency (Marsden et al., 1987). Therefore, in these cases, the resistant proportions are expected to be between 0.1667 and 0.225 for the 'aa' $\times$ 'AAaa' cross and between 0.0833 and 0.1125 for the 'Aa' $\times$ 'AAaa' cross (Table 4.2). $\mathrm{X}^{2}$ tests were conducted on the observed and expected frequencies. In cases of diploid $\times$ tetraploid crosses, where expected frequencies are included in an interval (according to the doublereduction frequency), if the observed value was found to be out of the interval, the observed value was compared with the closest value flanking this interval. 
Table 4.2. Expected proportions of $A B S$ locus allelic configuration (AAA, AAa, Aaa or aaa) for each population evaluated.

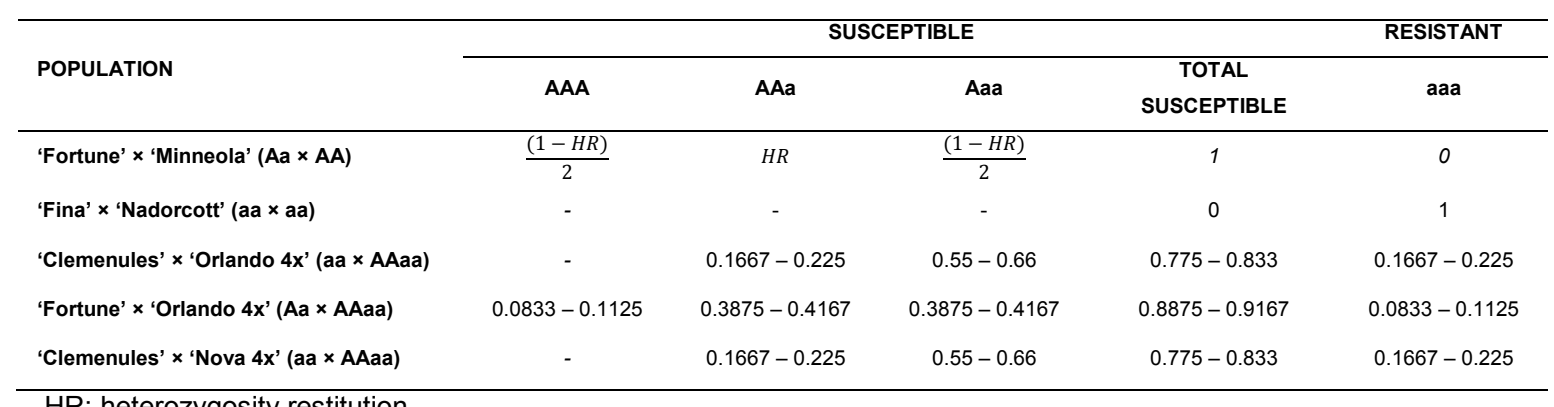

HR: heterozygosity restitution

\section{Estimation of the locus-centromere genetic distance under the hypothesis of monolocus inheritance}

Two segregating triploid progeny derived from crosses between 'Fortune' ('Aa') as the female parent and 'Willowleaf' ('aa') and 'Murcott' ('Aa') as male parents have been used to estimate the locus-centromere distance. Because SDR is the mechanism leading to unreduced gamete formation in 'Fortune' (Cuenca et al., 2011), the maternal HR frequency varies between 0 at the centromere to 0.66 if a model of no chromosome interference is assumed. However, Cuenca et al., (2011) demonstrated that the $\mathrm{Cx}(\mathrm{Co})^{4}$ model assuming partial chromosome interference (Zhao and Speed, 1998b) was better adapted to the observed HR in Fortune $2 n$ gametes.

The functions for estimating the frequency of diploid gametes that would be heterozygous for a given locus according to its distance from the centromere can be easily modified to estimate the expected genotypic frequency within resultant triploid progeny and even the expected segregation of phenotypic traits with monolocus inheritance. Considering that $A B S$ resistance is a recessive trait controlled by a single locus, susceptible triploid genotypes may have 'AAA', 'AAa' or 'Aaa' allele configurations, whereas resistant triploid genotypes should present only the 'aaa' configuration for this locus (Table 4.3). Therefore, the frequency of resistant genotypes within each population is informative for HR estimation, and therefore for determination of the locus-centromere distance. The relation between centromere distance and percentage of resistant hybrids in controlled progeny have been represented (Figure 4.2) for the two models of crosses corresponding to the 'Fortune' $\times$ 'Willowleaf' and 'Fortune' $\times$ 'Murcott' crosses ('Aa' $\times$ 'aa' and 'Aa' $\times$ 'Aa', respectively) under two models of chromosome interference (no interference and partial interference). It should be noted that under the $\mathrm{Cx}(\mathrm{Co})^{4}$ model of partial chromosome interference, the frequencies of resistant hybrids under $20 \%$ and $10 \%$ for the ' $\mathrm{Aa}$ ' $\times$ 'aa' and ' $\mathrm{Aa}$ ' $\times$ 'Aa' crosses, respectively, can correspond to two different distances from the centromere. 
Table 4.3. Expected susceptible and resistant proportions for 'Fortune' ('Aa') $\times$ 'Willowleaf' ('aa') and 'Fortune' ('Aa') × 'Murcott' ('Aa') populations.

\begin{tabular}{|c|c|c|c|c|c|c|}
\hline \multirow[b]{2}{*}{ POPULATION } & \multicolumn{5}{|c|}{ SUSCEPTIBLE } & \multirow{2}{*}{$\begin{array}{c}\text { RESISTANT } \\
\text { aaa }\end{array}$} \\
\hline & AAA & AAa & & Aaa & $\begin{array}{c}\text { TOTAL } \\
\text { SUSCEPTIBLE }\end{array}$ & \\
\hline 'Fortune' × 'Willowleaf' (Aa × aa) & - & $\frac{(1-H R)}{2}$ & & $H R$ & $\frac{(1+H R)}{2}$ & $\frac{(1-H R)}{2}$ \\
\hline 'Fortune' × 'Murcott' $(\mathrm{Aa} \times \mathrm{Aa})$ & $\frac{(1-H R)}{4}$ & $\frac{(1-H R)}{4}+\frac{H R}{2}=\frac{(1+H R)}{4}$ & $\frac{(1-H R)}{4}$ & $+\frac{H R}{2}=\frac{(1+H R)}{4}$ & $\frac{(3+H R)}{4}$ & $\frac{(1-H R)}{4}$ \\
\hline
\end{tabular}

HR: heterozygosity restitution

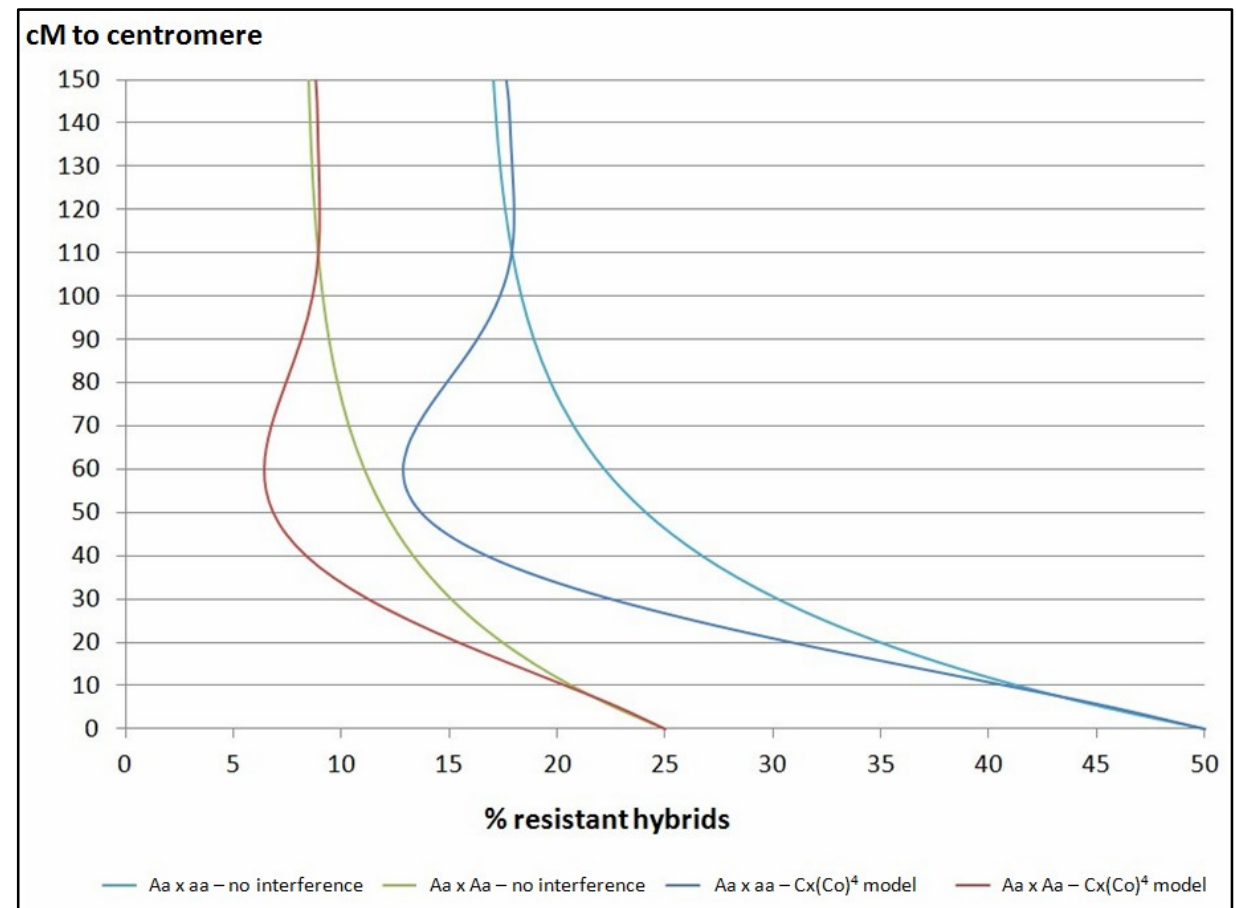

Figure 4.2. Locus-centromere distance estimated from the proportion of resistant hybrids observed in 'Aa' $\times$ 'aa' and 'Aa' $\times$ 'Aa' crosses under a model of no chromosome interference and the $\mathrm{Cx}(\mathrm{Co})^{4}$ model of partial chromosome interference.

\section{Bulk segregant analysis coupled with genome scan}

BSA (Michelmore et al., 1991) has been used to identify genomic regions linked to ABS resistance. To simplify the analysis with only one parental segregation of $A B S$ resistance, the 'Aa' × 'aa' population (rather than 'Aa' × 'Aa') was selected. Triploid hybrids from the 'Fortune' ('Aa') × 'Willowleaf' ('aa') population yielding conclusive phenotypes (resistant or susceptible) in both field and in vitro evaluations were selected for this purpose. Genomic DNA of triploid hybrids and their parents was isolated using the Plant DNeasy kit from Qiagen, Inc. (Valencia, CA, USA), following the manufacturer's protocol. DNA concentrations were estimated with PicoGreen $\circledast$ and adjusted to $30 \mathrm{ng} / \mu \mathrm{l}$. Four resistant and four susceptible DNA bulks were established by mixing DNA from five resistant or susceptible hybrids. Each bulk and the parents were genotyped using an Illumina GoldenGate ${ }^{\mathrm{TM}}$ array platform, which contains 1536 SNP 
markers (Ollitrault et al., 2012b). Six hundred and seventy-seven of these SNPs are mapped in the clementine's reference genetic map (Ollitrault et al., 2012a).

For the mapped markers that were heterozygous in the 'Fortune' genotype, we estimated the relative allele signal in each bulk by allelic composition measurement, called the "B allele frequency" (BAF) by Illumina ${ }^{\mathrm{TM}}$ (Fan et al., 2003), using the Illumina ${ }^{\circledR}$ GenomeStudio 2009. The BAF parameter varies between 0 and 1 and is related to the proportion of the $B$ allele versus $A+B$ (SNP genotyping in GoldenGate ${ }^{\mathrm{TM}}$ array is diallelic). For pooled samples, this parameter provides useful information on the BAF in the bulk.

ANOVA were performed using BAF information, and the significance of the differentiation between the resistant and susceptible bulks was tested by the $\mathrm{F}$ statistic. The pattern of this $\mathrm{F}$ parameter along the genome allowed identification of genomic regions with high probability of association with phenotype variation.

\section{Individual genotyping and mapping of the ABS resistance gene}

Ninety-three triploid hybrids for the 'Fortune' $\times$ 'Willowleaf' population and their diploid parents were genotyped using available SSR and SNP markers already mapped (Ollitrault et al., 2012a) in the interval identified by the BSA analysis or developed from the clementine genomic sequence as described below.

New SSR and SNP marker development: We have taken advantage of the recent release of the reference citrus genome sequence (haploid Clementine genome publicly available at http:://www.phytozome.net/clementine) by the International Citrus Genomics Consortium (ICGC) to develop new markers in the genomic region surrounding the SNPs identified by BSA genome scan as linked to ABS resistance. Microsatellites motifs were searched using Sputnik software (http://espressosoftware.com/sputnik/) and new SSR markers were developed and tested for useful polymorphisms. Moreover, $4.47 \mathrm{~kb}$ corresponding to four DNA fragments within this region were sequenced in 'Fortune' and 'Willowleaf' to find SNPs that could be heterozygous in 'Fortune' and homozygous in 'Willowleaf' mandarin (information on location of the corresponding sequences on the haploid Clementine reference genome and primers used to amplify these DNA fragments is given in Table 4.S2).

SSR analyses: Polymerase chain reactions (PCRs) were performed with wellRED oligonucleotides (Sigma-Aldrich ${ }^{\circledR}$, St Louis, MO, USA) using the following protocol: Mastercycler ep Gradient S (Eppendorf Scientific Inc., Westbury, NY, USA); reaction volume, 15 $\mu$; $0.8 \mathrm{U}$ Taq polymerase (Fermentas ${ }^{\circledR}$, Burlington, VT, USA); reaction buffer: $750 \mathrm{mM}$ Tris- $\mathrm{HCl}$ (pH 9), $50 \mathrm{mM} \mathrm{KCl}, 200 \mathrm{mM}\left(\mathrm{NH}_{4}\right)_{2} \mathrm{SO}_{4}, 0.001 \%$ bovine serum albumin, $0.1 \mathrm{mM}$ of each dNTP, $5 \mathrm{mM} \mathrm{MgCl}_{2}, 3 \mathrm{mM}$ of each primer, $30 \mathrm{ng}$ DNA. The PCR program was as follows: $94^{\circ} \mathrm{C}$ for 5 $\min ; 40$ cycles of $30 \mathrm{~s}$ at $94^{\circ} \mathrm{C}, 1 \mathrm{~min}$ at $55^{\circ} \mathrm{C}$ and $30 \mathrm{~s}$ at $72^{\circ} \mathrm{C}$; final elongation $10 \mathrm{~min}$ at $72^{\circ} \mathrm{C}$. Separation was carried out by capillary gel electrophoresis (CEQ 8000 Genetic Analysis 
System; Beckman Coulter Inc., Fullerton, CA, USA). Data collection and analysis were carried out using the GenomeLab GeXP (Beckman Coulter Inc.) version 10.0 software.

SNP analyses: SNP genotyping was performed by Kbioscience ${ }^{\circledR}$ services, using the KASPar technique. Detailed explanation of specific conditions and reactives can be found in Cuppen (2007).

Assignment of allelic configuration in heterozygous triploid hybrids was carried out using the MAC-PR method for SSR markers (Esselink et al., 2004), or using relative allele signal as proposed by Cuenca et al. (2013a) for SNPs genotyped by the KASPar (KBioscience $₫$, UK) technique. Maternal HRs within the triploid progeny were used for de novo mapping of the markers in relation to the centromere position, using the $\mathrm{Cx}(\mathrm{Co})^{4}$ model for SDR with partial interference (Zhao and Speed, 1998b; Cuenca et al., 2011).

Allelic phase of linked marker loci was inferred from the preferential association at the population level between the phenotype (resistant/susceptible) and the maternal alleles. Marker alleles linked with susceptibility were codified as 'a' alleles, and those linked with resistance as ' $b$ ' alleles. The global coherence of this phase attribution was checked by performing a correlation (Pearson's coefficient) from an individual/loci matrix with values of $1,0.5$, and 0 for the 'aa', 'ab', and 'bb' genotypes, respectively. These correlation values were also used to determine the locations of the various markers in the relative chromosome arms (i.e., on either side of the centromere) in the de novo mapping process.

The relative position of the $A B S r$ locus and markers were analyzed by performing a multiple correspondence analysis (MCA), considering markers as individuals and the various $2 n$ gametes as variables. From the previous matrix, we established the qualitative matrix for the factorial analysis by grouping 1 and 0.5 as the same modality (presence of the 'a' allele linked with the dominant susceptibility allele in 'Fortune') and considering the absence of the 'a' allele as the other modality. XLSAT was used to calculate the Pearson's correlation coefficient and to perform the MCA.

\section{Gene ontology}

All genes encountered within the genomic region between the two markers flanking the estimated location of the $A B S r$ locus were searched in the clementine whole genome assembly delivered by the ICGC and publicly available at http:://www.phytozome.net/clementine. The corresponding annotation data were then processed with Blast2GO (Conesa et al., 2005) to provide a global description of the cellular components and biological processes of the genes identified in this genome region. 


\section{Results}

\section{Segregation of ABS resistance in various triploid progeny arising from sexual polyploidization and interploid crosses}

\section{Field and in vitro evaluation of ABS resistance}

Symptoms of $A B S$ were evaluated for all parental accessions and hybrids both from visual inspection of the trees grown at orchards and by in vitro inoculations with a conidial suspension of the pathogen. Results obtained for parental genotypes were according to those cited in the literature: 'Fortune', 'Minneola', 'Murcott' and 'Orlando' exhibited symptoms of ABS both in the field and in vitro in all evaluations; 'Clemenules', 'Fina', 'Willowleaf' and 'Nadorcott' did not exhibit any ABS symptoms on their leaves at any time. Triploid hybrids derived from various evaluated crosses were susceptible (exhibiting typical ABS symptoms) or resistant at proportions depending on the progeny evaluated. No resistant genotypes were found within the 'Fortune' $\times$ 'Minneola' population, whereas all triploid hybrids from the cross between two resistant genotypes ('Fina' $\times$ 'Nadorcott') were resistant to ABS. Total concordance between field and in vitro evaluations was observed for all evaluated populations with the exception of 'Clemenules' x 'Orlando 4x', where it was over 97\% (Table 4.4).

Table 4.4. Results of field and in vitro phenotyping for Alternaria brown spot, showing the number of resistant hybrids within each population and the concordance between both types of evaluation.

\begin{tabular}{|c|c|c|c|c|c|c|c|}
\hline & $\begin{array}{l}\text { 'Fortune' x } \\
\text { 'Willoleaf' }\end{array}$ & $\begin{array}{l}\text { 'Fortune' x } \\
\text { 'Murcott' }\end{array}$ & $\begin{array}{l}\text { 'Fortune' × } \\
\text { 'Minneola' }\end{array}$ & $\begin{array}{l}\text { 'Clemenules' x } \\
\text { 'Orlando 4x' }\end{array}$ & $\begin{array}{l}\text { ‘Clemenules' } \\
\text { x 'Nova 4x’ }\end{array}$ & $\begin{array}{l}\text { 'Fortune' x } \\
\text { 'Orlando 4x' }\end{array}$ & $\begin{array}{c}\text { 'Fina' } \times \\
\text { 'Nadorcott' }\end{array}$ \\
\hline Nmber of hybrids evaluated & 93 & 148 & 127 & 180 & 100 & 116 & 50 \\
\hline Resistant hybrids by field evaluation & $\begin{array}{c}37 \\
(39.78 \%)\end{array}$ & $26(17.57 \%)$ & $0(0 \%)$ & $46(25.55 \%)$ & $16(16 \%)$ & $12(10.34 \%)$ & $50(100 \%)$ \\
\hline Resistant hybrids by in vitro evaluation & $\begin{array}{c}37 \\
(39.78 \%)\end{array}$ & $26(17.57 \%)$ & $0(0 \%)$ & $41(22.78 \%)$ & $16(16 \%)$ & $12(10.34 \%)$ & $50(100 \%)$ \\
\hline Field-in vitro concordance (\%) & $\begin{array}{c}93 / 93 \\
(100 \%)\end{array}$ & $\begin{array}{l}148 / 148 \\
(100 \%)\end{array}$ & $\begin{array}{l}127 / 127 \\
(100 \%)\end{array}$ & $\begin{array}{l}175 / 180 \\
(97.22 \%)\end{array}$ & $\begin{array}{l}100 / 100 \\
(100 \%)\end{array}$ & $\begin{array}{l}116 / 116 \\
(100 \%)\end{array}$ & $50 / 50(100 \%)$ \\
\hline Consensus hybrids evaluated & 93 & 148 & 127 & 175 & 100 & 116 & 50 \\
\hline Consensus resistant hybrids & $\begin{array}{c}37 / 93 \\
(39.78 \%)\end{array}$ & $\begin{array}{c}26 / 148 \\
(17.57 \%)\end{array}$ & $\begin{array}{l}0 / 127 \\
(0 \%)\end{array}$ & $\begin{array}{c}41 / 175 \\
(23.43 \%)\end{array}$ & $\begin{array}{l}16 / 100 \\
(16 \%)\end{array}$ & $\begin{array}{c}12 / 116 \\
(10.34 \%)\end{array}$ & $\begin{array}{c}50 / 50 \\
(100 \%)\end{array}$ \\
\hline
\end{tabular}




\section{Inheritance of ABS resistance}

Observed resistant proportions within the 'Fortune' ('Aa') × 'Minneola' ('AA'), 'Clemenules' ('aa') × 'Orlando 4x' ('AAaa'), 'Clemenules' ('aa') × 'Nova 4x' ('AAaa'), 'Fortune' ('aa') × 'Orlando 4x' ('AAaa') and 'Fina' ('aa') × 'Nadorcott' ('aa') populations are shown in Table 4.5. As expected, no resistant genotypes were observed within the 'Fortune' $\times$ 'Minneola' triploid population, whereas no susceptible ones were observed within the 'Fina' $\times$ 'Nadorcott' population. Regarding the interploid crosses, $41 / 175$ (23.43\%) and 16/100 (16\%) triploid hybrids were phenotyped as resistant within the 'Clemenules' $x$ 'Orlando 4x' and 'Clemenules' $\times$ 'Nova $4 x^{\prime}$ populations, respectively. These values are not significantly different $\left(x^{2}=0.087, p-\right.$ value $=0.769$ and $x^{2}=0.032, p$-value $=0.857$, respectively) to the closest value of the theoretical interval (16.67-22.5\%) under the hypothesis of single locus recessive inheritance of resistance in an 'aa' x 'AAaa' cross. In the same way, the observed proportion of resistant hybrids in 'Fortune' $x$ 'Orlando $4 x$ ' is within the theoretical interval under the same hypothesis for an 'Aa' $\times$ 'AAaa' cross.

Table 4.5. Expected and observed frequencies of Alternaria brown spot resistant hybrids under the hypothesis of single dominant inheritance within each population and significances of $x^{2}$ conformity tests.

\begin{tabular}{|c|c|c|c|c|c|}
\hline & $\begin{array}{l}\text { 'Fortune' X } \\
\text { 'Minneola' } \\
\text { ('Aa' × 'AA') }\end{array}$ & $\begin{array}{c}\text { ‘Clemenules' x } \\
\text { 'Orlando 4x' } \\
\text { ('aa' x 'AAaa') }\end{array}$ & $\begin{array}{c}\text { 'Clemenules' x } \\
\text { 'Nova 4x' } \\
\text { ('aa' x 'AAaa') }\end{array}$ & $\begin{array}{c}\text { 'Fortune' x } \\
\text { 'Orlando 4x' } \\
\text { ('Aa' x } \\
\text { 'AAaa') }\end{array}$ & $\begin{array}{c}\text { 'Fina' } \times \\
\text { 'Nadorcott' } \\
\text { ('aa' x 'aa') }\end{array}$ \\
\hline Number of evaluated hybrids & 127 & 175 & 100 & 116 & 50 \\
\hline Expected resistant proportion (\%) & $0 \%$ & $16.67 \%-22.5 \%$ & $16.67 \%-22.5 \%$ & $\begin{array}{l}8.33 \%- \\
11.25 \%\end{array}$ & $100 \%$ \\
\hline Observed resistant proportion (\%) & $0 \%$ & $23.43 \%$ & $16.00 \%$ & $10.34 \%$ & $100 \%$ \\
\hline $\mathrm{x}^{2}$ test; $\mathrm{p}$-value & NS & $\begin{array}{c}0.087 ; 0.769 \\
\text { (NS) }\end{array}$ & $\begin{array}{c}0.032 ; 0.857 \\
\text { (NS) }\end{array}$ & WTI & NS \\
\hline
\end{tabular}

WTI: within theoretical interval; NS: no significantly different than theoretical segregation or identical.

These results confirmed the single dominant inheritance of the ABS susceptibility in triploid populations. Moreover, results of the five additional triploid populations evaluated for ABS resistance (Table 4.S1) also confirm the single recessive inheritance of ABS resistance.

\section{Estimation of the genetic distance of the ABS resistance locus (ABSr) to the centromere}

For the two triploid populations arising from $2 x \times 2 x$ crosses ('Fortune' $\times$ 'Willowleaf' and 'Fortune' $\times$ 'Murcott'), the proportions of resistant and susceptible hybrids are related to the $A B S r$ locus-centromere distance. To estimate the locus-centromere distance, we used a simple cross model in which only the $2 n$ gametes segregate for the $A B S r$ locus ('Fortune' $\times$ 'Willowleaf'). This allows avoiding any eventual bias associated with distorted segregation from the male parent. 
The proportion of resistant hybrids in the 'Fortune' $x$ 'Willowleaf' population was $39.78 \%$, corresponding to an HR estimation value of 0.2043 , assuming that 'aa' and 'AA' $2 n$ gametes were equally represented. Only one value for centromere distance is associated with the observed proportion of resistant hybrids when the functions presented in Material and Methods are applied (Figure 4.2). Moreover, no interference and partial chromosome interference models gave very similar estimates for the centromere distance, which has been estimated to be $10.5 \mathrm{cM}$.

With such an $A B S r$ locus-centromere distance, the expected proportion of the resistant genotype in 'Fortune' $\times$ 'Murcott' progeny ('Aa' × 'Aa') should be $19.9 \%$. The observed value $(17.57 \%)$ is not significantly different $\left(x^{2}=0.501\right)$, confirming the proximity of the $A B S r$ locus to a centromere.

\section{Bulk segregant analysis coupled with genome scan}

BSA over the 'Fortune' ('Aa') × 'Willowleaf' ('aa') population has been used to identify a genomic region linked to the ABS resistance gene. Four resistant and four susceptible bulks were genotyped for 1536 SNP markers using a GoldenGate ${ }^{\text {TM }}$ array platform. Of these, 429 SNP markers were heterozygous for the 'Fortune' mandarin and were used to perform ANOVA analyses over relative allele signal for each bulk; significance of the differentiation between the resistant and susceptible bulks was tested by the $F$ statistic. A graphical example for the CiC3248-06 and CiC6243-03 markers, which differentiate resistant and susceptible bulks, is shown in Figure 4.3.

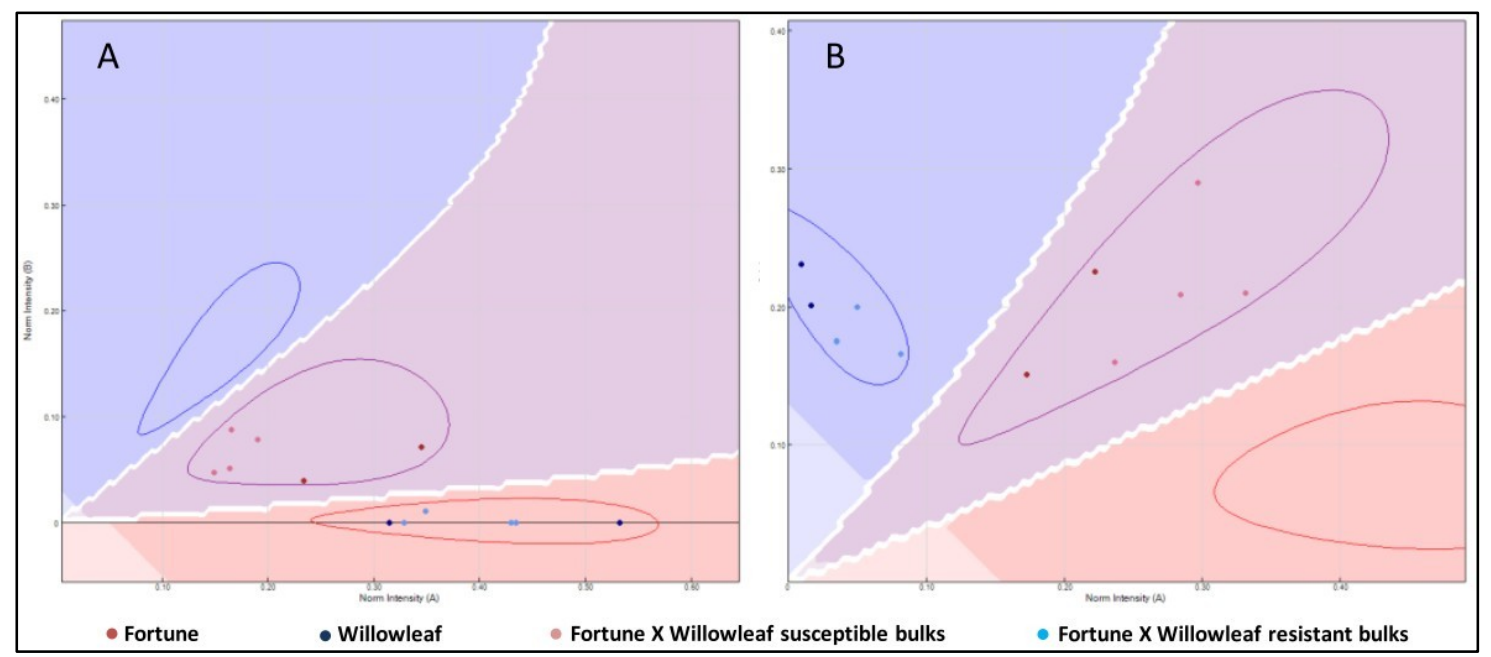

Figure 4.3. Plot showing Bulked Segregant Analysis results for the CiC3248-06 (A) and CiC6243-03 (B) markers, distinguishing between susceptible and resistant genotypes and bulks. 
The pattern of this $\mathrm{F}$ parameter along the nine linkage groups of the clementine's genetic map (Ollitrault et al., 2012a) led us to discard most genomic regions (Figure 4.S1) and allowed identification of a region containing numerous markers with a high probability ( $>99 \%)$ of association with phenotype variation, located on chromosome III (Figure 4.4). This region includes 25 significant SNP markers within an interval of 13.1 cM between markers CiC4831-03 (at $84.66 \mathrm{cM}$ ) and $\mathrm{CiC} 1875-01$ (at $97.76 \mathrm{cM}$ ) on the clementine's map. The maximum $\mathrm{F}$ value within this region is attained by marker CiC4681-02, located at $92.78 \mathrm{cM}(\mathrm{F}=2055)$. The genomic region between these two markers contains around $15 \mathrm{Mb}$. No significant marker clusters were found in any other area of the genome.

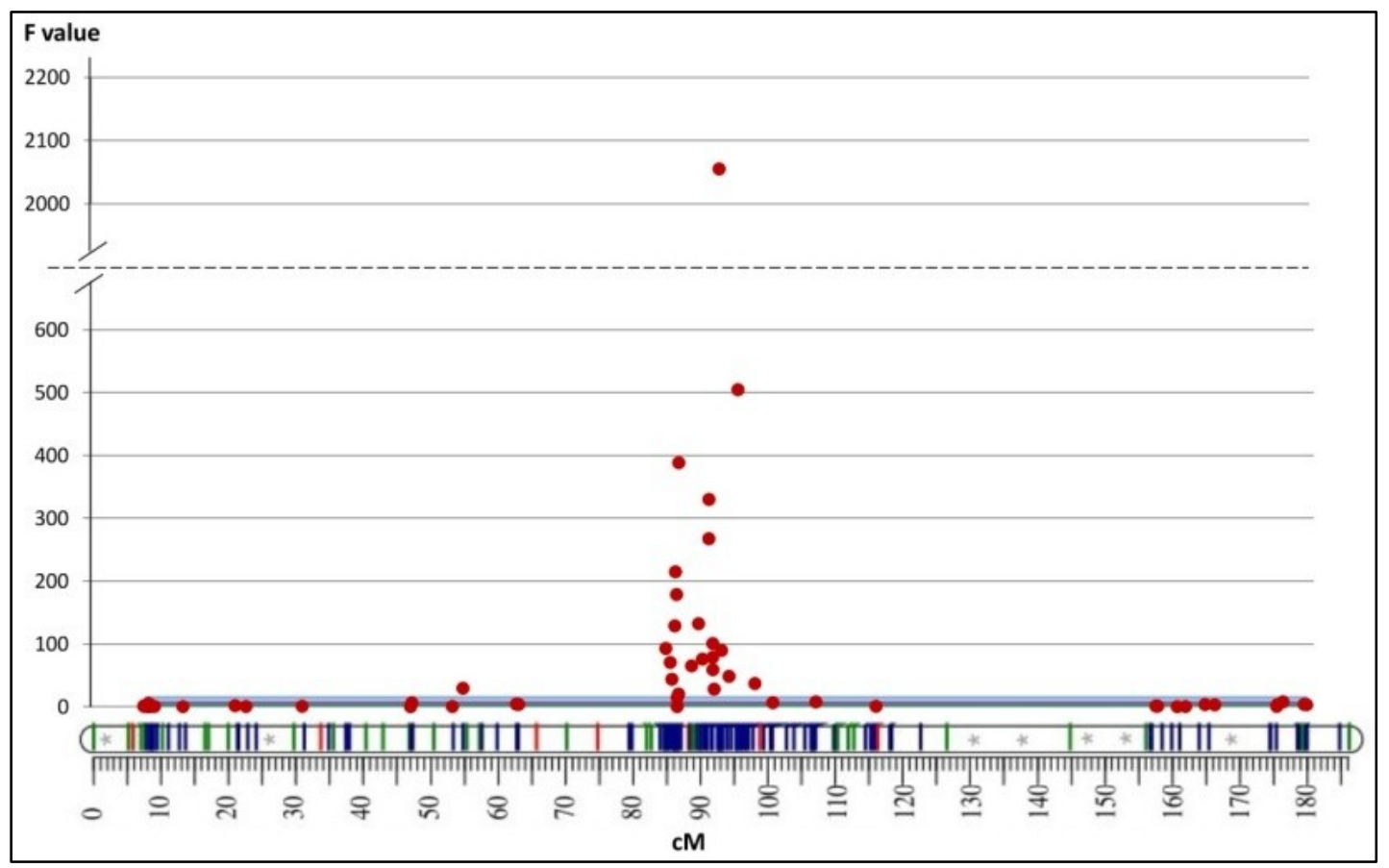

Figure 4.4. Pattern of $F$ statistic from ANOVA along chromosome III (the linkage group map under the $F$ value graph is taken from the genetic map of clementine (Ollitrault et al., 2012a). The blue line indicates the least significant value for $F$ at $p<0.01$.

\section{Genetic mapping of the genomic region surrounding the ABS locus}

Among the SNP markers with significant linkage to ABS resistance, five displayed the most convenient allelic conformation in the parents (heterozygous in 'Fortune' and homozygous in 'Willowleaf') for genetic mapping by individual genotyping of the 'Fortune' $\times$ 'Willowleaf' progeny. One SSR marker included in this segment in the clementine's genetic map (Ollitrault et al., 2012a) also displayed useful allelic polymorphisms between parents.

To develop additional markers with useful allelic conformation, the genomic region (from www.phytozome.net) surrounding the 25 significant SNPs was scanned to find new microsatellites and develop new SSR markers. Among 42 SSRs tested, four new SSR markers 
provided useful polymorphisms. Moreover, $4.47 \mathrm{~kb}$ (Table S2) within this region in 'Fortune' and 'Willowleaf' and two SNPs heterozygous in 'Fortune' and homozygous in 'Willowleaf' were sequenced. More detailed information on all markers used in this study is available as supplementary material in Table 4.S3 and Table 4.S4.

Next, five mapped SNP markers (Ollitrault et al., 2012a), one mapped SSR marker [CX0038: (Chen et al., 2008a)], and six newly developed markers (four SSRs and two SNP markers) were used to genotype all 93 triploid hybrids of the 'Fortune' $\times$ 'Willowleaf' population. Because the male parent was homozygous or different from the female parent at each selected locus, the genetic structure of the diploid female gamete (Table 4.S5) was deduced from the triploid hybrid genotyping [see (Cuenca et al., 2011) for details], and the marker HRs were estimated.

We took advantage of the direct link between HR in $2 n$ gametes and the locuscentromere distance for de novo mapping of genetic markers in relation to the centromere position, using the $\mathrm{Cx}(\mathrm{Co})^{4}$ model for SDR with partial interference (Cuenca et al., 2011). No recombination was observed between the centromere and the CiC1229-05 and CiC6116-04 markers. The markers next closest to centromere were SNP-ALT1 and SNP-ALT2 (with the same HTA data), $0.54 \mathrm{cM}$ away; the next closest marker was CX0038 (2.7 cM). To determine whether this marker was located at one side or the other of the centromere, we checked its correlation with the markers in distal positions on the draft map (at this step, CiC1229-05 and CiC6116-04 on one side, and SNP-ALT1 and SNP-ALT2 on the other side). Because the lower correlation was for SNP-ALT1 and SNP-ALT2, CX0038 was positioned on the opposite chromosome arm. The same process was applied at each subsequent step of marker addition to the map, proceeding according to increasing distance from the centromere. The order of the mapped markers in the de novo map was the same as in the map of clementine (Ollitrault et al., 2012a), and new (non-mapped) markers maintained the expected order of the assembled sequence available at www.phytozome.net (Figure 4.5a,b). However, the estimated genetic distances were higher than those on the clementine's map, suggesting that the recombination rate in this genomic region during the production of the $2 n$ gamete was higher in 'Fortune' than in clementine. A logically important modification of the slope of the physical distances according to genetic map is observed in the centromeric region (with lower recombination by physical distance unit).

No recombination was observed between the AT21 marker and the ABSr locus. The two flanking markers (TTC8 and CiC3248-06) were found at 3.77 and $1.71 \mathrm{cM}$, respectively, from the $A B S r$ locus, delimiting a $3.3 \mathrm{Mb}$ genome region. This position of the $A B S r$ locus was checked by an MCA based on a qualitative matrix (see Material and Methods). Most of the matrix diversity was represented in the first axis (72.9\%; Figure $4.5 \mathrm{c})$, where the order of markers and the relative position of the $A B S r$ locus was identical to the de novo mapping, based on HR. 


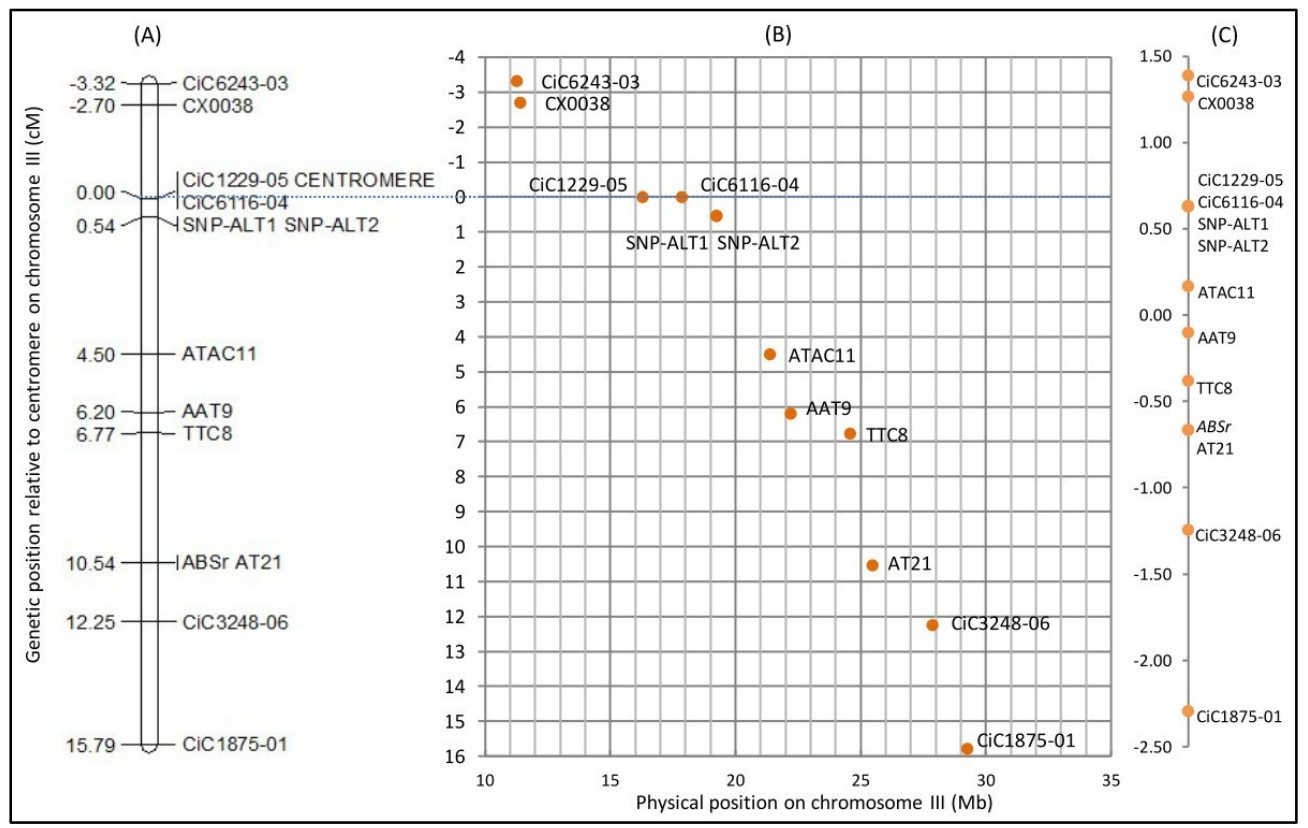

Figure 4.5. Order and location of markers and $A B S r$ locus. (A) De novo genetic mapping (cM) of markers and the $A B S r$ locus on chromosome III relative to the centromere by half-tetrad analysis, (B) relation between genetic and physical location in the clementine's reference genome (www.phytozome.net/clementine), and (C) representation of the markers on the first axis of the multiple correspondence analysis.

\section{Gene annotations around the $A B S r$ locus}

The assembled sequence (www.phytozome.org) of the region of chromosome III between the two markers flanking the ABSr locus (TTC8 and CiC3248-06) was examined for gene annotations. The results revealed several disease resistance genes along and at the extremes of the analyzed region, so the analysis was extended $1.5 \mathrm{Mb}$ down from the TTC8 marker and 1.7 $\mathrm{Mb}$ up from the CiC3248-06 marker. Ninety-five genes annotated as homologous to disease resistance genes were found within the corresponding $6.5 \mathrm{Mb}$ region. $\mathrm{A}$ genome-wide analysis of disease resistance gene homologs revealed that $17 \%$ of them are located within this region on chromosome III.

Within the 3.3-Mb region defined by the two flanking markers, 177 annotated genes were found (Table 4.S6). Gene ontology (GO) analysis of biological processes revealed that $69.1 \%$ of these genes are involved in metabolic processes and $21.9 \%$ are related to response or cell death (Figure 4.6a). GO also indicated that $25 \%$ of the genes are intrinsic to the membrane (Figure 4.6b), which is the target of the ACT-toxin produced by the tangerine pathotype of $A$. alternata. 


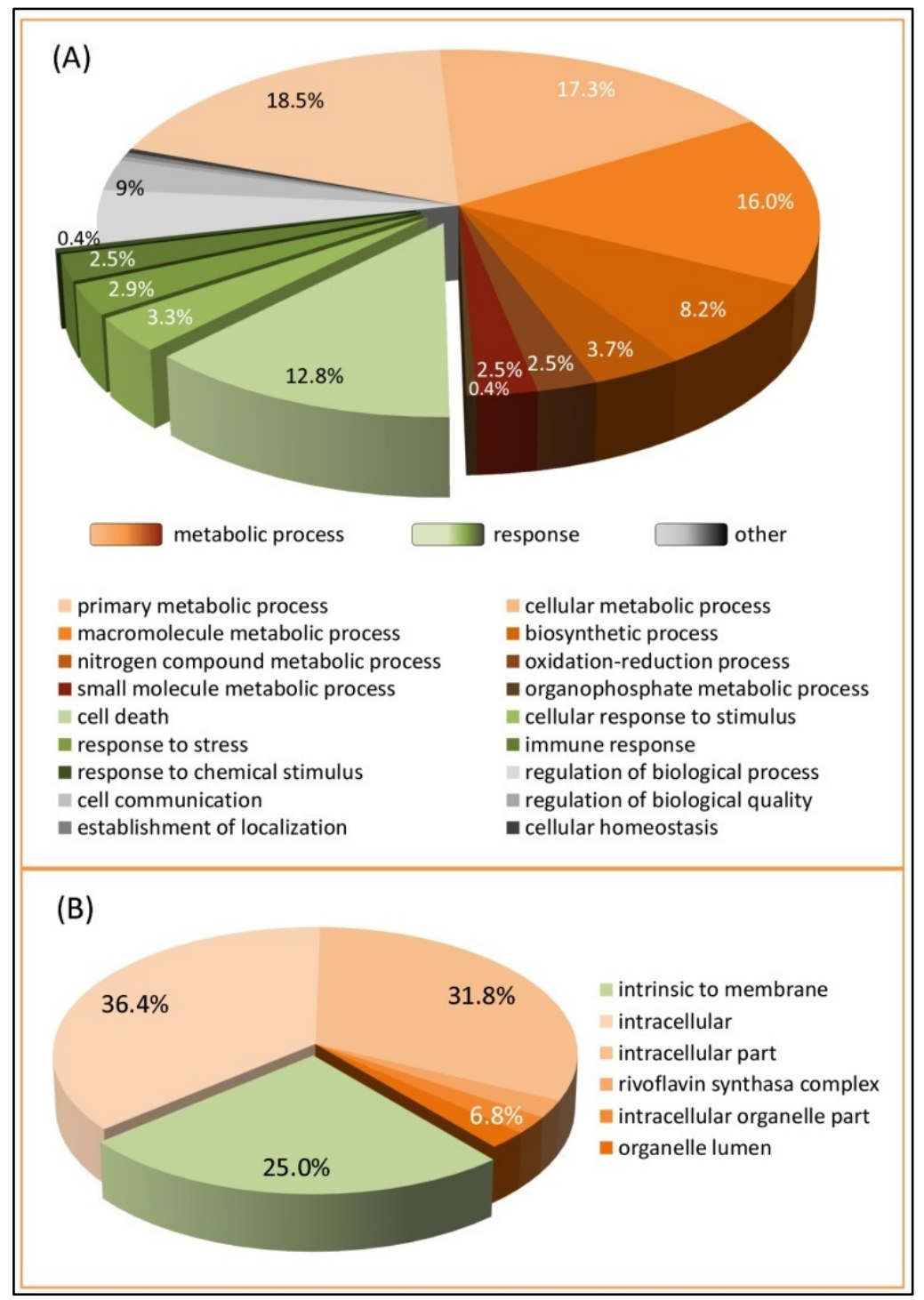

Figure 4.6. Classification of genes annotated between the TTC8 and CiC3248-06 markers according to gene ontology (GO) functional categories. (A) GO biological process categories. (B) GO cellular component categories.

In the region defined by the two flanking markers, which includes the $A B S r$ locus, 33 disease resistance homologous genes were found (Figure 4.7). Thirty of these genes encode proteins predicted to have a central nucleotide-binding site (NBS) domain, 28 are involved in apoptosis, and 29 have a C-terminal leucine-rich repeat (LRR) domain. Six of the 30 NBScontaining genes have transmembrane activity. Among the resistance genes identified, 15 are homologous to the LOV1 gene, which has been implicated in dominant susceptibility of Arabidopsis to the victorin toxin produced by Cochliobolus victoriae Nelson (Lorang et al., 2007). Other three of these resistance genes belong to the mlo family, which confer durable broad-spectrum resistance against the powdery mildew pathogen in barley (Büschges et al., 1997). 


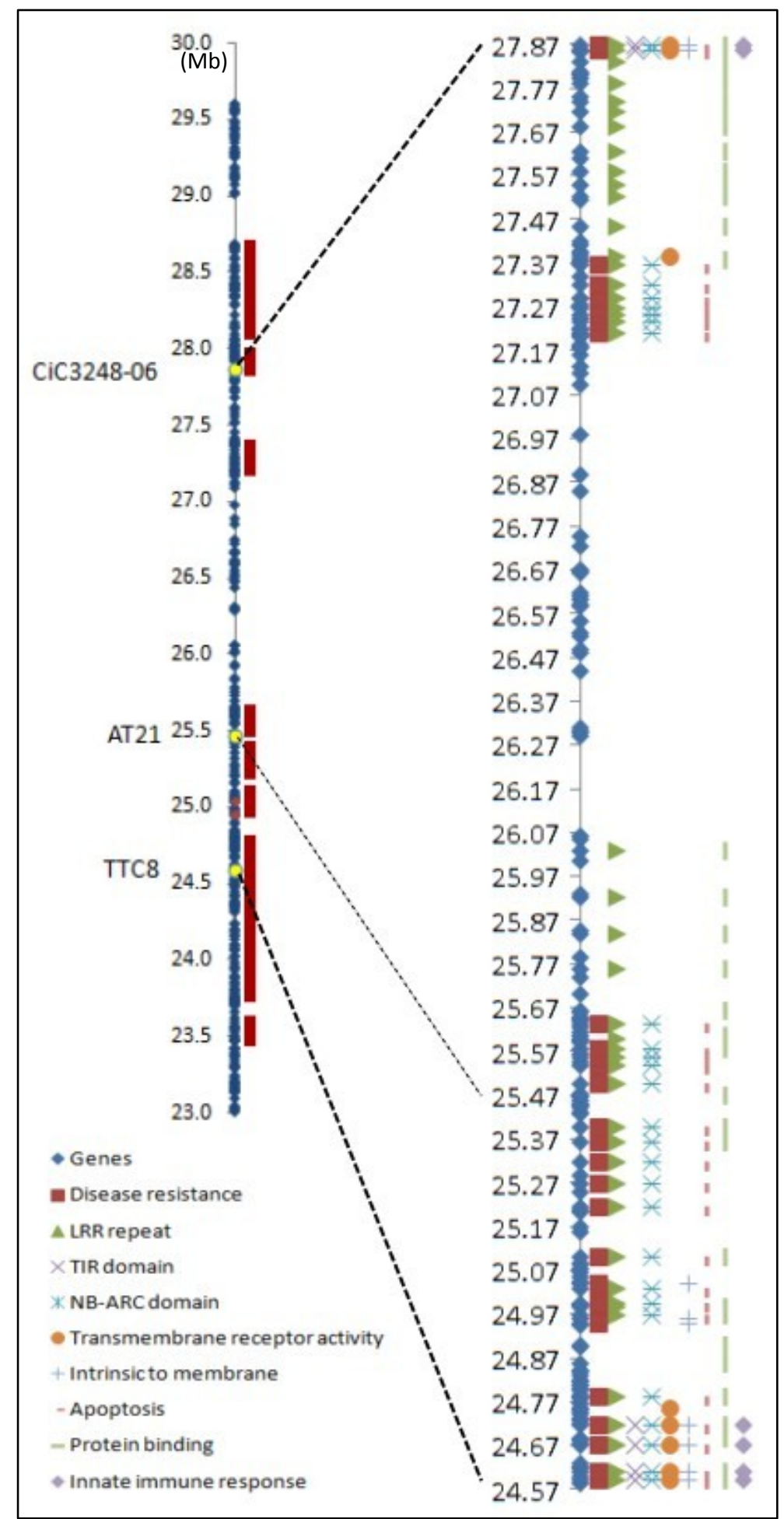

Figure 4.7. Genes found in the region around the $A B S r$ locus, indicating the disease resistance gene homologous and their major domains and annotations. 


\section{Discussion}

The monolocus inheritance and recessivity of $A B S$ resistance was confirmed in citrus triploid progeny, and the $A B S r$ locus was mapped in the chromosome III genetically close to the centromere

Several studies have reported the single dominance inheritance of ABS susceptibility in diploid citrus genotypes (Dalkilic et al., 2005; Gulsen et al., 2010); however, no data have been previously published regarding triploid progeny. In this present study, inheritance of resistance to the $A B S$ pathogen has been analyzed in triploid progeny produced by different strategies (sexual polyploidization and interploid crosses) over a wide range of genetic backgrounds. The segregations (resistance/susceptibility) observed for all the triploid populations we evaluated confirm the monolocus inheritance and recessivity of the disease in a triploid context. All progeny arising from a homozygous susceptible cultivar, such as 'Minneola', were susceptible, whereas in cases of heterozygous parents, segregations were as expected, depending on the hybridization strategy.

Genetic mapping and marker-trait association in polyploids are complicated by the diversity of the meiotic process (and therefore, recombination mechanisms) involved, as well as the distribution of markers into multiple dosage classes (Da Silva and Sorrells, 1996). Despite these limitations, genetic maps based on segregating molecular markers have been generated for a wide range of polyploids including tetraploid cotton (Reinisch et al., 1994), hexaploid tall fescue (Xu et al., 1995), hexaploid wheat (Gill et al., 1991) and octoploid sugar-cane mandarin (Da Silva and Sorrells, 1996; Ming et al., 2001).

In this study, the first information regarding the location of the $A B S r$ locus was given directly by the analysis of the segregation between susceptible and resistant triploid hybrids in progeny obtained by sexual polyploidization ( $2 n$ gametes), assuming monolocus recessive determination of the resistance. Indeed, for $2 n$ gametes resulting from either FDR or SDR, as in the 'Fortune' mandarin (Cuenca et al., 2011), there is a direct linkage between parental HR (and therefore, the proportion of resistant and susceptible hybrids) and the genetic distance to the centromere. HTA is therefore an efficient way to map loci relative to a centromere (Johnson et al., 1995; Zhao and Speed, 1998a; Lindner et al., 2000). At this step, we identified that the ABSr locus was relatively close $(10.5 \mathrm{cM})$ to one centromere.

The $A B S r$ locus was then located by combining two approaches. The first one was to perform BSA coupled with genome-scan using SNP markers mapped in the clementine's reference genetic map (Ollitrault et al., 2012a). This approach allowed localization of the ABS resistance locus within a $13.1 \mathrm{cM}$ area on chromosome III of the clementine's genetic map, corresponding to $15 \mathrm{Mb}$ of scaffold 3 of the current clementine whole genome assembly in pseudomolecules (www.phytozome.net). Our results confirm the potential for raw location of major genes involved in phenotypic trait variability by coupling BSA strategies with genomic 
scanning, as previously proposed by Brauer et al. (2006), and demonstrate that it can be successfully applied in a polyploid segregating population.

This genomic region was further examined for additional SSR and SNP markers, which were used for de novo mapping of the area by HTA of $2 n$ gamete inferred from triploid hybrid genotypes. Mapping functions relating HR and centromere distance (Zhao and Speed, 1998a; Cuenca et al., 2011) and an approach based on a correlation matrix have given convergent results in identification of the closest markers flanking the candidate ABS resistance gene. The AT21 marker appeared to be tightly linked to the $A B S r$ locus. However, it would be necessary to analyse many more progeny to estimate its linkage with the $A B S r$ locus precisely. The two flanking markers of AT21 and the ABSr locus are TTC8 and CiC3248-06, respectively, at 3.77 and $1.71 \mathrm{cM}$. This marker frame is much more closely linked than previous markers identified from diploid segregating progenies. Two RAPD markers are in loose linkage with the $A B S r$ locus (15.3 cM and $36.7 \mathrm{cM}$ far from the ABS locus in the same side) (Dalkilic et al., 2005). A more recent study identified two flanking SRAP markers at $3 \mathrm{cM}$ and $13 \mathrm{cM}$, and the authors of that study proposed that the genomic region of the $A B S r$ locus should display low polymorphism, explaining the difficulty of obtaining markers very close to the gene (Gulsen et al., 2010). The availability of the reference genetic map (Ollitrault et al., 2012a) and whole genome sequence (Xu et al., 2013) of clementine clearly increases the potential for marker-trait association studies in citrus, with co-dominant markers located both in the physical and genetic maps.

\section{Candidate genes for resistance to ABS were identified}

The $A B S r$ locus appears to be included in a genomic region very rich in disease resistance gene homologs. Indeed, $17 \%$ of all resistance genes annotated in the citrus reference genome (www.phytozome.net) are found in a $6.5 \mathrm{Mb}$ region $(2.2 \%$ of the whole genome) of chromosome III, surrounding the $A B S r$ locus. In the $3.3 \mathrm{Mb}$ region defined by the two flanking markers, 33 disease resistance gene homologs were identified. Six of them are considered to be intrinsic to the membrane, including three belonging to the mlo family and 28 related to apoptosis. These resistance genes are organised in clusters, as generally described in many crop species (Michelmore and Meyers, 1998; Yi and Richards, 2007), and as already demonstrated in citrus for resistance to Tristeza virus found in the Poncirus genome (Fang et al., 1998).

A. alternata is a necrotroph pathogen, which first kills host cells before parasitizing them and metabolising their contents. If the toxins used to kill host cells are not released at the right time, place, or concentration, or if a particular host genotype is insensitive to the toxin, the host cells will not die, the necrotroph will be unable to infect or reproduce, and the plant will be resistant (Guest and Brown, 1997). A. alternata, like other necrotrophs, produces host-selective toxins (ACT-toxins), defined as pathogen effectors, which induce toxicity and promote disease 
only in the host species expressing a specific and often dominant susceptibility gene (Friesen et al., 2008). Their pathogenic ability is conditioned by a gene in the pathogen that encodes production of the toxin and by a gene in the host that promotes sensitivity to the toxin. For this type of pathogen, plant resistance can be achieved via the loss or modification of the toxin's target or through detoxification (Hammond-Kosack and Jones, 1997).

Inheritance of ABS resistance in citrus has been described as monogenic (Dalkilic et al., 2005; Gulsen et al., 2010), controlled by a single recessive allele. The results of this study corroborate this hypothesis by demonstrating the predicted proportions of resistant and susceptible genotypes obtained from various crosses and the identification, by BSA, of a single genomic region highly associated with resistance. ACT-toxins from the tangerine pathotype of A. alternata, as well as AF-toxin from the strawberry pathotype and AK-toxin from the Japanese pear pathotype, have an epoxy-decatrienoic acid structure and exert their primary effect on the plasma membrane of susceptible cells, causing a rapid increase in electrolyte loss from tissues and invaginations in plasma membranes (Otani et al., 1995). Varietal resistance to ACT-toxin in citrus is very highly correlated with ABS resistance. Therefore, a probable function for the gene of interest is to encode a protein involved in ACT-toxin recognition, which would allow the toxin to cause cell death. Such a dominant gene should be present (homozygously or heterozygously) in susceptible cultivars, and absent or defective in resistant cultivars.

The most obvious candidate for providing recognition specificity to the pathogen effector is the LRR domain, which binds a corresponding ligand (Hammond-Kosack and Jones, 1997) with a putative nucleotide-binding (NB) site; these genes are classified as 'NB-LRR' genes (Toyoda et al., 2002). This class includes members that carry either $\mathrm{N}$-terminal homology to the Toll protein and interleukin-1 receptor (TIR-NB-LRR) or a putative coiled-coil (CC) at the Nterminus (CC-NB-LRR). Resistance (R) genes from both of these subclasses confer resistance against fungi, and several fungal resistance genes have been reported and used in crop improvement programs. NB-LRR genes have been identified that confer resistance against flax rust, maize rust, barley powdery mildew, rice blast and Fusarium wilt and downy mildew of tomato (Dangl and Jones, 2001). However, sequence variation within the central LRR domain, as well as variation in LRR copy number, plays an important role in determining recognition specificity (Gururani et al., 2012). Likewise, $R$ genes, first identified as dominant resistance genes, could be targets of pathogen effectors and therefore play roles in susceptibility (Lorang et al., 2012). Thus, avirulence (Avr) elicitors and HST may be recognising the same resistance genes in plants, leading to evolutionary outcomes that differ between necrotrophs and biotrophs while affecting the evolution of the corresponding $R$ genes (Stukenbrock and McDonald, 2009). In Arabidopsis, victorin (an HST produced by C. victoriae) sensitivity and disease susceptibility is conferred by the LOV1 gene, which encodes a NB-LRR protein. LOV1 is targeted by victorin, the pathogen effector, and this interaction results in disease susceptibility (Lorang et al., 2007). These NB-LRR proteins recognise specific pathogen-derived products and initiate a resistance response that often includes a type of cell death known as the hypersensitive response (Moffett 
et al., 2002). In the same way, the Pc locus of sorghum, which contains genes encoding NBLRR proteins, determines dominant susceptibility to HSTs produced by the necrotroph fungus Periconia circinata (L). Mangin Sacc. (Nagy et al., 2007; Nagy and Bennetzen, 2008). Together, these results suggest that for necrotroph fungi, the disease is favoured by inducing the resistance response (Otani et al., 1995; Lorang et al., 2012); this mode of susceptibility could also apply to $A$. alternata. In this study, thirty disease resistance gene homologous encoding proteins with NBSs were found in the ABS locus region, and 15 of them are homologous to the LOV1 gene. Therefore, disease resistance gene homologous should be considered as candidate genes for inducing susceptibility, especially in the case of LOV1 homologs found in this region.

Another class of resistance genes, belonging to the mlo family, has also been implicated in susceptibility to barley powdery mildew produced by Blumeria graminis $\mathrm{f}$. sp. hordei (Büschges et al., 1997). Mlo proteins are localised in the plasma membrane and possess seven transmembrane domains; it has been suggested that they function as receptors in plants (Jørgensen and Wolfe, 1994; Büschges et al., 1997; Devoto et al., 1999). The resistance trait conferred by $m / o$ is recessively inherited and non-race-specific, because it is effective against all isolates of the fungus B. graminis (Jørgensen, 1977; Qu et al., 2006). Three resistance genes found in the $A B S r$ locus region belong to this class. However, in citrus, two pathotypes of $A$. alternata have been described that produce HSTs that affect a narrow range of genotypes (ACT-toxin to tangerines, ACR-toxin to Rough lemon [C. jambhiri Lush.] and Rangpur lime [C. limonia Osbeck]), and resistance found in the germplasm was pathotype-specific (Timmer et al., 2003).

The identification of the gene for $A B S$ resistance will involve fine mapping with large diploid populations. SNP markers are currently being developed from each candidate gene for this purpose. From the reduced set of candidate genes that would result from this fine genetic mapping, functional validation could be performed by genetic transformation (Cervera et al., 2005) or viral vector-induced gene silencing (Folimonov et al., 2007; Agüero et al., 2013).

For susceptible genotypes it is probable that additional genes, but also environmental factors, affect the susceptibility level. QTLs analyses conducted in susceptible progeny should be necessary to decipher this quantitative component of susceptibility.

\section{Toward efficient breeding for ABS resistance}

ABS is a major fungal disease in certain mandarin cultivars around the world; the disease causes a substantial loss of production and fruit quality (Akimitsu et al., 2003; Timmer et al., 2003). Currently, ABS management relies mainly on the application of fungicides (Bhatia et al., 2003; Peres and Timmer, 2006; Vicent et al., 2007), but this control is expensive, not environmentally friendly, and not always efficient. As a consequence, the production of 
susceptible cultivars, such as 'Fortune' and 'Nova' among others, has declined significantly during recent years, and many trees of the most susceptible varieties have been removed and replaced by resistant cultivars that may lack some of the interesting agronomic traits of the susceptible cultivars (Navarro et al., 2005). Therefore, ABS resistance must be considered as a major selection criterion in mandarin breeding programs.

Our results demonstrate that it is possible to use susceptible parents heterozygous for the resistance gene to breed resistant triploid varieties. For instance, the susceptible cultivar 'Fortune', which is a very efficient female parent in producing high-quality triploid hybrids in $2 x \times$ $2 x$ hybridization (Aleza et al., 2010b), should not be discarded. Indeed, the $39 \%$ and $19 \%$ of resistant triploid hybrids produced when crossed with resistant or heterozygous susceptible genotypes, respectively, are acceptable if combined with early selection by controlled inoculation phenotyping or MAS. On the other hand, parents homozygous for the susceptible allele, such as 'Minneola', should be definitively ruled out. Our results also demonstrate that when heterozygous susceptible parents are used as producers of diploid gametes, it is much more efficient to integrate them in a $2 x \times 2 x$ strategy rather than to use them as doubled-diploid parents in interploid crosses. Indeed, the heterozygosity transmission of the $A B S r$ locus (associated with susceptibility transmission to the triploid progeny) is lower in the $2 n$ gametes than in the diploid gametes produced by doubled-diploids, due to its location close to the centromere of chromosome III and the SDR origin of unreduced gamete formation in most citrus genotypes (Aleza et al., 2012b).

HTA has permitted identification two flanking markers at 3.77 and $1.71 \mathrm{cM}$ of the $A B S r$ locus, as well as a third marker that did not exhibit any recombination with the $A B S r$ locus within the analyzed population. These markers should be used together for efficient early MAS for different parental combinations when the markers are heterozygous in the susceptible parent and polymorphic between the two parents. We are currently sequencing DNA fragments between these two markers to identify SNP loci that provide a useful allelic combination for the various crosses of our mandarin breeding program. These are examples of the very few identified markers for MAS in citrus, which include the SSR markers flanking the Citrus Tristeza virus resistance gene(s) of Poncirus [(Yang et al., 2003); Mikeal Roose, personal communication] and the dominant PCR assay for the anthocyanin content of pulp of blood orange due to a transposable element in the 5'extremity of the Ruby gene (Butelli et al., 2012). 


\section{Supplementary information}

Table 4.S1. Number of individuals $(\mathrm{N})$ evaluated within each population, and percentage of hybrids evaluated as resistant $(\% \mathrm{R})$

\begin{tabular}{|c|c|c|c|c|c|}
\hline & \multicolumn{5}{|c|}{ Population } \\
\hline & ‘Orri’ × ‘Oronules' & 'Clemenules' x 'Nova' & 'Fortune' x 'Scarlett' & $\begin{array}{c}\text { 'Fina' } x \\
\text { 'Fairchild } 4 x \text { ' }\end{array}$ & $\begin{array}{l}\text { 'Fortune' x } \\
\text { 'Kara 4x' }\end{array}$ \\
\hline Segregation & $<$ aa $\times$ aa $>$ & $<a a \times A a>$ & $<\mathrm{Aa} \times \mathrm{aa}>$ & $<$ aa $\times$ AAaa $>$ & $<$ Aa $\times$ aaaa $>$ \\
\hline $\mathbf{N}$ & 16 & 11 & 47 & 15 & 25 \\
\hline$\% \mathbf{R}$ & $100 \%$ & $54.55 \%$ & $38.3 \%$ & $20 \%$ & $52 \%$ \\
\hline
\end{tabular}

Table 4.S2. Primers used to sequence the $4.47 \mathrm{~kb}$ genomic region on scaffold 3 (http:://www.phytozome.net/clementine) surrounding the SNPs identified by BSA-genome scan as linked to ABS resistance

\begin{tabular}{cccc}
\hline Primer Forward & Primer Reverse & Product size & Position in scaffold $\mathbf{3}$ (bp) \\
\hline CAATTTGAGCTCGCTTATTT & GGTTCATCTAGGTCACCTTCT & 1154 & 19240437 to 19241590 \\
TAAAACTTGGCATGGATCTT & CATATGGAATCTTCCCAGTC & 1176 & 19241527 to 19242702 \\
TGCCAGCTATGATAAGAACA & AGACAAAATTATCCCACTGTGT & 1170 & 19242617 to 19243786 \\
ATTTAAATGATGAATTTGATGC & TTATCTTTGCTGCATTTGAA & 1175 & 19243732 to 19244906
\end{tabular}

Table 4.S3. Information about SSR and SNP markers used in this study, indicating the alleles in the parental lines and the expected genotypes within the 'Fortune' $(F) \times$ 'Willowleaf' $(W L)$ triploid progeny

\begin{tabular}{|c|c|c|c|c|c|}
\hline Marker id & Marker type & F alleles & WL alleles & Expected 3x genotypes & Reference \\
\hline CiC1229-05 & $\operatorname{SNP}(T / G)$ & TG & $\mathrm{TT}$ & TTT, TTG, TGG & Ollitrault et al., 2012a \\
\hline $\mathrm{CiC} 1875-01$ & $\mathrm{SNP}(\mathrm{T} / \mathrm{C})$ & TC & $\mathrm{CC}$ & CCC, TCC, TTC & Ollitrault et al., 2012a \\
\hline CiC3248-06 & $\operatorname{SNP}(A / G)$ & $A G$ & AA & AAA, AAG, AGG & Ollitrault et al., 2012a \\
\hline CiC6116-04 & $\mathrm{SNP}(\mathrm{T} / \mathrm{C})$ & TC & $\mathrm{CC}$ & CCC, TCC, TTC & Ollitrault et al., 2012a \\
\hline $\mathrm{CiC6243-03}$ & $\operatorname{SNP}(A / G)$ & $A G$ & GG & GGG, AGG, AAG & Ollitrault et al., 2012a \\
\hline CX0038 & SSR & $337 / 339$ & $339 / 339$ & $319 / 319 / 321,319 / 321 / 321,321 / 321 / 321$ & Chen et al., 2008 \\
\hline ATAC11 & SSR & $248 / 264$ & $256 / 264$ & $\begin{array}{l}248 / 248 / 256,248 / 248 / 264,248 / 256 / 264 \\
248 / 264 / 264,256 / 264 / 264,264 / 264 / 264\end{array}$ & new \\
\hline AAT9 & SSR & $260 / 266$ & $266 / 269$ & $\begin{array}{l}260 / 260 / 266,260 / 260 / 269,260 / 266 / 266 \\
260 / 266 / 269,266 / 266 / 266,266 / 266 / 269\end{array}$ & new \\
\hline TTC8 & SSR & $197 / 203$ & 203/null & $\begin{array}{l}\text { 197/197/203, 197/197/null, 197/203/203, } \\
\text { 197/203/null, 203/203/203, 203/203/null }\end{array}$ & new \\
\hline AT21 & SSR & $193 / 205$ & $177 / 205$ & $\begin{array}{l}\text { 177/193/193, 193/193/205, 177/193/205, } \\
\text { 193/205/205, 177/205/205, 205/205/205 }\end{array}$ & new \\
\hline SNPALT1-Y & $\mathrm{SNP}(\mathrm{C} / \mathrm{T})$ & CT & $\mathrm{CC}$ & ССС, ССТ, СТТ & new \\
\hline SNPALT2-K & $\operatorname{SNP}(G / T)$ & GT & TT & GGT, GTT, GGT & new \\
\hline
\end{tabular}


Table 4.S4. Information about new SSR and SNP markers developed

\begin{tabular}{|c|c|c|c|c|c|c|}
\hline Marker id & $\begin{array}{c}\text { Position in } \\
\text { scaffold } 3 \\
\text { (bp) }\end{array}$ & $\begin{array}{c}\text { Allele } \\
\text { polymorphism } \\
\text { or repeat motif }\end{array}$ & $\begin{array}{c}\text { Sequence flaking the } \\
\text { SNP }\end{array}$ & Forward primer & Reverse primer & $\begin{array}{l}\text { Melting Temp } \\
\left({ }^{\circ} \mathrm{C}\right)\end{array}$ \\
\hline SNPALT1-Y & 19241709 & $\mathrm{C} / \mathrm{T}$ & $\begin{array}{l}\text { CCAGACTCGTCACC } \\
\text { ACCACGCCTCCTTC } \\
\text { CATCCAAATCGGCT } \\
\text { GCACCTAATGTTGA } \\
\text { TGATACCACGCTGG } \\
\text { CT[C/T]TAACTGTTG } \\
\text { CCCAAGCCCGCCAA } \\
\text { ACCCAATCTAGGCC } \\
\text { CATTGACCCCAGCC } \\
\text { AACAC } \\
\text { GTATATGAATTTTTT }\end{array}$ & & & \\
\hline SNPALT2-K & 19243610 & $\mathrm{G} / \mathrm{T}$ & $\begin{array}{l}\text { TAGTTTTACGATGG } \\
\text { ATCTATT[G/T]TCAC } \\
\text { GTGAAAATTGGTTT } \\
\text { CCAATTGCCTTCGC } \\
\text { CTCACATACCATAT } \\
\text { G }\end{array}$ & & & \\
\hline ATAC11 & $\begin{array}{l}21375818 \text { to } \\
21376080\end{array}$ & ATAC & & GTCGGATTCCTCTATCAACA & TCAAGCAAGCATTTCAATAA & 55 \\
\hline AAT9 & $\begin{array}{l}22207742 \text { to } \\
22208005\end{array}$ & AAT & & TTACTTСАССТСССТGAAAA & CAAGAATTGGGACAACTGAT & 55 \\
\hline TTC8 & $\begin{array}{l}24579024 \text { to } \\
24579224\end{array}$ & TTC & & TACATATCAAGCGCACAGAC & GACAGAGCCGAATAGAGATG & 55 \\
\hline АT21 & $\begin{array}{l}25473601 \text { to } \\
25473785\end{array}$ & AT & & TAAAATTCTGCACCGATGA & GGCTTCATTTTATTTGCTTGT & 55 \\
\hline
\end{tabular}

Positions from http:://www.phytozome.net/clementine 
Table 4.S5. Allelic configuration for the analyzed markers of 93 diploid female gametes within the 'Fortune' $\times$ 'Willowleaf' population

\begin{tabular}{|c|c|}
\hline & CiC6243-03 \\
\hline & aa \\
\hline & aa \\
\hline & aа \\
\hline & $\mathrm{bb}$ \\
\hline & $a b$ \\
\hline & aа \\
\hline & aa \\
\hline & $\mathrm{bb}$ \\
\hline & aa \\
\hline & $\mathrm{bb}$ \\
\hline & $\mathrm{bb}$ \\
\hline & $\mathrm{bb}$ \\
\hline & aa \\
\hline & aa \\
\hline & aa \\
\hline & aa \\
\hline & $\mathrm{bb}$ \\
\hline & $\mathrm{bb}$ \\
\hline & $\mathrm{bb}$ \\
\hline & aa \\
\hline & aa \\
\hline & aa \\
\hline & $\mathrm{bb}$ \\
\hline & aa \\
\hline & aа \\
\hline & $\mathrm{bb}$ \\
\hline & $\mathrm{bb}$ \\
\hline & $\mathrm{bb}$ \\
\hline & $\mathrm{bb}$ \\
\hline & $\mathrm{bb}$ \\
\hline & aa \\
\hline & aa \\
\hline & aа \\
\hline & aa \\
\hline & aa \\
\hline & aа \\
\hline & $\mathrm{bb}$ \\
\hline & $\mathrm{bb}$ \\
\hline & aa \\
\hline & aa \\
\hline & aa \\
\hline & aa \\
\hline & $\mathrm{bb}$ \\
\hline & $\mathrm{bb}$ \\
\hline & $\mathrm{bb}$ \\
\hline & $\mathrm{bb}$ \\
\hline & aa \\
\hline & aa \\
\hline & aа \\
\hline & aa \\
\hline & $\mathrm{bb}$ \\
\hline & aa \\
\hline & aa \\
\hline & $\mathrm{bb}$ \\
\hline & aa \\
\hline & aa \\
\hline & $\mathrm{bb}$ \\
\hline & $\mathrm{bb}$ \\
\hline & $a b$ \\
\hline & $\mathrm{bb}$ \\
\hline & aa \\
\hline & aa \\
\hline & $\mathrm{bb}$ \\
\hline & aa \\
\hline & $a b$ \\
\hline & $\mathrm{bb}$ \\
\hline & $a b$ \\
\hline & aa \\
\hline & $\mathrm{bb}$ \\
\hline & $\mathrm{bb}$ \\
\hline & $a b$ \\
\hline & aa \\
\hline & $\mathrm{bb}$ \\
\hline & $\mathrm{bb}$ \\
\hline & aa \\
\hline & $\mathrm{bb}$ \\
\hline & aa \\
\hline & aa \\
\hline & $a b$ \\
\hline & $\mathrm{bb}$ \\
\hline & aa \\
\hline & aa \\
\hline & $\mathrm{bb}$ \\
\hline & $\mathrm{bb}$ \\
\hline & $\mathrm{bb}$ \\
\hline & aa \\
\hline & $\mathrm{bb}$ \\
\hline & $\mathrm{bb}$ \\
\hline & aa \\
\hline & $\mathrm{bb}$ \\
\hline & $\mathrm{bb}$ \\
\hline & $\mathrm{bb}$ \\
\hline & aa \\
\hline$\% \mathrm{HR}$ & $6.45 \%$ \\
\hline & \\
\hline position & 11.26 \\
\hline
\end{tabular}


Table 4.S6. Annotations between 24.57 Mb (TTC8 marker) and 27.87 Mb (CiC3248-06 marker) in scaffold 3 (www.phytozome.net). (Annotations related to resistance response are indicated in bold letters).

\begin{tabular}{|c|c|c|c|}
\hline $\begin{array}{l}\text { Initial position } \\
\text { (bp) }\end{array}$ & $\begin{array}{c}\text { final } \\
\text { position (bp) } \\
\end{array}$ & Locus name & Annotations \\
\hline 24584262 & 24588809 & Ciclev10023819m.g & Aluminium activated malate transporter family protein \\
\hline 24593002 & 24597811 & Ciclev10023283m.g & disease resistance protein (TIR-NBS-LRR class), putative \\
\hline 24598362 & 24600642 & Ciclev10020543m.g & alpha/beta-Hydrolases superfamily protein \\
\hline 24611867 & 24615456 & Ciclev10024092m.g & disease resistance protein (TIR-NBS-LRR class), putative \\
\hline 24617312 & 24619000 & Ciclev10021706m.g & alpha/beta-Hydrolases superfamily protein \\
\hline 24620623 & 24627357 & Ciclev10020009m.g & Enhancer of polycomb-like transcription factor protein \\
\hline 24629370 & 24637605 & Ciclev10018715m.g & Alkaline-phosphatase-like family protein \\
\hline 24669795 & 24674192 & Ciclev10018914m.g & disease resistance protein (TIR-NBS-LRR class), putative \\
\hline 24674735 & 24676674 & Ciclev10021413m.g & alpha/beta-Hydrolases superfamily protein \\
\hline 24683380 & 24686055 & Ciclev10023561m.g & FAR1-related sequence 5 \\
\hline 24687505 & 24689173 & Ciclev10023487m.g & F-box/RNI-like superfamily protein \\
\hline 24717374 & 24720944 & Ciclev10023733m.g & disease resistance protein (TIR-NBS-LRR class), putative \\
\hline 24722080 & 24724113 & Ciclev10021643m.g & alpha/beta-Hydrolases superfamily protein \\
\hline 24726485 & 24731694 & Ciclev10021199m.g & Enhancer of polycomb-like transcription factor protein \\
\hline 24732324 & 24734809 & Ciclev10023873m.g & Alkaline-phosphatase-like family protein \\
\hline 24741494 & 24743967 & Ciclev10021112m.g & RHOMBOID-like protein 14 \\
\hline 24744597 & 24750079 & Ciclev10019165m.g & $\mathrm{DEA}(\mathrm{D} / \mathrm{H})$-box RNA helicase family protein \\
\hline 24750794 & 24752907 & Ciclev10022561m.g & Ribosomal L18p/L5e family protein \\
\hline 24753302 & 24753667 & Ciclev10023727m.g & Plant self-incompatibility protein $\mathrm{S} 1$ family \\
\hline 24756088 & 24758749 & Ciclev10018885m.g & cation/H+ exchanger 19 \\
\hline 24768060 & 24768577 & Ciclev10023601m.g & NAC domain containing protein 46 \\
\hline 24777286 & 24779149 & Ciclev10024369m.g & Ankyrin repeat family protein \\
\hline 24779630 & 24784345 & Ciclev10018504m.g & NB-ARC domain-containing disease resistance protein \\
\hline 24785318 & 24795064 & Ciclev10019018m.g & MUTL-homologue 1 \\
\hline 24796351 & 24800588 & Ciclev10019689m.g & serine hydroxymethyltransferase 3 \\
\hline 24802124 & 24804993 & Ciclev10022715m.g & Surfeit locus protein 5 subunit 22 of Mediator complex \\
\hline 24806596 & 24809323 & Ciclev10023969m.g & ribosomal protein L24 \\
\hline 24809538 & 24814289 & Ciclev10020286m.g & Transducin/WD40 repeat-like superfamily protein \\
\hline 24815262 & 24816480 & Ciclev10023234m.g & bonsai \\
\hline 24819124 & 24831081 & Ciclev10018511m.g & Transducin/WD40 repeat-like superfamily protein \\
\hline 24831949 & 24837740 & Ciclev10020270m.g & methionine aminopeptidase $2 \mathrm{~B}$ \\
\hline 24837938 & 24840296 & Ciclev10021676m.g & Nucleic acid-binding, OB-fold-like protein \\
\hline 24840386 & 24845254 & Ciclev10019406m.g & methylenetetrahydrofolate reductase 2 \\
\hline 24856909 & 24862275 & Ciclev10024071m.g & histone-lysine $\mathrm{N}$-methyltransferase $\mathrm{ASHH} 3$ \\
\hline 24893551 & 24898675 & Ciclev10019906m.g & Peptidase family C54 protein \\
\hline 24899223 & 24901003 & Ciclev10020147m.g & Galactose oxidase/kelch repeat superfamily protein \\
\hline 24943610 & 24945394 & Ciclev10022372m.g & Ribosomal protein L6 family \\
\hline 24949255 & 24954319 & Ciclev10019784m.g & Seven transmembrane MLO family protein \\
\hline 24958927 & 24963659 & Ciclev10023336m.g & Seven transmembrane MLO family protein \\
\hline 24966135 & 24969178 & Ciclev10024611m.g & NB-ARC domain-containing disease resistance protein \\
\hline 24985138 & 24987298 & Ciclev10023902m.g & LRR and NB-ARC domains-containing disease resistance protein \\
\hline 24991889 & 24992787 & Ciclev10024232m.g & NB-ARC domain-containing disease resistance protein \\
\hline 24993845 & 24995370 & Ciclev10024038m.g & NB-ARC domain-containing disease resistance protein \\
\hline 25026668 & 25030809 & Ciclev10024551m.g & LRR and NB-ARC domains-containing disease resistance protein \\
\hline 25039430 & 25044580 & Ciclev10020313m.g & Seven transmembrane MLO family protein \\
\hline 25044600 & 25051607 & Ciclev10020879m.g & protein serine/threonine kinases;ATP binding;catalytics \\
\hline 25053425 & 25057795 & Ciclev10020158m.g & guanosine nucleotide diphosphate dissociation inhibitor 1 \\
\hline 25067469 & 25072314 & Ciclev10019310m.g & Ankyrin repeat family protein \\
\hline 25074163 & 25076367 & Ciclev10022861m.g & auxin-regulated gene involved in organ size \\
\hline 25085745 & 25086451 & Ciclev10023183m.g & \\
\hline 25087317 & 25089114 & Ciclev10020871m.g & Late embryogenesis abundant protein, group 2 \\
\hline 25100778 & 25104843 & Ciclev10018688m.g & NB-ARC domain-containing disease resistance protein \\
\hline 25158172 & 25162574 & Ciclev10019028m.g & Prolyl oligopeptidase family protein \\
\hline 25169542 & 25170675 & Ciclev10023618m.g & \\
\hline 25204996 & 25205221 & Ciclev10024113m.g & Chaperone DnaJ-domain superfamily protein \\
\hline 25205365 & 25207063 & Ciclev10023518m.g & \\
\hline 25216526 & 25220629 & Ciclev10024119m.g & LRR and NB-ARC domains-containing disease resistance protein \\
\hline
\end{tabular}




\begin{tabular}{|c|c|c|c|}
\hline 25248367 & 25251368 & Ciclev10023445m.g & indole-3-acetate beta-D-glucosyltransferase \\
\hline 25269003 & 25272836 & Ciclev10018531m.g & LRR and NB-ARC domains-containing disease resistance protein \\
\hline 25286483 & 25288105 & Ciclev10019912m.g & UDP-glucosyl transferase 75B2 \\
\hline 25318178 & 25322601 & Ciclev10018594m.g & LRR and NB-ARC domains-containing disease resistance protein \\
\hline 25361089 & 25365339 & Ciclev10018499m.g & LRR and NB-ARC domains-containing disease resistance protein \\
\hline 25398286 & 25402615 & Ciclev10023525m.g & NB-ARC domain-containing disease resistance protein \\
\hline 25426124 & 25427403 & Ciclev10024201m.g & basic helix-loop-helix (bHLH) DNA-binding superfamily protein \\
\hline 25432861 & 25433406 & Ciclev10024286m.g & BED zinc finger ; hAT family dimerization domain \\
\hline 25441988 & 25444731 & Ciclev10019183m.g & RAP \\
\hline 25445568 & 25448031 & Ciclev10023789m.g & ADP-glucose pyrophosphorylase small subunit 2 \\
\hline 25448858 & 25451858 & Ciclev10022149m.g & $\begin{array}{l}\text { 6,7-dimethyl-8-ribityllumazine synthase / DMRL synthase / lumazine synthase / } \\
\text { riboflavin synthase }\end{array}$ \\
\hline 25452062 & 25455844 & Ciclev10020914m.g & Dihydrodipicolinate reductase, bacterial/plant \\
\hline 25458171 & 25463466 & Ciclev10019560m.g & Poly (ADP-ribose) glycohydrolase (PARG) \\
\hline 25463711 & 25465970 & Ciclev10020069m.g & FBD, F-box, Skp2-like and Leucine Rich Repeat domains containing protein \\
\hline 25470795 & 25473216 & Ciclev10020065m.g & F-box/RNI-like/FBD-like domains-containing protein \\
\hline 25474880 & 25476924 & Ciclev10024256m.g & Thioredoxin superfamily protein \\
\hline 25495290 & 25499648 & Ciclev10023260m.g & LRR and NB-ARC domains-containing disease resistance protein \\
\hline 25539228 & 25543442 & Ciclev10018540m.g & LRR and NB-ARC domains-containing disease resistance protein \\
\hline 25546089 & 25546373 & Ciclev10023953m.g & mitochondrial ribosomal protein L11 \\
\hline 25558189 & 25563873 & Ciclev10018510m.g & LRR and NB-ARC domains-containing disease resistance protein \\
\hline 25563004 & 25563956 & Ciclev10024474m.g & \\
\hline 25577398 & 25580479 & Ciclev10023481m.g & NB-ARC domain-containing disease resistance protein \\
\hline 25591667 & 25592171 & Ciclev10022922m.g & \\
\hline 25596184 & 25598211 & Ciclev10019166m.g & \\
\hline 25598722 & 25601734 & Ciclev10020079m.g & F-box family protein \\
\hline 25605171 & 25606024 & Ciclev10023014m.g & F-box/RNI-like superfamily protein \\
\hline 25612741 & 25615635 & Ciclev10023374m.g & uridine-ribohydrolase 2 \\
\hline 25625682 & 25630835 & Ciclev10019447m.g & inositol 1,3,4-trisphosphate 5/6-kinase 4 \\
\hline 25633452 & 25636420 & Ciclev10018897m.g & Disease resistance protein (CC-NBS-LRR class) family \\
\hline 25639011 & 25644826 & Ciclev10019649m.g & RNA-binding protein \\
\hline 25645230 & 25649184 & Ciclev10021021m.g & chloroplast outer envelope protein 37 \\
\hline 25649848 & 25653317 & Ciclev10024361m.g & S-adenosyl-L-methionine-dependent methyltransferases superfamily protein \\
\hline 25657664 & 25663490 & Ciclev10024293m.g & Endonuclease/exonuclease/phosphatase family protein \\
\hline 25663967 & 25668616 & Ciclev10019293m.g & Ankyrin repeat family protein \\
\hline 25702085 & 25702716 & Ciclev10023674m.g & \\
\hline 25740008 & 25740471 & Ciclev10023198m.g & Pectin lyase-like superfamily protein \\
\hline 25756520 & 25759773 & Ciclev10018637m.g & Leucine-rich repeat receptor-like protein kinase family protein \\
\hline 25784246 & 25784449 & Ciclev10023998m.g & \\
\hline 25838882 & 25842061 & Ciclev10023511m.g & Leucine-rich repeat receptor-like protein kinase family protein \\
\hline 25844828 & 25845232 & Ciclev10024127m.g & Plant self-incompatibility protein S1 family \\
\hline 25920662 & 25925208 & Ciclev10023567m.g & Leucine-rich repeat receptor-like protein kinase family protein \\
\hline 25929095 & 25929878 & Ciclev10024445m.g & Leucine-rich repeat receptor-like protein kinase family protein \\
\hline 26006287 & 26009481 & Ciclev10024013m.g & Leucine-rich repeat receptor-like protein kinase family protein \\
\hline 26027989 & 26031836 & Ciclev10024332m.g & Leucine-rich repeat receptor-like protein kinase family protein \\
\hline 26054584 & 26055280 & Ciclev10023832m.g & Leucine-rich repeat receptor-like protein kinase family protein \\
\hline 26061449 & 26062187 & Ciclev10023220m.g & gamma-glutamyl hydrolase 1 \\
\hline 26288659 & 26290508 & Ciclev10021937m.g & response regulator 9 \\
\hline 26297949 & 26304739 & Ciclev10021153m.g & Plant protein 1589 of unknown function \\
\hline 26303573 & 26304130 & Ciclev10023069m.g & \\
\hline 26308767 & 26309588 & Ciclev10023742m.g & FAR1-related sequence 5 \\
\hline 26439998 & 26440627 & Ciclev10024302m.g & FAR1-related sequence 5 \\
\hline 26480614 & 26486649 & Ciclev10020055m.g & cystathionine beta-lyase \\
\hline 26487045 & 26487269 & Ciclev10023935m.g & Ribosomal protein L39 family protein \\
\hline 26517176 & 26525778 & Ciclev10019027m.g & Trimeric LpxA-like enzyme \\
\hline 26526425 & 26531920 & Ciclev10021922m.g & tubulin folding cofactor B \\
\hline 26552200 & 26563660 & Ciclev10018515m.g & binding \\
\hline 26585748 & 26586352 & Ciclev10023130m.g & \\
\hline 26591205 & 26592308 & Ciclev10024114m.g & Glutaredoxin family protein \\
\hline 26603126 & 26608232 & Ciclev10021999m.g & Eukaryotic rpb5 RNA polymerase subunit family protein \\
\hline 26610747 & 26615954 & Ciclev10021431m.g & \\
\hline 26618336 & 26621274 & Ciclev10022600m.g & Tetratricopeptide repeat (TPR)-like superfamily protein \\
\hline
\end{tabular}




\begin{tabular}{|c|c|c|c|}
\hline 26660974 & 26662413 & Ciclev10021720m.g & S-adenosyl-L-methionine-dependent methyltransferases superfamily protein \\
\hline 26666978 & 26668075 & Ciclev10024496m.g & S-adenosyl-L-methionine-dependent methyltransferases superfamily protein \\
\hline 26671216 & 26672059 & Ciclev10024436m.g & S-adenosyl-L-methionine-dependent methyltransferases superfamily protein \\
\hline 26724892 & 26726825 & Ciclev10023900m.g & S-adenosyl-L-methionine-dependent methyltransferases superfamily protein \\
\hline 26747398 & 26748527 & Ciclev10023903m.g & TTF-type zinc finger protein with HAT dimerization domain \\
\hline 26847877 & 26850055 & Ciclev10021728m.g & S-adenosyl-L-methionine-dependent methyltransferases superfamily protein \\
\hline 26886018 & 26886467 & Ciclev10023695m.g & \\
\hline 26976583 & 26978658 & Ciclev10021734m.g & S-adenosyl-L-methionine-dependent methyltransferases superfamily protein \\
\hline 27092414 & 27093612 & Ciclev10024663m.g & Zinc-binding dehydrogenase family protein \\
\hline 27120138 & 27122618 & Ciclev10024396m.g & S-locus lectin protein kinase family protein \\
\hline 27132311 & 27137357 & Ciclev10023678m.g & cysteine-rich RLK (RECEPTOR-like protein kinase) 8 \\
\hline 27160750 & 27163015 & Ciclev10024040m.g & $\mathrm{Na}+/ \mathrm{H}+$ antiporter 6 \\
\hline 27174902 & 27177223 & Ciclev10023619m.g & MuDR family transposase \\
\hline 27179651 & 27180616 & Ciclev10024633m.g & \\
\hline 27182222 & 27186798 & Ciclev10018865m.g & Prolyl oligopeptidase family protein \\
\hline 27202252 & 27203036 & Ciclev10023045m.g & hemoglobin 1 \\
\hline 27203532 & 27205968 & Ciclev10024617m.g & Zinc-binding dehydrogenase family protein \\
\hline 27206738 & 27207496 & Ciclev10023412m.g & Zinc-binding dehydrogenase family protein \\
\hline 27210508 & 27212925 & Ciclev10023669m.g & NB-ARC domain-containing disease resistance protein \\
\hline 27218280 & 27219176 & Ciclev10023093m.g & \\
\hline 27222437 & 27223126 & Ciclev10022330m.g & Ribosomal protein L2 family \\
\hline 27236430 & 27242516 & Ciclev10018492m.g & LRR and NB-ARC domains-containing disease resistance protein \\
\hline 27243916 & 27244600 & Ciclev10023862m.g & \\
\hline 27252187 & 27258492 & Ciclev10023613m.g & LRR and NB-ARC domains-containing disease resistance protein \\
\hline 27267893 & 27272240 & Ciclev10018507m.g & LRR and NB-ARC domains-containing disease resistance protein \\
\hline 27274447 & 27274841 & Ciclev10023703m.g & Ribosomal protein L2 family \\
\hline 27288919 & 27290352 & Ciclev10023361m.g & Zinc-binding dehydrogenase family protein \\
\hline 27291189 & 27295420 & Ciclev10024454m.g & NB-ARC domain-containing disease resistance protein \\
\hline 27320758 & 27322899 & Ciclev10024530m.g & NB-ARC domain-containing disease resistance protein \\
\hline 27338257 & 27339658 & Ciclev10023645m.g & Ribosomal protein L2 family \\
\hline 27365802 & 27371376 & Ciclev10018509m.g & LRR and NB-ARC domains-containing disease resistance protein \\
\hline 27373577 & 27374040 & Ciclev10024425m.g & Ribosomal protein L2 family \\
\hline 27378259 & 27383779 & Ciclev10019887m.g & Integrin-linked protein kinase family \\
\hline 27385466 & 27391796 & Ciclev10018983m.g & LETM1-like protein \\
\hline 27392621 & 27394211 & Ciclev10020021m.g & HXXXD-type acyl-transferase family protein \\
\hline 27395608 & 27398058 & Ciclev10020092m.g & UDP-glucosyltransferase 74F2 \\
\hline 27411566 & 27413326 & Ciclev10023826m.g & UDP-glucosyltransferase 74F2 \\
\hline 27420861 & 27421928 & Ciclev10024366m.g & Protein kinase family protein with leucine-rich repeat domain \\
\hline 27453996 & 27456865 & Ciclev10023662m.g & Leucine-rich repeat receptor-like protein kinase family protein \\
\hline 27512875 & 27514002 & Ciclev10024240m.g & Leucine-rich repeat receptor-like protein kinase family protein \\
\hline 27522643 & 27525763 & Ciclev10023288m.g & Leucine-rich repeat receptor-like protein kinase family protein \\
\hline 27550207 & 27553496 & Ciclev10024387m.g & Leucine-rich repeat receptor-like protein kinase family protein \\
\hline 27579560 & 27591874 & Ciclev10024208m.g & Leucine-rich repeat receptor-like protein kinase family protein \\
\hline 27610925 & 27611502 & Ciclev10023474m.g & Leucine-rich repeat receptor-like protein kinase family protein \\
\hline 27624874 & 27626398 & Ciclev10021536m.g & Protein kinase family protein with leucine-rich repeat domain \\
\hline 27682550 & 27684073 & Ciclev10024553m.g & Protein kinase family protein with leucine-rich repeat domain \\
\hline 27717305 & 27722483 & Ciclev10023899m.g & Protein kinase family protein with leucine-rich repeat domain \\
\hline 27737586 & 27740735 & Ciclev10018816m.g & Leucine-rich repeat receptor-like protein kinase family protein \\
\hline 27750059 & 27750755 & Ciclev10022950m.g & Ribosomal protein S5/Elongation factor G/III/V family protein \\
\hline 27780847 & 27783988 & Ciclev10018798m.g & Leucine-rich repeat receptor-like protein kinase family protein \\
\hline 27792547 & 27797748 & Ciclev10020409m.g & BTB and TAZ domain protein 3 \\
\hline 27798973 & 27801782 & Ciclev10023071m.g & Small nuclear ribonucleoprotein family protein \\
\hline 27802944 & 27807050 & Ciclev10019655m.g & Thioesterase/thiol ester dehydrase-isomerase superfamily protein \\
\hline 27807172 & 27813248 & Ciclev10018774m.g & formin homology 1 \\
\hline 27827995 & 27830405 & Ciclev10019217m.g & Leucine-rich repeat receptor-like protein kinase family protein \\
\hline 27852621 & 27853757 & Ciclev10023555m.g & Eukaryotic release factor 1 (eRF1) family protein \\
\hline 27856160 & 27856424 & Ciclev10024351m.g & \\
\hline 27857215 & 27861301 & Ciclev10018573m.g & Disease resistance protein (TIR-NBS-LRR class) family \\
\hline 27867691 & 27874119 & Ciclev10018528m.g & Disease resistance protein (TIR-NBS-LRR class), putative \\
\hline
\end{tabular}




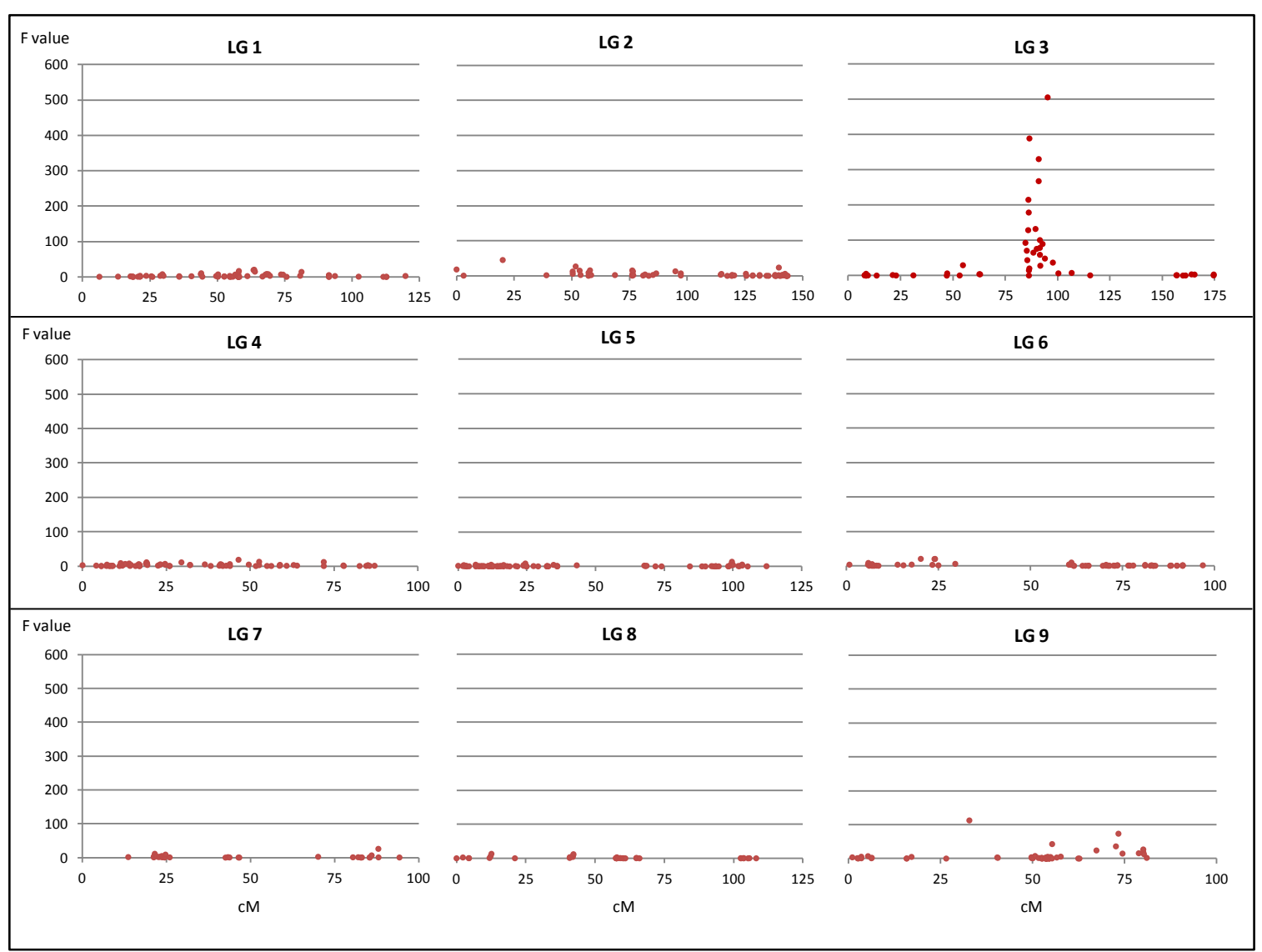

Figure 4.S1. Values of $F$ parameter from ANOVA along the nine linkage groups of the clementine's genetic map (Ollitrault et al., 2012a) 
General discussion 



\section{Background}

Polyploidy is a major component of angiosperms evolution (Grant, 1981; Soltis and Soltis, 1993; Wendel and Doyle, 2005) and sexual polyploidization is considered as the major mechanism leading to polyploidy (Harlan and DeWet, 1975; Bretagnolle and Thompson, 1995; Ramsey and Schemske, 1998). In sexual polyploidization, polyploids are generated by the formation of diploid $(2 n)$ gametes, i.e., pollen or eggs having the somatic chromosome number rather than the gametophytic number (Harlan and DeWet, 1975; Bretagnolle and Thompson, 1995; Ramsey and Schemske, 1998; Otto and Whitton, 2000), mainly resulting from a restitution of the meiotic cell cycle. This phenomenon is referred to as meiotic restitution and it is the predominant mechanism of unreduced gamete formation in plants (Harlan and DeWet, 1975; Bretagnolle and Thompson, 1995; Otto and Whitton, 2000; Soltis and Soltis, 2009). The types of unreduced gametes produced result essentially from one of two basic processes depending on the mode of meiotic restitution (Bretagnolle and Thompson, 1995; Tavoletti et al., 1996), i.e., first-division restitution (FDR) and second-division restitution (SDR), which occur, respectively, during abnormal development of the first and second meiotic division.

A FDR- $2 n$ gamete contains non-sister chromatids, while a SDR- $2 n$ gamete contains two sister chromatids (Bretagnolle and Thompson, 1995; Tavoletti et al., 1996; Cai and Xu, 2007). Under FDR, non-sister chromatids retain the parental heterozygosity from the centromere to the first crossover point, and hence, the gametes transfer a large part of this parental heterozygosity and epistatic interactions to the progenies. Under SDR, the two sister chromatids are homozygous between the centromere and the first crossover point, and the resultant gametes have reduced levels of heterozygosity compared with FDR ones (Bretagnolle and Thompson, 1995). Therefore, the genetic constitution of unreduced gametes depends on the mechanism of their formation: a tighter distribution is expected in FDR-derived populations than in SDR ones because a higher percentage of the parental genome is transferred intact, resulting in a more uniform gamete production (Douches and Maas, 1998). In this context, insights in the mechanism underlying meiotic nuclear restitution producing unreduced gametes are crucial to optimize breeding strategies based on sexual hybridization (Errico et al., 2005).

Sexual polyploidization is currently a central approach in citrus triploid breeding programs, aiming to develop new seedless mandarin cultivars (Ollitrault et al., 2008). Citrus triploid hybrids can be recovered mainly from sexual hybridizations of $2 x \times 2 x$ [through unreduced gametes; (Aleza et al., 2010b)], $2 x \times 4 x$ (Aleza et al., 2012c) and $4 x \times 2 x$ (Cameron and Bernett, 1978; Esen et al., 1978; Aleza et al., 2012d).

Esen et al. (1979) proposed that unreduced gametes in citrus result from the abortion of the second meiotic division (SDR) in the megaspore. This hypothesis has been corroborated by molecular marker analysis for clementines (Citrus clementina) (Luro et al., 2004; Aleza et al., $2012 b$ ). However, Chen et al. (2008a) proposed that $2 n$ eggs of sweet orange (C. sinensis) resulted from first meiotic division restitution (FDR). 
Molecular marker analysis has proved as a very useful tool to estimate the heterozygosity transmission through the diploid gametes to polyploid progenies and, therefore, to identify the mechanism underlying unreduced gamete formation. This strategy was previously successfully applied for several crops (Barone et al., 1995; Vorsa and Rowland, 1997; Bastiaanssen et al., 1998; Barcaccia et al., 2003; Luro et al., 2004; Chen et al., 2008a; Hayashi et al., 2009). However, the estimation of molecular marker allele copy number has long been considered as a challenge for polyploid species with polysomic inheritance. Assignment of allelic configurations for different types of heterozygous polyploids is essential for accurate genetic studies, such as segregation analyses and marker-trait association. Moreover, single nucleotide polymorphisms (SNPs) have emerged as the most widely used genotyping markers due to their abundance in the genome and increasing available data from sequencing projects. In addition, newly developed genetic maps have utilized information on SNP marker segregations. In this context, new methods to assign SNP allele configuration in polyploids should be considered.

On the other hand, trait segregations in triploid populations are still not well understood, due to the complexity of polyploid genomes and eventually non-Mendelian segregations. In the case of citrus, very few characters have been studied on the basis of triploid genomes, and genetics underlying their segregations have not been characterized in any case.

In this thesis, we have (i) developed a new method for genotyping heterozygous polyploid plants with SNP markers, (ii) proposed two methods for the identification of the origin of $2 n$ gametes from genetic markers segregation data and (iii) applied them to study the origin of $2 n$ ovules in mandarin germplasm. Finally, (iv) we analyzed the inheritance of resistance to the fungus causing Alternaria brown spot as a case of single trait segregation on triploid populations. We have taken advantage of the acquired knowledge on $2 n$ gamete origin to locate a genome region controlling the resistance trait by half tetrad analysis, and to identify candidate genes. From these data, we have developed SSR and SNP markers for MAS.

\section{Competitive Allele-Specific PCR is an efficient method to assign SNP allelic configuration in heterozygous polyploid genotypes}

When analysing microsatellite markers (SSRs), the microsatellite allele counting - peak ratios method [MAC-PR; (Esselink et al., 2004)] is especially useful in assignment of allelic configurations in polyploids. However, SSR analysis remains relatively costly and time consuming compared with SNP genotyping methods. In this sense, several SNP genotyping methods have been developed (Ronaghi et al., 1998; Sapolsky et al., 1999; Ahmadian et al., 2000; Fan et al., 2003; Kwok and Xiao, 2003; Lavebratt et al., 2004; Ishikawa et al., 2005; Tabone et al., 2009). The KBiosciences Competitive Allele-Specific PCR SNP genotyping system [KASPar; (Cuppen, 2007)] is a simple and cost-effective system compared with other 
SNP genotyping assays and is well adapted to low- to medium- throughput genotyping projects (Chen et al., 2010). In this thesis, we have demonstrated that the relative allele signal of KASPar technique was highly correlated with relative allele doses and this method, combined with analysis of the allele signal data, has been useful for genotyping citrus triploid and tetraploid progenies (Cuenca et al., 2013a). Moreover, it could also be used in the semiquantitative analysis of relative allele-specific expression. KASPar technique is much more adapted for small- to medium- scale studies than the SNP genotyping methods previously used in polyploidy species (Bérard et al., 2009; Trick et al., 2009; Oliver et al., 2011; Trebbi et al., 2011; Voorrips et al., 2011; Byers et al., 2012; Han et al., 2012). Indeed, these methods are more suitable for high-throughput genotyping than for performing small-scale analysis, and lack flexibility in terms of the numbers and panels of SNP loci that can be analyzed, while it is possible to design targeted KASPar assay for each specific study. Moreover, several of the previously used methods (Bérard et al., 2009; Voorrips et al., 2011) base the assignment of allele doses in polyploidy plants on statistical approach, assuming Hardy-Weinberg equilibrium, which is often not respected, particularly when working with progenies arising from $2 n$ gametes. In our work, we have demonstrated that Competitive Allele-Specific PCR is an effective and versatile method to infer SNP allelic configurations in polyploid plants and developed KASPar markers that are currently routinely used for triploid and tetraploid genotyping in the IVIA citrus breeding program.

Two new alternative approaches to identify the mechanism leading to unreduced gamete formation based on molecular marker (HR restitution) analysis have been developed

Identifying the restitution mechanism using molecular markers can be achieved by several approaches. Half-tetrad analysis (HTA) developed by Mendiburu and Peloquin (1979) is a powerful method for mapping centromeres, or for determining the mode(s) of $2 n$ gamete formation. Tavoletti et al. (1996) developed a multilocus maximum likelihood method of HTA that allows the estimation of both the relative frequencies of FDR and SDR $2 n$ gametes and the centromere location within a linkage group without relying on previously identified centromeric markers. However, all these models assume complete chiasma interference.

In this study, two alternative approaches have been proposed to check FDR/SDR hypothesis and, eventually, map the centromeres within linkage groups. For these two methods, molecular markers are selected to be heterozygous in the $2 n$ gamete producer parent and to be polymorphic between the two parents. With this marker configuration, it is possible to infer the $2 n$ gamete genotypes from the triploid progeny ones. The first developed approach is based on functions of parental heterozygosity restitution in the $2 n$ gamete $(H R)$, along a chromosome in relation with locus-centromere distance (d) (Zhao and Speed, 1998a). Indeed, under FDR or SDR, HR is a direct function of the crossing over frequency between the considered locus and the centromere. It is therefore possible to implement functions $(H R=f(d))$ according to the FDR 
and SDR hypothesis taking into account different models of chromosome interference (no interference, partial interference or complete chiasma interference). This strategy has been successfully applied during this thesis in 'Fortune' mandarin. The second alternative proposed to check FDR/SDR hypothesis is a maximum likelihood approach, based on the HR of independent markers closely linked to centromere of different chromosomes. Taking advantage of the centromere location (Aleza et al., 2012b) within all nine linkage groups of the current clementine's reference genetic map (Ollitrault et al., 2012a), centromeric markers were selected to analyze the predominant mechanisms for 16 mandarin genotypes used as female parents and to check potential variability of origin between $2 n$ gametes of a same parent.

The first newly developed method allows the identification of the unreduced gamete formation mechanism without any previous knowledge about centromere location, but it is necessary to analyze numerous markers with good dispersion in the chromosomes in large populations. In this method, the information on the mechanism is obtained at population level. Compared with previously published approaches of HTA (Mendiburu and Peloquin, 1979; Werner et al., 1992; Johnson et al., 1995; Tavoletti et al., 1996; Park et al., 2007) this new approach has the advantage to allow testing for no interference or partial interference models, but needs a set of previously mapped markers; on the other hand, HTA models assume total interference, but they could be applied without any previous information on marker order. In addition, this new method allows the identification of the restitution model and the estimation of the centromere location at the same time. During this thesis, it has been used to locate the centromere on chromosome II of 'Fortune' mandarin (Cuenca et al., 2011) and recently to map the centromeres on all 9 clementine chromosomes (Aleza et al., 2012b).

The second developed approach requires a previous location of centromeres, but is much more efficient than all previous methods. Indeed, it need a limited number of centromeric markers and has the advantage that allows deducing the restitution mechanism both at individual and population level, while the first developed one is only applicable at population level, requiring larger number of genotyping points (numerous markers and individuals) to give robust conclusions.

\section{SDR is the preeminent mechanism leading to unreduced ovule formation in mandarins}

In this thesis, the restitution mechanism leading to unreduced gamete formation has been uncovered for 16 mandarin genotypes by molecular marker analysis. Firstly, all the analyzed triploid hybrids in the progenies of $2 x \times 2 x$ crosses were found to arise from unreduced megaspores. This result is in agreement with the cytogenetic observations of Esen and Soost (1971), and with previous molecular observations (Luro et al., 2004; Chen et al., 2008a; Ferrante et al., 2010). To date, very few cases of citrus triploid hybrids occurrence in $2 x$ $\times 2 x$ crosses from unreduced pollen has been reported (Luro et al., 2004; Chen et al., 2008a). 
The first approach described above allowed concluding that SDR, rather than FDR, was much more likely to be the mechanism underlying unreduced gamete formation in 'Fortune' mandarin and evidenced positive chiasma interference. Using the second approach, SDR has been identified as the preeminent restitution mechanism leading to unreduced gamete formation in all mandarin genotypes analyzed. Indeed among 497 triploid hybrids arising from 16 female genotypes studied, significant conclusions for SDR were obtained for $85.3 \%$, but only $0.6 \%$ for FDR. The un-conclusive results for $14.1 \%$ of the analyzed triploids can be explained by insufficient number of markers analyzed in some families and/or the higher distance of some of these markers to the centromere.

This global conclusion for SDR restitution mechanism is in agreement with that proposed by Luro et al. (2004), who observed low heterozygosity restitution in clementine $2 n$ megagametophyte. The conclusion of FDR given for sweet orange (Chen et al., 2008a) is questionable because of the low number of analyzed markers without knowledge of their distance to centromere. Indeed, the unambiguous identification of FDR without previous location of the centromere must be based on a large set of markers with good genome coverage. In the same way, the results of Ferrante et al. (2010), based on a very low number of individuals and markers for each parental genotype are not sufficient to prove the authors's conclusions of SDR for 'Fortune' and 'Wilking' mandarin and FDR for lemon.

\section{Triploid recovery strategy and restitution mechanism leading to unreduced gamete formation directly affect single character segregations in triploid progenies. The case of Alternaria brown spot resistance}

The main factor affecting trait inheritance in triploid progenies is the strategy of triploid breeding (Ollitrault et al., 2008) with strong differences between the sexual polyploidization approach $(2 x \times 2 x$ crosses with unreduced gamete formation) and interploid crosses $(2 x \times 4 x$ or $4 x \times 2 x)$. Indeed, it affects the transmission of the parental heterozygosity to the diploid gamete.

In sexual polyploidization, two factors affect the transmission of the parental heterozygosity to the offspring: the mechanism of the $2 n$ gamete formation (FDR or SDR), and the genetic distance from the considered locus to the chromosome centromere (Douches and Quiros, 1988). In $2 x \times 2 x$ citrus crosses, most studies have demonstrated that triploid progeny arose from diploid megagametophyte (Esen and Soost, 1971, 1973). In this thesis, we have demonstrated that $2 n$ megagametophyte resulted from SDR in the mandarin group, as previously proposed by Luro et al. (2004) for clementines. For interploid crosses, most of the tetraploid parents used in citrus breeding arise from chromosome doubling in nucellar cells of apomictic diploid parents (Aleza et al., 2011). Therefore, doubled diploid mandarins should be considered as autotetraploids and tetrasomic inheritance should be expected (Kamiri et al., 2011). In such situation, the frequency of diploid gametes that receive a locus in heterozygosis 
from the tetraploid parent varies between 0.55 and 0.66 depending on the double reduction frequency (Marsden et al., 1987).

Segregations for the single inherited character Alternaria brown spot (ABS) resistance have been analyzed in this study for several triploid recovery strategies and parental combinations. $A B S$ is a major fungal disease in some mandarin cultivars that causes a substantial loss of production and fruit quality worldwide (Akimitsu et al., 2003; Timmer et al., 2003). As a consequence, the production of susceptible cultivars, such as 'Fortune' or 'Nova', among others, has declined significantly during recent years and many trees of the most susceptible varieties have been removed and replaced by resistant cultivars, which may lack some of the interesting agronomic traits of these susceptible cultivars (Navarro et al., 2005). In addition, many of actual triploid breeding programs (Mourao Fo et al., 1996; McCollum, 2007; Aleza et al., 2010a, 2010b; Cuenca et al., 2010; Grosser et al., 2010; Aleza et al., 2012c, 2012d; Froelicher et al., 2012; Navarro et al., 2012) use ABS susceptible cultivars as parents, due to their interest for other important traits (fruit quality, maturing period, production) and particular reproductive biology (monoembryony, high rate of unreduced $2 n$ gamete formation). Therefore, ABS resistance must be considered as a major selection criterion in the mandarin breeding programs and early efficient selection of ABS resistant hybrids is of central importance.

In this thesis, the monolocus dominant inheritance of the susceptibility, proposed from diploid population studies (Dalkilic et al., 2005; Gulsen et al., 2010), was corroborated in triploid progenies by studying the segregations in several parent combinations and triploid recovery strategies. Moreover, a genome region including the ABS resistance ( $A B S r$ locus) was identified by genetic studies based in linkage disequilibrium.

The first information regarding the location of the $A B S r$ locus was given directly by the analysis of the segregation between susceptible and resistant triploid hybrids in progeny obtained by sexual polyploidization ( $2 n$ gametes), assuming monolocus recessive determination of the resistance. Indeed, for $2 n$ gametes, there is a direct linkage between parental HR (and therefore, the proportion of resistant and susceptible hybrids) and the genetic distance to the centromere. At this step, $A B S r$ locus was identified to be relatively close $(10.5 \mathrm{cM})$ to one centromere.

The $A B S r$ locus was then located performing Bulk Segregant Analysis (BSA) coupled with genome-scan using SNP markers mapped in the clementine's reference genetic map (Ollitrault et al., 2012a). This approach allowed localization of the ABS resistance locus within a $13.1 \mathrm{cM}$ area on chromosome III of the genetic map of clementine, corresponding to $15 \mathrm{Mb}$ of scaffold 3 of the current clementine whole genome assembly (www.phytozome.net). This genomic region was further examined for additional SSR and SNP markers, which were used for de novo mapping of the area by HTA of $2 n$ gamete inferred from triploid hybrid genotypes. Results allowed identifying two flanking markers, located at 3.77 and $1.71 \mathrm{cM}$ of the candidate 
$A B S$ resistance gene, and another one that appeared to be tightly linked to the $A B S r$ locus. This marker frame is much more closely linked than previous markers identified from diploid segregating progenies by Dalkilic et al. (2005) (15.3 and $36.7 \mathrm{cM}$ ) and Gulsen et al. (2010) (3 and $13 \mathrm{cM}$ ). A $3.3 \mathrm{Mb}$ is now delimited and it has been found that a large number of resistance genes, organized in several clusters, which have been annotated.

The closest markers are being currently used for molecular marker-assisted selection in our triploid breeding program. However, it would be necessary to analyze many more hybrids to accurately estimate their linkage with the $A B S r$ locus and to perform fine mapping with additional markers mined in the corresponding genomic sequence.

Due to the centromeric position of this gene and the recessivity of the resistant trait, the $2 x \times 2 x$ breeding strategy appears much more efficient to obtain resistant hybrids than the interploid strategy when susceptible heterozygous parents need to be used as diploid gamete producer. Indeed, with the $2 x \times 2 x$, about $40 \%$ of resistant genotypes are obtained, whereas this percentage varies between $16.7 \%$ and $22.5 \%$ with the interploid strategy.

\section{Global implication of the diploid gamete origin on triploid breeding strategy}

Cultivar breeding implies selection on multiple traits, many of them having a complex genetic determinism. If restrictive traits such as ABS susceptibility can orient a strategy when heterozygous susceptible parent is used, the choice of the breeding scheme should be globally more conducted by the targeted kind of innovation. Assuming an SDR origin of $2 n$ gametes in mandarins, sexual polyploidization may lead to lower average of heterozygosity restitution than interploid hybridization, whatever the segregation model considered for the doubled diploid (Marsden et al., 1987). As heterozygosity and epistatic interactions are maintained for a great number of individuals in the progeny from interploid crosses with doubled-diploid, this triploid breeding strategy should be more efficient than $2 x \times 2 x$ hybridization for developing new cultivars that are phenotypically close to the genitor giving the diploid gamete. Conversely, $2 x \times$ $2 x$ hybridization should produce more polymorphic progenies, by creating larger number of new multilocus allelic combinations (David et al., 1995), providing the opportunity to select innovative products within the perspective of market segmentation as a commercial strategy. 


\section{Perspectives}

An alternative way for SNP genotyping in polyploids, based in Competitive AlleleSpecific PCR, has been proposed and successfully applied in triploid populations. This approach is very powerful and particularly adapted for studies needing a limited number of markers (a few hundred). However, for pangenomic studies (particularly, in progeny of two highly heterozygous parents as in Citrus), methods based on next-generation sequencing such as Genotyping-by-sequencing (GBS) should be much more adapted. With enough sequencing coverage, these method should be applied efficiently to estimate allele doses in polyploid plants in a pangenomic way and should be the preeminent approach for marker-trait association studies both in diploid and polyploid citrus.

The mechanism of unreduced megagametophyte formation has been elucidated for several monoembryonic mandarin genotypes. Further studies on polyembryonic mandarin genotypes and other ancestral and secondary species, such as citron, pummelo, grapefruit, sweet orange, lemon or lime could determine whether the same mechanism or any other is involved in the unreduced female gamete formation in citrus germplasm. The use of $2 n$ pollen, revealed at low frequency by a few works should also be explored to produce triploid progeny in $2 x \times 2 x$ crosses. Moreover, further knowledge on environment influence as well as molecular insights on unreduced gamete formation in citrus would aid in altering frequencies of unreduced gamete formation.

Segregations for the single inherited character Alternaria brown spot (ABS) resistance have been analyzed in this study for several triploid recovery strategies and parental combinations. In addition, molecular markers have been developed for marker-assisted selection. With the genomic region linked to ABS resistance indentified, further sequence analyses would allow selecting markers closer to the ABS resistance gene for selection within many parental combinations. Several candidate genes have been identified within this region; therefore, fine mapping based on large progeny genotyped with additional markers and functional analyses of the genes remaining between newly identified flanking markers would permit identifying the gene(s) controlling ABS resistance in citrus. In the same way, inheritance in other agronomic traits should be studied, even those with complex determinism. 
Conclusions 



\section{A new method for genotyping heterozygous polyploids using SNP markers by competitive-allele specific PCR (KASPar) has been developed}

KASPar technique combined with analysis of the allele signal data is an alternative method to infer SNP allelic configurations in polyploid plants that offers a wider spectrum of genotyping possibilities. Moreover, quantitative analyses for correlation of the allele signals and the allele doses and sample clustering carried out in this work were powerful techniques for assigning allelic configurations. Therefore, it could also be used in the quantitative analysis of allele-specific expression.

Two alternative approaches identify SDR as the mechanism leading to unreduced gamete formation in mandarins, based on molecular marker heterozygosity restitution analysis

The first approach is based on functions of heterozygosity restitution along a chromosome in relation with locus-centromere distance. This strategy has been successfully applied in this study for 'Fortune' mandarin and allowed mapping the centromere on chromosome II of the current clementine's genetic map. This strategy was used to conclude that SDR, rather than FDR, is much more likely to be the mechanism underlying unreduced gamete formation in 'Fortune' mandarin and evidenced positive chiasma interference. This same strategy has been later applied by Aleza et al. (2012b) to map centromeres on all nine citrus chromosomes.

The second approach proposed to check FDR/SDR hypothesis is a maximum likelihood approach, based in the heterozygosity restitution of independent markers closely linked to centromere of different chromosomes. This method has the advantage that allows deducing the restitution mechanism at population level or even at individual level. Using this second approach, SDR has been identified as the restitution mechanism leading to unreduced gamete formation in a wide range of mandarin genotypes used as female parents in triploid breeding programs.

The monolocus inheritance and recessivity of the Alternaria brown spot (ABS) resistance was confirmed in triploid progeny and the ABSr locus was mapped in the chromosome III genetically close to the centromere

The monolocus inheritance of the resistance to ABS, proposed on the basis of diploid segregation studies was corroborated in triploid progeny by studying the segregations in several parent combinations and triploid recovery strategy. Taking advantage of the particular genetic structures of $2 n$ gametes resulting from second division restitution (SDR), segregation analysis allowed mapping the $A B S r$ locus genetically at $10.5 \mathrm{cM}$ close to a centromere at a first step. 
Bulk segregant analysis coupled with genome-scan using SNP markers mapped in the reference genetic map allowed locating the ABS resistance locus within a $13.1 \mathrm{cM}$ area on chromosome III, corresponding to $15 \mathrm{Mb}$ of the scaffold 3 in the current whole genome assembly.

Molecular markers flanking the $A B S r$ locus were selected for use in marker-assisted selection (MAS)

Two flanking markers at 3.77 and $1.71 \mathrm{cM}$ of the $A B S r$ locus, as well as a third marker that did not exhibit any recombination are currently being used in marker-assisted selection in the IVIA mandarin breeding program. These markers should be used together for efficient early MAS for different parental combinations when the markers are heterozygous in the susceptible parent and polymorphic between the two parents. We are currently sequencing DNA fragments between these two markers to identify SNP loci that provide a useful allelic combination for a wider range of crosses of our mandarin breeding program.

Gene ontology reveals clusters of resistance genes in the $A B S r$ locus: a first step towards identification of ABS resistance gene

The $A B S r$ locus is included in a genomic region very rich in disease resistance homologous genes, organized in clusters. A probable function for the gene of interest is to encode a protein involved in ACT-toxin recognition, which would allow the toxin to cause cell death. With the genomic region containing $A B S r$ locus mapped, the identification of the gene for $A B S$ resistance will involve fine mapping with large diploid populations. For this purpose, SNP markers are currently being developed from each candidate gene. From the reduced set of candidate genes that would result from this fine genetic mapping, functional validation could be performed by genetic transformation or viral vector-induced gene silencing. 


\section{Annex}

Other scientific publications and congress communications developed during the thesis 

Aleza P, Cuenca J, Juárez J, Pina JA, Navarro L. 2010. 'Garbi' mandarin: a new late-maturing triploid hybrid. HortScience 45(1): 139-141.

Aleza P, Juárez J, Cuenca J, Ollitrault P, Navarro L. 2010. Recovery of citrus triploid hybrids by embryo rescue and flow cytometry from $2 \times x 2 x$ sexual hybridisation and its application to extensive breeding programs. Plant Cell Reports 29(9): 1023-1034.

Aleza P, Juárez J, Cuenca J, Ollitrault $\mathbf{P}$, Navarro L. 2012. Extensive citrus triploid hybrid production by $2 \mathrm{x} \times 4 \mathrm{x}$ sexual hybridizations and parent-effect on the length of the juvenile phase. Plant Cell Reports 31(9): 1723-1735.

Cuenca J, Aleza P, Juárez J, Pina JA, Navarro L. 2010. 'Safor' mandarin: a new citrus midlate triploid hybrid. HortScience 45(6): 977-980.

Ollitrault P, Terol J, Chen C, Federici C, Lotfy S, Hippolyte I, Ollitrault F, Bérard A, Chauveau A, Cuenca J, Costantino G, Kacar Y, Mu L, García-Lor A, Froelicher Y, Aleza P, Boland A, Billot C, Navarro L, Luro F, Roose M, Gmitter FG, Talón M, Brunel D. 2012. A reference genetic map of $C$. clementina Hort. ex Tan.; citrus evolution inferences from comparative mapping. BMC Genomics 13: 593.

\section{Congress comunications}

Aleza P, Cuenca J, García A, Arregui JM, Juárez J, Froelicher Y, Luro F, Ollitrault P, Navarro L. 2010. Mejora genética de cítricos. Obtención de híbridos triploides. $V$ Congreso de Mejora Genética de Plantas. Madrid (España): 7-9 Julio 2010.

Aleza P, Cuenca J, Juárez J, Ollitrault $P$, Navarro L. 2012. Differences in the genetic structure of citrus triploid hybrids recovered from $2 x \times 2 x$ and $4 x \times 2 x$ sexual hybridisations. XII International Citrus Congress. 19-23 December 2012. Valence, Spain. International Society of Citriculture.

Aleza P, Cuenca J, Juárez J, Navarro L, Ollitrault P. 2012. Mechanism of $2 n$ gametes formation and centromere mapping in citrus. XII International Citrus Congress. 19-23 December 2012. Valence, Spain. International Society of Citriculture.

Aleza P., Juárez J., Cuenca J., Navarro L., Ollitrault P. 2012. Differences in the genetic structure of citrus triploid hybrids recovered from $2 x \times 2 x$ and $4 x \times 2 x$ sexual hybridizations. 19th EUCARPIA General Congress "Plant Breeding for future generations". Budapest (Hungary): 21 24 Mayo 2012. Plant breeding for future generations, 341.

Bassimba DDM., Vicent A., Cuenca J., Aleza P., Navarro L. 2012. Screening for Alternaria Brown Spot resistance in the triploid mandarin breeding program in Spain. XII International Citrus Congress. Valence (Spain): 18-23 November 2012. International Society of Citriculture.

Cuenca J, Navarro L, Ollitrault P. 2008. Parental heterozygosity and origin of $2 n$ gametes in mandarin: two key parameters for citrus triploid breeding projects. 18th EUCARPIA General 
Congress "Modern Variety Breeding for Present and Future Needs". Valencia (Spain). 9-12 Septiembre 2008. Modern Variety Breeding for Present and Future Needs, 697-698.

Cuenca J, Navarro L, Ollitrault P. 2009. Origin of $2 n$ gametes in C. reticulata cv Fortune mandarin. International Conference on Polyploidy, Hybridization and Biodiversity. Saint Malo (France). 17-20 Mayo 2009

Cuenca J, Navarro L, Ollitrault P. 2010. Mecanismo de origen de los gametos $2 n$ en el mandarino 'Fortune' y su implicación en las estructuras genéticas y fenotípicas de sus poblaciones de híbridos triploides. V Congreso de Mejora Genética de Plantas. Madrid (España): 7-9 Julio 2010.

Cuenca J, Aleza P, Navarro L, Ollitrault P. 2012. Assignment of SNP allelic configuration in polyploids using Competitive Allele-Specific PCR: application to triploid citrus progenies. XII International Citrus Congress. Valence (Spain): 18-23 November 2012. International Society of Citriculture.

Cuenca J, Aleza P, Iborra E, Vicent A, Ollitrault P, Navarro L. 2012. Location of a chromosome region linked to Alternaria Brown Spot resistance from the evaluation of triploid mandarin populations. XII International Citrus Congress. Valence (Spain): 18-23 November 2012. International Society of Citriculture.

Cuenca, J, Aleza, P, Juarez, J, Pina, JA, Navarro, L. 2012. Two new IVIA triploid hybrids of mandarin; IVIA-592 and IVIA-599. XII International Citrus Congress. Valence (Spain): 18-23 November 2012. International Society of Citriculture.

Cuenca J, Iborra E, Aleza P, Vicent A, Ollitrault P, Navarro L. 2012. Location of a chromosome region linked to Alternaria alternata pv. citri resistance from the evaluation of triploid mandarin populations. 19th EUCARPIA General Congress "Plant breeding for future generations". Budapest (Hungary): 21-24 Mayo 2012. Plant breeding for future generations 135140

Navarro L, Aleza P, Cuenca J, Juárez J, Pina JA, Pensabene-Bellavia G, Hernández M, Ortega C, Navarro A, Ortega V. 2009. The mandarin triploid breeding program in Spain. Second International Citrus Biotechnology Symposium. Catania (Italy)

Navarro L, Aleza P, Cuenca J, Juárez J, Pina JA. 2010. 'Garbí' and 'Safor' mandarins, two new mandarin triploid hybrids obtained by embryo rescue and flow cytometry. 28th International Horticultural Congress. Lisboa (Portugal): 22-27 Agosto 2010.

Navarro L, Aleza P, Cuenca J, Juárez J, Pina JA, Ortega C, Navarro A, Ortega V. 2012. The triploid mandarin breeding program in Spain. XII International Citrus Congress. Valence (Spain): 18-23 November 2012. International Society of Citriculture.

Ollitrault P, Terol J, Chen C, Federici CT, Lotfy S, Hippolyte I, Ollitrault F, Bérard A, Chauveau A, Costantino G, Kacar Y, Mu L, Cuenca J, Garcia A, Froelicher Y, Aleza P, Boland A, Billot C, Navarro L, Luro F, Roose ML, Gmitter FG Jr, Talon M, Brunel D. 2011. A reference linkage map of $C$. clementina based on SNPs, SSRs and Indels. Plant and Animal Genome XIX Conference San Diego, CA, January 15-19, 2011: P477

Ollitrault P, Terol J, Chen C, Federici CT, Lotfy S, Hippolyte I, Ollitrault F, Bérard A, Chauveau A, Cuenca J, Costantino G, Kacar Y, Mu L, García-Lor A, Froelicher Y, Aleza P, Boland A, Billot C, Navarro L, Luro F, Roose ML, Gmitter FG, Talón M, Brunel D. 2012. A reference genetic map of Citrus clementina; citrus evolution inferences from comparative 
mapping. XII International Citrus Congress. Valence (Spain): 18-23 November 2012. International Society of Citriculture.

Sdiri S, Navarro P, Cuenca J, Pardo J, Salvador A. 2012. Postharvest behavior of new mandarins cultivars obtained in the IVIA. XII International Citrus Congress. Valence (Spain): 1823 November 2012. International Society of Citriculture.

Sdiri S, Navarro P, Monterde A, Salvador A, Cuenca J, Aleza P, Ben Abda J. 2012. Postharvest behavior of 'Garbi' and 'Safor' - new triploid mandarins. Acta Hort. (ISHS) 945:255262. 

Literature cited 

Agarwal M, Shrivastava N, Padh H. 2008. Advances in molecular marker techniques and their applications in plant sciences. Plant Cell Reports 27: 617-631.

Agüero J, Vives M, Velázquez K, Ruiz-Ruiz S, Juárez J, Navarro L, Moreno P, Guerri J. 2013. Citrus leaf blotch virus invades meristematic regions in Nicotiana benthamiana and citrus. Molecular Plant Pathology: 10.1111/mpp.12031.

Ahmadian A, Gharizadeh B, Gustafsson AC, Sterky F, Nyren P, Uhlen M, Lundeberg J. 2000. Single-nucleotide polymorphism analysis by pyrosequencing. Analytical Biochemistry 280: $103-110$.

Ajiro N, Miyamoto Y, Masunaka A, Tsuge T, Yamamoto M, Ohtani K, Fukumoto T, Gomi K, Peever TL, Izumi Y, Tada Y, Akimitsu K. 2010. Role of the host-selective ACT-toxin synthesis gene ACTTS2 encoding an enoyl-reductase in pathogenicity of the tangerine pathotype of Alternaria alternata. Phytopathology 100: 120-126.

Akhunov E, Nicolet C, Dvorak J. 2009. Single nucleotide polymorphism genotyping in polyploid wheat with the Illumina GoldenGate assay. Theoretical and Applied Genetics 119: 507-517.

Akimitsu K, Peever TL, Timmer LW. 2003. Molecular, ecological and evolutionary approaches to understanding Alternaria diseases of citrus. Molecular Plant Pathology 4: 435-446.

Aleza P, Juárez J, Hernández M, Pina JA, Ollitrault P, Navarro L. 2009a. Recovery and characterization of a Citrus clementina Hort. ex Tan. 'Clemenules' haploid plant selected to establish the reference whole Citrus genome sequence. BMC Plant Biology 9: 110.

Aleza P, Juárez J, Ollitrault P, Navarro L. 2009b. Production of tetraploid plants of non apomictic citrus genotypes. Plant Cell Reports 28.

Aleza P, Cuenca J, Juárez J, Pina JA, Navarro L. 2010a. 'Garbi' mandarin: a new latematuring triploid hybrid. HortScience 45(1): 139-141.

Aleza P, Juárez J, Cuenca J, Ollitrault P, Navarro L. 2010b. Recovery of citrus triploid hybrids by embryo rescue and flow cytometry from $2 \times \mathrm{x} 2 \mathrm{x}$ sexual hybridisation and its application to extensive breeding programs. Plant Cell Reports 29(9): 1023-1034.

Aleza P, Froelicher Y, Schwarz S, Agustí M, Hernández M, Juárez J, Luro F, Morillon R, Navarro L, Ollitrault P. 2011. Tetraploidization events by chromosome doubling of nucellar cells are frequent in apomictic citrus and are dependent on genotype and environment. Annals of Botany 108(1): 37-50.

Aleza P, Cuenca J, Juárez J, Ollitrault P, Navarro L. 2012a. Differences in the genetic structure of citrus triploid hybrids recovered from $2 x \times 2 x$ and $4 x \times 2 x$ sexual hybridisations. XII International Citrus Congress. 19-23 December 2012. Valence, Spain.

Aleza P, Cuenca J, Juárez J, Navarro L, Ollitrault P. 2012b. Mechanism of 2n gametes formation and centromere mapping in citrus. XII International Citrus Congress. 19-23 December 2012. Valence, Spain.

Aleza P, Juárez J, Cuenca J, Ollitrault $P$, Navarro L. 2012c. Extensive citrus triploid hybrid production by $2 \mathrm{x} \times 4 \mathrm{x}$ sexual hybridizations and parent-effect on the length of the juvenile phase. Plant Cell Reports 31(9): 1723-1735. 
Aleza P, Juárez J, Hernández M, Ollitrault P, Navarro L. 2012d. Implementation of extensive citrus triploid breeding programs based on $4 \mathrm{x} \times 2 \mathrm{x}$ sexual hybridizations. Tree Genetics and Genomes 8(6): 1293-1306.

Allario T, Brumos J, Colmenero-Flores J, Tadeo F, Froelicher $\mathrm{Y}$, Talón M, Navarro L, Ollitrault P, Morillon R. 2011. Large changes in anatomy and physiology between diploid Rangpur lime (Citrus limonia) and its autotetraploid are not associated with large changes in leaf gene expression. Journal of Experimental Botany 62(8): 2507-2519.

Alquézar B, Zacarías L, Rodrigo MJ. 2009. Molecular and functional characterization of a novel chromoplast-specific lycopene ß-cyclase from Citrus and its relation to lycopene accumulation. Journal of experimental botany 60: 1783-1797.

Alquézar B, Ayres AJ, Bento JMS, De Noronha NC Jr, Enrique A, Pedreira M, Peña L, Peris J, Postali JR, Rodríguez A, Spósito MB, Teixeira D, Wulff NA, Yamamoto PT. 2012. Repellent compositions and genetic approaches for controlling Huanglongbing. WIPO Patent Application WO/2011/050432.

Arumuganathan K, Earle DE. 1991. Nuclear DNA content of some important plant species. Plant Molecular Biology Reporter 9(3): 208-218.

Asins MJ, Bernet GP, Ruiz C, Cambra M, Guerri J, Carbonell EA. 2004. QTL analysis of Citrus tristeza virus-citradia interaction. Theoretical and Applied Genetics 108:603-611.

Barba-González R, Lokker AC, Lim KB, Ramanna MS, Van Tuyl J. 2004. Use of $2 n$ gametes for the production of sexual polyploids from sterile Oriental- Asiatic hybrids of lilies (Lilium). Theoretical and Applied Genetics 109:1125-1132.

Barba-González R, Lim KB, Ramanna MS, Visser R, Van Tuyl J. 2005. Occurrence of 2n gametes in the F1 hybrids of Oriental- Asiatic lilies (Lilium): Relevance to intergenomic recombination and backcrossing. Euphytica 143: 67-73.

Barba-González R, Lim KB, Zhou S, Ramanna MS, Van Tuyl JM. 2008. Interspecfic hybridization in Lily: the use of $2 n$ gametes in interspecific lily hybrids. In: JAT Silva, ed. Floriculture, Ornamental and Plant Biotechnology: Advances and Topical Issues, 1 edn. Global Science Books: UK.

Barcaccia G, Tavoletti S, Mariani A, Veronesi F. 2003. Occurrence, inheritance and use of reproductive mutants in alfalfa improvement. Euphytica 133.

Barkley NA, Roose ML, Krueger RR, Federici CT. 2006. Assessing genetic diversity and population structure in a citrus germplasm collection utilizing simple sequence repeat markers (SSRs). Theoetical and Applied Genetics 112: 1519-1531.

Barkley NA, Krueger RR, Federici CT, Roose ML. 2009. What phylogeny and gene genealogy analyses reveal about homoplasy in citrus microsatellite alleles. Plant Systematics and Evolution 282.

Barone A, Gebhardt C, Frusciante L. 1995. Heterozygosity in 2n gametes of potato evaluated by RFLP markers. Theoretical and Applied Genetics $\mathbf{9 1 .}$

Barret HC. 1974. Colchicine-induced polyploidy in Citrus. Botanical Gazette 135(1): 29-41.

Barrett HC, Rhodes AM. 1976. A numerical taxonomic study of affinity relationships in cultivated Citrus and its close relatives. Systematic Botany 1: 105-136. 
Bastiaanssen HJM, van dB, Lindhout P, Jacobsen E, Ramanna MS. 1998. Postmeiotic restitution in $2 n$-egg formation of diploid potato. Heredity 81: 20-27.

Bauer F, Elbers CC, Adan RA, Loos RJ, Onland-Moret NC, Grobbee DE, van VlietOstaptchouk JV, Wijmenga C, van der Schow YT. 2009. Obesity genes identified in genomewide association studies are associated with adiposity measures and potentially with nutrientspecific food preference. American Journal of Clinical Nutrition 90.

Bausher MG, Singh ND, Lee SB, Jansen RK, Daniell H. 2006. The complete chloroplast genome sequence of Citrus sinensis (L.) Osbeck var 'Ridge Pineapple': organization and phylogenetic relationships to other angiosperms. BMC Plant Biology 6: 21.

Becker A, Chao D, Zhang X, Salt DE, Baxter I. 2011. Bulk Segregant Analysis using Single Nucleotide Polymorphism microarrays. Plos One 6(1): e15993.

Bérard A, Le Paslier MC, Dardevet M, Exbrayat-Vinson F, Bonnin I, Cenci A, Haudry A, Brunel D, Ravel C. 2009. High-throughput single nucleotide polymorphism genotyping in wheat (Triticum spp.). Plant Biotechnology Journal 7(4): 364-374.

Bernet GP, Bretó MP, Asins MJ. 2004. Expressed sequence enrichment for candidate gene analysis of Citrus tristeza virus resistance. Theoretical and Applied Genetics 108:592-602.

Bertrand C, Collar Y, Mackill DJ. 2008. Marker-assisted selection: an approach for precision plant breeding in thetwenty-first century. Philosophical Transactions of the Royal Society B 363: 557-572.

Bhatia A, Roberts PD, Timmer LW. 2003. Evaluation of the alter-rater model for timing of fungicide applications for control of Alternaria Brown Spot of citrus. Plant Disease 87: 10891093.

Bjornsson HT, Albert TJ, Ladd-Acosta C, Green RD, Rongione MA, Middle CM, Irizarry RA, Broman KW, Feinberg AP. 2008. SNP-specific array-based allele-specific expression analysis. Genome Research 18(5): 771-779.

Brauer MJ, Christianson CM, Pai DA, Dunham MJ. 2006. Mapping novel traits by arrayassisted bulk segregant analysis in Saccharomyces cerevisiae. Genetics 173: 1813-1816.

Bretagnolle F, Thompson JD. 1995. Tansley Review no-78 - Gametes with the somatic chromosome-number - mechanisms of their formation and role in the evolution of autopolyploid plants. New Phytologist 129: 1-22.

Bretó MP, Ruiz C, Pina JA, Asíns MJ. 2001. The diversification of Citrus clementina Hort. ex Tan., a vegetatively propagated crop species. Molecular Phylogenetics and Evolution 21: 285293.

Broman KW, Rowe LB, Churchill GA, Paigen K. 2002. Crossover interference in the mouse. Genetics 160.

Brownfield L, Kohler C. 2011. Unreduced gamete formation in plants: mechanisms and prospects. Journal of Experimental Botany 62: 1659-1668.

Büschges R, Hollricher K, Panstruga R, Simons G, Wolter M, Frijters A, van Daelen R, van der Lee T, Diergaarde P, Groenendijk J, Topsch S, Vos P, Salamini F, Schulze-Lefert P. 1997. The barley Mlo gene: a novel control element of plant pathogen resistance. Cell 88(5): 695-705. 
Buso JA, Boiteux LS, Tai GCC, Peloquin SJ. 1999. Chromosome regions between centromeres and proximal crossovers are the physical sites of major effect loci for yield in potato: Genetic analysis employing meiotic mutants. Proceedings of the National Academy of Sciences of the United States of America 96(4): 1773-1778.

Buteler MI, Jarret RL, LaBonte DR. 1999. Sequence characterization of microsatellites in diploid and polyploid Ipomoea. Theoretical and Applied Genetics 99.

Butelli E, Licciardello C, Zhang Y, Liu J, Mackay S, Bailey P, Recupero GR, Martin C. 2012. Retrotransposons control fruit-specific, cold-dependent accumulation of anthocyanins in blood oranges. Plant Cell 24(3): 1242-1255.

Byers R, Harker D, Yourstone S, Maughan P, Udall J. 2012. Development and mapping of SNP assays in allotetraploid cotton. Theoretical and Applied Genetics 124: 1201-1214.

Cai X, Xu SS. 2007. Meiosis-driven genome variation in plants. Current Genomics 8(3): 151161.

Cameron JW, Frost HB. 1968. Genetics, breeding and nucellar embryony. In: W Reuther, LD Batcherlor, HJ Webber, eds. The Citrus Industry, Vol II. Univ. Calif. Press: Berkeley, 325-370.

Cameron JW, Bernett RH. 1978. Use of sexual tetraploid seed parents for production of triploid citrus hybrids. HortScience 13: 167-169.

Canihos Y, Peever TL, Timmer LW. 1999. Temperature, leaf wetness, and isolate effects on infection of Minneola tangelo leaves by Alternaria spp. Plant Disease 83: 429-433.

Cervera M, Juárez J, Navarro L, Peña L. 2005. Genetic transformation of mature citrus plants. Methods in Molecular Biology 286: 177-188.

Chao CT. 2005. Pollination study of mandarins and the effect on seediness and fruit Size: Implications for seedless mandarin production. HortScience 40: 362-365.

Chapot H. 1975. Citrus, Technical Monograph No.4. Ciba-Geigy Agrochem: Basle, Switzerland.

Chen ZJ. 2007. Genetic and Epigenetic Mechanisms for Gene Expression and Phenotypic Variation in Plant Polyploids. Annual Review of Plant Biology 58: 377-406.

Chen C, Zhou P, Choi YA, Huang S, Gmitter FG. 2006. Mining and characterizing microsatellites from citrus ESTs. Theoretical and Applied Genetics 112: 1248-1257.

Chen C, Lyon MT, O'Malley D, Federici CT, Gmitter J, Grosser JW, Chaparro JX, Roose ML, Gmitter FG, Jr 2008a. Origin and frequency of $2 n$ gametes in Citrus sinensis x Poncirus trifoliata and their reciprocal crosses. Plant Science 174: 1-8.

Chen C, Bowman KD, Choi YA, Dang PM, Rao MN, Huang S, Soneji JR, McCollum TG, Gmitter FG, Jr. 2008b. EST-SSR genetic maps for Citrus sinensis and Poncirus trifoliata. Tree Genetics \& Genomes 4: 1-10.

Chen W, Mingus J, Mammadov J, Backlund JE, Greene T, Thompson S, Kumpatla S. 2010. KASPar: a simple and cost-effective system for SNP genotyping. Plant and Animal Genomes XVII Conference: 194.

Cheng FS, Roose ML. 1995. Origin and inheritance of dwarfing by the Citrus rootstock Poncirus trifoliata 'Flying Dragon'. Journal of the American Society for Horticultural Science 120: 286-291. 
Comai L. 2003. The advantages and disadvantages of being polyploid. Nature Reviews Genetics 6: 836-846.

Conesa A, Götz S, García-Gómez JM, Terol J, Talón M, Robles M. 2005. Blast2GO: a universal tool for annotation, visualization and analysis in functional genomics research. Bioinformatics 21(18): 3674-3676.

Conicella C, Barone A, Del Giudice A, Frusciante L, Monti LM. 1991. Cytological evidences of SDR-FDR mixture in the formation of $2 n$ eggs in a potato diploid clone. Theoretical and Applied Genetics 81(1):.59-63.

Coop G, Witonsky D, Di Rienzo A, Pritchard JK. 2010. Using Environmental Correlations to Identify Loci Underlying Local Adaptation. Genetics doi: 10.1534/genetics.110.114819.

Copenhaver GP, Housworth EA, Stahl FW. 2002. Crossover Interference in Arabidopsis. Genetics 160: 1631-1639.

Cortés AJ, Chavarro MC, Blair MW. 2011. SNP marker diversity in common bean (Phaseolus vulgaris L.). Theoretical and Applied Genetics 123(5): 827-845.

Crespel L, Gudin S. 2003. Evidence for the production of unreduced gametes by tetraploid Rosa hybrida L. Euphytica 133: 65-69.

Cuenca J, Aleza P, Juárez J, Pina JA, Navarro L. 2010. 'Safor' mandarin: a new citrus midlate triploid hybrid. HortScience 45: 977-980.

Cuenca J, Froelicher Y, Aleza P, Juárez J, Navarro L, Ollitrault P. 2011. Multilocus halftetrad analysis and centromere mapping in citrus: evidence of SDR mechanism for $2 \mathrm{n}$ megagametophyte production and partial chiasma interference in mandarin cv 'Fortune'. Heredity 107: 462-470.

Cuenca J, Aleza P, Iborra E, Vicent A, Ollitrault P, Navarro L. 2012. Location of a chromosome region linked to Alternaria Brown Spot resistance from the evaluation of triploid mandarin populations. XII International Citrus Congress. 19-23 December 2012. Valence, Spain.

Cuenca J, Aleza P, Navarro L, Ollitrault P. 2013a. Assignment of SNP allelic configuration in polyploids using Competitive Allele-Specific PCR: application to triploid citrus progenies. Annals of Botany 111: 731-742.

Cuenca J, Aleza P, Vicent A, Brunel D, Ollitrault P, Navarro L. 2013b. Genetically based location from triploid populations and gene ontology of a 3.3-Mb genome region linked to Alternaria brown spot resistance in citrus reveal clusters of resistance genes. PLoS ONE 8(10): e76755.

Cuppen E. 2007. Genotyping by Allele-Specific Amplification (KASPar). Cold Spring Harbor Protocols 2007: 172-173.

Da Silva J, Sorrells M. 1996. Linkage Analysis in Polyploids Using Molecular Markers. In: PP Jauhar, ed. Methods of genome analysis in plants. CRC Press: Boca Raton, 211-228.

Da Y, Jarrell VL, Wang TL, Fernando RL, Wheeler MB, Lewin HA. 1995. Multilocus analysis for gene centromere mapping using first polar bodies and secondary oocytes. Genetics 139(2): 1091-1097. 
Dalkilic Z, Timmer LW, Gmitter FG. 2005. Linkage of an Alternaria disease resistance gene in mandarin hybrids with RAPD fragments. Journal of the American Society for Horticultural Science 130(2): 191-195.

Dambier D, Benyahia H, Pensabene-Bellavia G, Kacar YA, Froelicher Y, Belfalah Z, Lhou B, Handaji N, Printz B, Morillon R, Yesiloglu T, Navarro L, Ollitrault P. 2011. Somatic hybridization for citrus rootstock breeding: an effective tool to solve some important issues of the Mediterranean citrus industry. Plant Cell Reports 30.

Dangl J, Jones JD. 2001. Plant pathogens and integrated defence responses to infection. Nature 411(6839): 826-833.

Danzmann RG, Bogart JP. 1983. Further evidence for a polymorphism in gametic segregation in the tetraploid treefrog Hyla versicolor using a glutamate oxaloacetic transaminase locus. Genetics 103(4): 753-769.

David JL, Boudec P, Gallais A. 1995. Quantitative genetics of $4 x-2 x$ hybrid populations with First-Division Restitution and 2nd-Division Restitution $2 \mathrm{n}$ gametes produced by diploid parents. Genetics 139.

Davies FS, Albrigo LG. 1994. Citrus. Crops Production Science in Horticulture. CAB International, UK.

De Jong WS, De Jong DM, Bodis M. 2003. A fluorogenic 5 ' nuclease (TaqMan) assay to assess dosage of a marker tightly linked to red skin color in autotetraploid potato. Theoretical and Applied Genetics 107.

De Souza MC, Stuchi ES, de Goes A. 2009. Evaluation of tangerine hybrid resistance to Alternaria alternata. Scientia Horticulturae 123: 1-4.

De Storme N, Geelen D. 2011. The Arabidopsis mutant jason produces unreduced first division restitution male gametes through a parallel/fused spindle mechanism in meiosis II. Plant Physiology 155: 1403-1415.

De Storme N, Geelen D. 2013. Sexual polyploidization in plants - cytological mechanisms and molecular regulation. New Phytologist 198: 670-684.

D'Erfurth I, Jolivet S, Froger N, Catrice O, Novatchkova M, Simon M, Jenczewski E, Mercier R. 2008. Mutations in AtPS1 (Arabidopsis thaliana Parallel Spindle 1) lead to the production of diploid pollen grains. PLoS Genetics 4: e1000274.

D'Erfurth I, Jolivet S, Froger N, Catrice O, Novatchkova M, Mercier R. 2009. Turning meiosis into mitosis. PLoS Biology 7: e1000124.

Devoto A, Piffanelli P, Nilsson I, Wallin E, Panstruga R, von Heijne G, Schulze-Lefert P. 1999. Topology, subcellular localization, and sequence diversity of the Mlo family in plants. The Journal of Biological Chemistry 274(49): 34993-35004.

Dewitte A, Van Laere K, Van Huylenbroeck J. 2012. Use of $2 n$ fametes in plant breeding. In: DI Abdurakhmonov, ed. Plant Breeding. InTech.

Douches DS, Quiros CF. 1987. Use of $4 x-2 x$ crosses to determine gene centromere map distances of isozyme loci in Solanum species. Genome 29: 519-527.

Douches DS, Quiros CF. 1988. Genetic strategies to determine the mode of $2 \mathrm{n}$ egg formation in diploid potatoes. Euphytica 38(3): 247-260. 
Douches DS, Maas DL. 1998. Comparison of FDR and SDR derived tetraploid progeny from $2 x$ $x 4 x$ crosses using haploids of Solanum tuberosum $L$. that produce mixed modes of $2 \mathrm{n}$ eggs. Theoretical and Applied Genetics 97.

Drouaud J, Mercier R, Chelysheva L, Berard A, Falque M, Martin O, Zanni V, Brunel D, Mezard C. 2007. Sex-specific crossover distributions and variations in interference level along Arabidopsis thaliana chromosome 4. Plos Genetics 3(6): e106. doi:10.1371/journal.pgen.0030106.

Edwards D, Batley J. 2010. Plant genome sequencing: applications for crop improvement. Plant Biotechnology Journal 8(1): 2-9.

Elena K. 2006. Alternaria brown spot of Minneola in Greece; evaluation of citrus species susceptibility. European Journal of Plant Pathology 115(2): 259-262.

Errico A, Cammareri M, Conicella C. 2005. Meiotic nuclear restitution mechanisms in a triploid lily. Caryologia 58(4): 367-373.

Esch E, Weber E. 2002. Investigation of crossover interference in barley (Hordeum vulgare L.) using the coefficient of coincidence. Theoretical and Applied Genetics 104(5): 786-796.

Esen A, Soost RK. 1971. Unexpected triploids in Citrus: their origin, identification, and possible use. Journal of Heredity 62(6): 329-333.

Esen A, Soost RK. 1973. Precocious development and germination of spontaneous triploid seeds in Citrus. Journal of Heredity 64(3): 147-154.

Esen A, Soost RK, Geraci G. 1978. Seed set, size, and development after 4x x 2x and 4x x 4x crosses in citrus. Euphytica 27: 283-294.

Esen A, Soost RK, Geraci G. 1979. Genetic evidence for the origin of diploid megagametophytes in Citrus. Journal of Heredity 70: 5-8.

Esselink GD, Nybom H, Vosman B. 2004. Assignment of allelic configuration in polyploids using the MAC-PR (microsatellite DNA allele counting-peak ratios) method. Theoretical and Applied Genetics 109: 402-408.

Everts KL, Lacy ML. 1996. Factors influencing infection of onion leaves by Alternaria porri and subsequent lesion expansion. Plant Disease 80(3): 276-280.

Fan J, Oliphant A, Shen R, Kermani B, Garcia F, Gunderson K, Hansen M, Steemers F, Butler S, Deloukas P, Galver L, Hunt S, McBride C, Bibikova M, Rubano T, Chen J, Wickham E, Doucet D, Chang W, Campbell D, Zhang B, Kruglyak S, Bentley D, Haas J, Rigault P, Zhou L, Stuelpnagel J, Chee M. 2003. Highly parallel SNP genotyping. Cold Spring Harbor Symposia on Quantitative Biology 68: 69-78.

Fang DQ, Federici CT, Roose ML. 1997. Development of molecular markers linked to a gene controlling fruit acidity in citrus. Genome $\mathbf{4 0}$.

Fang DQ, Federici CT, Roose ML. 1998. A high-resolution linkage map of the citrus tristeza virus resistance gene region in Poncirus trifoliata (L.) Raf. Genetics 150(2): 883-890.

FAO. 2013. www.faostat.fao.org. 
Fatta Del Bosco S, Matranga G, Geraci G. 1992. Micro and macro-sporogenesis of two triploid hybrids of citrus. Proceedings of $7^{\text {th }}$ International Citrus Congress. International Society of Citriculture, Acireale, Italy 1: 122-124.

Federici CT, Fang DQ, Scora RW, Roose ML. 1998. Phylogenetic relationships within the genus Citrus (Rutaceae) and related genera as revealed by RFLP and RAPD analysis. Theoretical and Applied Genetics 94: 812-822.

Ferrante SP, Lucretti S, Reale S, De Patrizio A, Abbate L, Tusa N, Scarano M. 2010. Assessment of the origin of new citrus tetraploid hybrids $(2 n=4 x)$ by means of SSR markers and PCR based dosage effects. Euphytica 173(2): 223-233.

Folimonov AS, Folimonova SY, Bar-Joseph M, Dawson WO. 2007. A stable RNA virusbased vector for citrus trees. Virology 368(1): 205-216.

Foss E, Lande R, Stahl F, Steinberg C. 1993. Chiasma interference as a function of genetic distance. Genetics 133(3): 681-691.

Friesen T, Faris J, Solomon P, Oliver RP. 2008. Host-specific toxins: effectors of necrotrophic pathogenicity. Cellular Microbiology 10(7): 1421-1428.

Froelicher Y, Dambier D, Costantino G, Lotfy S, Didout C, Beaumont V, Brottier P, Risterucci A, Luro F, Ollitrault P. 2007. Characterization of microsatellite markers in Citrus reticulata Blanco. Molecular Ecology Note.

Froelicher Y, Dambier D, Bassene JB, Costantino G, Lotfy S, Didout C, Beaumont V, Brottier P, Risterucci AM, Luro F, Ollitrault P. 2008. Characterization of microsatellite markers in mandarin orange (Citrus reticulata Blanco). Molecular Ecology Resources 8(1): 119122.

Froelicher Y, Bouffin J, Dambier D, Ollitrault P. 2012. Triploid seedless mandarin breeding in France. XII International Citrus Congress. 19-23 December 2012. Valence, Spain.

Frost HB. 1948. Genetics and breeding. In: W Reuther, HJ Webber, LD Batchelor, eds. The Citrus Industry, Vol. 1. University of California Press, Berkeley, USA, 817-914.

Frost HB, Soost RK. 1968. Seed reproduction, development of gametes and embryos. In: W Reuther, LD Batchelor, HJ Webber, eds. The Citrus Industry, Vol. 2. University of California Press, Berkeley, USA, 290-324.

Gallais A. 2003. Quantitative Genetics and Breeding Methods in Autopolyploids Plants, 2 edn. INRA: France.

García R, Asins MJ, Forner J, Carbonell EA. 1999. Genetic analysis of apomixis in Citrus and Poncirus by molecular markers. Theoretical and Applied Genetics 99(3-4): 511-518.

García-Lor A, Curk F, Snoussi-Trifa H, Morillon R, Ancillo G, Luro F, Navarro L, Ollitrault P. 2012. A nuclear phylogenetic analysis: SNPs, indels and SSRs deliver new insights into the relationships in the 'true citrus fruit trees' group (Citrinae, Rutaceae) and the origin of cultivated species. Annals of Botany: doi: 10.1093/aob/mcs227.

García-Lor A, Ancillo G, Navarro L, Ollitrault P. 2013a. Citrus (Rutaceae) SNP markers based on Competitive Allele-Specific PCR; transferability across the Aurantioideae subfamily . Applications in Plant Sciences 1(4): doi:10.3732/apps.1200406. 
García-Lor A, Luro F, Ancillo G, Ollitrault P, Navarro L. 2013b. Genetic diversity and population-structure analysis of mandarin germplasm by nuclear (SSR, indel) and mitochondrial markers. Submitted .

Geraci G, Esen A, Soost RK. 1975. Triploid progenies from 2x x 2x crosses of Citrus cultivars. Journal of Heredity 66: 177-178.

Geraci G, De Pasquale F, Tusa N. 1977. Percentages of spontaneous triploids in progenies of diploid lemons and mandarins. International Citrus Congress (2nd, Orlando, Florida), International Society of Citriculture 2: 596-597.

Gill KS, Lubbers EL, Gill BS, Raupp WJ, Cox TS. 1991. A genetic linkage map of Triticum tauschii (DD) and its relationship to the D genome of bread wheat (AABBDD). Genome 34: 361 374.

Giraut L, Falque M, Drouaud J, Pereira L, Martin OC, Mézard C. 2011. Genome-wide crossover distribution in Arabidopsis thaliana meiosis reveals sex-specific patterns along chromosomes. PLoS Genetics 7: e1002354.

Gmitter FG Jr, Ling XB, Deng XX. 1990. Induction of triploid citrus plants from endosperm calli in vitro. Theoretical and Applied Genetics 80: 785-790.

Gmitter FG Jr, Ling XB. 1991. Embryogenesis in vitro and nonchimeric tetraploid plant recovery from undeveloped Citrus ovules treated with colchicine. Journal of the American Society for Horticultural Science 116(2): 317-321.

Gmitter FG Jr, Ling XB, Deng XX. 1991. Colchicine-induced polyploidy in Citrus embryogenic cultures, somatic embryos, and regenerated plantlets. Plant Science 74(1): 135-141.

Gmitter FG Jr, Grosser JW, Moore GA. 1992. Citrus. In: F Hammerschlag, RL Litz, eds. Biotechnology of perennial crops. CAB Intl.: Wallingford, Oxon, U.K., 335-369.

Gmitter FG Jr, Xiao SY, Huang S, Hu XL, Garnsey SM, Deng Z. 1996. A localized linkage map of the citrus tristeza virus resistance gene region. Theoretical and Applied Genetics $\mathbf{9 2}$.

Gmitter FG, Jr., Chen C, Machado MA, de Souza AA, Ollitrault P, Froehlicher Y, Shimizu T. 2012. Citrus genomics. Tree Genetics \& Genomes 8(3): 611-626.

Goes A, Montes de Oca AG, Reis RF. 2001. Ocurrencia de las mancha de Alternaria en mandarina 'Dancy' en el estado de Rio de Janeiro. Fitopatologia Brasileira 26: 386.

Golmohammadi M, Andrew M, Peever TL, Peres NA, Timmer LW. 2006. Brown spot of tangerine hybrid cultivars Minneola, Page and Fortune caused by Alternaria alternata in Iran. Plant Pathology 55(4): 578.

Grant V. 1981. Plant Speciation, 2nd ed. Columbia University Press, New York, USA.

Grant W. 2010. A multicountry ecological study of risk-modifying factors for prostate cancer: apolipoprotein E epsilon4 as a risk factor and cereals as a risk reduction factor. Anticancer Research 30(1): 189-199.

Griffiths A, Miller J, Suzuki D, Lewontin R, Gelbart W. 1996. An introduction to genetic analysis, $6^{\text {th }}$ ed. W. H. Freeman and Company, New York, USA.

Grosser JW, Gmitter FG Jr. 1990. Protoplast fusion and citrus improvement. Plant Breeding Reviews 8: 339-374. 
Grosser JW, Ollitrault P, Olivares-Fuster O. 2000. Somatic hybridization in citrus: An effective tool to facilitate variety improvement. In Vitro Cellular \& Developmental Biology - Plant 36: 434449.

Grosser JW, An H, Calovic M, Lee D, Chen C, Vasconcellos M, Gmitter FG. 2010. Production of new allotetraploid and autotetraploid citrus breeding parents: focus on zipperskin mandarins. HortScience 45(8): 1160-1163.

Grosser JW, Gmitter FG Jr. 2011. Protoplast fusion for production of tetraploids and triploids: applications for scion and rootstock breeding in citrus. Plant Cell Tissue and Organ Culture 104: 343-357.

Gruber JD, Colligan PB, Wolford JK. 2002. Estimation of single nucleotide polymorphism allele frequency in DNA pools by using Pyrosequencing. Human Genetics 110(5): 395-401.

Guest D, Brown J. 1997. Plant defences against pathogens. In: J Brown, H Ogle, eds. Plant pathogens and plant diseases. Rockvale Publications, 242-262.

Gulsen O, Roose ML. 2001. Chloroplast and nuclear genome analysis of the parentage of lemons. J Amer Soc Hort Sci 126: 210-215.

Gulsen O, Uzun A, Canan I, Seday U, Canihos E. 2010. A new citrus linkage map based on SRAP, SSR, ISSR, POGP, RGA and RAPD markers. Euphytica 173(2): 265-277.

Guo M, Davis D, Birchler JA. 1996. Dosage effects on gene expression in a maize ploidy series. Genetics 142(4): 1349-1355.

Guo M, Rupe MA, Zinselmeier C, Habben J, Bowen BA, Smith OS. 2004. Allelic variation of gene expression in maize hybrids. Plant Cell 16(7): 1707-1716.

Guo WW, Deng XX, Yi HL. 2000. Somatic hybrids between navel orange (Citrus sinensis) and grapefruit (C. paradisi) for seedless triploid breeding. Euphytica 116: 281-285.

Gururani MA, Venkatesh J, Upadhyaya CP, Nookaraju A, Pandey SK, Park SW. 2012. Plant disease resistance genes: Current status and future directions. Physiological and Molecular Plant Pathology 78: 51-65.

Gustafsson A. 1935. Studies on the mechanisms of parthenogenesis. Hereditas 21: 1-112.

GVA. 2013. http://www.agricultura.gva.es/la-conselleria/estadisticas. Superficies y producciones de la Comunitat Valenciana (Principales cultivos).

Hammond-Kosack K, Jones JD. 1997. Plant disease resistance genes. Annual Review of Plant Physiology and Plant Molecular Biology 48: 575-607.

Han Y, Khu D, Monteros MJ. 2012. High-resolution melting analysis for SNP genotyping and mapping in tetraploid alfalfa (Medicago sativa L.). Molecular Breeding 29(2): 489-501.

Harlan JR, DeWet J. 1975. On O. Winge and a prayer: the origins of polyploidy. The Botanical Review 41: 361-390.

Hauber DP, Reeves A, Stack SM. 1999. Synapsis in a natural autotetraploid. Genome 42: 936949.

Hayashi M, Kato J, Ohashi H, Mii M. 2009. Unreduced 3x gamete formation of allotriploid hybrid derived from the cross of Primula denticulata $(4 \mathrm{x}) \times P$. rosea $(2 \mathrm{x})$ as a causal factor for 
producing pentaploid hybrids in the backcross with pollen of tetraploid $P$. denticulata. Euphytica 169: 123-131.

Hearn CJ. 1984. Development of seedless orange and grapefruit cultivars through seed irradiation. Journal of the American Society for Horticultural Science 109: 270-273.

Henry IM, Dilkes BP, Young K, Watson B, Wu H, Comai L. 2005. Aneuploidy and genetic variation in the Arabidopsis thaliana triploid response. Genetics 170: 1979-1988.

Hensz RA. 1971. 'Star Ruby', a new deep-red-fleshed grapefruit variety with distinct tree characteristics. Journal of the Rio Grande Valley Horticultural Society 25: 54-58.

Herrero M. 1929. Variedades de grapefruit. Agricultura 1: 322-324.

Herrero R, Asins MJ, Carbonell EA, Navarro L. 1996. Genetic diversity in the orange subfamily Aurantioideae. I. Intraspecifies and intragenus genetic variability. Theoretical and Applied Genetics 92: 599-609.

Herzing LBK, Cook EH Jr, Ledbetter DH. 2002. Allele-specific expression analysis by RNAFISH demonstrates preferential maternal expression of UBE3A and imprint maintenance within 15q11-q13 duplications. Human Molecular Genetics 11(15): 1707-1718.

Hutten R, Scholberg E, Huigen DJ, Hermsen JGT, Jacobsen E. 1993. Analysis of dihaploid induction and production ability and seed parent $x$ pollinator interaction in potato. Euphytica 72: 61-64.

Hutton DG, Mayers PE. 1988. Brown spot of Murcott tangor caused by Alternaria alternata in Queensland. Australasian Plant Pathololgy 17: 69-73.

Hyten DL, Smith JR, Frederick RD, Tucker ML, Song Q, Cregan PB. 2009. Bulked Segregant Analysis using the GoldenGate assay to locate the Rpp3 locus that confers resistance to Soybean Rust in soybean. Crop Science 49: 265-271.

Ishikawa S, Komura D, Tsuji S, Nishimura K, Yamamoto S, Panda B, Huang J, Fukayama M, Jones KW, Aburatani H. 2005. Allelic dosage analysis with genotyping microarrays. Biochemical and Biophysical Research Communications 333(4): 1309-1314.

Iwamasa M. 1966. Study on the steriliy in genus Citrus with special reference to the seedlessness. Bulletin of the Horticultural Research Station of Japan, Series B 6: 2-77.

Iwamasa M, Iwasaki T. 1963. On the sterility phenomenon caused by low temperatures in the Mexican lime (Citrus aurantifolia Swing.). Bulletin of the Horticultural Research Station of Japan, Series $B$ 2: 25-45.

Iwamasa M, Nito N, Ling JT. 1988. Intra and intergeneric hybridization in the orange subfamily, Auranthioideae Proceedings of $6^{\text {th }}$ International Citrus Congress. Balaban, PA: International Society of Citriculture: 123-130.

Iwasaki T. 1943. On the big leaf and small leaf strain of trifoliate orange (Poncirus trifoliata). Journal of the Horticultural Association of Japan 14: 302-305.

Jackson RC, Jackson JW. 1996. Gene segregation in autotetraploids: prediction from meiotic configurations. American Journal of Botany 83(6): 673-678.

Jaskani M, Husnain S, Bashir MA, Khan LA. 1996. Morphological description of citrus colchiploids. Proceedings of the International Society of Citriculture 1: 130-132. 
Jaskani MJ, Omura M, Khan IA. 2007. Cytogenetics. In: IA Khan, ed. Citrus Genetics, Breeding and Biotechnology. CABI: Wallingford, UK.

JinPing X, LiGeng C, Ming X, HaiLin L, WeiQi Y. 2009. Identification of AFLP fragments linked to seedlessness in Ponkan mandarin (Citrus reticulata Blanco) and conversion to SCAR markers. Scientia Horticulturae 121: 505-510.

Johnson SL, Africa D, Horne S, Postlethwait JH. 1995. Half-tetrad analysis in zebrafish: mapping the ros mutation and the centromere of linkage group I. Genetics 139(4): 1727-1735.

Jongedijk E, Ramanna MS, Sawor Z, Hermsen JGT. 1991. Formation of first division restitution (FDR) 2n-megaspores through pseudohomotypic division in ds-1 (desynapsis) mutants of diploid potato: routine production of tetraploid progeny from 2xFDR x 2xFDR crosses. Theoretical and Applied Genetics 82(5): 645-656.

Jørgensen JH, Wolfe M. 1994. Genetics of powdery mildew resistance in barley. Critical Reviews in Plant Sciences 13: 97-119.

Jørgensen JH. 1977. Spectrum of resistance conferred byml-o powdery mildew resistance genes in barley. Euphytica 26: 55-62.

Julier B, Flajoulot S, Barre P, Cardinet G, Santoni S, Huguet T, Huyghe C. 2003. Construction of two genetic linkage maps in cultivated tetraploid alfalfa (Medicago sativa) using microsatellite and AFLP markers. BMC Plant Biology 3: 9.

Kamiri M, Stift M, Srairi I, Costantino G, El Moussadik A, Hmyene A, Bakry F, Ollitrault P, Froelicher Y. 2011. Evidence for non-disomic inheritance in a Citrus interspecific tetraploid somatic hybrid between $C$. reticulata and $C$. limon using SSR markers and cytogenetic analysis. Plant Cell Reports 30(8): 1415-1425.

Kamiri M, Stift M, Srairi I, Chahidi B, Poullet T, Costantino G, Dambier D, Ollitrault P, Froelicher Y. 2012. Gametic configuration and inheritance of SSR markers in tetraploid interspecific and intergeneric citrus somatic hybrids. XII International Citrus Congress. 19-23 December 2012. Valence, Spain.

Karlov GI, Khrustaleva LI, Lim KB, Van Tuyl JM. 1999. Homoeologous recombination in 2 ngametes producing interspecific hybrids of Lilium (Liliaceae) studied by genomic in situ hybridization (GISH). Genome 42(4): 681-686.

Kauffman E, Gestl E, Kim D, Walker C, Hite J, Yan G, Rogan P, Johnson S, Cheng K. 1995. Microsatellite-centromere mapping in the Zebrafish (Danio rerio). Genomics 30(2): 337341.

Kepiro JL, Roose ML. 2010. AFLP markers closely linked to a major gene essential for nucellar embryony (apomixis) in Citrus maxima x Poncirus trifoliata. Tree Genetics \& Genomes 6: 1-11.

Khan IA, Kender WJ. 2007. Citrus breeding: introduction and objectives. In: IA Khan, ed. Citrus Genetics, Breeding and Biotechnology. CABI: Wallingford, UK.

Kijas J, Thomas MR, Fowler J, Roose ML. 1997. Integration of trinucleotide microsatellites into a linkage map of citrus. Theoretical and Applied Genetics 94: 701-706.

Kirov G, Nikolov I, Georgieva L, Moskvina V, Owen MJ, O'Donovan MC. 2006. Pooled DNA genotyping on Affymetrix SNP genotyping arrays. BMC Genomics 7: 27. 
Kobayashi S, Ohgawara T, Saito W, Nakamura Y, Shimizu J. 1995. Fruit characteristics and pollen fertility of citrus somatic hybrids. Journal of the Japanese Society for Horticultural Science 64(2): 283-289.

Kohmoto K, Itoh Y, Shimomura N, Kondoh Y, Otani H, Kodama M, Nishimura S, Nakatsuka S. 1993. Isolation and biological-activities of 2 Host-Specific Toxins from the tangerine pathotype of Alternaria alternata. Phytopathology 83: 495-502.

Kohmoto K, Akimitsu K, Otani H. 1991. Correlation of resistance and susceptibility of citrus to Alternaria alternata with sensitivity to Host-Specific Toxins. Phytopathology 81: 719-722.

Koltunow AM, Brennan P, Protopsaltis S. 2000. Regeneration of West Indian limes (Citrus aurantifolia) containing genes for decreased seed set. ISHS Acta Horticulturae. First International Citrus Biotechnology Symposium 535: 81-91.

Kono Y, Gardner JM, Takeuchi S. 1986. Structure of the host-selective toxins produced by a pathotype of Alternaria citri causing brown spot disease of mandarins. Agricultural and Biological Chemistry 50: 801-804.

Krezdorn AH, Robinson FA. 1958. Unfruitfulness in the 'Orlando' tangelo. Proceedings of the Florida State Horticultural Society 21: 86-91.

Krueger RR, Navarro L. 2007. Citrus germplasm resources. In: IA Khan. Citrus Genetics, Breeding and Biotechnology. CABI: Wallingford, UK.

Krug C. 1943. Chromosome number in the subfamily Aurantioideae with special reference to the genus Citrus. Botanical Gazette 104: 602-611.

Kwok PY, Xiao M. 2003. SNP genotyping and molecular haplotyping of DNA pools. Cold Spring Harbor Symposia on Quantitative Biology 68: 65-67.

Kwok PY. 2001. Methods for genotyping single nucleotide polymorphisms. Annual Review of Genomics and Human Genetics 2: 235-258.

Ladaniya M. 2008. Citrus fruit: Biology, Technology and Evaluation. Elsevier Inc., India.

Lander E, Botstein D. 1989. Mapping Mendelian factors underlying quantitative traits using RFLP linkage maps. Genetics 121: 185-199.

Landergott U, Naciri Y, Schneller JJ, Holderegger R. 2006. Allelic configuration and polysomic inheritance of highly variable microsatellites in tetraploid gynodioecious Thymus praecox agg. Theoretical and Applied Genetics 113(3): 453-465.

Lapin WK. 1937. Investigation on polyploidy in Citrus. USSR All Union Scientific Research Institute 1(4): 1-68.

Lavebratt C, Sengul S, Jansson M, Schalling M. 2004. Pyrosequencing-based SNP allele frequency estimation in DNA pools. Human Mutation 23(1): 92-97.

Lelley T, Mahmoud AA, Lein V. 1987. Genetics and cytology of unreduced gametes in cultivated rye (Secale cereale L.). Genome 29(4): 635-638.

Lewis CM, Knight J. 2012. Introduction to genetic association studies. Cold Spring Harbor Protocols 2012: doi:10.1101/pdb.top068163. 
Li DD, Shi W, Deng X. 2002. Agrobacterium-mediated transformation of embryogenic calluses of Ponkan mandarin and the regeneration of plants containing the chimeric ribonuclease gene. Plant Cell Reports 21: 153-156.

Li DD, Shi W, Deng XX. 2003. Factors influencing Agrobacterium-mediated embryogenic callus transformation of Valencia sweet orange (Citrus sinensis) containing the pTA29-barnase gene. Tree Physiology. 23: 1209-1215.

Li X, Xie R, Lu Z, Zhou Z. 2010. The origin of cultivated Citrus as inferred from internal transcribed spacer and chloroplast DNA sequence and Amplified Fragment Length Polymorphism fingerprints. Journal of the American Society for Horticultural Science, 135: 341350 .

Lian J, Yin Y, Oliver-Bonet M, Liehr T, Ko E, Turek P, Sun F, Martin RH. 2008. Variation in crossover interference levels on individual chromosomes from human males. Human Molecular Genetics 17(17): 2583-2594.

Liang G, Xiong G, Guo Q, He Q, Li X. 2007. AFLP analysis and the taxonomy of Citrus. Acta Horticulturae 760: 137-142.

Lim KB, Ramanna MS, de Jong JH, Jacobsen E, van Tuyl JM. 2001. Indeterminate meiotic restitution (IMR): a novel type of meiotic nuclear restitution mechanism detected in interspecific lily hybrids by GISH. Theoretical and Applied Genetics 103: 219-230.

Lim KB, Shen TM, Barba-González R, Ramanna MS, van Tuyl JM. 2004. Occurrence of SDR $2 n$ gametes in Lilium hybrids. Breeding Science 54(1): 13-18.

Lindner K, Seeb J, Habicht C, Knudsen KL, Knudsen K, Kretschmer E, Reedy, DJ, Spruell P, Allendorf FW. 2000. Gene-centromere mapping of 312 loci in pink salmon by half-tetrad analysis. Genome 43(3): 538-549.

Ling P, Duncan LW, Deng Z, Dunn D, Hu X, Huang S, Gmitter FG Jr. 2000. Inheritance of citrus nematode resistance and its linkage with molecular markers. Theoretical and Applied Genetics 100: 1010-1017.

Liu B, Wendel JF. 2003. Epigenetic phenomena and the evolution of plant allopolyploids. Molecular Phylogenetics and Evolution 29: 365-379.

Liu S, Yeh C, Tang HM, Nettleton D, Schnable PS. 2012. Gene Mapping via Bulked Segregant RNA-Seq (BSR-Seq). PLoS ONE 7: e36406.

Lo HS, Wang ZN, Hu Y, Yang HH, Gere S, Buetow KH, Lee MP. 2003. Allelic variation in gene expression is common in the human genome. Genome Research 13(8): 1855-1862.

Longley AE. 1925. Polycarpy, polyspory and polyploidy in Citrus and Citrus relatives. Journal of the Washington Academy of Sciences 15: 347-357.

Lorang J, Sweat T, Wolpert T. 2007. Plant disease susceptibility conferred by a "resistance" gene. Proceedings of the National Academy of Sciences of the United States of America 104(37): 14861-14866.

Lorang J, Kidarsa T, Bradford CS, Gilbert B, Curtis M, Tzeng S, Maier CS, Wolpert TJ. 2012. Tricking the guard: exploiting plant defense for disease susceptibility. Science 338: 659662. 
Lotfy S, Luro F, Carreel F, Froelicher Y, Rist D, Ollitrault P. 2003. Application of Cleaved Amplified Polymorphic Sequence method for analysis of cytoplasmic genome among Aurantioideae intergeneric somatic hybrids. Journal of the American Society for Horticultural Science 128: 225-230.

Louzada EA, Grosser JW, Gmitter FG Jr, Nielsen B, Chandler JL, Deng XX, Tusa N. 1992. Eight new somatic hybrid citrus rootstocks with potential for improved disease resistance. HortScience 27: 1033-1036.

Louzada ES, Grosser JW, Gmitter FG Jr. 1993. Intergeneric somatic hybridization of sexually incompatible parents: Citrus sinensis and Atalantia ceylanica. Plant Cell Reports 12: 687-690.

Luciano M, Houlihan L, Harris S, Gow A, Hayward C, Starr J, Deary I. 2010. Association of existing and new candidate genes for anxiety, depression and personality traits in older people. Behavior Genetics 40: 518-532.

Luro F, Lorieux M, Laigret F, Bove JM, Ollitrault P. 1994. Genetic mapping of an intergeneric Citrus hybrid using molecular markers. Fruits 49: 404-408.

Luro F, Rist D, Ollitrault P. 2001. Evaluation of genetic relationships in Citrus genus by means of sequence tagged microsatellites. Proceedings of the International Symposium on Molecular Markers for Characterizing Genotypes and Identifying Cultivars in Horticulture 546: 537-542.

Luro F, Maddy F, Jacquemond C, Froelicher Y, Morillon R, Rist D, Ollitrault P. 2004. Identification and evaluation of diplogyny in clementine (Citrus clementina) for use in breeding. Acta Horticulturae 663(2): 841-848.

Luro F, Costantino G, Terol J, Argout X, Allario T, Wincker P, Talon M, Ollitrault P, Morillon R. 2008. Transferability of the EST-SSRs developed on Nules clementine (Citrus clementina Hort ex Tan) to other Citrus species and their effectiveness for genetic mapping. BMC Genomics 9: 287.

Mabberley DJ. 1997. A classiication for edible Citrus. Telopea 7: 167-172.

MacQueen JB. 1966. Some Methods for classification and analysis of multivariate observations. Proceedings of 5-th Berkeley Symposium on Mathematical Statistics and Probability 1: 281-297.

Maekawa N, Yamamoto M, Nishimura S, Kohmoto K, Kuwata M. 1984. Studies on hostspecific AF-toxins produced by Alternaria alternata strawberry pathotype causing Alternaria black spot of strawberry. I. Production of host-specific toxins and their biological activity. Annals of the Phytopathology Society of Japan 50: 600-609.

MAGRAMA. 2013. Superficies y producciones anuales de cultivos.

Main BJ, Bickel RD, Mclntyre LM, Graze RM, Calabrese PP, Nuzhdin SV. 2009. Allelespecific expression assays using Solexa. BMC Genomics 10: 422.

Marsden JE, Schwager SJ, May B. 1987. Single-locus inheritance in the tetraploid treefrog hyla-versicolor with an analysis of expected progeny ratios in tetraploid organisms. Genetics 116(2): 299-311.

Martins FA, Carneiro PCS, Guimaraes CT, Magalhaes JV, Carneiro JES, Cruz CD. 2009. Distinction between plant samples according to allele dosage by semiquantitative polymerase chain reaction. Genetics and Molecular Research 8(1): 319-327. 
Mason A, Nelson M, Yan G, Cowling W. 2011. Production of viable male unreduced gametes in Brassica interspecific hybrids is genotype specific and stimulated by cold temperatures. BMC Plant Biology 11(1): 103.

Mather K. 1936. Segregation and linkage in autotetraploids. Journal of Genetics 32: 287-314.

Matsumoto R, Okudai N, Oiyama I, Takahara T, Yamamoto M, Asada K, Ishiuchi D, Murata H. 1991. New citrus cultivar "Tsunokaori". Bulletin of the Fruit Tree Research Station 21: 59-65.

McCollum TG. 2007. Update of the USDA, ARS citrus scion improvement project. Proc Fla State Hort Soc 120: 285-287.

McQuown E, Gall GAE, May B. 2002. Characterization and inheritance of six microsatellite loci in lake sturgeon. Transactions of the American Fisheries Society 131(2): 299-307.

Meaburn E, Butcher LM, Schalkwyk LC, Plomin R. 2006. Genotyping pooled DNA using 100K SNP microarrays: a step towards genomewide association scans. Nucleic Acids Research 34(4): e28.

Mendes BJ, Filho FM, Farias P, Benedito V. 2001. Citrus somatic hybridization with potential for improved blight and CTV resistance. In Vitro Cellular \& Developmental Biology - Plant 37: 490-495.

Mendiburu AO, Peloquin SJ. 1976. Sexual polyploidization and depolyploidization: some terminology and definitions. Theoretical and Applied Genetics 48: 137-143.

Mendiburu AO, Peloquin SJ. 1979. Gene-centromere mapping by $4 X-2 X$ matings in potatoes. Theoretical and Applied Genetics 54: 177-180.

Michelmore RW, Paran I, Kesseli RV. 1991. Identification of markers linked to diseaseresistance genes by bulked segregant analysis: a rapid method to detect markers in specific genomic regions by using segregating populations. Proceedings of the National Academy of Sciences, USA 88: 9828-9832.

Michelmore RW, Meyers BC. 1998. Clusters of resistance genes in plants evolve by divergent selection and a Birth-and-Death process. Genome Research 8: 1113-1130.

Ming R, Liu ,S.C., Moore PH, Irvine J, Paterson AH. 2001. QTL analysis in a complex autopolyploid: genetic control of sugar content in sugarcane. Genome Research 11(12): 20752084.

Miwa T. 1951. Pollination, fertilization and fruit drop in Citrus tamurana Hort. Bulletin of the Faculty of Agriculture, Miyazaki University 2: 1-67.

Moffett P, Farnham G, Peart J, Baulcombe DC. 2002. Interaction between domains of a plant NBS-LRR protein in disease resistance-related cell death. The EMBO Journal 21: 4511-4519.

Mok DWS, Peloquin SJ. 1975. Three mechanisms of $2 \mathrm{n}$ pollen formation in diploid potatoes. Canadian Journal of Genetics and Cytology 17: 217-225.

Moore GA, Tozlu I, Weber CA, Guy CL. 2000. Mapping quantitative trait loci for salt tolerance and cold tolerance in Citrus grandis (L.) Osb. x Poncirus trifoliata (L.) Raf. hybrid populations. Acta Horticulturae 535: 37-45.

Mourao-Fo F, Gmitter FJ Jr, Grosser J. 1996. New tetraploid breeding parents for triploid seedless citrus cultivar development. Fruit Varieties Journal. 50: 76-80. 
Muller HJ. 1914. A new mode of segregation in Gregory's tetraploid primulas. American Naturalist 48: 508-512.

Murad A, Lewis S, Smith G, Collin S, Chen L, Hamdy F, Neal D, Donovan J, Martin RM. 2009. PTGS2-899G $>C$ and prostate cancer risk: a population-based nested case-control study (ProtecT) and a systematic review with meta-analysis. Prostate Cancer and Prostatic Diseases 12(3): 296-300.

Mustard MJ, Lynch SJ, Nelson RO. 1956. Pollination and floral studies of the Minneola tangelo. Proceedings of the Florida State Horticultural Society 69: 277-281.

Nadeem K, Barba-González R, Ramanna MS, Arens P, Visser R, van Tuyl JM. 2010. Relevance of unilateral and bilateral sexual polyploidization in relation to intergenomic recombination and introgression in Lilium species hybrids. Euphytica 171(2): 157-173.

Nagy E, Lee T, Ramakrishna W, Xu Z, Klein P, SanMiguel P, Cheng C, Li J, Devos K, Schertz K, Dunkle L, Bennetzen J. 2007. Fine mapping of the Pc locus of Sorghum bicolor, a gene controlling the reaction to a fungal pathogen and its host-selective toxin. Theoretical and Applied Genetics 114(6): 961-970.

Nagy E, Bennetzen J. 2008. Pathogen corruption and site-directed recombination at a plant disease resistance gene cluster. Genome Research 18(12): 1918-1923.

Nakamura M. 1943. Cytological and ecological studies on the genus Citrus with special reference to the occurrence of sterile pollen grains. Memoirs of the Faculty of Science and Agriculture, Taihoku Imperial University 27: 53-159.

Nakano M, Nesumi H, Yoshioka T, Yoshida T. 2001. Segregation of plants with undeveloped anthers among hybrids derived from the seed parent, 'Kiyomi' (Citrus unshiu x C. sinensis). Journal of the Japanese Society for Horticultural Science 70(5): 539-545.

Nakashima Y, Ueno T, Fukami H, Taga T, Masuda H, Osaki K, Otani H, Kohmoto K, Nishimura S. 1985. Isolation and structures of AK-toxin I and II, host-specific metabolites produced by Alternaria alternata Japanese pear pathotype. Agricultural and Biological Chemistry 49: 807-815.

Nakatsuka S, Ueda K, Goto T, Yamamoto M, Nishimura S, Kohmoto K. 1986. Structure of AF-toxin II, one of the host-specific toxins, produced by Alternaria alternata strawberry pathotype. . Tetrahedron Letters 27: 2753-2756.

Navarro L, Roistacher CN, Murashige T. 1975. Improvement of shoot-tip grafting in vitro for virus-free citrus. Journal of the American Society for Horticultural Science 100(5): 471-479.

Navarro L, Olivares-Fuster O, Juárez J, Aleza P, Pina JA, Ballester-Olmos J, Cervera M, Fagoaga C, Durán-Vila N, Peña L. 2004. Applications of biotechnology to citrus improvement in Spain. In: LG Albrigo, VG Sauco, eds.

Navarro L, Juárez J, Aleza P, Pina J, Olivares-Fuster O, Cuenca J, Julve J. 2005. Programa de obtención de híbridos triploides de mandarino en España. Phytoma 170: 36-41.

Navarro L, Aleza P, Cuenca J, Juárez J, Pina J, Ortega C, Navarro A, Ortega V. 2012. The triploid mandarin breeding program in Spain. XII International Citrus Congress. 19-23 December 2012. Valence, Spain. 
Nesumi H, Nakano M, Yoshida T. 2001. Mode of inheritance on the abnormal development of impregnated ovules derived from Mukaku-kishu. Journal of the Japanese Society of Horticultural Science 70(2): 869.

Neve B, Froguel P, Corset L, Vaillant E, Vatin V, Boutin P. 2002. Rapid SNP allele frequency determination in genomic DNA pools by Pyrosequencing ${ }^{\mathrm{TM}}$. BioTechniques 32(5): 1138-1142.

Nicolosi E. 2007. Origin and taxonomy. In: IA Khan, ed. Citrus Genetics, Breeding and Biotechnology. CABI: Wallingford, UK.

Nicolosi E, Deng ZN, Gentile A, La Malfa S, Continella G, Tribulato E. 2000. Citrus phylogeny and genetic origin of important species as investigated by molecular markers. Theoretical and Applied Genetics 100: 1155-1166.

Nijman IJ, Kuipers S, Verheul M, Guryev V, Cuppen E. 2008. A genome-wide SNP panel for mapping and association studies in the rat. BMC Genomics 9: 95.

Nishiura M. 1964. Citrus breeding and bud selection in Japan. American Society for Horticultural Science Citrus Breeding Symposium, Boulder, Colo, USA 1964: 79-83.

Ohgawara T, Kobayashi S, Ohgawara E, Uchimaya H, Ishi S. 1985. Somatic hybrid plants obtained by protoplast fusion between Citrus sinensis and Poncirus trifoliata. Theoretical and Applied Genetics 71: 1-4.

Oiyama I, Okudai N, Takahara T. 1981. Ploidy levels of seedlings obtained from $2 \mathrm{x} X 4 \mathrm{x}$ crosses in citrus. Proceedings of the International Society of Citriculture: 32-34.

Okagaki RJ, Jacobs MS, Stec AO, Kynast RG, Buescher E, Rines HW, Vales MI, RieraLizarazu O, Schneerman M, Doyle G, Friedman KL, Staub RW, Weber DF, Kamps TL, Amarillo IFE, Chase CD, Bass HW, Phillips RL. 2008. Maize centromere mapping: a comparison of physical and genetic strategies. Journal of Heredity 99: 85-93.

Olivares-Fuster O, Hernández-Garrido M, Guerri J, Navarro L. 2007. Plant somatic hybrid cytoplasmic DNA characterization by single-strand conformation polymorphism. Tree Physiology. 27: 785-792.

Oliver R, Lazo G, Lutz J, et al. 2011. Model SNP development for complex genomes based on hexaploid oat using high-throughput 454 sequencing technology. BMC Genomics 12: 77.

Ollitrault F, Terol J, Martin AA, Pina JA, Navarro L, Talon M, Ollitrault P. 2012. Development of indel markers from Citrus clementina (Rutaceae) BAC-end sequences and interspecific transferability in Citrus. American Journal of Botany 99(7): e268-73.

Ollitrault P, Vanel F, Froelicher Y, Dambier D. 1995. Creation of triploid citrus hybrids by electrofusion of haploid and diploid protoplasts. Acta Horticulturae 535: 191-198.

Ollitrault P, Dambier D, Jacquemont C, Allent V, Luro F. 1996a. In vitro rescue and selection of spontaneous triploid by flow cytometry for easy peeler citrus breeding. Proceedings of the International Society of Citriculture 1: 254-258.

Ollitrault P, Dambier D, Sudahono S, Luro F. 1996b. Somatic hybridisation in citrus: some new hybrid and alloplasmic plants Proc Int Soc Citriculture: 907-912.

Ollitrault P, Guo W, Grosser JW. 2007a. Somatic Hybridization. In: IA Khan, ed. Citrus Genetics, Breeding and Biotechnology . CABI: Wallingford, UK, 238. 
Ollitrault P, Luro F, Yamamoto M. 2007b. Seedlessness and ploidy manipulations. In: IA Khan. Citrus Genetics, Breeding and Biotechnology. CABI: Wallingford, UK.

Ollitrault P, Dambier D, Luro F, Froelicher Y. 2008. Ploidy manipulation for breeding seedless triploid citrus. Plant Breeding Reviews 30: 323-352.

Ollitrault P, Terol J, Chen C, Federici CT, Lotfy S, Hippolyte I, Ollitrault F, Bérard A, Chauveau A, Costantino G, Kacar Y, Mu L, Cuenca J, Garcia A, Froelicher Y, Aleza P, Boland A, Billot C, Navarro L, Luro F, Roose ML, Gmitter FG Jr, Talon M, Brunel D. 2011. A reference linkage map of $C$. clementina based on SNPs, SSRs and Indels. Plant and Animal Genome XIX Conference San Diego, CA, January 15-19, 2011: P477.

Ollitrault P, Navarro L. 2012. Citrus. In: ML Badenes, DH Byrne, eds. Springer US, 623-662.

Ollitrault P, Terol J, Chen C, Federici C, Lotfy S, Hippolyte I, Ollitrault F, Bérard A, Chauveau A, Cuenca J, Costantino G, Kacar Y, Mu L, García-Lor A, Froelicher Y, Aleza P, Boland A, Billot C, Navarro L, Luro F, Roose M, Gmitter FG, Talón M, Brunel D. 2012a. A reference genetic map of $C$. clementina Hort. ex Tan.; citrus evolution inferences from comparative mapping. BMC Genomics 13: 593.

Ollitrault P, Terol J, García-Lor A, Bérard A, Chauveau A, Froelicher Y, Belzile C, Morillon R, Navarro L, Brunel D, Talon M. 2012b. SNP mining in C. clementina BAC end sequences; transferability in the Citrus genus (Rutaceae), phylogenetic inferences and perspectives for genetic mapping. BMC Genomics 13: 13.

Ortiz R. 1997. Occurrence and Inheritance of 2n pollen in Musa. Annals of Botany 79: 449-453.

Ortiz R, Peloquin SJ. 1991. Breeding for $2 \mathrm{n}$-egg production in haploid-X-species $2 \mathrm{x}$-potato hybrids. American Potato Journal 68(10): 691-703.

Osawa I. 1912. Cytological and experimental studies in Citrus. Journal of the College of Agriculture, Tokyo University 4: 83-116.

Osborn TC, Chris Pires J, Birchler JA, Auger DL, Jeffery Chen Z, Lee H, Comai L, Madlung A, Doerge RW, Colot V, Martienssen RA. 2003. Understanding mechanisms of novel gene expression in polyploids. Trends in Genetics 19: 141-147.

Otani H, Kohmoto K, Kodama M. 1995. Alternaria toxins and their effects on host plants. Canadian Journal of Botany 73: 453-458.

Otto SP, Whitton J. 2000. Polyploid incidence and evolution. Annual Review of Genetics 34: 401-437.

Pang X, Hu C, Deng X. 2007. Phylogenetic relationships within Citrus and its related genera as inferred from AFLP markers. Genetic Resources and Crop Evolution 54: 429-436.

Park T, Kim J, Hutten RCB, van Eck HJ, Jacobsen E, Visser RGF. 2007. Genetic positioning of centromeres using half-tetrad analysis in a 4x-2x cross population of potato. Genetics 176.

Pécrix Y, Rallo G, Folzer H, Cigna M, Gudin S, Le Bris M. 2011. Polyploidization mechanisms: temperature environment can induce diploid gamete formation in Rosa sp. Journal of Experimental Botany. doi:10.1093/jxb/err052.

Peever TL, Canihos Y, Olsen L, Ibáñez A, Liu YC, Timmer LW. 1999. Population genetic structure and host specificity of Alternaria spp. causing brown spot of Minneola tangelo and rough lemon in Florida. Phytopathology 89(10): 851-860. 
Pegg KG. 1966. Studies of a strain of Alternaria citri Pierce, the causal organism of brown spot of Emperor mandarin. Queensland Journal of Agriculture and Animal Science 23(1): 15-28.

Peloquin SJ, Yerk GL, Werner JE, Darmo E. 1989. Potato breeding with haploids and $2 \mathrm{n}$ gametes. Genome 31(2): 1000-1004.

Peloquin SJ, Boiteux LS, Simon PW, Jansky SH. 2008. A chromosome-specific estimate of transmission of heterozygosity by $2 n$ gametes in potato. Journal of Heredity 99: 177-181.

Penjor T, Yamamoto M, Uehara M, Ide M, Matsumoto N, Matsumoto R, Nagano Y. 2013. Phylogenetic relationships of Citrus and its relatives based on matK gene sequences. PLoS ONE 8: e62574.

Peres NA, Timmer LW. 2006. Alternaria brown spot of citrus in Brazil: Evaluation of the AlterRater for spray timing and effects on yield of Murcott tangor. Crop Protection 25: 454-460.

Predieri S. 2001. Induced mutation and tissue culture in fruits. Plant Cell Tissue Organ Culture 64(3): 185-210.

Qu DY, Zhu DW, Wang DS, Gao ZW. 1995. Genetic analysis of $2 n$ gamete formation in potato. Acta Horticulturae Sinica 22(1): 61-66.

Qu S, Liu G, Zhou B, Bellizzi M, Zeng L, Dai L, Han B, Wang G. 2006. The broad-spectrum Blast resistance gene Pi9 encodes a Nucleotide-Binding Site-Leucine-Rich Repeat protein and is a member of a multigene family in rice. Genetics 172(3): 1901-1914.

Quarrie SA, Lazic-Jancic V, Kovacevic D, Steed A, Pekic S. 1999. Bulk segregant analysis with molecular markers and its use for improving drought resistance in maize. Journal of Experimental Botany 50: 1299-1306.

Raghuvanshi SS. 1962. Cytogenetical studies in genus Citrus. IV. Evolution in genus Citrus. Cytologia 27: 172-188.

Ramanna MS. 1974. The origin of unreduced microspores due to aberrant cytokinesis in the meiocytes of potato and its genetic significance. Euphytica 23: 20-30.

Ramanna MS. 1979. A re-examination of the mechanisms of $2 n$ gametes formation in potato and its implications for breeding. Euphytica 28: 537-561.

Ramanna MS, Jacobsen E. 2003. Relevance of sexual polyploidization for crop improvement A review. Euphytica 133: 3-8.

Ramsey J. 2007. Unreduced gametes and neopolyploids in natural populations of Achillea borealis. Heredity 98: 143-150.

Ramsey J, Schemske DW. 1998. Pathways, mechanisms, and rates of polyploid formation in flowering plants. Annual Review of Ecology and Systematics 29: 467-501.

Ramsey J, Schemske DW. 2002. Neopolyploidy in flowering plants. Annual Review of Ecology and Systematics 33: 589-639.

Raza H, Mumtaz-Khan M, Ali-Khan A. 2003. Review: seedlessness in Citrus. International Journal of Agriculture and Biology 5: 388-391.

Recupero GR, Russo G, Recupero S. 2005. New promising citrus triploid hybrids selected from crosses between monoembryonic diploid female ant tetraploid male parents. HortScience 40: $516-520$. 
Reinisch AJ, Dong JM, Brubaker CL, Stelly DM, Wendel JF, Paterson AH. 1994. A Detailed RFLP Map of Cotton, Gossypium Hirsutum X Gossypium Barbadense: Chromosome Organization and Evolution in a Disomic Polyploid Genome. Genetics 138(3): 829-847.

Reis RF, de Almeida TF, Stuchi ES, de Goes A. 2007. Susceptibility of citrus species to Alternaria alternata, the causal agent of the Alternaria Brown Spot. Scientia Horticulturae 113(4): 336-342.

Rhoades MM, Dempsey E. 1966. Induction of chromosome doubling at meiosis by the elongate gene in maize. Genetics 54(2): 505-522.

Ricci G, Astolfi A, Remondini D, Cipriani F, Formica S, Dondi A, Pession A. 2011. Pooled genome-wide analysis to identify novel risk loci for pediatric allergic asthma. PLoS ONE 6: e16912.

Rickert AM, Premstaller A, Gebhardt C, Oefner PJ. 2002. Genotyping of SNPs in a polyploid genome by pyrosequencing ${ }^{\mathrm{TM}}$. BioTechniques 32(3): 592-593, 596-598 passim.

Ritland K. 2002. Estimation of gene frequency and heterozygosity from pooled samples. Molecular Ecology Notes 2: 370-372.

Rockman MV, Kruglyak L. 2006. Genetics of global gene expression. Nature Reviews Genetics 7: 862-872.

Ronaghi M, Uhlen M, Nyren P. 1998. A sequencing method based on real-time pyrophosphate. Science 281(5375): 363-365.

Ronald J, Akey JM, Whittle J, Smith EN, Yvert G, Kruglyak L. 2005. Simultaneous genotyping, gene-expression measurement, and detection of allele-specific expression with oligonucleotide arrays. Genome Research 15(2): 284-291.

Roose ML. 1988. Isozymes and DNA restriction fragment length polymorphisms in Citrus breeding and systematics. Proceedings of the XVI International Citrus Congress, Tel Aviv, Israel : 155-165-165.

Roose ML, Williams TA, Soost RK, Cameron JW. 2002. US Patents: USPP 15,461, USPP 15,703, USPP 16,289. University of California, Riverside, USA.

Roose ML, Williams TE. 2007. Mutation Breeding. In: IA Khan. Citrus Genetics, Breeding and Biotechnology. CABI: Wallingford, UK.

Rosenberg O. 1927. Die Semiheterotypische Teilung und Ihre Bedeutung für die Entstehung verdoppelter Chromozomenzahlen. Hereditas 8: 305-358.

Rosso ML, Burleson S, Maupin L, Rainey K. 2011. Development of breeder-friendly markers for selection of MIPS1 mutations in soybean. Molecular Breeding 28: 127-132.

Rozowsky J, Abyzov A, Wang J, Alves P, Raha D, Harmanci A, Leng J, Bjornson R, Kong Y, Kitabayashi N, Bhardwaj N, Rubin M, Snyder M, Gerstein M. 2011. AlleleSeq: analysis of allele-specific expression and binding in a network framework. Molecular Systems Biology 7: 522.

Ruiz C, Bretó MP, Asins MJ. 2000. A quick methodology to identify sexual seedlings in citrus breeding programs using SSR markers. Euphytica 112: 89-94. 
Ruiz C, Asins MJ. 2003. Comparison between Poncirus and Citrus genetic linkage maps. Theoretical and Applied Genetics 106: 826-36.

Saintenac C, Falque M, Martin OC, Paux E, Feuillet C, Sourdille P. 2009. Detailed recombination studies along chromosome $3 \mathrm{~B}$ provide new insights on crossover distribution in wheat (Triticum aestivum L.). Genetics 181: 393-403.

Saleh B, Allario T, Dambier D, Ollitrault P, Morillon R. 2008. Tetraploid citrus rootstocks are more tolerant to salt stress than diploid. Comptes Rendus Biologies 331(9): 703-710.

Sapolsky RJ, Hsie L, Berno A, Ghandour G, Mittmann M, Fan JB. 1999. High-throughput polymorphism screening and genotyping with high-density oligonucleotide arrays. Genetic Analysis-Biomolecular Engineering 14: 187-192.

Schinor E, Pacheco C, Bastianel M, Azevedo F, Cristofani-Yali M. 2012. New tangors for Brazilian citriculture. XII International Citrus Congress 19-23 December 2012 Valence, Spain.

Scora RW. 1975. On the history and origin of citrus. Bulletin of the Torrey Botanical Club 102: 369-375.

Scora RW. 1988. Biochemistry, taxonomy and evolution of modern cultivated citrus. Citriculture: Proceedings of the Sixth International Citrus Congress, Tel Aviv, Israel, March 6-11, 1988.

Sdiri S, Bermejo A, Aleza P, Navarro P, Salvador A. 2012. Phenolic composition, organic acids, sugars, vitamin $C$ and antioxidant activity in the juice of two new triploid late-season mandarins. Food Research International 49(1): 462-468.

Shaw S, Carrasquillo M, Kashuk C, Puffenberger E, Chakravarti A. 1998. Allele frequency distributions in pooled DNA samples: applications to mapping complex disease genes. Genome Research 8(2): 111-123.

Shu QY. 2009. Induced plant mutations in the genomics era. Food and Agriculture Organization of the United Nations: Rome.

Singh S, Sharma SR, Kalia P, Deshmukh R, Kumar V, Sharma P, Sharma TR. 2012. Molecular mapping of the downy mildew resistance gene Ppa3 in cauliflower (Brassica oleracea var. botrytis L.). Journal of Horticultural Science \& Biotechnology 87(2): 137-143.

Sjoling A, Walentinsson A, Nordlander C, Karlsson A, Behboudi A, Samuelson E, Levan G, Rohme D. 2005. Assessment of allele dosage at polymorphic microsatellite loci displaying allelic imbalance in tumors by means of quantitative competitive-polymerase chain reaction. Cancer Genetics and Cytogenetics 157(2): 97-103.

Solel Z. 1991. Alternaria Brown Spot on Minneola tangelos in Israel. Plant Pathology 40(1): 145-147.

Solel Z, Kimchi M. 1997. Susceptibility and resistance of citrus genotypes to Alternaria alternata pv. citri. Journal of Phytopathology 145: 389-391.

Soltis DE, Soltis PS. 1993. Molecular data and the dynamic nature of polyploidy. Critical Reviews in Plant Science 12: 243-273.

Soltis PS, Soltis DE. 2000. The role of genetic and genomic attributes in the success of polyploids. Proceedings of the National Academy of Sciences 97: 7051-7057. 
Soltis PS, Soltis DE. 2009. The role of hybridization in plant apeciation. Annual Review of Plant Biology 60: 561-588.

Soost R. 1987. Breeding citrus-genetics and nucellar embryony. In: AJ Abbott, R Atkin, eds. Improving vegetatively propagated crops. Academic Press, London, 83-110.

Spiegel-Roy P. 1990. Economic and agricultural impact of mutation breeding in fruit trees. Mutation Breeding Reviews. Vienna 5: 215-235.

Spiegel-Roy P, Vardi A. 1992. 'Shani,' 'Orah' and 'Winola': Three new selections from our breeding program, Proceedings of the $7^{\text {th }}$ International Citrus Congress of the International Society of Citriculture. Acireale, Italy: 72-73.

Ssebuliba RN, Tenkouano A, Pillay M. 2008. Male fertility and occurrence of $2 n$ gametes in East African Highland bananas (Musa spp.). Euphytica 164(1): 53-63.

Starrantino A. 1992. Use of triploids for production of seedless cultivars in citrus improvement program. Proceedings of the International Society of Citriculture 1: 117-121.

Starrantino A, Recupero GR. 1981. Citrus hybrids obtained in vitro from $2 x$ females and $4 x$ male. Proceedings of the International Society of Citriculture 1: 31-32.

Stebbins GL. 1932. Cytology of Antennaria. II. Parthenogenetic species. Botanical Gazzete 94: 322-344.

Stebbins GL. 1950. Variation and Evolution in Plants. Columbia University Press, New York, USA.

Stebbins GL. 1971. Chromosomal Evolution in Higher Plants. Addison-Wesley, London, UK.

Stelly DM, Peloquin SJ. 1986. Diploid female gametophyte formation in 24-chromosome potatoes - genetic-evidence for the prevalence of the 2 nd meiotic division restitution mode. Canadian Journal of Genetics and Cytology 28(1): 101-108.

Steer S, Abkevich V, Gutin A, Cordell HJ, Gendall KL, Merriman ME, Rodger RA, Rowley KA, Chapman P, Gow P, Harrison AA, Highton J, Jones PBB, O'Donnell J, Stamp L, Fitzgerald L, Iliev D, Kouzmine A, Tran T, Skolnick MH, Timms KM, Lanchbury JS, Merriman TR. 2007. Genomic DNA pooling for whole-genome association scans in complex disease: empirical demonstration of efficacy in rheumatoid arthritis. Genes and Immunity 8(1): 57-68.

Stift M, Berenos C, Kuperus P, van Tienderen PH. 2008. Segregation models for disomic, tetrasomic and intermediate inheritance in tetraploids: a general procedure applied to Rorippa (yellow cress) microsatellite data. Genetics 179(4): 2113-2123.

Stukenbrock E, McDonald BA. 2009. Population genetics of fungal and oomycete effectors involved in gene-for-gene interactions. Molecular Plant-Microbe Interactions 22(4): 371-380.

Swart SH, Wingfield MJ, Swart WJ, Schute GC. 1998. Chemical control of Alternaria brown spot on Minneola tangelo in South Africa. Annals of Applied Biology 133: 17-30-30.

Swingle WT. 1943. The botany of Citrus and its wild relatives in the orange subfamily (family Rutaceae, subfamily Aurantioideae). University of California Press, Berkeley, USA. 
Swingle WT, Reece PC. 1967. The botany of Citrus and its wild relatives. In: W Reuther, H Webber, L Batchelor, eds. The Citrus Industry, Vol 1. University of California, Berkeley, USA, 190-430.

Swinnen S, Schaerlaekens K, Pais T, Claesen J, Hubmann G, Yang Y, Demeke M, Foulquié-Moreno M, Goovaerts A, Souvereyns K, Clement L, Dumortier F, Thevelein J. 2012. Identification of novel causative genes determining the complex trait of high ethanol tolerance in yeast using pooled-segregant whole-genome sequence analysis. Genome Research 22: 975-984.

Sybenga J. 1996. Chromosome pairing affinity and quadrivalent formation in polyploids: do segmental allopolyploids exist? Genome 39(6): 1176-1184.

Szelinger S, Pearson J, Craig D. 2011. Microarray-based genome-wide association studies using pooled DNA. In: JK DiStefano, ed. Disease Gene Identification: Methods and Protocols. Humana Press, 49-60.

Tabone T, Mather DE, Hayden MJ. 2009. Temperature Switch PCR (TSP): Robust assay design for reliable amplification and genotyping of SNPs. BMC Genomics 10: 580.

Tabor G, Kubisiak T, Klopfenstein N, Hall R, McNabb HS. 2000. Bulked Segregant Analysis Identifies Molecular Markers Linked to Melampsora medusae Resistance in Populus deltoides. Phytopathology 90(9): 1039-1042.

Tachikawa T, Tanaka Y, Hara S. 1961. Investigation on the breeding of Citrus trees. Study on the breeding of triploid Citrus varieties. Bulletin of the Shizuoka Prefectural Citrus Experiment Station 4: 33-44.

Tai G, DeJong H. 1997. A comparison of performance of tetraploid progenies produced by diploid and their vegetatively doubled (tetraploid) counterpart parents. Theoretical and Applied Genetics 94: 303-308.

Takahashi C, Leitch IJ, Ryan A, Bennett MD, Brandham PE. 1997. The use of genomic in situ hybridization (GISH) to show transmission of recombinant chromosomes by a partially fertile bigeneric hybrid, Gasteria lutzii $\times$ Aloe aristata (Aloaceae), to its progeny. Chromosoma 105(6): $342-348$

Tanaka T. 1977. Fundamental discussion of Citrus classification. Studia Citrologica 14: 1-6.

Tang XY, Luo ZR. 2002. Cytology of $2 n$ pollen formation in nonastringent persimmon. Agricultural Sciences in China 1(6): 680-683.

Tavoletti S, Bingham ET, Yandell BS, Veronesi F, Osborn TC. 1996. Half tetrad analysis in alfalfa using multiple restriction fragment length polymorphism markers. Proceedings of the National Academy of Sciences of the United States of America 93(20): 10918-10922.

Terol J, Conesa A, Colmenero JM, Cercos M, Tadeo F, Agusti J, Alos E, Andres F, Soler G, Brumos J, Iglesias DJ, Gotz S, Legaz F, Argout X, Courtois B, Ollitrault P, Dossat C, Wincker $\mathbf{P}$, Morillon R, Talon M. 2007. Analysis of 13000 unique Citrus clusters associated with fruit quality, production and salinity tolerance. BMC Genomics 8: 31.

Terol J, Naranjo MA, Ollitrault P, Talon M. 2008. Development of genomic resources for Citrus clementina: Characterization of three deep-coverage BAC libraries and analysis of 46,000 BAC end sequences. BMC Genomics 9: 423. 
Timmer LW, Peever TL, Solel Z, Akimitsu K. 2003. Alternaria diseases of citrus-novel pathosystems. Phytopathologia Mediterranea 42: 99-112.

Ton LD, Krezdorn AH. 1967. Growth of pollen tubes in three incompatible varieties of Citrus. Proceedings of American Society of Horticultural Science 89: 211-215.

Torres AM, Soost RK, Diendenhofen U. 1978. Leaf isozymes as genetic markers in Citrus. American Journal of Botany 65: 869-881.

Torres AM, Soost RK, Mau-Lastovicka T. 1982. Citrus isozymes: Genetics and distinguishing nucellar from zygotic seedlings. Journal of Heredity 73: 335-338.

Toyoda K, Collins N, Takahashi A, Shirasu K. 2002. Resistance and Susceptibility of Plants to Fungal Pathogens. Transgenic Research 11: 567-582.

Trebbi D, Maccaferri M, De Heer P, Sorensen A, Giuliani S, Salvi S, Sanguineti M, Massi A, Van der-Vossen E, Tuberosa R. 2011. High-throughput SNP discovery and genotyping in durum wheat (Triticum durum Desf). Theoretical and Applied Genetics 123: 555-569.

Trick M, Long Y, Meng J, Bancroft I. 2009. Single nucleotide polymorphism (SNP) discovery in the polyploid Brassica napus using Solexa transcriptome sequencing. Plant Biotechnology Journal 7: 334-346.

Trick M, Adamski NM, Mugford SG, Jiang C, Febrer M, Uauy C. 2012. Combining SNP discovery from next-generation sequencing data with bulked segregant analysis (BSA) to finemap genes in polyploid wheat. BMC Plant Biology 12: 14.

Tsuge T, Harimoto Y, Akimitsu K, Ohtani K, Kodama M, Akagi Y, Egusa M, Yamamoto M, Otani H. 2012. Host-selective toxins produced by the plant pathogenic fungus Alternaria alternata. FEMS Microbiology Reviews 37(1): 44-66.

USDA. 2013. http://www.fas.usda.gov/. Citrus: World Markets and Trade.

Uzun A, Yesiloglu T. 2012. Genetic diversity in Citrus. Genetic Diversity in Plants. In M Caliskan ed., InTech, doi: 10.5772/32885.

Vardi A, Elhanati A, Frydman-Shani A, Neumann H. 1996. Strategies and considerations in mandarin improvement programmes. Proceedings $8^{\text {th }}$ Citrus Congress International. Society of Citriculture, Sun City, Florida, USA. 109-112.

Vardi A, Levin I, Carmi N. 2008. Induction of seedlessness in Citrus: From classical techniques to emerging biotechnological approaches. Journal of the American Society for Horticultural Science 133: 117-126.

Veilleux R. 1985. Diploid and polyploid gametes in crop plants: mechanisms of formation and utilization in plant breeding. Plant Breeding Reviews 3: 253-288.

Vicent A, Armengol J, Sales R, García-Jiménez J, Alfaro-Lassala F. 2000. First Report of Alternaria Brown Spot of Citrus in Spain. Plant Disease 84(9): 1044.

Vicent A, Badal J, Asensi MJ, Sanz N, Armengol J, García-Jimenez J. 2004. Laboratory evaluation of citrus cultivars susceptibility and influence of fruit size on Fortune mandarin to infection by Alternaria alternata pv. citri. European Journal of Plant Pathology 110: 245-251.

Vicent A, Armengol J, García-Jimenez J. 2007. Rain fastness and persistence of fungicides for control of Alternaria Brown Spot of citrus. Plant Disease 91: 393-399. 
Vicent A, Armengol J, García-Jiménez J. 2009. Protectant activity of reduced concentration copper sprays against Alternaria brown spot on 'Fortune' mandarin fruit in Spain. Crop Protection 28: 1-6.

Voorrips RE, Gort G, Vosman B. 2011. Genotype calling in tetraploid species from bi-allelic marker data using mixture models. BMC Bioinformatics 12: 172.

Vorsa N, Rowland LJ. 1997. Estimation of $2 n$ megagametophyte heterozygosity in a diploid blueberry (Vaccinium darrowi Camp) clone using RAPDs. Journal of Heredity 88(5): 423-426.

Wagner A, Blackstone N, Cartwright P, Dick M, Misof B, Snow P, Wagner GP, Bartels J, Murtha M, Pendleton J. 1994. Surveys of gene families using Polymerase Chain-Reaction PCR selection and PCR drift. Systematic Biology 43(2): 250-261.

Wakana A, Iwamasa M, Uemoto S. 1981. Seed development in relation to ploidy of zygotic embryo and endosperm in polyembryonic Citrus. Proceedings of the International Society of Citriculture 1: 135-139.

Wang DY, Chang CJ. 1978. Triploid Citrus plantlets from endosperm. Scientia Sinica 21: 822827.

Wang XF, Li ZA, Tang KZ, Zhou CY, Yi L. 2010. First report of Alternaria Brown Spot of Citrus caused by Alternaria alternata in Yunnan Province, China. Plant Disease 94(3): 375.

Wasson J, Skolnick G, Love-Gregory L, Permutt MA. 2002. Assessing allele frequencies of single nucleotide polymorphisms in DNA pools by Pyrosequencing ${ }^{\mathrm{TM}}$ technology. BioTechniques 32(5): 1144-1146, 1148, 1150 passim.

Webber HJ. 1967. History and development of the Citrus industry. In: W Reuther, HJ Webber, LD Batchelor, eds. The Citrus Industry, Vol. 1. University of California Press: Berkeley, USA, 139

Wendel JF, Doyle JJ. 2005. Polyploidy and evolution in plants. In: R Henry, ed. Plant Diversity and Evolution. CABI Publishing: Wallingford, UK, 97-117.

Wenger JW, Schwartz K, Sherlock G. 2010. Bulk segregant analysis by high-throughput sequencing reveals a novel xylose utilization gene from Saccharomyces cerevisiae. PLoS Genetics 6: e1000942.

Werner JE, Peloquin SJ. 1991. Occurence and mechanisms of $2 n$ egg formation in $2 x$ potato. Genome 34(6): 975-982.

Werner JE, Douches DS, Freyre R. 1992. Use of half-tetrad analysis to discriminate between 2 types of $2 n$ egg formation in a potato haploid. Genome 35 : 741-745.

Werner JE, Peloquin SJ. 1990. Inheritance and 2 mechanisms of $2 n$ egg formation in $2 x$ potatoes. Journal of Heredity 81(5): 371-374.

Williams TE. 2012. Experiences in the development, release and commercialization of new irradiated citrus varieties from the citrus breeding program at the University of California, Riverside. XII International Citrus Congress. 19-23 December 2012. Valence, Spain.

Wu SS, Wu R, Ma ,C.X., Zeng ZB, Yang MC, Casella G. 2001a. A multivalent pairing model of linkage analysis in autotetraploids. Genetics 159(3): 1339-1350. 
Wu R, Gallo-Meagher M, Littell ,R.C., Zeng ZB. 2001b. A general polyploid model for analyzing gene segregation in outcrossing tetraploid species. Genetics 159(2): 869-882.

Wu GA, Prochnik S, Jenkins J, Salse J, Hellsten U, Murat F, Perrier X, Ruiz M, Scalabrin S, Takita MA, Labadie K, Poulain J, Couloux A, Jabbari K, Cattonaro F, Del Fabbro C, Pinosio S, Zuccolo A, Chapman J, Grimwood J, Terol J, Tadeo FR, Estornell LH, MuñozSanz JV, Ibánez V, Herrero-Ortega A, Aleza P, Pérez Pérez J, Ramón D, Brunel D, Luro F, Chen C, Farmerie WG, Desany B, Kodira C, Mohiuddin M, Harkins T, Fredrikson K, Burns P, Lomsadze A, Borodovsky M, Reforgiato G, Freitas-Astúa J, Quetier F, Navarro L, Roose M, Wincker P, Schmutz J, Morgante M, Machado MA, Talon M, Jaillon O, Ollitrault P, Gmitter F, Rokhsar D. 2013. Genome sequencing reveals complex history of admixture during citrus domestication. Nature Genetics, submitted.

Xu WW, Sleper DA, Chao S. 1995. Genome mapping of polyploid tall fescue (Festuca arundinacea Schreb.) with RFLP markers. Theoretical and Applied Genetics 91: 947-955.

Xu Q, Chen L, Ruan X, Chen D, Zhu A, Chen C, Bertrand D, Jiao W, Hao B, Lyon MP, Chen J, Gao S, Xing F, Lan H, Chang J, Ge X, Lei Y, Hu Q, Miao Y, Wang L, Xiao S, Biswas MK, Zeng W, Guo F, Cao H, Yang X, Xu X, Cheng Y, Xu J, Liu J, Luo OJ, Tang Z, Guo W, Kuang H, Zhang H, Roose ML, Nagarajan N, Deng X, Ruan Y. 2013. The draft genome of sweet orange (Citrus sinensis). Nature Genetics 45: 59-66.

Yamamoto M, Kobayashi S, Yoshioka T, Matsumoto R. 2001. Cybridization in Citrus unshiu Marc. (satsuma mandarin) and C. sinensis (L.) Osbeck (sweet orange). In: T Nagata, YPS Bajaj, eds. Springer Berlin Heidelberg, 124-138.

Yan W, Ye S, Jin Q, Zeng L, Peng Y, Yan D, Yang W, Yang D, He Z, Dong Y, Zhang X. 2010. Characterization and mapping of a novel mutant sms1 (senescence and male sterility 1) in rice. Journal of Genetics and Genomics 37(1): 47-55.

Yang Z, Ye X, Molina J, Roose M, Mirkov T. 2003. Sequence analysis of a 282-kilobase region surrounding the citrus Tristeza virus resistance gene (Ctv) locus in Poncirus trifoliata L. Raf. Plant Physiology 131(2): 482-492.

Yang J, Zhu J, Williams RW. 2007. Mapping the genetic architecture of complex traits in experimental populations. Bioinformatics 23(12): 1527-1536.

Yang SL, Chung KR. 2012. The NADPH oxidase-mediated production of $\mathrm{H}_{2} \mathrm{O}_{2}$ and resistance to oxidative stress in the necrotrophic pathogen Alternaria alternata of citrus. Molecular Plant Pathology 13: 900-914.

Yi H, Richards EJ. 2007. A cluster of disease resistance genes in Arabidopsis is coordinately regulated by transcriptional activation and RNA silencing. The Plant Cell Online 19: 2929-2939.

Zaragoza S. 2007. Aproximación a la historia de los cítricos. Origen, dispersión y evolución de su uso y cultivo, Universidad Politécnica de Valencia. Valencia, España.

Zhang WC, Shao ZY, Lo JH, Deng CH, Deng SS, Wang F,. 1988. Investigation and utilization of citrus varietal resources in China. Citriculture Sixth international citrus congress, Middle East, Tel Aviv, Israel, 6-11 March 1988 1: 291-294.

Zhang $\mathrm{CH}$, Shen SX, Wang YH. 2000. Genetic analysis of $2 n$ gamete formation in Chinese cabbage. Acta Horticulturae Sinica 27(4): 295-296.

Zhang CH, Xuan SX, Zhu HY. 2007. Studies on the formation and transmission of $\mathrm{n}+1$ gametes of cabbage primary trisomics. Agricultural Sciences in China, 6(7): 786-791. 
Zhang X, Borevitz JO. 2009. Global Analysis of Allele-Specific Expression in Arabidopsis thaliana. Genetics 182: 943-954.

Zhang G, Chen L, Xiao G, Xiao Y, Chen X, Zhang S. 2009. Bulked segregant analysis to detect QTL related to heat tolerance in rice (Oryza sativa L.) using SSR markers. Agricultural Sciences in China 8(4): 482-487.

Zhao H, Speed TP, McPeek MS. 1995. Statistical analysis of crossover interference using the Chi-Square model. Genetics 139: 1045-1056.

Zhao H, Speed T. 1996. On genetic map functions. Genetics 142: 1369-1377.

Zhao H, Speed TP. 1998a. Statistical analysis of half-tetrads. Genetics 150(1): 473-485.

Zhao H, Speed TP. 1998b. Statistical analysis of ordered tetrads. Genetics 150(1): 459-472.

Zheng BB, Wu X, Ge X, Deng X, Grosser JW, Guo W. 2012. Comparative transcript profiling of a male sterile cybrid pummelo and its fertile type revealed altered gene expression related to flower development. PLOS ONE 7: e43758. 